\title{
ANDREA RODRIGUES VASCONCELOS
}

\section{INFLUENCIA DOS RECEPTORES TLR4 E TLR2 \\ NOS EFEITOS COMPORTAMENTAIS E BIOQUÍMICOS \\ INDUZIDOS PELA DIETA INTERMITENTE \\ EM CAMUNDONGOS NOCAUTE}

Dissertação apresentada ao Departamento de Farmacologia do Instituto de Ciências Biomédicas da Universidade de São Paulo, para obtenção de Título de Doutor em Ciências. 


\section{ANDREA RODRIGUES VASCONCELOS}

\section{INFLUÊNCIA DOS RECEPTORES TLR4 E TLR2 NOS EFEITOS COMPORTAMENTAIS E BIOQUÍMICOS INDUZIDOS PELA DIETA INTERMITENTE EM CAMUNDONGOS NOCAUTE}

Dissertação apresentada ao departamento de Farmacologia do Instituto de Ciências Biomédicas da Universidade de São Paulo, para obtenção do Título de Doutor em Ciências.

Área de Concentração: Farmacologia

Orientador: Prof. Dr. Cristoforo Scavone

Co-Orientador: Profa. Dra. Elisa Mitiko Kawamoto

Versão Original

São Paulo

2016 
DADOS DE CATALOGAÇÃO NA PUBLICAÇÃO (CIP)

Serviço de Biblioteca e Informação Biomédica do Instituto de Ciências Biomédicas da Universidade de São Paulo

reprodução não autorizada pelo autor

Vasconcelos, Andrea Rodrigues.

Influência dos receptores TLR4 e TLR2 nos efeitos comportamentais e bioquímicos induzidos pela dieta intermitente / Andrea Rodrigues Vasconcelos. -- São Paulo, 2016.

Orientador: Prof. Dr. Cristoforo Scavone.

Tese (Doutorado) - Universidade de São Paulo. Instituto de Ciências Biomédicas. Departamento de Farmacologia. Área de concentração: Farmacologia. Linha de pesquisa: Neuroproteção.

Versão do título para o inglês: Influence of TLR4 and TLR2 in behavioral and biochemical effects induced by intermittent fasting.

1. Inflamação 2. Estresse oxidativo 3. Memória 4. Receptores celulares 5. Sistema nervoso central 6. Dieta I. Scavone, Prof. Dr. Cristoforo II. Universidade de São Paulo. Instituto de Ciências Biomédicas. Programa de Pós-Graduação em Farmacologia III. Título. 


\section{UNIVERSIDADE DE SÃO PAULO \\ INSTITUTO DE CIÊNCIAS BIOMÉDICAS}

Candidato(a):

Título da Tese:

Orientador(a):
Andrea Rodrigues Vasconcelos.

Influência dos receptores TLR4 e TLR2 nos efeitos comportamentais e bioquímicos induzidos pela dieta intermitente.

Prof. Dr. Cristoforo Scavone.

A Comissão Julgadora dos trabalhos de Defesa da Tese de Doutorado, em sessão pública realizada a ................., considerou

\section{( ) Aprovado(a) \\ ( ) Reprovado(a)}

\begin{tabular}{|c|c|}
\hline Examinador(a): & $\begin{array}{l}\text { Assinatura: } \\
\text { Nome: ....... } \\
\text { Instituição: }\end{array}$ \\
\hline Examinador(a): & $\begin{array}{l}\text { Assinatura: } \\
\text { Nome: ....... } \\
\text { Instituição: }\end{array}$ \\
\hline Examinador(a): & $\begin{array}{l}\text { Assinatura: } \\
\text { Nome: ........ } \\
\text { Instituição: }\end{array}$ \\
\hline Examinador(a): & $\begin{array}{l}\text { Assinatura: } \\
\text { Nome: ....... } \\
\text { Instituição: }\end{array}$ \\
\hline Presidente: & $\begin{array}{l}\text { Assinatura: } \\
\text { Nome: ........ } \\
\text { Instituição: }\end{array}$ \\
\hline
\end{tabular}




\section{CerTIFICADO}

Certificamos que o protocolo registrado sob $n^{\circ} 108$ nas fls. 108 do livro 02 para uso de animais em experimentação, sob a responsabilidade do Prof(a) $\operatorname{Dr}(a)$ ) Cristoforo Scavone, Coordenador(a) da Linha de pesquisa "Influência do receptor TLR4 nos efeitos comportamentais e bioquímicos induzidos pela dieta intermitente em camundongos $\mathrm{C} 3 \mathrm{H} / \mathrm{HeJ}^{\prime \prime}$ do qual participam o(s) alunos Andrea Rodrigues Vasconcelos, Lidia Mitiko Yshii e a pesquisadora Elisa Mitiko Kawamoto, está de acordo com os Princípios Éticos de Experimentação Animal adotado pela Sociedade Brasileira de Ciência de Animais de Laboratório (SBCAL) e foi aprovado pela COMISSÃO DE ÉTICA NO USO DE ANIMAIS (CEUA) em $\mathbf{1 5 . 0 7 . 2 0 1 1}$, com validade de 3 anos.

São Paulo, 18 de julho de 2011.
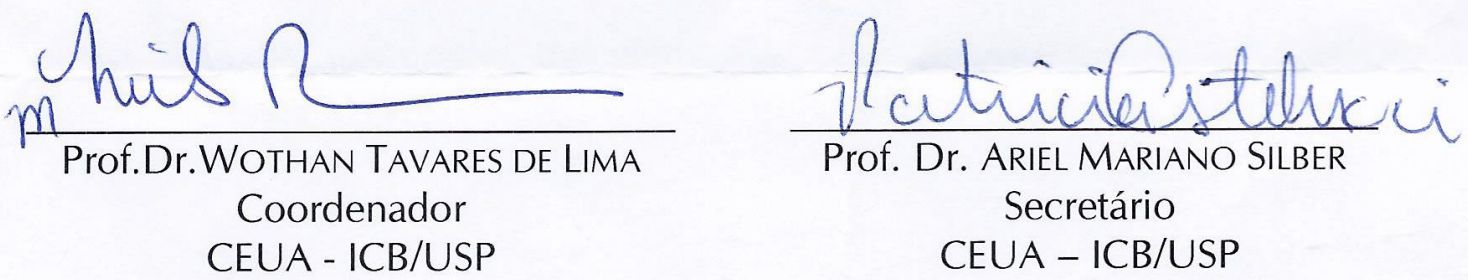
Of.CEUA. 047.14

São Paulo, 24 de julho de 2014.

\section{REF.: Protocolo ${ }^{0}$ 108/11.}

"Influência do receptor TLR4 nos efeitos comportamentais e bioquímicos induzidos pela dieta intermitente em camundongos $\mathrm{C} 3 \mathrm{H} / \mathrm{HeJ}$ "

Prezado $^{(a)}$ Professor $^{(a)}$

Informo que a sua licença para uso de animais em experimentação, constante no protocolo em epígrafe, foi prorrogada até 15.07.17.

Reitero que havendo alteração de metodologia e inserção de novos alunos ao projeto de pesquisa vinculado à referida licença a CEUA/ICB deverá ser informada.

\section{Cordialmente,}

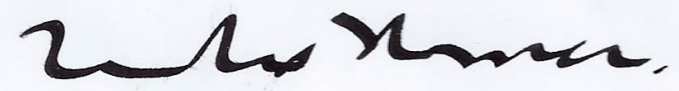

Prof. Dr. Wothan TAVARES DE LIMA

Coordenador - CEUA-ICB/ /USP

$\operatorname{Ilmo}^{(\mathrm{a})} \cdot \mathrm{Sr}^{(\mathrm{a})}$

Prof. ${ }^{(\mathrm{a}) .}$ Dr $^{\text {(a) }}$ Cristoforo Scavone

Departamento Farmacologia

Instituto de Ciências Biomédicas - USP 


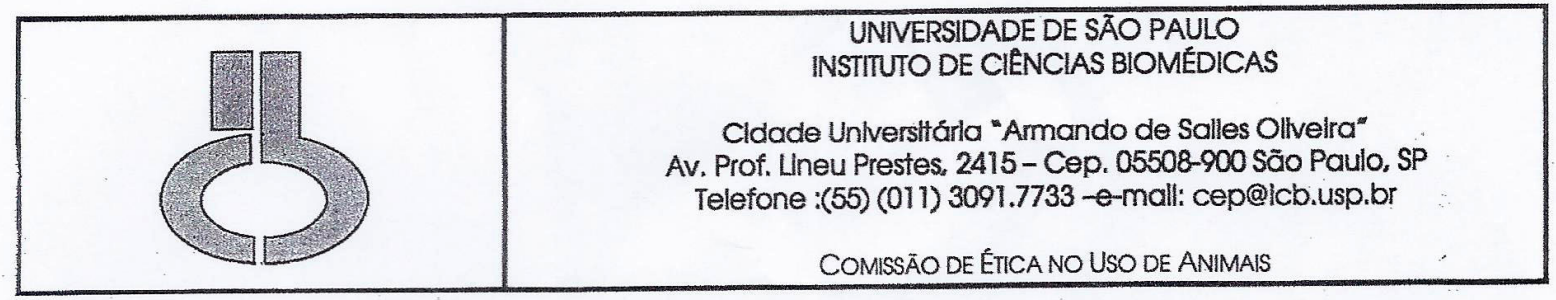

Decl. CEUA.028/2013.

DECLARAÇ Ã O

Em adendo ao Certificado 108/11/CEUA, aprovado em 15.07.11 e por solicitação do Prof. Dr. Cristoforo Scavone, responsável pela linha de Pesquisa, considerando a justificativa apresentada informo que o título da linha de pesquisa: "Influência do receptor TLR4 nos efeitos comportamentais e bioquímicos induzidos pela Influência do receptor TLR4 nos efeitos comportamentais e bioquímicos induzidos pela dieta intermitente em camundongos C3H/HeJ" foi alterado para "Influência dos receptores TLR4 e TLR2 nos efeitos comportamentais e bioquímicos induzidos pela dieta intermitente em camundongos nocaute", sem alteração da metologia empregada.

São Paulo, 02 de maio de 2013.

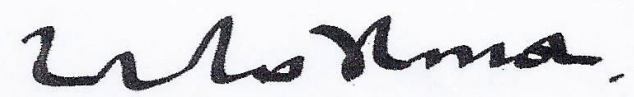

Prof. Dr. Wothan Tavares de Lima

Coordenador da CEUA

ICB/USP 


\section{DECLARAÇÃO}

Declaro para os devidos fins que ANDREA RODRIGUES VASCONCELOS foi aprovado no Curso de Proteção Radiológica, promovido pelo Núcleo de Radioproteção do ICB/USP, no período de 10/12 a 12/12/2007 com carga horária de 15 horas.

São Paulo, 13 de dezembro de 2007.

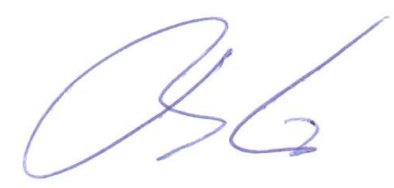

Prof. Dr. BENY SPIRA NUCLEO DE PROTEÇÃO RADIOLÓGICA 
Ao Vitor e aos meus pais, por todo o amor e dedicação. Sem o apoio de vocês não teria chegado até aqui. 


\section{AGRADECIMENTOS}

Ao meu orientador, Prof. Dr. Cristoforo Scavone, por me receber em seu laboratório, pelo tempo dedicado, paciência, incentivos, confiança, amizade, pelas oportunidades oferecidas e por todos os ensinamentos que me serão úteis para a vida toda.

À minha co-orientadora, Dra. Elisa Mitiko Kawamoto, pelo estímulo, confiança, auxílio, por todos os ensinamentos e pela sua importante contribuição e colaboração durante todo o desenvolvimento deste estudo.

Aos meus colegas do Laboratório de Neurofarmacologia Molecular e Laboratório de Neurobiologia Molecular e Funcional do departamento de Farmacologia da Universidade de São Paulo, que tornaram os meus dias de trabalho muito mais agradáveis.

Ao Dr. Mark Mattson e aos meus colegas do Laboratory of Neurosciences do National Institute on Aging, Baltimore, pela colaboração, ensinamentos e amizade durante o tempo que passamos juntos.

À Larissa Lima, pela paciência e pelo apoio técnico e burocrático que me foram dispensados.

À Diana Zucas Andreotti pelo auxílio nos experimentos do dia a dia e a Fernando de Souza Lula pelo apoio com o biotério.

Às secretárias do Departamento de Farmacologia Selma Rigonatti, Mônica Nunes e Camila Trindade, por todo apoio burocrático e pronto atendimento.

Às bibliotecárias, Renata Maria dos Santos e Tereza Cristina Soutto Mayor, pelo trabalho de revisão e normalização do manuscrito.

Aos meus pais, Therezinha de Jesus e Luiz Jether Vasconcelos, pela compreensão, apoio, incentivo e amor que sempre recebi.

A Vitor Schmid, por todo o apoio, companheirismo, carinho e paciência durante o doutorado.

A todos aqueles que contribuíram para que este momento pudesse acontecer.

À Fundação de Amparo à Pesquisa do Estado de São Paulo (FAPESP), pelo apoio financeiro (Doutorado FAPESP Processo 2011/12255-8).

Finalmente, agradeço a Deus pela vida que tenho e por me reservar saúde e proteção. 


\section{RESUMO}

Vasconcelos AR. Influência dos receptores TLR4 e TLR2 nos efeitos comportamentais e bioquímicos induzidos pela dieta intermitente em camundongos nocaute [Tese (Doutorado em Farmacologia)]. São Paulo: Instituto de Ciências Biomédicas da Universidade de São Paulo; 2016.

Hormese é uma resposta adaptativa das células e do organismo a um estresse moderado, normalmente intermitente, que pode gerar muitos efeitos benéficos e protetores em diversas espécies. Exemplos incluem a exposição a baixas doses de certos fitoquímicos, como curcumina, isotocianatos e resveratrol, o exercício físico e a restrição de energia da dieta (RED). Esta última, quando não causa desnutrição, expõe os organismos a um estresse nutricional moderado que não apenas estimula as proteínas de estresse, mas também os mecanismos de defesa do organismo, tornando-o mais resistente a estímulos tóxicos ou potencialmente deletérios. Em linhas gerais, a RED parece atuar em vias associadas à resposta inflamatória, autofagia e sobrevivência celular, além de aumentar a resistência contra o estresse oxidativo, envolvendo com isso a modulação de fatores de transcrição como o fator nuclear kappa B (NF-кB), o fator 2 relacionado ao NF-E2 (NRF2) e o Forkhead box O (FOXO). No entanto, pouco se sabe sobre os mecanismos moleculares envolvidos, assim como o papel dos receptores tipo Toll- (TLR) 4 e TLR2 na modulação dos efeitos benéficos da RED. Este projeto teve como objetivo avaliar a influência do TLR4 e TLR2 nos efeitos induzidos pela dieta intermitente sobre a memória e nos mecanismos de sinalização associados aos fatores de transcrição NF- $\mathrm{B}$, NRF2 e FOXO em camundongos nocaute para TLR2 ou TLR4. Os nossos resultados sugerem que os receptores TLR4 e TLR2 participam da modulação pela dieta intermitente dos níveis de estresse oxidativo, biomarcadores periféricos

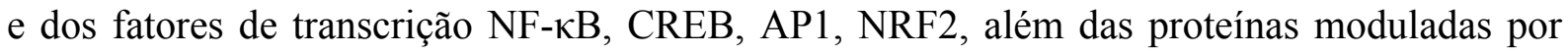
esses fatores de transcrição como o BDNF, HO1, enzimas antioxidantes, chaperonas e diversas citocinas inflamatórias. Os resultados desse estudo permitem um maior entendimento dos processos fisiológicos que visam o desenvolvimento de novas estratégias para intervenções farmacológicas objetivando a promoção da longevidade e o envelhecimento saudável, bem como para o tratamento de distúrbios neurodegenerativos.

Palavras-chave: Dieta intermitente. TLR2. TLR4. Memória. Estresse oxidativo. 


\begin{abstract}
Vasconcelos AR. Influence of TLR4 and TLR2 in behavioral and biochemical effects induced by intermittent fasting in knockout mice [Ph.D Thesis (Pharmacology)]. São Paulo: Instituto de Ciências Biomédicas da Universidade de São Paulo; 2016.
\end{abstract}

Hormesis is an adaptive response of cells and organisms to a moderate stress, usually intermittent, which may have many beneficial effects to the biological system. Examples include exposure to low doses of certain phytochemicals such as curcumin, resveratrol and isothiocyanates, exercise and intermittent fasting dietary restriction. The latter, when it does not cause malnutrition, induces a moderate nutritional stress to the organism, which not only stimulates the stress proteins, but also the body's defense mechanisms, making the cell or the organism more resistant to toxic stimuli. In general, intermittent fasting seems to act by mechanisms associated with cell survival, autophagy, inflammatory response and enhancing oxidative stress resistance, thereby involving the modulation of transcription factors such as nuclear transcription factor kappa B (NF-кB), NF-E2-related factor 2 (NRF2) and Forkhead box $\mathrm{O}(\mathrm{FOXO})$. However, little is known about the molecular mechanisms underlying these processes, as well as the involvement of Toll-like receptors (TLR) 4 and TLR2 on the beneficial effects induced by the intermittent fasting protocol. The present work investigated the effects of intermittent fasting on memory and on the signaling mechanisms associated with the transcription factors NF-KB, NRF2 and FOXO in TLR2 KO or TLR4 KO mice. The results suggest that TLR4 and TLR2 participate in the modulatory effects of intermittent fasting on oxidative stress levels, peripheral biomarkers, and on the transcription factors NF$\kappa \mathrm{B}, \mathrm{CREB}, \mathrm{AP} 1$ and NRF2, as well as proteins modulated by these transcription factors such as BDNF, HO1, antioxidant enzymes, chaperones and several inflammatory cytokines. These results allow a better understanding of the physiological processes that aim at developing new strategies for pharmacological interventions to promote longevity and healthy aging, as well as for the treatment of neurodegenerative disorders.

Keywords: Intermittent fasting. TLR2. TLR4. Memory. Oxidative stress. 


\section{LISTA DE ABREVIATURAS E SIGLAS}

AKT Serina-treonina quinase

AMPK Proteína quinase dependente de AMP

ANOVA Análise de variância

AP1 Proteína ativadora 1

ARE Elemento de resposta antioxidante

BDNF Fator neurotrófico derivado do encéfalo

CAT Catalase

CREB Elemento de resposta ao AMP cíclico

DA Doença de Alzheimer

DAMP Padrão molecular associado a dano celular

DP Doença de Parkinson

ELISA Ensaio imunoabsorvente ligado à enzima

ERK Quinase regulada por sinal extracelular

EROs Espécies reativas de oxigênio

FOXO Forkhead box O

GDNF Fator neurotrófico derivado da glia

GPx Glutationa peroxidase

GR Glutationa redutase

GST Glutationa-S-transferase

HO1 hemeoxigenase 1

HNE 4-hidroxi-2-nonenal

HSP Proteína de choque térmico (Heat shock protein)

IGF-1 Fator de crescimento semelhante à insulina tipo 1

ІкB Inibidor de NF-кB

IKK I I B quinase

IL Interleucina

JNK Jun N-terminal quinase

KEAP1 Proteína associada à ECH semelhante à kelch 1

LPS Lipopolissacarídeo

LTP Potenciação de longa duração (Long-term potentiation)

mTOR Alvo da rapamicina em mamíferos

NEMO Modulador essencial do NF- $\mathrm{BB}$ 
NF-кB Fator de transcrição nuclear kappa B

NMDA Receptor N-metil-D-aspartato

NRF2 Fator 2 relacionado ao NF-E2

NOSi Oxido nítrico sintase induzida

PAMP Padrão molecular associado ao patógeno

PI3K Fosfatidilinositol-3-quinase

RED Restrição de energia da dieta

RNAm RNA mensageiro

SNC Sistema nervoso central

SOD Superóxido dismutase

TLR Receptor do tipo Toll

TNF Fator de necrose tumoral

Trk Quinase relacionada a tropomiosina

WT Selvagem (wild type) 


\section{SUMÁRIO}

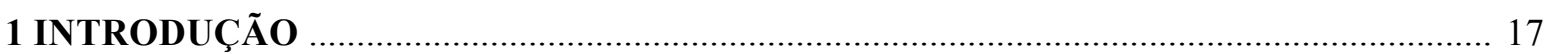

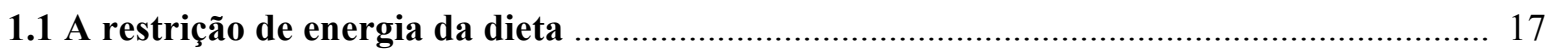

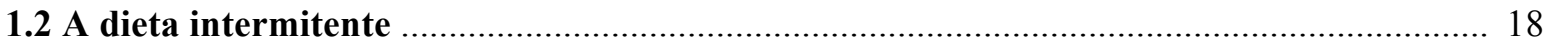

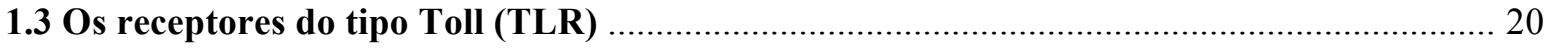

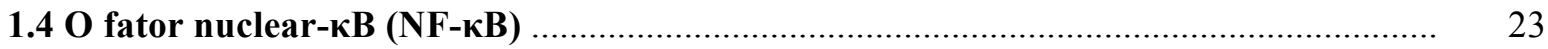

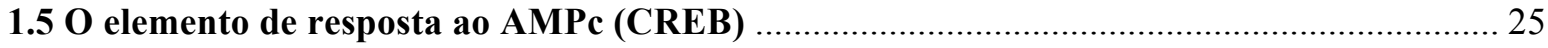

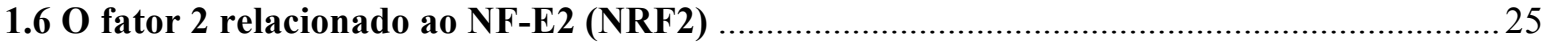

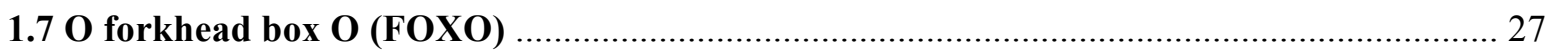

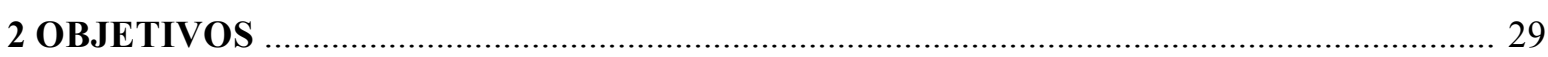

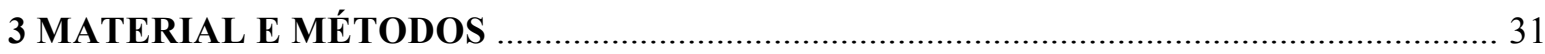

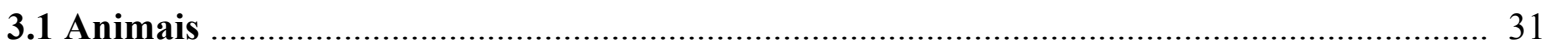

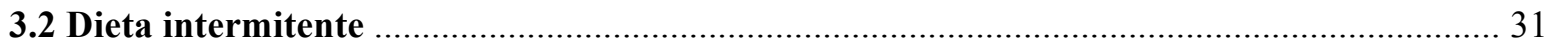

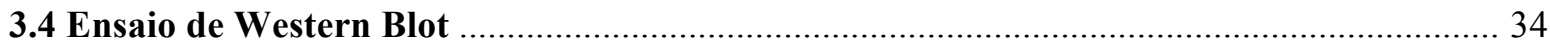

3.5 Ensaio de retardamento da mobilidade eletroforética em gel de poliacrilamida (gel

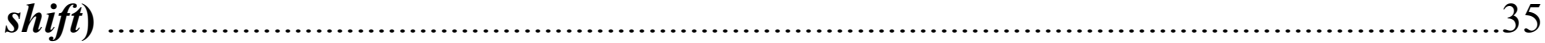

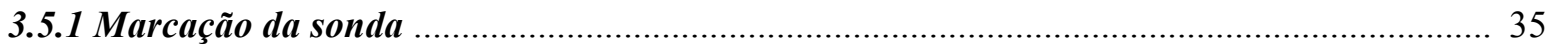

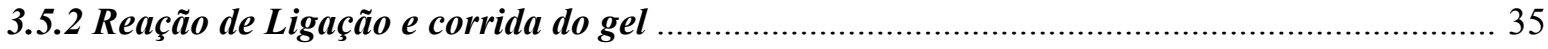

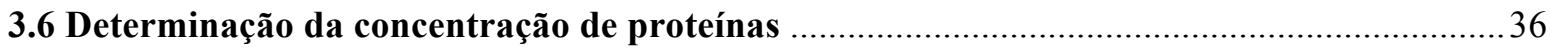

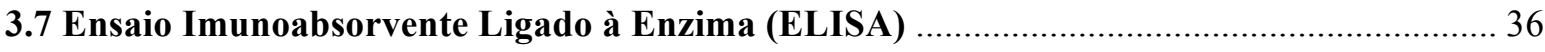

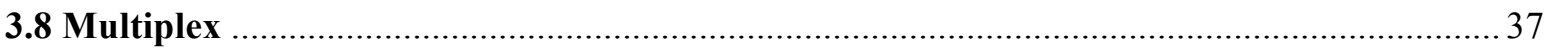

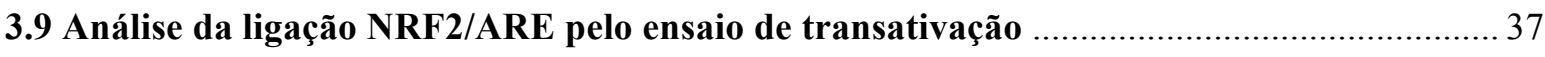

3.10 Reação em cadeia da polimerase - transcrição reversa (RT-PCR) em tempo real .............37

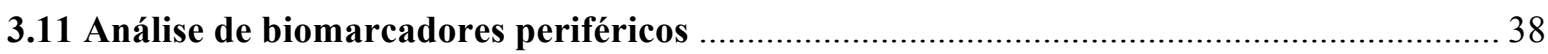

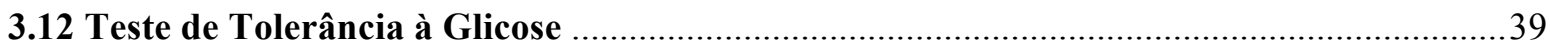

3.13 Teste comportamental: campo aberto …….............................................................. 39

3.14 Teste comportamental: labirinto em cruz elevado.............................................................. 40

3.15 Teste comportamental: labirinto aquático de Morris........................................................ 40

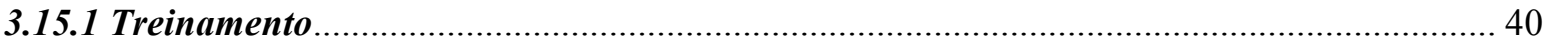

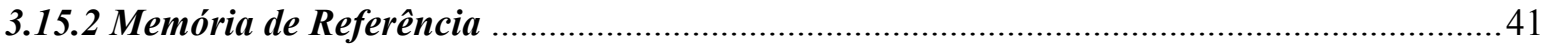

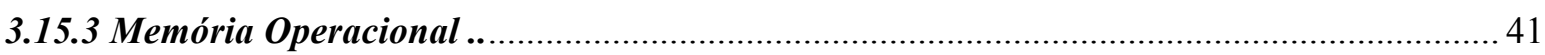

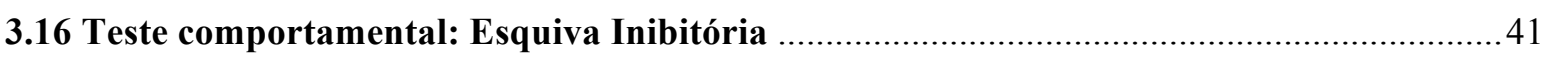

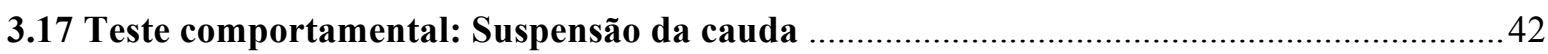

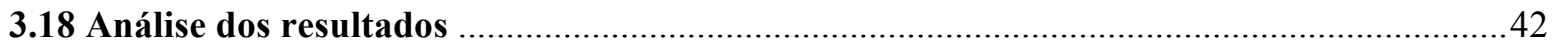

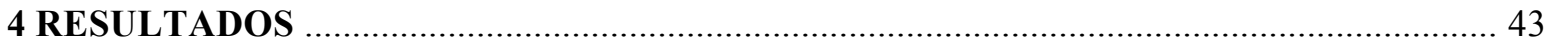


4.1 Efeitos da dieta intermitente no peso e consumo de alimento de camundongos na presença/ausência de TLR2 ou TLR4

4.2 Efeitos da dieta intermitente na atividade dos fatores de transcrição NF-кB, CREB e AP1 na presença/ausência de TLR2 ou TLR4 no hipocampo e hipotálamo.

4.3 Efeitos da dieta intermitente sobre as citocinas e quimiocinas na ausência/presença de TLR2 ou TLR4 no hipocampo e soro

4.4 Efeitos da dieta intermitente na expressão proteica de BDNF na presença/ausência de TLR2 ou TLR4 no hipocampo e hipotálamo

4.5 Efeitos da dieta intermitente na expressão proteica na sinalização de NRF2 e HO1 na presença/ausência de TLR4 e TLR2 no hipocampo

4.6 Efeitos da dieta intermitente na expressão proteica de AKT total e fosforilada na presença/ausência de TLR2 no hipocampo

4.7 Efeitos da dieta intermitente na expressão proteica de ERK1 e ERK2 total e fosforilada na presença/ausência de TLR4 ou TLR2 no hipocampo

4.8 Efeitos da dieta intermitente na expressão proteica de mTOR total e fosforilado na presença/ausência de TLR4 ou TLR2 no hipocampo

4.9 Efeitos da dieta intermitente na expressão proteica de AMPK total e fosforilada na presença/ausência de TLR4 no hipocampo

4.10 Efeitos da dieta intermitente na expressão proteica de FOXO1 total e fosforilado na presença/ausência de TLR4 ou TLR2 no hipocampo

4.11 Efeitos da dieta intermitente nos níveis de estresse oxidativo e na atividade e expressão de enzimas antioxidantes na presença/ausência de TLR4 ou TLR2 no hipocampo 65

4.12 Efeitos da dieta intermitente na expressão proteica de P53 na presença/ausência de TLR4 no hipocampo

4.13 Efeitos da dieta intermitente na expressão proteica de proteínas de choque térmico na presença/ausência de TLR4

4.14 Efeitos da dieta intermitente nos biomarcadores periféricos na presença/ausência de TLR4

4.15 Efeitos da dieta intermitente na tolerância à glicose na presença/ausência de TLR4 e TLR2

4.16 Efeitos da dieta intermitente nos ensaios comportamentais na presença/ausência de TLR2 e

TLR4

4.16.1 Campo aberto .

4.16.2 Labirinto em cruz elevado .76

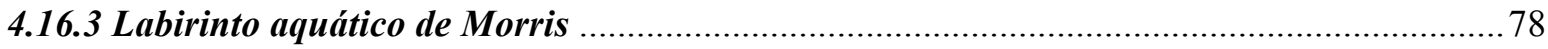

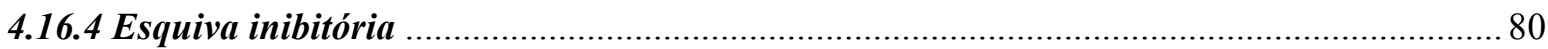

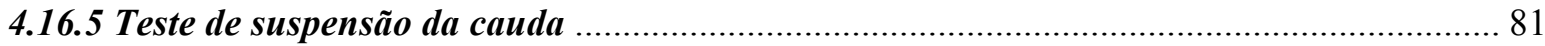




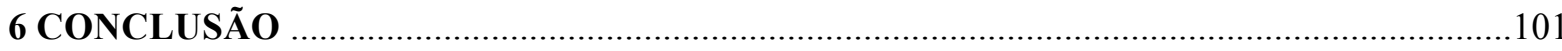

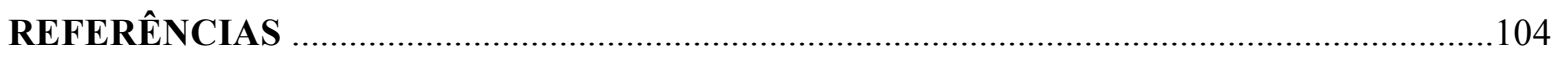

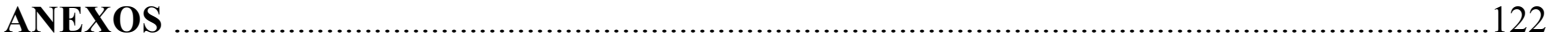

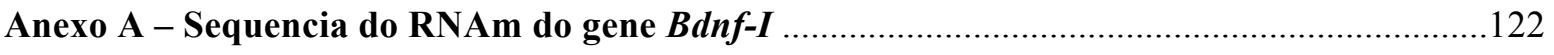

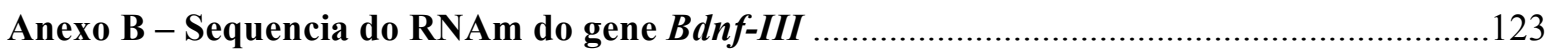

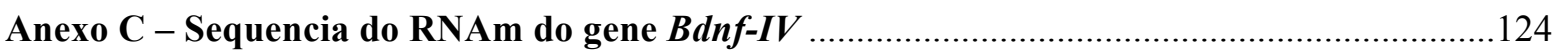

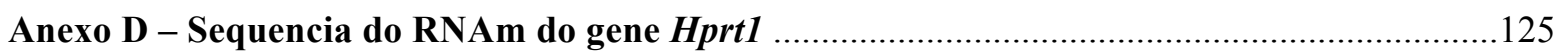

Anexo E - Tabela com o resumo dos resultados do trabalho (TLR4) .....................................126

Anexo F - Tabela com o resumo dos resultados do trabalho (TLR2) .....................................127 


\section{INTRODUÇÃO}

\subsection{A restrição de energia da dieta}

O termo hormese é definido como um fenômeno dose-resposta bifásico caracterizado por estimulação em baixas doses e inibição em altas doses $(1,2)$. A hormese é uma resposta de compensação adaptativa do organismo a um estímulo estressor ambiental moderado, que os torna mais resistentes frente a uma situação de estresse mais intenso (3). Entende-se por estímulo estressor não apenas a exposição a substâncias tóxicas, mas também qualquer outro estímulo com consequências potencialmente deletérias para o organismo, como, por exemplo, o aumento ou diminuição de temperatura, o exercício físico e a restrição de energia da dieta (RED) (1).

A RED sem desnutrição atrasa o surgimento de várias alterações fisiológicas que ocorrem durante o envelhecimento e promove um aumento da expectativa de vida em animais de várias espécies $(4,5)$ como roedores $(6)$, peixes (7), drosófilas (8), vermes (9), leveduras (10) e primatas (11), podendo provavelmente ocorrer também em humanos, embora ainda não confirmado.

Além dos efeitos na longevidade, muitos estudos têm demonstrado diversos efeitos benéficos da RED sobre a saúde. Por exemplo, a RED pode atenuar ou prevenir a incidência de câncer de ocorrência espontânea (12), induzido quimicamente (13) ou por radiação (14). A RED também protege as células do cérebro (15) e do coração (16) em modelos de derrame cerebral e infarto do miocárdio. Além disso, a RED inibe o desenvolvimento de doenças autoimunes em várias linhagens de roedores (17) e atrasa o surgimento e progressão de dermatite alérgica espontânea (18) ou quimicamente induzida (19). Ainda, a RED aumentou a resistência a neurotoxinas em modelos experimentais de doença de Huntington, doença de Alzheimer (DA) e doença de Parkinson (DP) (20-22). Corroborando com estas evidências, dados epidemiológicos sugerem que as incidências de DA e DP são menores em países com menor consumo de comida por pessoa (por exemplo, Japão e China) em comparação com países onde esse consumo é maior (por exemplo, Estados Unidos e Canadá) (23) e que indivíduos com baixa ingestão calórica diária parecem ter um risco menor de desenvolver DA e DP $(24,25)$.

A RED em camundongos atenuou os déficits no aprendizado e memória relacionados à idade (26) e diminuiu os níveis de estresse oxidativo em vários órgãos incluindo o cérebro (27). Em humanos, a RED reduziu a inflamação e o estresse oxidativo em asmáticos (28). 
Esses e outros efeitos benéficos e protetores da RED são provavelmente mediados por mecanismos horméticos (29).

Dois mecanismos gerais têm sido propostos para a RED e seus efeitos benéficos; um deles é a diminuição do estresse oxidativo e da produção de radicais livres (30) e a outra é a indução de uma resposta de estresse celular moderada que aumenta a capacidade das células de lidar com situações de estresse mais graves (31).

Além da associação entre a RED e o estresse oxidativo, estudos têm demonstrado outro possível mecanismo da RED, onde se observa uma inibição da resposta inflamatória e da inflamação relacionada à idade $(32,33)$. A RED modula a atividade e a expressão de várias citocinas pró-inflamatórias, como fator de necrose tumoral (TNF)- $\alpha$, interleucina (IL)-1 $\beta$ e IL-6 (32, 34-36). Estudos têm mostrado que o envelhecimento está associado a um aumento da inflamação cerebral $(37,38)$. Além disso, a inflamação sistêmica pode estar associada a doenças coronarianas, diabetes, esclerose múltipla, DA e DP (39). De fato, estudos recentes demonstram uma forte associação entre neurodegeneração e inflamação (revisão em (40)); por exemplo, tem sido observada a presença de processos inflamatórios (ativação de microglia e aumento da produção de citocinas pró-inflamatórias) no sistema nervoso central (SNC) de pacientes com DA (41). Dados tanto epidemiológicos quanto clínicos têm descrito a importância da terapia anti-inflamatória para retardar a progressão da doença, amenizando os sintomas graves da DA $(42,43)$. Em muitos indivíduos, uma dieta mal adaptada é a maior causa desta inflamação crônica $(39,44)$.

Várias alterações bioquímicas e moleculares têm sido observadas em animais mantidos em RED que são consistentes com mecanismos de hormese nos efeitos benéficos da restrição. Proteínas de choque térmico protetoras têm sido encontradas em concentrações elevadas em vários tecidos de animais submetidos a RED como, por exemplo, a proteína de choque térmico (HSP)-70 em células do fígado de ratos (45). Em outro estudo, a dieta intermitente aumentou as concentrações desta e de outra proteína de choque térmico, a proteína-78 regulada pela glicose, em sinapses de cérebros de ratos (46). Uma classe de moléculas citoprotetoras estimulada pela RED são as enzimas antioxidantes como superóxido dismutase (SOD) e glutationa peroxidase (GPx) (47). Além disso, cérebros de ratos mantidos em uma dieta de calorias reduzidas exibiram quantidades maiores de vitamina E e coenzima Q10 quando comparados com cérebros de animais com alimentação ad libitum (48). Quando roedores ou macacos foram mantidos em RED, concentrações de fator neurotrófico derivado do encéfalo (BDNF) e fator neurotrófico derivado da glia (GDNF) estavam aumentadas em várias regiões do encéfalo $(49,50)$. 
Contudo, apesar de uma extensa literatura que demonstra efeitos benéficos da RED na saúde, a RED pode não induzir uma resposta benéfica adaptativa em todas as células. Por exemplo, a concentração de HSP-70 não aumentou em motoneurônios da medula espinhal em modelos de camundongos com esclerose lateral amiotrófica mantidos em RED (51). As células envolvidas na cicatrização de feridas não respondem adaptativamente à RED e, de fato, tem sido demonstrado que a RED pode prejudicar a cicatrização de feridas em roedores (52). Dependendo da magnitude da restrição de energia, a RED pode não ser benéfica ou pode até mesmo causar efeitos adversos em órgãos reprodutores, como infertilidade, irregularidades menstruais, perda de libido, hipertensão, depressão, irritabilidade, particularmente nas fêmeas de mamíferos em geral $(53,54)$. Assim, apesar dos efeitos benéficos da RED listados na literatura, um melhor entendimento dos seus efeitos e dos mecanismos moleculares é importante para que se possam desenvolver protocolos de RED adequados para a saúde humana.

Há poucos estudos sobre os efeitos da RED em humanos, mas informações disponíveis até o momento sugerem que a RED reduz o risco de desenvolver diabetes tipo 2 e aterosclerose, além de induzir muitas das respostas adaptativas que ocorrem em animais de laboratório em restrição $(55,56)$. Desta forma, um melhor entendimento dos mecanismos horméticos da RED poderá também trazer novos avanços no tratamento ou até mesmo na prevenção de patologias como as doenças neurodegenerativas.

\subsection{A dieta intermitente}

Os efeitos benéficos da RED foram relatados em vários protocolos experimentais diferentes. Em um dos protocolos de RED, a restrição calórica, é feita a restrição de $20 \%$ a $40 \%$ das calorias totais consumidas diariamente $(12,57)$. Uma forma comum de restrição calórica é limitar o consumo diário de alimento, ocorrendo então uma restrição total de nutrientes em longo prazo (58). Assim, a quantidade de comida fornecida ao animal é ajustada diariamente a $60-80 \%$ do consumo diário do grupo alimentado ad libitum (18).

Outro protocolo muito utilizado de RED é a dieta intermitente, na qual os animais alternam entre dias em que são alimentados ad libitum e dias de jejum, quando não têm acesso ao alimento (59). Nesse protocolo ocorre uma restrição na frequência de consumo alimentar, e não na quantidade total de alimento ingerido. A dieta intermitente promove efeitos benéficos semelhantes ao da restrição calórica; ambos os protocolos diminuem os riscos de doenças cardiovasculares, aumentam a expectativa de vida e diminuem a produção de radicais livres 
geradores de estresse oxidativo, além de melhorarem a atividade dos mecanismos protetores $(60,61)$.

Sabe-se ainda que a dieta intermitente resulta em cetogênese, promove mudanças potentes em vias metabólicas e processos celulares relacionados à resistência ao estresse, lipólise e autofagia, e pode ser uma estratégia efetiva para a redução de peso, prevenir doenças relacionadas ao envelhecimento e otimizar a saúde $(62,63)$.

De maneira geral, pode-se dizer que a dieta intermitente promove diversos efeitos benéficos ao organismo, mesmo se o período de jejum for seguido por um período de acesso livre ao alimento de forma que o consumo calórico total não seja alterado. De qualquer modo, tanto o protocolo de restrição da quantidade (restrição calórica) quanto da frequência de alimentação (dieta intermitente) protegem contra várias doenças, provavelmente por mecanismos horméticos que aumentam a resistência celular contra estímulos estressores (29).

\subsection{Os receptores do tipo Toll (TLR)}

Os TLRs compreendem uma família de receptores de proteínas de superfície celular que são importantes mediadores da imunidade inata, respondendo a diversos produtos microbiais e ligantes endógenos induzidos por dano tecidual (64). Esses receptores são bastante homólogos à proteína Toll da drosófila $(65,66)$, onde inicialmente foram descobertos dando origem a seu nome, e à família do receptor de IL-1 em humanos (67).

Os TLRs estão presentes em diversas células do sistema imune de mamíferos, e ainda no SNC, onde, até recentemente, se acreditava que sua expressão se limitava somente a microglia (68), astrócitos (69) e oligodendrócitos (70). Entretanto, hoje já se sabe que neurônios, assim como células tronco neuronais, também expressam TLRs (71).

Atualmente são conhecidos 11 tipos de TLRs em humanos e 13 tipos em camundongos, todos eles apresentando pequenas diferenças nas cadeias de aminoácidos que compõe as proteínas que os formam (72). Devido a essas diferenças, cada TLR é capaz de reconhecer classes diferentes de padrões moleculares associados ao patógeno (PAMPs) presentes em diversos microorganismos patogênicos; por exemplo, o TLR4 reconhece predominantemente o lipopolissacarídeo (LPS) de bactérias gram-negativas enquanto que o TLR2 não é necessário para a resposta ao LPS, mas se dimeriza com TLR1 ou TLR6 para reconhecer lipopeptídeos de bactérias gram-negativas (73). Quando ativados, os TLRs iniciam cascatas de sinalização que envolvem a ativação de fatores de transcrição como o fator nuclear 
(NF)-кB ou AP1, por exemplo; ambos ativam genes de citocinas inflamatórias, além de genes associados a processos de proliferação celular e apoptose (74).

Além dos PAMPs que ativam diferentes TLRs, já foram também identificados ligantes endógenos de padrão molecular associado a dano celular (DAMP), e outros produtos da inflamação tecidual. Vários ligantes endógenos já foram escritos, como o ácido hialurônico de baixo peso molecular, fibrinogênio, $\beta$-defensinas e proteínas de choque térmico $(75,76)$. É importante ressaltar que as sinalizações resultantes da ativação de TLRs por PAMPs e DAMPs parecem ser diferentes, o que pode ser devido à necessidade de diferenciar entre a ativação de TLR induzida por patógenos que requer uma intervenção imune e a ativação de TLRs por dano tecidual que requer um balanço entre a intervenção imune e o reparo do dano tecidual (77-79).

Os TLRs são classicamente estudados em relação à imunidade; porém, o campo mais promissor na linha de pesquisa que envolve os TLRs atualmente é sua ativação endógena, já que se notou que os TLRs não só evocam respostas imunes relacionadas ao patógeno, mas também levam a papéis físiológicos e patológicos não relacionados à inflamação. Por exemplo, evidências recentes têm relacionado os TLRs com a plasticidade no SNC, como explorado adiante $(80,81)$.

Muitos TLRs estão envolvidos na modulação da neurogênese de mamíferos adultos. Camundongos deficientes em TLR2 apresentaram neurogênese hipocampal significativamente reduzida (80). Ao contrário, camundongos deficientes em TLR4 exibiram neurogênese aumentada, apesar de as células formadas morrerem e não conseguirem formar neurônios maduros. Por outro lado, esses camundongos exibiram um nível basal maior de neurônios e menor de glia no hipocampo, o que pode indicar que durante a neurogênese as células tronco neurais diferenciam-se mais em neurônios (80).

Os efeitos modulatórios dos TLRs sobre a neurogênese sugerem uma possível modulação dos TLRs sobre processos cognitivos (81). De fato, recentemente foi mostrado que o TLR3 exerce uma modulação na performance cognitiva de camundongos dependente e independente do hipocampo (81). A extinção da memória espacial em camundongos deficientes em TLR3 ocorre mais lentamente do que nos camundongos selvagens e a deficiência de TLR3 também exerceu uma melhora no desempenho dos animais envolvendo a memória de medo contextual. Além disso, a deficiência em TLR3 melhorou, enquanto que a ativação de TLR3 pela infusão intracerebroventricular de PolyI:C, um ligante do TLR3, piorou o desempenho dos camundongos envolvendo a memória de trabalho. Além disso, recentemente foi mostrado que o TLR4 contribui para o impacto negativo da diabetes sobre a 
função cognitiva (82). Atualmente pouco se sabe sobre papéis modulatórios dos receptores TLR4 e TLR2 sobre a cognição, mas é provável que ocorra já que há evidencias anteriormente relatadas de suas influências sobre a proliferação e diferenciação de células tronco neurais.

Além do envolvimento com a neuroplasticidade, estudos recentes sugerem que o TLR4 exerce uma função importante no desenvolvimento de distúrbios metabólicas como a obesidade e resistência à insulina (83-86). Foi demonstrado que ácidos graxos saturados podem estimular diretamente a sinalização inflamatória dependente do TLR4, atuando como ligantes desse receptor $(83,87-90)$. Corroborando com essas evidências, camundongos deficientes em TLR4 não desenvolvem resistência à insulina associada à obesidade (83-85) e pessoas obesas com diabetes tipo 2 apresentam níveis de expressão gênica e proteica de TLR4 significativamente elevados no músculo, o que se correlaciona com a severidade da resistência à insulina nesses indivíduos (91). Outro estudo demonstrou que a alimentação rica em gordura aumenta a proporção de bactérias gram-negativas que contém LPS na microbiota intestinal, além de aumentar os níveis plasmáticos de LPS em camundongos. Esse estado é definido como endotoxemia metabólica e resulta em um aumento do tônus inflamatório mediado pela ativação do TLR4, em ganho de peso e em diabetes (92-94).

Do mesmo modo que ocorre com diversos outros tecidos, o SNC, especialmente o hipotálamo, também é susceptível a excesso de nutrientes da dieta. Foi mostrado que uma dieta rica em gordura é capaz de gerar um estado pró-inflamatório local no hipotálamo de ratos (95), e vários estudos indicam o TLR4 como um regulador chave da resistência à insulina e no SNC (96-98).

A despeito dos vários estudos correlacionando o TLR4 com os efeitos negativos do excesso de ingestão de alimentos, pouco se sabe sobre a influência desse receptor sobre os efeitos da RED. O que se sabe é que a RED, ao contrário do alto consumo calórico, diminui a resistência à insulina e seus níveis plasmáticos em roedores, macacos e humanos (99-101). Como a resistência à insulina envolve a participação do TLR4, sua diminuição determinada pela RED também deve envolver a participação desse receptor. Além disso, recentemente um estudo mostrou que pacientes obesos com diabetes tipo 2 tiveram uma redução da expressão de RNA mensageiro de TLR2 e TLR4 em monócitos periféricos após 2 semanas de restrição calórica (102).

Os TLRs também vêm sendo correlacionados com o estresse oxidativo; por exemplo, vários estudos in vivo demonstraram a importância da sinalização do TLR4 na mediação de danos por estresse oxidativo em situações de isquemia/reperfusão e choque hemorrágico 
(revisão em (103)). Durante situações de estresse oxidativo, ocorre a liberação de DAMPs, que podem acionar cascatas inflamatórias tanto pela ativação de TLRs quanto por serem liberados como consequência da sinalização dos TLRs amplificando ainda mais a inflamação, já que a ativação de TLRs nessas situações induz à produção de mais espécies reativas de oxigêno (EROs) (103).

PAMPs originados de patógenos e DAMPs de origem endógena são igualmente efetivos na ativação do sistema imune via TLRs, e estresse de origem tanto oxidativa quanto infecciosa compartilham a mesma sinalização via TLRs (104-106). Desta forma, a mobilização de DAMPs para ativar a sinalização do TLR4 deve representar uma ligação entre estresse oxidativo e inflamação. $O$ entendimento das vias que envolvem a sinalização inflamatória no estresse oxidativo é essencial para o desenvolvimento de estratégias que limitem as suas consequências deletérias. Por fim, dados obtidos durante o meu mestrado mostraram que a dieta intermitente reduz significativamente os níveis de RNA mensageiro de TLR4 em hipocampo de ratos (36).

\section{$1.4 \mathrm{O}$ fator nuclear- $\kappa \mathrm{B}(\mathrm{NF}-\kappa \mathrm{B})$}

Os maiores mecanismos de sinalização ativados pelo TLR2 e TLR4 incluem as cascatas que levam à ativação do $\mathrm{NF}-\kappa \mathrm{B}$, um fator de transcrição que é um heterodímero constituído de combinações de diferentes subunidades. O NF-אB é encontrado em uma variedade de tipos celulares, incluindo neurônios e microglia (107), e pode ser ativado por diversos estímulos, como o LPS, EROs e citocinas tais como TNF e IL-1 $\beta(108,109)$.

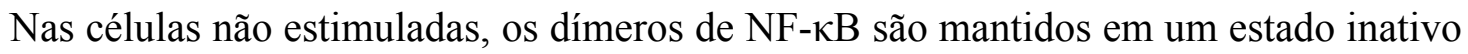

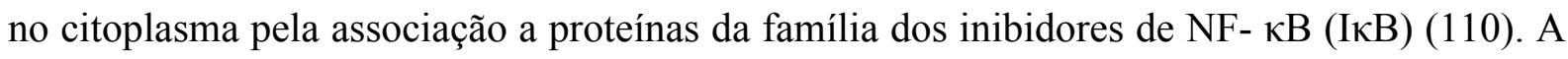

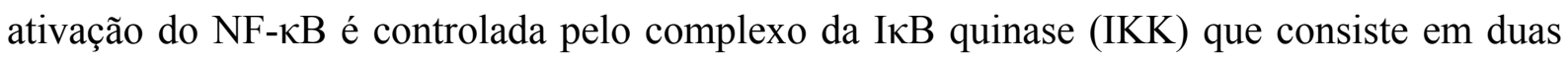
subunidades catalíticas (IKK $\alpha$ e IKK $\beta$ ) (111-114) e a subunidade regulatória NEMO (modulador essencial do NF- $\kappa \mathrm{B}$, também conhecida como IKK $\gamma$ ) $(115,116)$. Após a estimulação celular, o complexo IKK fosforila duas serinas N-terminal específicas das proteínas IאB resultando em sua poliubiquitinação e degradação pelo proteossoma 26S,

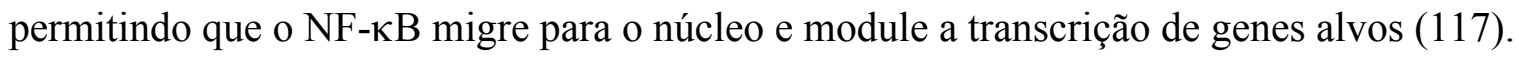

Experimentos envolvendo plasticidade e potenciação de longa duração sugerem a participação do NF-кB na atividade sináptica e na plasticidade neuronal $(109,118,119)$. Além disso, tem sido demonstrado em culturas de neurônios do hipocampo e do cerebelo de

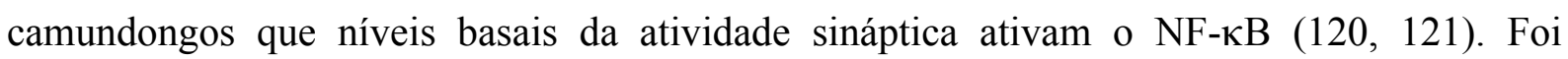




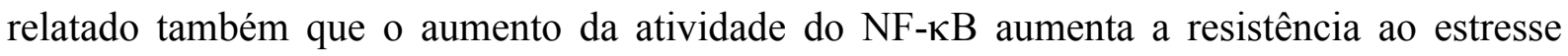
oxidativo em células neuronais, evidenciando uma ação neuroprotetora para este fator de transcrição por suprimir o sinal de morte celular (122).

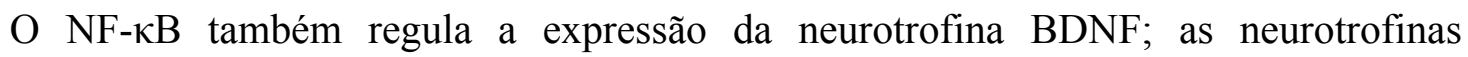
controlam sobrevivência, diferenciação e sinaptogênese, além de exercer importantes funções na plasticidade sináptica no SNC. As respostas fisiológicas das neurotrofinas são mediadas pela ativação de duas classes distintas de receptores transmembrana, os receptores da família da quinase relacionada a tropomiosina (Trk) e a p $75^{\text {NTR }}$ (revisão em $(123,124)$ ). Os efeitos do BDNF dependem de sua ligação ao receptor $\operatorname{TrkB}$ e subsequente ativação de tirosinas quinases presentes no citoplasma. Dessa forma, essa neurotrofina exerce uma importante função na proteção neuronal, podendo proteger os neurônios de danos oxidativos resultantes de vários tipos de injúrias (125).

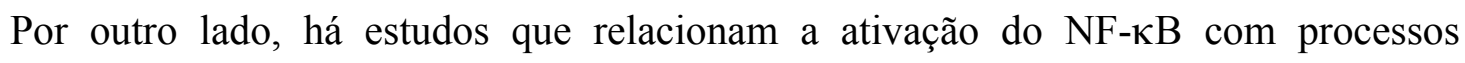
neurodegenerativos, como lesões obtidas por estimulações dopaminérgicas, DP (126) e DA (127). Além disso, dados da literatura demonstram que a ativação da resposta imune periférica pela administração de LPS em roedores com consequente ativação do NF- $\kappa \mathrm{B}$ e aumento na produção de citocinas pró-inflamatórias pode ocasionar dano cognitivo, ocasionando prejuízo no aprendizado e na memória (128-130), uma vez que os receptores de citocinas próinflamatórias estão bem concentrados em áreas associadas à aprendizagem e memória como o hipocampo $(131,132)$.

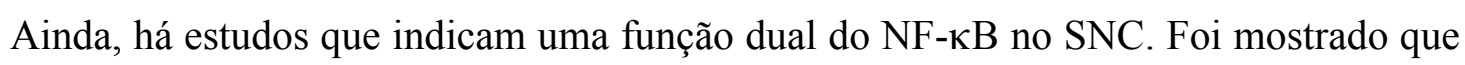
a ativação do NF-אB em neurônios promove sua sobrevivência, enquanto a ativação em células gliais e imunes podem mediar processos patológicos inflamatórios (133).

$\mathrm{O} N F-\kappa B$ modula a transcrição de genes implicados em vários processos celulares, tais como oxido nítrico sintase induzida (Nosi), Il-1 $\beta, T n f-\alpha, I \kappa B \alpha$, além de genes relacionados à neuroproteção, como o $B d n f$. Uma vez que a regulação da expressão destes genes tem

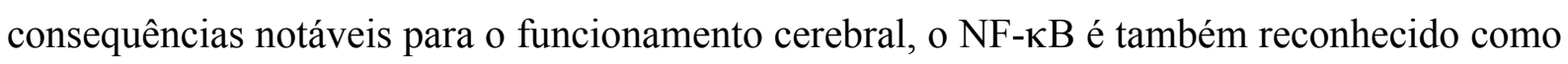
um importante modulador dos processos de desenvolvimento, de plasticidade, neurodegenerativos e inflamatórios $(109,122,134,135)$. Em linhas gerais, a RED parece atuar, dentre outras, em vias associadas à modulação de fatores de transcrição como o NF-кB. No entanto, pouco se sabe sobre os mecanismos moleculares da RED envolvendo a via de

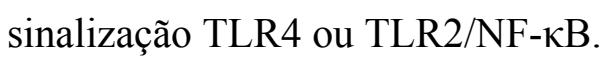




\subsection{0 elemento de resposta ao AMPc (CREB)}

O CREB é um fator de transcrição nuclear constitutivamente expresso que regula a transcrição de genes envolvidos no funcionamento e na sobrevivência neuronais (136-138). Este fator de transcrição, quando ativado, é fosforilado no sítio de serina $133 \mathrm{em}$ resposta a múltiplas vias de sinalização $(139,140)$. Estudos em várias espécies mostraram que, para a formação da memória de longa duração, é essencial que ocorra a ativação do CREB e a indução da transcrição de genes dependentes de CREB, como c-fos e $B d n f$ (revisão em (141, 142)). São observadas deficiências na memória espacial de ratos após infusão intrahipocampal de oligonucleotídeos antisense de CREB (143). Além disso, estudos mostraram alterações na fosforilação de CREB na região CA1 do hipocampo correlacionadas com o dano da memória espacial que ocorre durante o envelhecimento (144).

Apesar da importância da fosforilação do CREB ser bem documentada para a formação de memória de longa duração e da existência de estudos que correlacionam a RED com melhora cognitiva, pouco se sabe sobre os efeitos da dieta intermitente sobre a modulação do CREB além da participação dos receptores TLR2 e TLR4.

\subsection{O fator 2 relacionado ao NF-E2 (NRF2)}

O NRF2 é outro fator de transcrição investigado neste projeto. Ele exerce uma importante função na regulação das respostas de detoxificação celular, atuando tanto em situações de estresse oxidativo agudo quanto na regulação da atividade oxidativa basal. A exposição a estresse oxidativo leva a um aumento da atividade do NRF2 com consequente ativação de muitos genes protetores (145-148).

Alguns dos produtos gênicos regulados pelo NRF2 são enzimas de detoxificação de fase II, assim como uma grande quantidade de reguladores redox que inclui, entre outros, a hemeoxigenase 1 (HO1) (revisão em (149)). Esta enzima catalisa a conversão do grupo heme pró-inflamatório em ferro $\left(\mathrm{Fe}^{3+}\right)$ e nos componentes anti-inflamatórios monóxido de carbono (CO) e biliverdina (150-152), que é subsequentemente convertida em bilirrubina com propriedades antioxidantes $(153,154)$.

Pelo menos alguns dos efeitos benéficos da RED são devidos a um aumento da resistência contra estresse oxidativo e muito provavelmente devem envolver sinalizações como a do NRF2, que é conhecido por suas funções antioxidantes e preventivas do câncer, além de, assim como a RED, ser relacionado com aumento de expectativa de vida. Por 
exemplo, o envelhecimento está associado com um declínio nos níveis de proteínas antioxidantes no organismo; a ativação farmacológica do NRF2 mostrou ser capaz de reverter esse declínio $(155,156)$. Apesar de em geral estudos indicarem que o NRF2 é um provável efetor de alguns dos efeitos beneficiais da RED, mais estudos ainda são necessários para a elucidação dos possíveis mecanismos de ação e as vias de sinalização que envolvem a participação desse fator de transcrição.

Além do envolvimento com a RED, estudos recentes demonstraram um efeito modulatório do NRF2 sobre a resposta imune inata mediada pelo TLR4. Por exemplo, camundongos $\mathrm{Nrf}^{-/-}$são mais sensíveis à inflamação mediada por bactéria e LPS (157-159), um agonista do TLR4. Em um modelo de peritonite aguda e choque induzido por LPS, camundongos $\mathrm{Nrf}^{-/-}$apresentaram uma maior mortalidade quando comparados com camundongos $\mathrm{Nrf}^{+/+}$. Da mesma forma, o desafio com LPS induz uma hiperinflamação no pulmão de camundongos $\mathrm{Nrf}^{-/ \text {.- }}$. Análise de expressão gênica global por microarray revelou um aumento da expressão de citocinas, quimiocinas, moléculas de adesão e outros efetores da resposta imune inata no pulmão de camundongos $\mathrm{Nrf}^{-/-}$após desafio com LPS (157). Além disso, a estimulação com LPS resulta em um aumento da atividade da IKK e subsequente

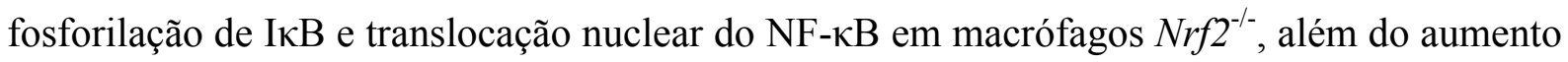
da produção de EROs induzido por LPS, quando comparados com macrófagos $\mathrm{Nrf}^{+/+}$(157, 160). Entretanto, os eventos de sinalização responsáveis pela amplificação da resposta imune inata desencadeada pelo TLR4 ou TLR2 em animais $\mathrm{Nrf}^{-/-}$são desconhecidos.

\subsection{O forkhead box O (FOXO)}

Os fatores de transcrição da família FOXO, que incluem FOXO1, FOXO3, FOXO4 e FOXO6, são reguladores transcricionais caracterizados pelo domínio de ligação ao DNA “forkhead Box" conservado (161). Essas proteínas modulam uma grande variedade de genes, todos ligados ao controle sobre o metabolismo energético em resposta a alterações ambientais como, por exemplo, a restrição ou disponibilidade de alimento. Além disso, assim como o NRF2, o FOXO também é ativado e regulado por estresse oxidativo, e um aumento dos EROs intracelulares induz a sua translocação para o núcleo, onde encontra-se transcricionalmente ativo (revisão em (162)).

A estimulação dos receptores de insulina após o consumo de alimentos leva à ativação da via PI3K/AKT, que atua inativando os fatores de transcrição FOXO por fosforilação. Dessa forma, durante a RED ocorre uma complexa interação entre a ativação e desativação 
dos fatores FOXO, que pode resultar em efeitos potencialmente benéficos dependendo das condições celulares predominantes. Em situações de estresse, a família de FOXO de mamíferos promovem a sobrevivência celular através da regulação da apoptose, o controle dos pontos de checagem do ciclo celular e a resistência a estresse oxidativo $(163,164)$. A ativação de FOXO3 ou FOXO4 leva a um aumento do intervalo da fase G1 do ciclo celular e aumenta a apoptose, provavelmente como uma forma de eliminar as células afetadas por estresse oxidativo (165). Dessa forma, a modulação na via PI3K/AKT pode exercer uma grande influência sobre a sobrevivência celular e essa modulação pode ser crítica para a ocorrência dos efeitos benéficos da RED no organismo.

A RED desacopla a sinalização da insulina e FOXO através da redução dos níveis plasmáticos de insulina em ratos (166). Essa redução resulta em diminuição da fosforilação de AKT no fígado (167) e diminuição da expressão de PI3K no músculo (168). Além disso, ocorre um aumento compensatório da expressão de FOXO pela RED (167, 169-171). Portanto, quando a sinalização da insulina é reduzida, por exemplo durante a RED, ocorre o aumento tanto da translocação de FOXO para núcleo quanto da expressão de FOXO (167, 169-171).

Em ratos, foi mostrado que a RED atenua a redução da atividade transcricional do FOXO1 no fígado que ocorre em resposta à sinalização da insulina ativada pela glicose circulante (172). Outro estudo mostrou que células tumorais humanas implantadas em camundongos que não respondiam ao efeito antineoplásico da RED possuíam mutações que causavam a ativação constitutiva da via PI3K/AKT e com isso uma menor ativação de FOXO1. A hiperexpressão de FOXO1 aumentou a resposta dessas células à RED e análises imunohistoquímicas também mostraram uma maior localização nuclear de FOXO1 após a RED. Esse estudo mostrou claramente a necessidade da via PI3K/AKT/FOXO1 funcionando corretamente para que ocorra os efeitos antineoplásicos da RED (173). Ainda, recentemente foi mostrado que a RED aumenta a expressão de genes relacionados com a proteção contra estímulos estressores, apoptose e reparo de DNA em resposta ao estresse oxidativo no fígado e hipocampo e que esses efeitos benéficos da RED foram diminuídos nesses tecidos em camundongos com expressão de FOXO1 reduzida (174)

Atualmente ainda há poucas evidências do papel do FOXO1 nos efeitos da RED no SNC e, apesar de um estudo recente que mostra um importante papel do FOXO na homeostase da imunidade inata (175), pouco se sabe sobre sua relação com os receptores TLR4. O que se sabe é que o FOXO traduz os estímulos ambientais, incluindo o estímulo 
estressor induzido pela RED, em mudanças nos programas de expressão gênica que podem resultar em longevidade e envelhecimento saudável do organismo. 


\section{OBJETIVOS}

Dados da literatura que sugerem que: a) A RED tem efeitos neuroprotetores frentes a diferentes estímulos tóxicos e protege contra o estresse oxidativo; b) Tanto os receptores

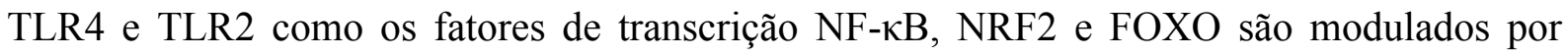
estresse oxidativo e podem estar envolvidos nos efeitos mediados pela RED; c) O NF- $\kappa B$, cuja ativação pode ocorrer via TLR4 e TLR2, pode estar associado à neuroproteção como por exemplo pela indução da expressão de BDNF, mas também podem estar envolvido na neurodegeneração e inflamação; d) Os TLRs podem exercer efeitos sobre a neuroplasticidade e possivelmente sobre a cognição.

A partir disto, este projeto teve como objetivo avaliar a influência dos receptores TLR2 e TLR4 sobre efeitos induzidos pela dieta intermitente na memória e aprendizagem, e sobre os fatores de transcrição NF- $\mathrm{B}$, NRF2 e FOXO1 nas regiões cerebrais do hipocampo e hipotálamo de camundongos nocaute para o receptor TLR2 ou TLR4 (esquema 1).

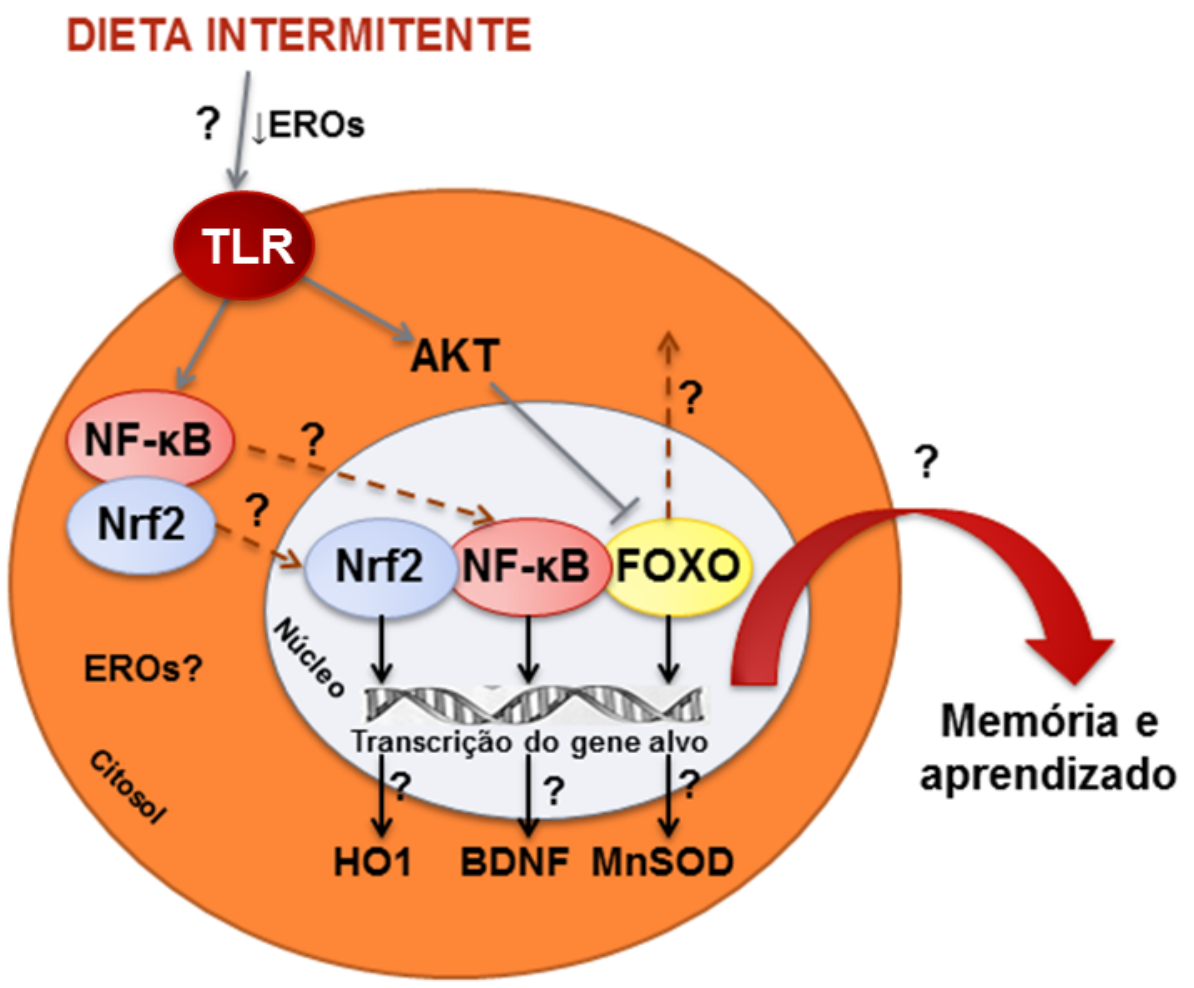

Esquema 1. Representação esquemática dos objetivos do estudo. Os receptores TLR2 e TLR4 podem ativar vias de sinalização intracelulares que resultam na modulação de fatores de transcrição como no NRF2, NF- $\kappa \mathrm{B}$ e FOXO e consequentemente de seus genes alvos como, por exemplo, a HO1, BDNF e $\mathrm{MnSOD}$, respectivamente. Esse efeito modulatório pode resultar em alterações nos processos relacionados à memória e aprendizagem. Uma vez que sabe-se que a dieta intermitente também é capaz de modular as vias associadas a esses fatores de transcrição e a função cognitiva, o objetivo desse estudo é avaliar a possível influência dos receptores TLR2 e TLR4 nesse processo. 
Foram avaliados em camundongos nocaute para os receptores TLR2 e TLR4 e em seus respectivos controles submetidos à dieta controle ou intermitente:

1) Comportamentos ansiosos e depressivos e processos cognitivos (memória e aprendizagem), através dos testes comportamentais de campo aberto, labirinto em cruz elevado, labirinto aquático de Morris, esquiva inibitória e teste de suspensão da cauda;

2) $\mathrm{O}$ fator de transcrição $\mathrm{NF}-\kappa \mathrm{B}$, através da realização do ensaio de retardamento da mobilidade eletroforética (gel shift);

3) O fator de transcrição FOXO1, através da medição dos níveis de fosforilação do FOXO1 e da proteína AKT que regula sua atividade transcricional por western blot, e de MnSOD, um gene alvo regulado pelo FOXO1, por RT-PCR em tempo real;

4) O fator de transcrição NRF2 por western blot e por ensaio de transativação, e a enzima HO1 cuja expressão gênica é regulada por esse fator;

5) $\mathrm{O}$ fator de transcrição $\mathrm{CREB}$, através da realização do ensaio de retardamento da mobilidade eletroforética (gel shift);

6) O fator de transcrição AP1, através da realização do ensaio de retardamento da mobilidade eletroforética ( $\mathrm{gel}$ shift);

7) O BDNF, neurotrofina modulada por NF- $\kappa B$ e CREB, através do ensaio de ELISA e da avaliação dos níveis de RNAm dos transcritos de $B d n f-I, B d n f-I I I$ e $B d n f-I V$;

8) Os marcadores de autofagia mTOR, AMPK e P53, através do ensaio de western blot;

9) Os níveis de estresse oxidativo, através da dosagem dos níveis de peroxidação lipídica por western blot de 4-hidroxi-2-nonenal (HNE) e dos níveis de 8-epi-Prostaglandin F2 $\alpha$ pelo analisador imuno-enzimático Cobas Fara II;

10) As atividades antioxidantes no hipocampo, através da avaliação dos níveis de RNAm de catalase, SOD1 e SOD2 por RT-PCR em tempo real e da atividade das enzimas antioxidantes GR, GST e GPx;

11) Os níveis das chaperonas HSP70 e HSP90 por western blot;

12) Os níveis das citocinas/quimiocinas inflamatórias TNF, IFN- $\gamma$, IL-1 $\beta$, IL-2, IL-4, IL-6, IL-10, IL-12, IL-15 e RANTES por ensaios de multiplex e ELISA;

13) Os biomarcadores periféricos colesterol, corpos cetônicos, creatina e corticosticosterona pelo analisador imuno-enzimático Cobas Fara II e

14) A tolerância à glicose, através da realização de curva glicêmica. 


\section{MATERIAL E MÉTODOS}

\subsection{Animais}

Foram utilizados camundongos machos C57B16 com nocaute do receptor TLR4 ou TLR2 e, como controle, camundongos C57B16 wild type (WT) com TLR4 e TLR2 normais, provenientes do Centro de Desenvolvimento de Modelos Experimentais para Medicina e Biologia (CEDEME) da Universidade Federal de São Paulo (UNIFESP). O protocolo experimental está de acordo com os Princípios Éticos de Experimentação Animal adotado pelo Colégio Brasileiro de Experimentação Animal (COBEA) e foi aprovado pela Comissão de Ética em Experimentação Animal (CEEA) sob no 108 nas fls. 108 do livro 02.

Os animais foram transferidos para o biotério do Laboratório de Neurofarmacologia Molecular do Departamento de farmacologia - ICB, USP/SP com aproximadamente 2 meses de idade e mantidos em grupos de 5 em gaiolas plásticas ventiladas por aproximadamente 1 mês antes do início dos experimentos. A temperatura ambiente foi mantida constante $(22 \pm 2$ ${ }^{\circ} \mathrm{C}$ ) e os animais foram mantidos sob um ciclo de iluminação controlado claro/escuro (claro entre 7 - 19 h). Durante o período que os animais estiverem em nosso biotério, foi mantido o fornecimento de água e ração ad libitum antes do início da dieta intermitente.

\subsection{Dieta intermitente}

Os animais foram divididos em 4 grupos, com aproximadamente 5 animais cada um, por experimento, sendo um grupo C57B16 selvagem com acesso livre ao alimento (controle), um grupo selvagem submetidos à RED, um grupo com nocaute do receptor TLR4 controle $\left(T l r 4^{-/}\right)$, e um grupo nocaute do TLR4 submetido à RED. O mesmo foi feito com os camundongos com nocaute do receptor TLR2 (Esquema 2A). O protocolo de RED empregado foi o da dieta intermitente, ou seja, 1 dia com ração, no dia seguinte sem ração, no outro com, e assim sucessivamente, por um período total de 30 dias com água ad libitum, de acordo com Mattson e Wan (60). A dieta começou quando os animais completaram 3 meses e a ração foi colocada e retirada sempre pela manhã. O grupo controle recebeu ração e água ad libitum durante todo o experimento.

Para os ensaios bioquímicos (Esquema 2B), no $31^{\circ}$ dia de dieta intermitente, os animais foram anestesiados com isofluorano e submetidos à eutanásia por decapitação, que foi realizada pela manhã para a extração dos encéfalos. O sangue foi rapidamente coletado e 
centrifugado a $3.000 \mathrm{x}$ g por 10 minutos e o soro foi coletado e estocado à $-80^{\circ} \mathrm{C}$ até o dia dos ensaios. Ainda, as estruturas cerebrais do hipocampo e hipotálamo foram dissecada sobre uma placa gelada, e estocadas a $-80{ }^{\circ} \mathrm{C}$ até o dia dos ensaios. No dia que antecede o sacrifício, os camundongos permaneceram com ração. Portanto, o sacrifício foi realizado com os animais tendo tido contato com a ração nas últimas 24 horas para retirar qualquer efeito do jejum agudo.

Para os ensaios comportamentais (Esquema 2C), 30 dias após o início do protocolo de dieta intermitente, os camundongos foram submetidos ao teste do campo aberto, seguido pelo teste do labirinto em cruz elevado no dia seguinte. Nos 10 próximos dias, os animais foram avaliados no labirinto aquático de Morris, sendo 5 dias de treino, 1 dia de teste de memória de referência e 4 dias de teste de memória operacional. Após o término do labirinto aquático, os camundongos foram submetidos sucessivamente ao treino e teste da esquiva inibitória e ao teste de suspensão da cauda. 


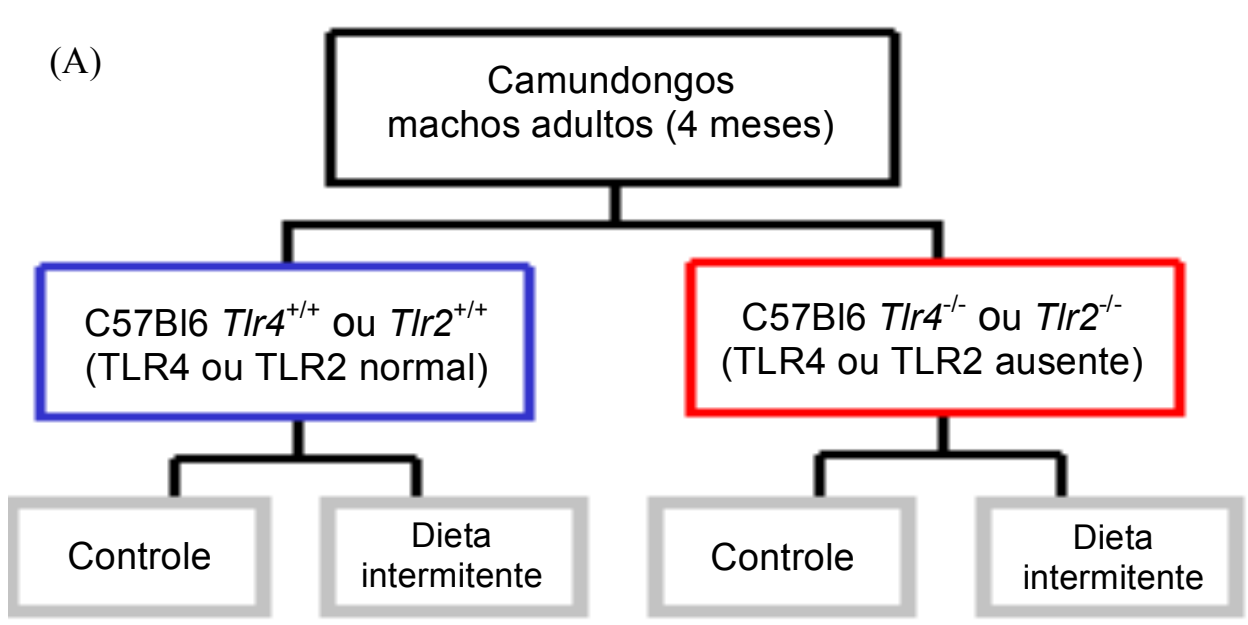

(B)
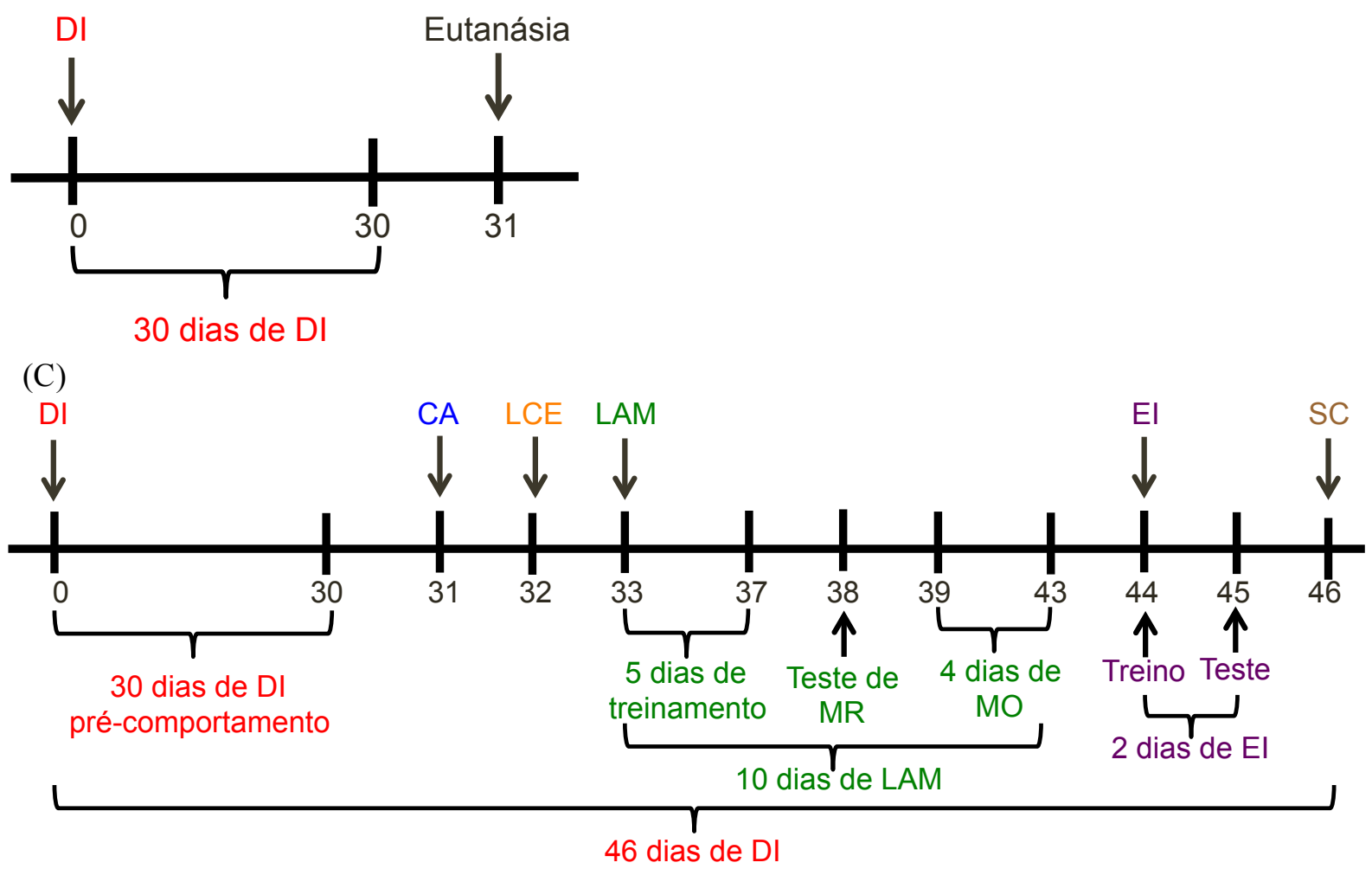

Esquema 2. Esquema do delineamento experimental. (A) Camundongos machos adultos foram divididos em 4 grupos: C57Bl6 Tlr4 ${ }^{+/+}$(TLR4 funcional) controle, C57Bl6 Tlr4 ${ }^{+/+}$submetidos à dieta intermitente, C57B16 Tlr4 $4^{-/-}$(TLR4 nocauteado) controle e C57B16 Tlr $4^{-/ /}$submetidos à dieta intermitente. A mesma divisão de grupos foi feita com os animais $\mathrm{Tlr}^{-/}{ }^{-\alpha}$. Em B e C, consideramos o dia zero aquele em que se iniciou a dieta intermitente (DI). (B) Para os experimentos bioquímicos, os animais foram submetidos ao protocolo de DI por 30 dias e no $31^{\circ}$ dia foram submetidos à eutanásia. (C) Para os experimentos comportamentais, após 30 dias do início da dieta intermitente, os animais foram submetidos ao teste de campo aberto (CA) no $31^{\circ}$ dia, e no dia seguinte ao teste de labirinto em cruz elevado (LCE). No $33^{\circ}$ dia, foram submetidos ao teste do labirinto aquático de Morris (LAM) e passaram por 5 dias de treinamento no LAM até o $37^{\circ}$ dia. No $38^{\circ}$ dia, foram submetidos ao teste de memória de referência (MR) do LAM, e nos 4 dias consecutivos $\left(39^{\circ}\right.$ a $\left.43^{\circ}\right)$ tiveram a memória operacional (MO) avaliada no LAM. Nos dias consecutivos, foram submetidos ao treino da esquiva inibitória (EI), ao teste da EI e por último ao teste de suspensão da cauda (SC), no $44^{\circ}, 45^{\circ}$ e $46^{\circ}$ dia, respectivamente. O protocolo de DI foi mantido durante todos os experimentos comportamentais, totalizando 46 dias de DI (DI, dieta intermitente; CA, campo aberto; LCE, labirinto em cruz elevado; LAM, labirinto aquático de Morris; MR, memória de referência; MO, memória operacional; EI, esquiva inibitória; SC, suspensão da cauda). 


\subsection{Extração de proteínas citosólicas e nucleares}

O método utilizado foi descrito em Rong e Baudry (176). As estruturas foram descongeladas e homogeneizadas em homogeneizadores vidro-vidro com tampão fosfatosalina (PBS: $\mathrm{NaCl} 137 \mathrm{mM}, \mathrm{KCl} 2,68 \mathrm{mM}, \mathrm{KH}_{2} \mathrm{PO}_{4} 1,27 \mathrm{mM}, \mathrm{Na}_{2} \mathrm{HPO}_{4} 8,06 \mathrm{mM}$ ) gelado adicionado de inibidores de proteases e fosfatase (PMSF 0,5 M; leupeptina 2,5 $\mu \mathrm{g} / \mathrm{mL}$; antipaína $2 \mu \mathrm{g} / \mathrm{mL}$; NaF $30 \mathrm{mM}$; Pirofosfato de sódio $20 \mathrm{mM}$; B-GP $5 \mathrm{mM}$ ) e EDTA 0,1 mM. Em seguida o homogenato foi centrifugado a $12.000 \mathrm{x}$ g por 30 segundos à $4{ }^{0} \mathrm{C}$. $\mathrm{O}$ sobrenadante foi reservado para os ensaios de western blot. O pellet foi ressuspendido em tampão de lise (HEPES $10 \mathrm{mM}$; $\mathrm{MgCl}_{2}$ 1,5 mM; KCl $10 \mathrm{mM}$; PMSF 0,5 mM; leupeptina $2 \mu \mathrm{g} / \mathrm{mL}$; antipaína $2 \mu \mathrm{g} / \mathrm{mL}$; NaF $30 \mathrm{mM}$; Pirofosfato de sódio $20 \mathrm{mM}$; B-GP $5 \mathrm{mM}$ ) e incubado em gelo durante 10 minutos. Foi adicionado em seguida $10 \mu \mathrm{L}$ de NP-40 10\% com agitação vigorosa, centrifugando-se à $12.000 \mathrm{x}$ g por 30 segundos a $4{ }^{0} \mathrm{C}$, e o sobrenadante resultante foi descartado. O pellet obtido foi ressuspendido em tampão de extração (HEPES 20 mM; Glicerol 25 ; $\mathrm{MgCl}_{2}$ 1,5 mM; $\mathrm{NaCl} 300 \mathrm{mM}$; EDTA 0,25 mM; PMSF 0,5 mM; leupeptina $2 \mu \mathrm{g} / \mathrm{mL}$; antipaína $2 \mu \mathrm{g} / \mathrm{mL}$; NaF $30 \mathrm{mM}$; Pirofosfato de sódio $20 \mathrm{mM}$; B-GP 5 $\mathrm{mM}$ ) e incubado 20 minutos em gelo, centrifugando-se o extrato à $12.000 \mathrm{x}$ g por 20 minutos a $4{ }^{0} \mathrm{C}$. O sobrenadante, correspondente ao extrato nuclear, foi recolhido e estocado a $-80{ }^{0} \mathrm{C}$ para posterior utilização nos ensaios.

\subsection{Ensaio de western blot}

As amostras para o ensaio de western blot foram preparadas como descrito no item anterior. O ensaio de western blot usado é baseado no descrito por Laemmli (177). As proteínas foram preparadas com o tampão de amostra (0,125 M tris- $\mathrm{HCl} ; 4 \%$ de SDS; 20\% v/v glicerol; 0,2 M de DTT; 0,02\% de azul de bromofenol; $\mathrm{pH}$ 6,8) e fervidas por 5 minutos a $95{ }^{\circ} \mathrm{C}$. As amostras foram aplicadas no gel de SDS-poliacrilamida $10 \%$ (acrilamida/bisacrilamida [37,5:1], 1\% SDS) para que houvesse a separação das proteínas contidas na amostra. No mesmo gel foi adicionado um padrão de peso molecular. Para a eletroforese foi utilizado um tampão de corrida consistindo em $25 \mathrm{mM}$ de tris-base; 0,192 M de glicina; $0,1 \%$ de SDS. O gel foi corrido por volta de 2 horas a $100 \mathrm{~V}$. Ao final da corrida, as proteínas separadas e contidas no gel foram transferidas eletroforeticamente para uma membrana de nitrocelulose (Biorad, Hercules, CA, EUA) por aproximadamente 2 horas a 80 V. Para a transferência foi usado um tampão contendo $25 \mathrm{mM}$ de tris-base, $192 \mathrm{mM}$ de 
glicina, $20 \%$ de metanol e água bidestilada. Após a transferência, as membranas foram coradas com solução de vermelho de Ponceau ( $0,5 \%$ Ponceau-S; $5 \%$ ácido tricloro acético e água bidestilada), lavadas com água bidestilada até retirar todo o excesso da solução corante e deixadas overnight a $4{ }^{\circ} \mathrm{C}$ numa solução contendo TBS $(100 \mathrm{mM}$ tris-base; $0,9 \% \mathrm{NaCl}$ e água), $0,05 \%$ de Tween 20 e 5\% de leite desnatado e para bloquear ligações inespecíficas com o anticorpo. Após essa etapa, as membranas foram incubadas com o anticorpo primário diluído em TBS-T overnight a $4{ }^{\circ} \mathrm{C}$. As membranas foram então lavadas 5 vezes com TBS-T e incubadas com o anticorpo secundário por 90 minutos. A revelação foi feita através de kit de quimioluminescência (Millipore, Billerica, MA, EUA).

\subsection{Ensaio de retardamento da mobilidade eletroforética em gel de poliacrilamida (gel shift)}

\subsubsection{Marcação da sonda}

Este protocolo foi realizado de acordo com o método utilizado em publicações anteriores de nosso grupo (36). Os oligonucleotídeos do NF-кB (5'-AGT TGA GGG GAC TTT CCC AGG C-3'), CREB (5'-AGA GAT TGC CTG ACG TCA GAG AGC-3') ou AP1 (5'-CGC TTG ATG AGT CAG CCG GAA-3') foram marcados com a adição de $\gamma^{-32}$ P ATP numa solução contendo Tampão $\mathrm{T}_{4}$ quinase (em mM: Tris- $\mathrm{HCl} 700, \mathrm{pH} 7,6 ; \mathrm{MgCl}_{2} 100$ e DTT 50), $\mathrm{T}_{4}$ quinase e água; nas concentrações de: 3,5 pmol de oligonucleotídeo, $1 \mathrm{U} / \mu \mathrm{L}$ de $\mathrm{T}_{4}$ quinase, $1 \mu \mathrm{L}$ de $\gamma_{-}{ }^{32} \mathrm{P}$ ATP (3Ci/mmol), $1 \mu$ de tampão $\mathrm{T}_{4}$ Kinase Buffer $(10 \mathrm{X})$ em 10 $\mu \mathrm{L}$ de volume de reação). Após incubação a $37{ }^{\circ} \mathrm{C}$ por $10 \mathrm{~min}$, o excesso de $\gamma^{32} \mathrm{P}$ ATP foi retirado com resina sephadex G-25. Foram colocadas colunas (Microspin G-25) em um tubo de microcentrífuga, centrifugando-se por $1 \mathrm{~min}$ a $3.000 \mathrm{rpm}$. A coluna foi transferida para um novo tubo aplicando-se a sonda marcada no centro da resina. Após centrifugação, o eluato foi recolhido, e no dia do ensaio a atividade da sonda foi determinada, utilizando-se uma atividade final de aproximadamente $30.000 \mathrm{cpm} / \mu \mathrm{L}, 25.000 \mathrm{cpm} / \mu \mathrm{L}$ ou $20.000 \mathrm{cpm} / \mu \mathrm{L}$ para o NF- $\mathrm{B}, \mathrm{CREB}$ e AP1 respectivamente.

\subsubsection{Reação de Ligação e corrida do gel}

Foram adicionados a um tubo de microcentrífuga: $4 \mu \mathrm{L}$ de tampão de ligação $5 \mathrm{X}$ $\left(\mathrm{MgCl}_{2} 5\right.$ mM; EDTA 2,5 mM; DTT 2,5 mM; NaCl 300 mM; Tris-HCl 50 mM pH 7,5; Poly dIdc $0,25 \mu \mathrm{g} / \mu \mathrm{L}$; glicerol $20 \%$ ), extrato nuclear (10 $\mu$ g de proteína) e $\mathrm{H}_{2} \mathrm{O}$ q.s.p. para $20 \mu \mathrm{L}$ de volume final. $\mathrm{O}$ tubo foi incubado por 20 minutos a temperatura ambiente, adicionando-se 
em seguida a sonda marcada radioativamente $(1 \mu \mathrm{L})$, e novamente o tubo foi incubado por 30 minutos a temperatura ambiente. A corrida foi visualizada com a adição de $1 \mu \mathrm{L}$ de azul de bromofenol ao controle negativo. O conteúdo total do meio de reação foi aplicado no gel de poliacrilamida 5,5\% [acrilamida/bisacrilamida (37,5:1)]. Para a eletroforese foi utilizado um tampão de corrida consistindo em 0,5 x TBE (1 X TBE = Tris $90 \mathrm{mM}$, Ácido Bórico $90 \mathrm{mM}$, EDTA $1 \mathrm{mM}$ ). O gel foi corrido por cerca de 2 horas a $150 \mathrm{~V}$. Ao final da corrida, o gel foi secado procedendo-se em seguida a exposição do filme ao gel em cassete a $-80{ }^{\circ} \mathrm{C}$.

\subsection{Determinação da concentração de proteínas}

A dosagem foi realizada através do método de Bradford (178) utilizando reagente da Bio-Rad e subsequente medição da absorbância no comprimento de onda de $595 \mathrm{~nm}$ em um leitor de microplacas. A comparação com uma curva padrão de albumina forneceu a concentração de proteínas presente nas amostras.

\subsection{Ensaio Imunoabsorvente Ligado à Enzima (ELISA)}

As concentrações de BDNF e TNF no hipocampo e hipotálamo ou de corticosterona no plasma foram medidas por meio do ensaio de ELISA de acordo com as instruções do fabricante (eBioscience, San Diego, CA, EUA). Resumidamente, placas de 96 poços foram sensibilizadas com anticorpos monoclonais específicos. As placas foram incubadas por 18 horas a $4{ }^{\circ} \mathrm{C}$, e lavadas com PBST $(0,05 \%$ Tween $20 \mathrm{em}$ PBS). Em seguida, as placas foram bloqueadas com $200 \mu \mathrm{L} /$ poço de gelatina a $3 \%$ em PBST a $37{ }^{\circ} \mathrm{C}$ x $3 \mathrm{~h}$. Logo depois, as placas foram lavadas com PBST e $100 \mu \mathrm{L}$ das amostras ou dos padrões de BDNF ou TNF. As placas foram incubadas por mais $18 \mathrm{~h} \mathrm{a} 4{ }^{\circ} \mathrm{C}$. Após lavagem, $100 \mu \mathrm{L}$ do anticorpo biotinilado específico para a proteína analisada foram acrescentados por $1 \mathrm{~h}$ a temperatura ambiente. Após a lavagem das placas, $100 \mu \mathrm{L}$ de estreptavidina-peroxidase foram adicionados por 30 minutos. As reações foram reveladas pela adição de $50 \mu \mathrm{L}$ de ácido cítrico $0,2 \mathrm{M}$ por poço. A leitura da reação foi realizada a $450 \mathrm{~nm}$ em espectrofotômetro Espectra Max plus 384 (Molecular Devices, Sunnyvale, CA, EUA). As concentrações das amostras foram calculadas a partir da curva-padrão de 6 pontos obtidas com o padrão de BDNF, corticosterona ou TNF diluídos. 


\subsection{Multiplex}

As concentrações de citocinas e quimiocinas foram simultaneamente medidas em $25 \mathrm{uL}$ de soro ou homogenatos de hipocampo utilizando-se um kit MILLIPLEX MAP para camudongos (Millipore, Billerica, MA) seguindo instruções do fabricante. Resumidamente, as amostras de hipocampo foram homogeneizadas em um tampão contendo Tris- $\mathrm{HCl} 20 \mathrm{mM}(\mathrm{pH}$ 7,5), $\mathrm{NaCl} 150 \mathrm{mM}, 0,05 \%$ de Tween-20, PMSF $1 \mathrm{mM}$, Antipaína 2,5 ug / mL e leupeptina $2,5 \mathrm{ug} / \mathrm{mL}$. A concentração de proteína de cada amostra foi medida pela técnica anteriormente descrita. Esferas magnéticas com anticorpos imobilizados específicos para os analitos foram detectados em uma máquina Luminex 100 xMAP (Austin, TX). Foram geradas curvas padrões para cada analito usando o padrão incluso no kit diluído em matriz para amostras de soro ou em tampão de lise para amostras de tecido. A intensidade de fluorescência média para cada analito foi calculada usando uma curva de parâmetros logísticos de cinco pontos e normalizada pela quantidade de proteína em cada amostra.

\subsection{Análise da ligação NRF2/ARE pelo ensaio de transativação}

A ativação do NRF2 e a eficácia de sua ligação com a região promotora ARE foram avaliadas em extratos nucleares de hipocampo e hipotálamo utilizando o TransAM NRF2 Kit (Active Motif, Carlsbad, CA) seguindo as instruções do fabricante. Resumidamente, alíquotas de $10 \mathrm{mg}$ de proteína nuclear foram incubadas com oligonucleotídeos imobilizados contendo o sítio de ligação ARE (5'-GTCACAGTACTCAGCAGAATCTG-3'). A forma ativa do NRF2 ligada ao oligonucleotídeo foi detectada com anticorpo primário anti-NRF2 após o tratamento com anticorpo secundário conjugado com HRP. O cromógeno formado como resultado da atividade específica do fator de transcrição nos extratos nucleares foi determinada utilizando um leitor de placas a $450 \mathrm{~nm}$, e a absorbância foi expressa como a atividade do NRF2.

\subsection{Reação em cadeia da polimerase - transcrição reversa (RT-PCR) em tempo real}

O RNA total do tecido foi extraído utilizando o reagente Trizol (Invitrogen, Carlsbad, CA, EUA) e $3 \mu \mathrm{g}$ foram tratados com DNAse I e submetidos à transcrição reversa utilizando oligo(dT) $)_{20}$ e a transcriptase reversa MMLV de acordo com instruções do fabricante (Invitrogen). Os transcritos foram amplificados utilizando-se oligonucleotídeos iniciadores específicos para os genes avaliados (Tabela 1) ou sondas Taqman (Applied Biosystems, 
Forster City, CA, EUA). Como controle negativo, reações foram realizadas na ausência de cDNA. Cada reação foi realizada em triplicata contendo $3 \mu \mathrm{L}$ de cDNA diluído (diluição variável dependendo do gene avaliado), além de $6 \mu \mathrm{L}$ de Power SyBr Green PCR Master Mix (Applied Biosystems) e $300 \mathrm{nM}$ de cada oligonucleotídeo iniciador. A condição da reação foi: $95^{\circ} \mathrm{C}$ por 5 minutos, seguido de 45 ciclos de $95{ }^{\circ} \mathrm{C}$ por 10 segundos, $60{ }^{\circ} \mathrm{C}$ por 10 segundos e $72{ }^{\circ} \mathrm{C}$ por 30 segundos. Uma análise de curva de melting de $76{ }^{\circ} \mathrm{C}$ a $84{ }^{\circ} \mathrm{C}$ foi realizada no final de cada reação para controle de qualidade. O cycle threshold $(\mathrm{Ct})$ e a eficiência dos pares de oligonucleotídeos iniciadores foram estabelecidos automaticamente de acordo com algoritmos do sistema do termociclador 7500 Fast Real-Time PCR System (Applied Biosystems). A expressão gênica relativa foi determinada utilizando o teste de randomização e recolocação Pair Wise P(H1) (179) realizado no programa REST 2009.

Tabela 1. Sequências dos oligonucleotideos iniciadores utilizados para a reação de RT-PCR em tempo real, para amplificação da região codificadora de $B d n f-1, B d n f-3, B d n f-4$ e do controle endógeno Hprt.

\begin{tabular}{|c|c|}
\hline \multirow{2}{*}{$\begin{array}{c}B d n f-1 \\
(\operatorname{Anexo} A)\end{array}$} & 5' GCTTTGCGGATATTGCGAAGGGTT -3' \\
\hline & Reverso 5'- ACCTGGTGGAACATTGTGGCTTTG -3' \\
\hline \multirow{2}{*}{$\begin{array}{c}B d n f-3 \\
\text { (Anexo B) }\end{array}$} & 5' CCAGAGCAGCTGCCTTGATGTTTA -3' \\
\hline & Reverso 5' CCGCCTTCATGCAACCGAAGTAT -3' \\
\hline \multirow{2}{*}{$\begin{array}{c}B d n f-4 \\
\text { (Anexo C) }\end{array}$} & 5' TGACAACAATGTGACTCCACTGCC -3' \\
\hline & Reverso 5' ATGGTCATCACTCTTCTCACCTGG -3' \\
\hline \multirow{2}{*}{$\begin{array}{c}\text { Hprt } \\
\text { (Anexo D) }\end{array}$} & 5' TATGCCGAGGATTTGGAAAA -3' \\
\hline & Reverso 5' ACAGAGGGCCACAATGTGA -3' \\
\hline
\end{tabular}

\subsection{Análise de biomarcadores periféricos}

As concentrações séricas de 3-hidroxibutirato, colesterol, glicose e creatina foram medidas utilizando o equipamento Roche Cobas Fara II (Roche Diagnostic Systems, Montclair, NJ) como descrito anteriormente (23). 


\subsection{Teste de Tolerância à Glicose}

Este protocolo foi realizado como descrito por Andrikopoulos (2008) (180), com algumas modificações. A glicemia foi avaliada através do aparelho Accu-Chek Active (Roche Diagnostics, Mannheim, Alemanha), utilizando uma gota de sangue extraída da cauda do animal a cada intervalo de tempo. Os animais foram colocados em jejum por $15 \mathrm{~h}$, tiveram sua glicemia basal avaliada ( 0 min) e, em seguida, foram submetidos a uma injeção intraperitoneal de glicose a $2 \mathrm{~g} / \mathrm{Kg}$ de massa corpórea. A glicemia foi avaliada nos intervalos de tempo de $15 \min , 30 \mathrm{~min}, 90 \mathrm{~min}$ e $120 \mathrm{~min}$ após a injeção.

\subsection{Teste comportamental: campo aberto}

O ensaio do campo aberto é utilizado para avaliar a mobilidade e o comportamento associado ao medo e à ansiedade. O protocolo utilizado foi baseado no descrito por Kawamoto et al., (2013) (181). Resumidamente, o teste consiste em avaliar o perfil de atividade do animal em um aparato de plástico de aproximadamente $40 \mathrm{~cm}$ x $40 \mathrm{~cm} \times 15 \mathrm{~cm}$, por 5 min. A atividade geral dos camundongos foi avaliada por meio do sistema de captação de imagens ANY-maze (Stoelting CO, Wood Dale, IL, EUA) no qual é retirada uma foto do campo aberto a partir da qual é delineada uma arena virtual subdividida em duas regiões: uma central e uma periférica. Após o delineamento da arena, foi realizada a calibração da mesma para $40 \mathrm{~cm}$ de lateral. O tipo de captação utilizada foi baseado no sistema de subtração, que consiste na geração de contraste entre a cor da pelagem do animal e o interior do campo aberto de cor azul. Esse contraste permite distinguir o animal do aparato e, portanto, visualizálo como um objeto em movimento. Após o delineamento do campo aberto, o processo de filmagem foi realizado. Os animais foram colocados individualmente no centro da arena e observados durante o período de $5 \mathrm{~min}$. Avaliou-se a mobilidade do animal, bem como a intensidade de eventos de freezing e a proporção do tempo no qual o animal permaneceu na região central. A região central consiste em uma área na qual o animal encontra-se mais exposto, portanto o tempo total no qual o animal fica na região é inversamente associado ao comportamento ansioso. Após a captura da imagem, o campo aberto foi limpo com uma solução de álcool 5\% antes do próximo animal a fim de evitar possíveis rastros de odor deixados pelo animal anterior. 


\subsection{Teste comportamental: labirinto em cruz elevado}

O ensaio do labirinto em cruz elevado é utilizado para avaliação de comportamento associado ao medo e ansiedade e foi realizado com base no protocolo descrito por Texel et al., (2012) (182), com algumas modificações. O labirinto em cruz elevado consiste em um aparato com dois braços abertos e opostos $(25 \mathrm{~cm} \times 5 \mathrm{~cm} \times 0,5 \mathrm{~cm})$ e outros dois braços opostos do mesmo tamanho fechados com paredes laterais de $16 \mathrm{~cm}$ de altura. Os braços abertos e fechados, elevados $50 \mathrm{~cm}$ do solo, cruzam-se perpendicularmente formando uma cruz, delimitada por uma área central de $5 \times 5 \mathrm{~cm}$. Os animais foram colocados individualmente na área central do labirinto, com a cabeça direcionada para o braço aberto na direção oposta ao experimentador e pôde explorar livremente o equipamento por $5 \mathrm{~min}$. O perfil de exploração do animal em relação às regiões do labirinto - braços abertos, fechados e centro - é avaliado, considerando-se com um comportamento menos ansioso um animal com maior mobilidade e com maior proporção de exploração do braço aberto. Entre um animal e outro foi realizada a assepsia do labirinto com solução de álcool 5\%.

\subsection{Teste comportamental: labirinto aquático de Morris}

Este protocolo é baseado nos trabalhos de Shaw et al., 2001 (129) e Okun et al., (2010) (81). O labirinto aquático é uma piscina circular com água a $25 \pm 1{ }^{\circ} \mathrm{C}$ corada com tinta branca não tóxica. Os animais apenas conseguem escapar da água subindo em uma plataforma de $9 \mathrm{~cm}$ de diâmetro posicionada em um dos quadrantes da piscina. Na sala experimental, foram posicionadas pistas ambientas para a facilitação da localização espacial pelo animal. A observação comportamental foi acompanhada por um sistema de captação digital computadorizado com o programa ANY-maze (Stoelting Co., Wood Dale, IL, EUA).

\subsubsection{Treinamento}

Os animais foram treinados para buscar e memorizar a localização da plataforma por 5 dias. A cada dia, os animais foram submetidos a 4 seções de até $60 \mathrm{~s}$, nas quais deveriam encontrar a localização da plataforma submersa $1 \mathrm{~cm}$ abaixo da superfície do líquido - e, portanto, não visível -, do contrário eram conduzidos até a mesma e mantidos por $10 \mathrm{~s}$. A latência média para encontrar a plataforma no decorrer dos dias foi utilizada para avaliar o aprendizado. 


\subsubsection{Memória de Referência}

Para avaliação da memória espacial de referência, os animais foram colocados na piscina $24 \mathrm{~h}$ após o último treino, por um tempo de $60 \mathrm{~s}$. Para a realização destes testes, a plataforma foi retirada e avaliou-se o tempo no qual o animal passava no quadrante da plataforma. A natação persistente no quadrante da plataforma é um indicativo da formação de memória espacial, e o tempo foi quantificado para a comparação entre os grupos.

\subsubsection{Memória Operacional}

Para avaliação da memória operacional, o procedimento é semelhante ao da etapa de treinamento, porém os testes são realizados por 4 dias e, a cada dia, a plataforma é realocada para uma posição diferente. A cada tentativa em um mesmo dia espera-se que a latência para buscar a plataforma seja reduzida, uma vez que o animal reaprende a localização da plataforma. A média dos valores encontrados entre as mesmas tentativas dos 4 dias de teste é utilizada para avaliar a capacidade do animal em armazenar a memória operacional da localização da plataforma entre o intervalo das tentativas.

\subsection{Teste comportamental: esquiva inibitória}

Para avaliação da memória gerada por estímulo aversivo, será utilizado o método de esquiva inibitória. O equipamento de esquiva inibitória (Insight, São Paulo, Brasil) consiste de uma gaiola dividida em dois compartimentos iguais, sendo um iluminado, e outro escuro, separados por uma porta-guilhotina. Os animais foram colocados individualmente na parte iluminada da gaiola e foi medida a latência, em segundos, para que os mesmos passassem para o compartimento escuro. Estando no lado escuro, o animal recebeu um choque de $2 \mathrm{~mA}$ por $2 \mathrm{~s}$, deflagrado pelas barras metálicas localizadas no chão desse compartimento. A latência máxima permitida para cada animal foi de $300 \mathrm{~s}$. Foi realizado um treino e $24 \mathrm{~h}$ depois um teste para avaliação da memória de longa duração. O treino foi realizado no dia seguinte ao último dia do teste do Labirinto Aquático de Morris (Esquema 2C). 


\subsection{Teste comportamental: suspensão da cauda}

O teste de suspensão da cauda avalia comportamento depressivo em camundongos (183). Os camundongos foram suspensos pela ponta da cauda por 6 minutos e foi avaliado o tempo em que os animais permaneceram imóveis durante os 4 últimos minutos desse período. A imobilidade foi definida como a ausência de movimentos não relacionados à respiração. Os camundongos retornaram para suas gaiolas após o teste.

\subsection{Análise dos resultados}

Os dados decorrentes do ensaio de gel-shift e de western blot foram analisados quantitativamente através da análise de densidade óptica utilizando o programa Image $J$ (National Institute of Health, EUA). Os dados de western blot, gel-shift, peso dos animais, multiplex e ELISA receberam tratamento estatístico pelo teste de análise de variância (ANOVA) de uma via seguido do pós-teste Student-Newman-Kewls. Os dados obtidos no ensaio de RT-PCR em tempo real foram analisados pelo teste de randomização e recolocação Pair Wise P(H1) (179) realizado no programa REST 2009 (Qiagen, Duesseldorf, ALE). Os dados adquiridos no teste comportamental de labirinto aquático de Morris receberam tratamento estatístico pelo teste ANOVA de duas vias (tratamento $\mathrm{X}$ tempo) com medidas repetidas (dias de teste) seguido pelo pós-teste de Student-Newman-Kewls. Os dados dos experimentos realizados em esquiva inibitória e campo aberto foram analisados pelo teste de Kruskal-Wallis seguido pelo pós-teste de Dunns para dados não-paramétricos. Os outros testes comportamentais receberam tratamento estatístico pelo teste ANOVA de uma via seguido do pós-teste Student-Newman-Kewls.

Todos os gráficos foram representados como média dos valores \pm E.P.M, e as diferenças entre os grupos foram consideradas significativas quando $p<0,05$. Com exceção dos resultados obtidos por RT-PCR em tempo real, os outros dados foram analisados utilizando o programa Prism 6 (GraphPad Software, San Diego, CA, EUA). Os grupos nos gráficos estão representados da seguinte forma e ordem: C para o grupo controle, D para o grupo submetido à dieta intermitente, $T l r 4^{-/-}$ou $T l r 2^{-/-}$para os camundongos com nocaute do receptor TLR4 ou TLR2 em dieta normal, e $T l r 4^{-/-} \mathrm{D}$ ou $T l r 2^{-/-} \mathrm{D}$ para camundongos nocaute do receptor TLR4 ou TLR2 submetidos à dieta intermitente. 


\section{RESULTADOS}

\subsection{Efeitos da dieta intermitente no peso e consumo de alimento de camundongos na presença/ausência de TLR2 ou TLR4}

Primeiramente, nós avaliamos as alterações de peso dos animais submetidos à dieta intermitente (dias alternos com e sem ração e água ad libitum) em relação ao grupo controle. Nós pesamos os animais do grupo controle e dieta intermitente dos camundongos selvagens e nocaute $T l r 2^{-/-}$e $T l r 4^{-/-}$antes e após o tratamento calculamos a diferença entre esses valores para comparação entre os grupos. Foi observado que camundongos em dieta intermitente, independente de seu genótipo, tiveram aumento de massa corpórea após os 30 dias de dieta intermitente, porém esse aumento foi menor que o do grupo controle (Figura 1).

(A)

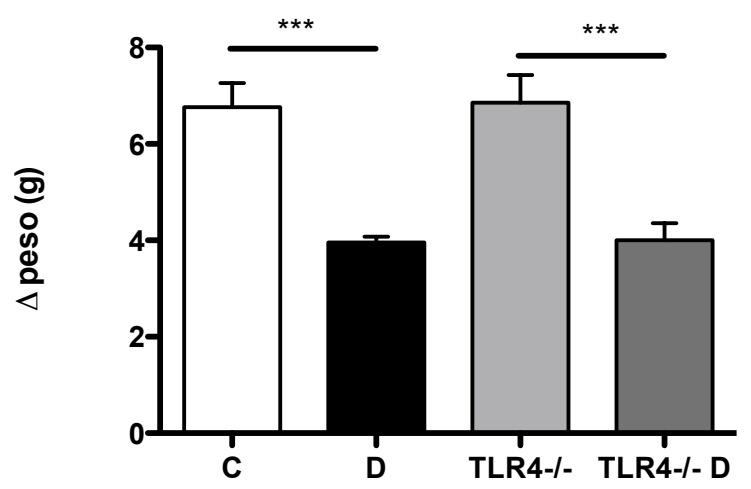

(B)

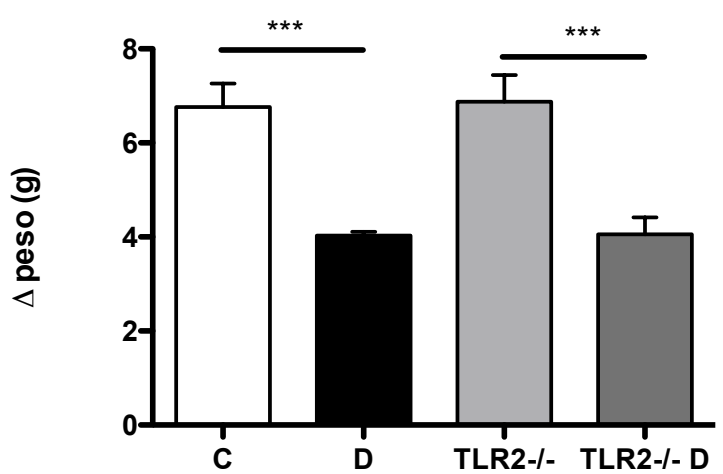

Figura 1. Diferença dos pesos dos grupos de camundongos controle e nocaute (A) Tlr $4^{-/-}$e (B) Tlr2 ${ }^{-/-}$. Os dados representam as médias das diferenças das massas corpóreas dos grupos antes e após os 30 dias de dieta intermitente ou dieta controle \pm EPM. $* * * \mathrm{p}<0,001$ (ANOVA de uma via, seguido de StudentNewman-Kewls).

Em seguida, acompanhamos o consumo de alimento dos animais por dia. Verificamos que os camundongos em dieta, independente de seu genótipo, consumem maior quantidade de comida nos dias de livre acesso ao alimento em relação ao grupo controle. Porém, a média geral de consumo de alimento por dia (considerando os dias de jejum) é significativamente menor do que os seus respectivos controles (Figura 2). 
(A)

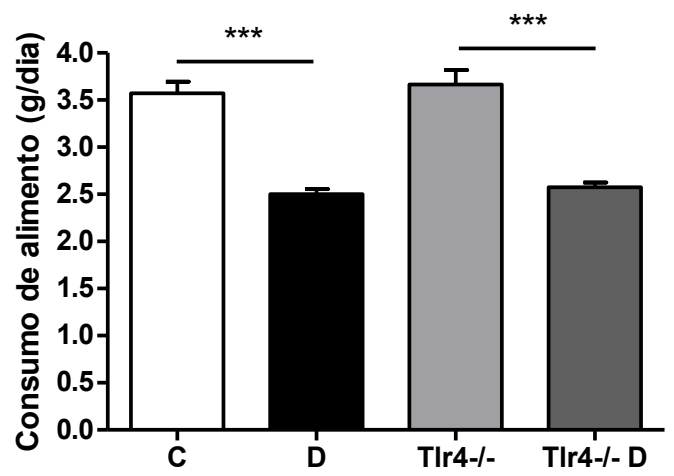

(B)

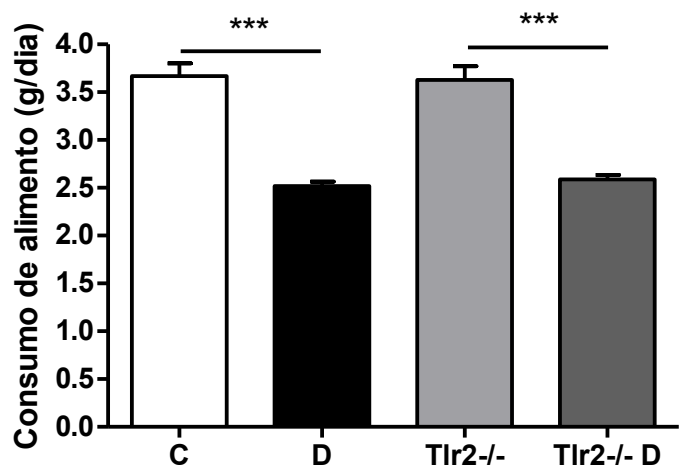

Figura 2. Consumo de alimento dos camundongos controle e nocaute (a) Tlr4 $4^{-/-}$e (b) Tlr2 $2^{-/-}$. Os dados representam as médias de consumo de alimento $(\mathrm{g})$ por dia dos grupos \pm EPM. *** $\mathrm{p}<0,001$. (ANOVA de uma via, seguido de Student-Newman-Kewls).

\subsection{Efeitos da dieta intermitente na atividade dos fatores de transcrição NF- $\mathrm{B}, \mathrm{CREB}$ e AP1 na presença/ausência de TLR2 ou TLR4 no hipocampo e hipotálamo}

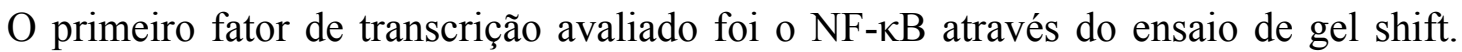

Nós observamos no hipocampo de camundongos $\mathrm{Tlr}^{4^{-/}}$uma redução da atividade deste fator de transcrição no grupo $T l r 4^{-/-}$submetido à dieta intermitente em relação aos outros grupos experimentais (Figuras 3A e 3B). A avaliação da atividade do NF-kB no hipotálamo de camundongos $\mathrm{Tlr} 4^{-/-}$não revelou uma diferença significativa entre os grupos (Figuras $3 \mathrm{C}$ e 3D).

Quanto ao hipocampo de camundongos $T l r 2^{-/}$, foi observado que a atividade deste fator de transcrição é significativamente menor no grupo de animais $T l r 2^{-/-}$submetidos à dieta intermitente quando comparado com os animais $\mathrm{Tlr} 2^{-/-}$sem dieta intermitente ou ao grupo controle submetidos à dieta intermitente (Figuras 3E e 3F). Não foi possível avaliar a atividade do NF- $\kappa \mathrm{B}$ no hipotálamo de camundongos $T l r 2^{-/-}$devido ao fato de não termos conseguido obter quantidade de proteína suficiente para repetir o ensaio quando não obtivemos sucesso na primeira tentativa. 
(A) Hipocampo em T/r4 ${ }^{-1-}$
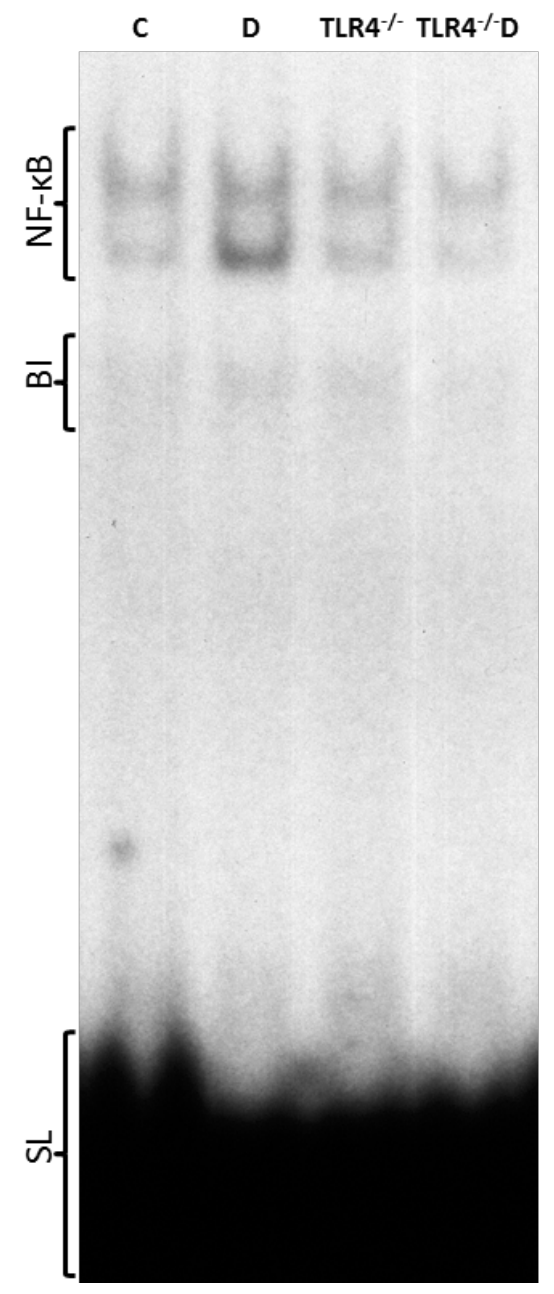

(B)

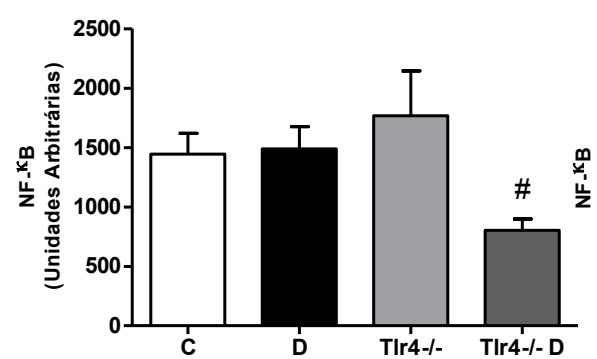

(C) Hipotálamo em TIr4 ${ }^{-/-}$
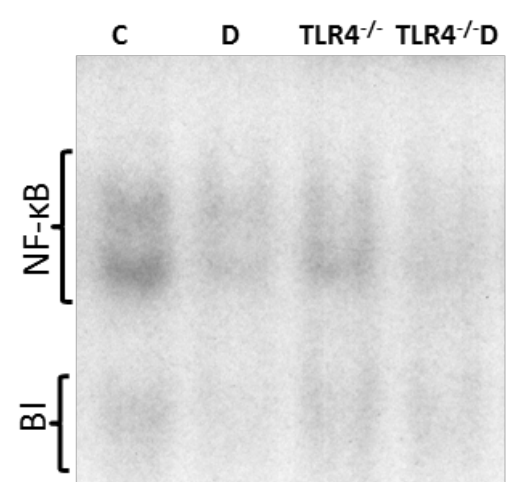

(D)
(E) Hipocampo em TIr2 ${ }^{-/-}$

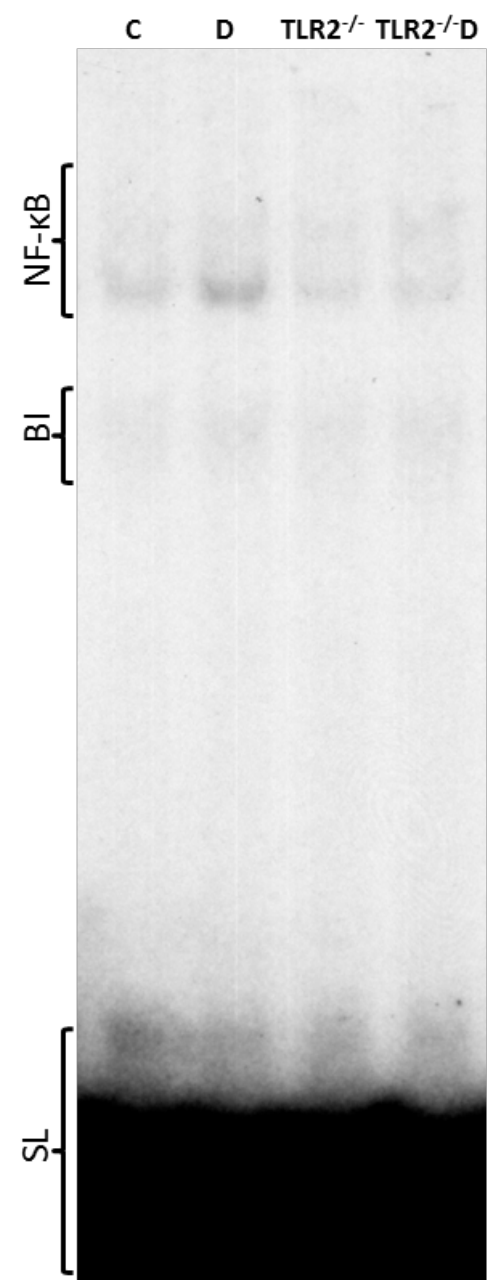

$(\mathrm{F})$

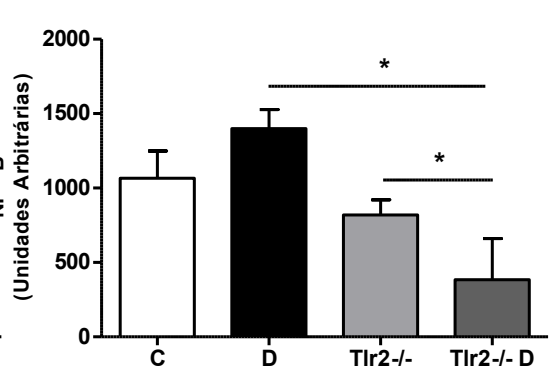

Figura 3. Efeito da dieta intermitente na atividade do fator de transcrição $N F-\kappa B$ em camundongos $T l r 2^{-/} e$ $T l r 4^{-/}$. As proteínas nucleares $(10 \mu \mathrm{g})$ foram extraídas do hipocampo e hipotálamo de camundongos e usadas para o ensaio de gel shift. Estão indicadas as posições do complexo NF-kB/DNA, a banda inespecífica $(\mathrm{BI})$ resultante da ligação de outras proteínas que não as pertencentes à família NF-

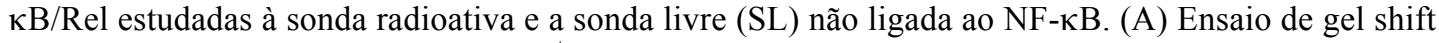
com hipocampo de camundongos $T l r 4^{-/ /}$. (B) Análise densitométrica da banda do NF-אB representada na figura A. (C) Ensaio de gel shift de hipotálamo de camundongos $T l r 4^{-1 /}$. (D) Análise densitométrica da banda do NF-kB representada na figura C. (E) Ensaio de gel shift com hipocampo de camundongos $\mathrm{TLR}^{-/}$. (F) Análise densitométrica da banda do NF-KB representada na figura E. Os resultados são expressos como média \pm E.P.M. * $\mathrm{p}<0,05$, \# $\mathrm{p}<0,05$ vs. C, D e Tlr $4^{-1-}$ (ANOVA de uma via, seguido de Student-Newman-Kewls). 
Com relação ao CREB, podemos observar pelo ensaio de gel shift que a atividade deste fator de transcrição é significativamente menor no hipocampo dos animais nocaute para o TLR4 e TLR2 submetidos à dieta intermitente (Figuras 4A, 4B, 4E e 4F). Nos animais Tlr2/-, a redução no hipocampo ocorre não só em relação ao grupo controle, mas em comparação a todos os outros grupos experimentais (Figuras 4E e 4F). No hipotálamo não observamos diferenças significativas de atividade do CREB entre os grupos tanto nos animais $\mathrm{Tlr}^{-/-}$ quanto nos animais Tlr2 $2^{-/-}$(Figuras 4C, 4D, 4G e 4H).

\section{(A) Hipocampo em TIr4 ${ }^{-1-}$}
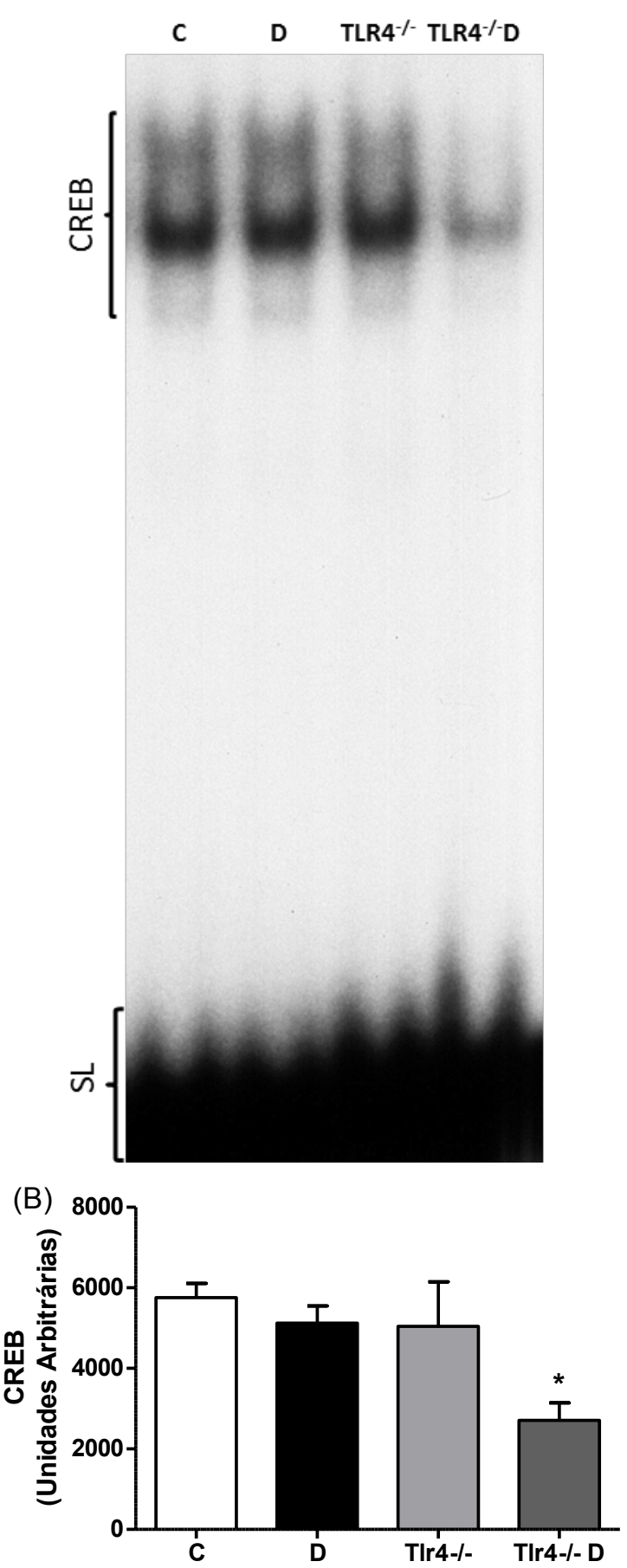

(C) Hipotálamo em TIr ${ }^{-1-}$

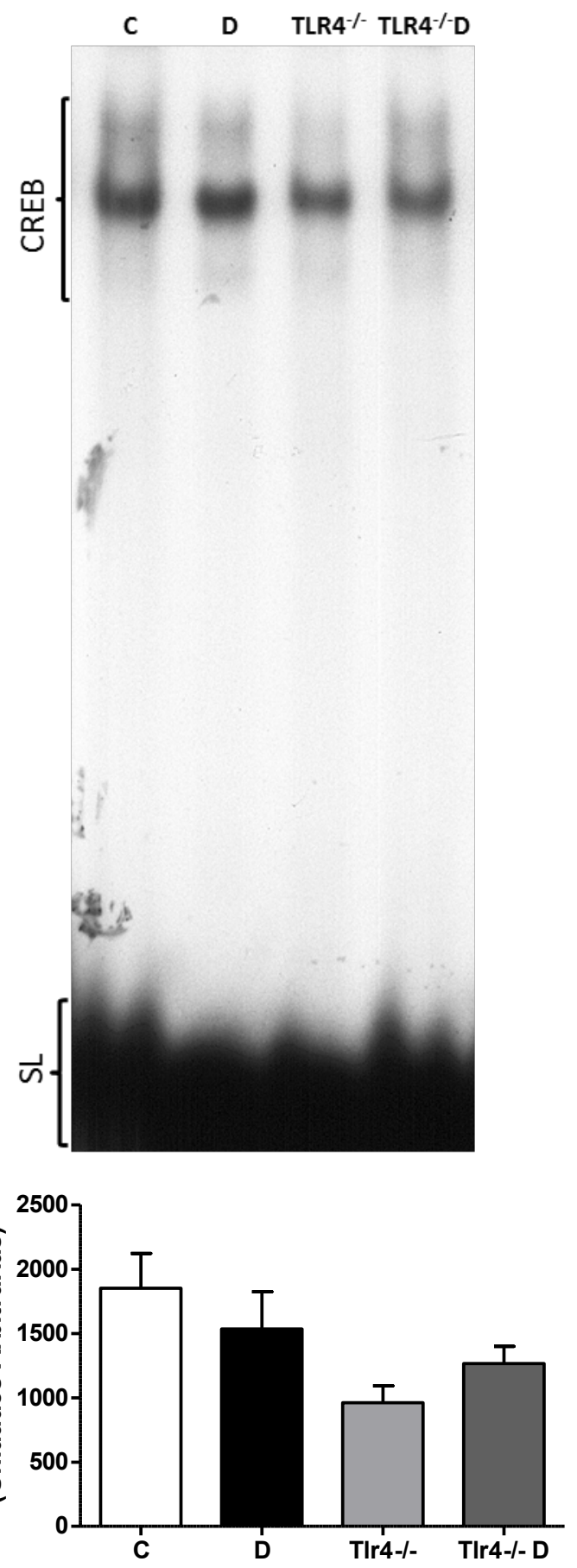


(E) Hipocampo em TIr2-/

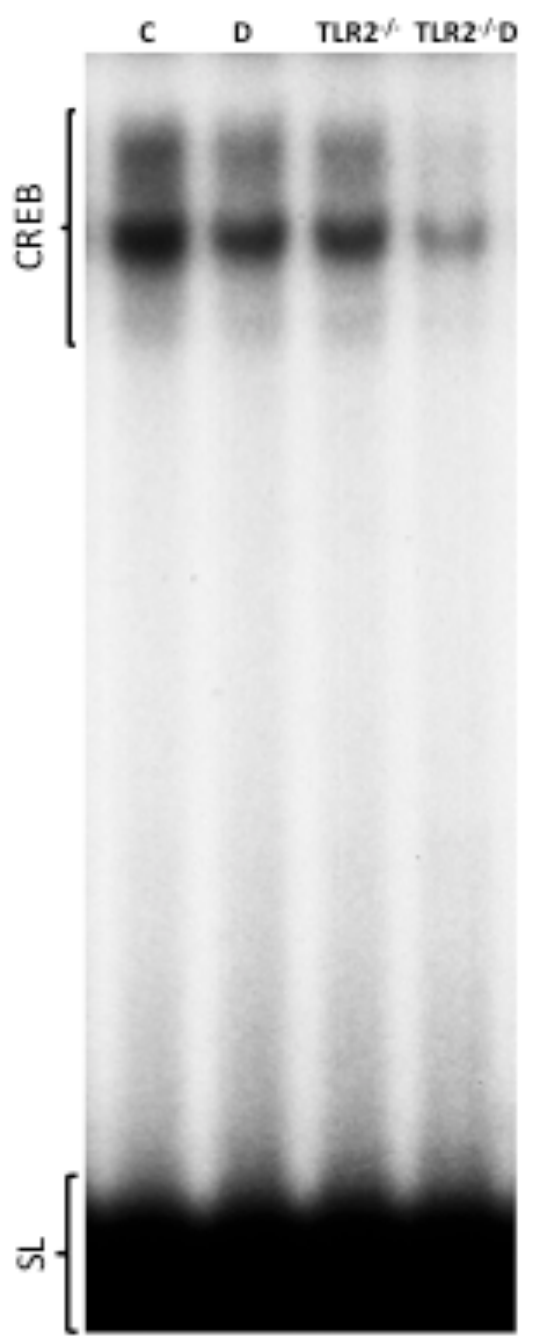

(F)

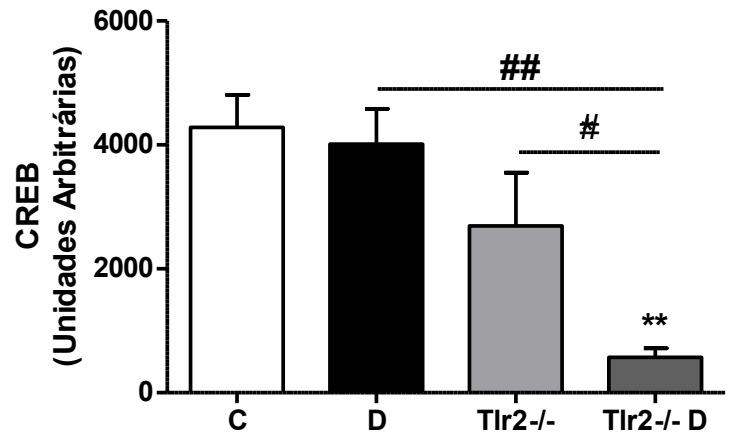

(G) Hipotálamo em T/r2 ${ }^{-/}$

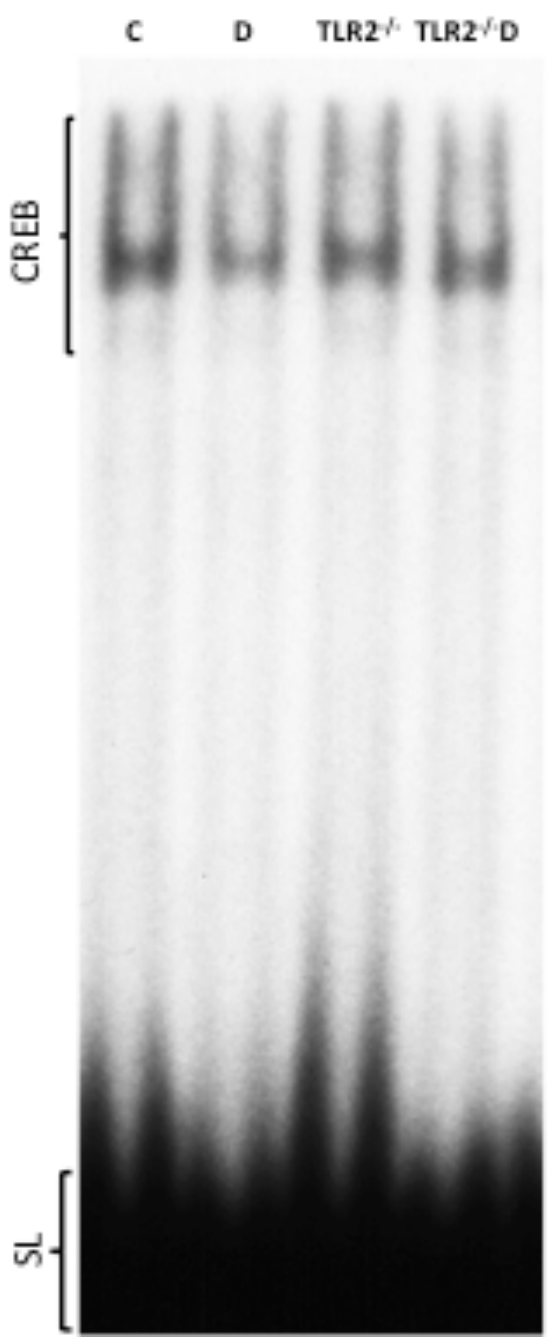

(H)

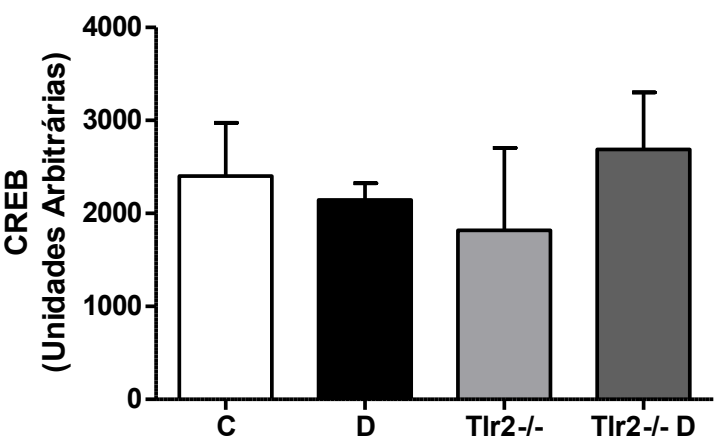

Figura 4. Efeito da dieta intermitente na atividade do fator de transcrição CREB em camundongos Tlr2 $2^{-/-}$e Tlr $4^{-/-}$. As proteínas nucleares $(10 \mu \mathrm{g})$ foram extraídas do hipocampo e hipotálamo de camundongos e usadas para o ensaio de gel shift. Estão indicadas as posições do complexo CREB/DNA e a sonda livre (SL) não ligada ao CREB. As amostras no gel shift são de animais pertencentes a grupos na mesma ordem dos grupos nos gráficos. (A) gel shift com hipocampo de camundongos $T l r 4^{-/-}$. (B) Análise densitométrica da banda do CREB representada na figura A. (C) gel shift de hipotálamo de camundongos $T l r 4^{-/ /}$. (D) Análise densitométrica da banda do CREB representada na figura C. (E) Ensaio de gel shift com hipocampo de camundongos $T l r 2^{-/-}$. (F) Análise densitométrica da banda do CREB representada na figura E. (G) gel shift com hipotálamo de camundongos $T l r 2^{--}$. (H) Análise densitométrica da banda do CREB representada na figura G. Os resultados são expressos como média \pm E.P.M. ${ }^{*} \mathrm{p}<0,05$ vs. C, $* * \mathrm{p}<0,01$ vs. C, \# p<0,05 e \#\# p<0,01 (ANOVA de uma via, seguido de Student-Newman-Kewls). 
Outro fator de transcrição cuja atividade foi investigada pelo ensaio de gel shift, foi a proteína ativadora 1 (AP1). Nas Figuras 5A e 5B, podemos observar que a atividade do AP1 é significativamente maior no hipocampo de camundongos $T l r 4^{-/-}$submetidos ou não à dieta intermitente em relação aos seus respectivos controles. Em 5E e 5F, podemos observar que o grupo de animais $T l r 2^{-/-}$em dieta intermitente apresenta a atividade do AP1 no hipocampo significativamente maior em comparação aos outros grupos. Com relação ao hipotálamo, mais uma vez não obtivemos diferenças estatisticamente significativas entre os grupos analisados (Figuras 5C, 5D, 5G e 5H).

(A) Hipocampo em TIr4 ${ }^{-1-}$

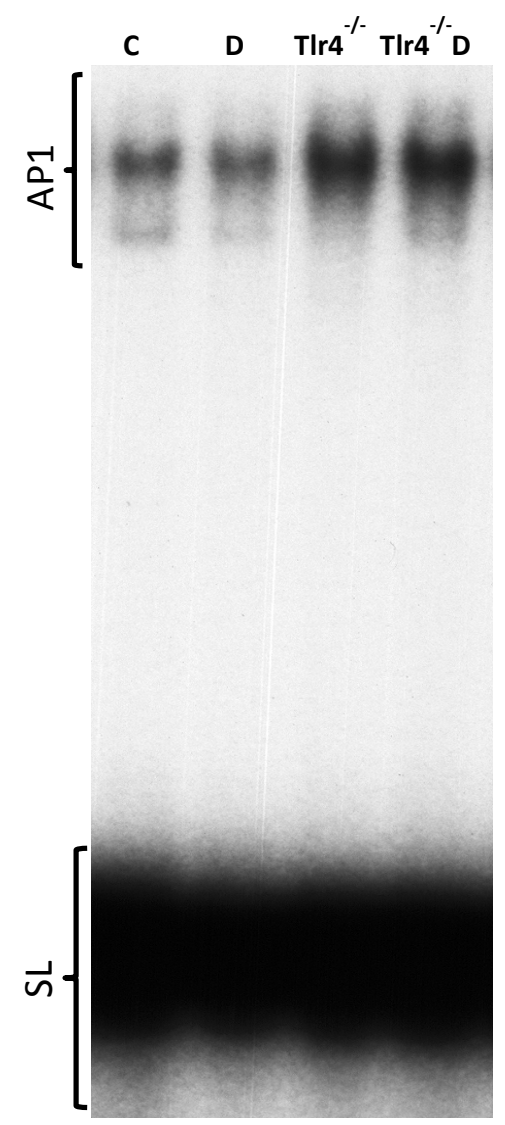

(B)

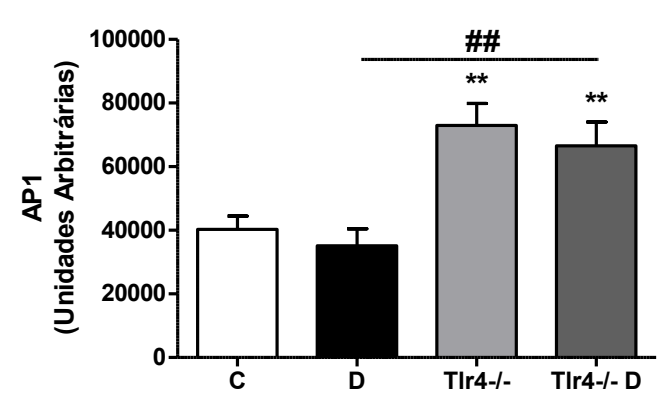

(C) Hipotálamo em TIr4 $4^{-1-}$

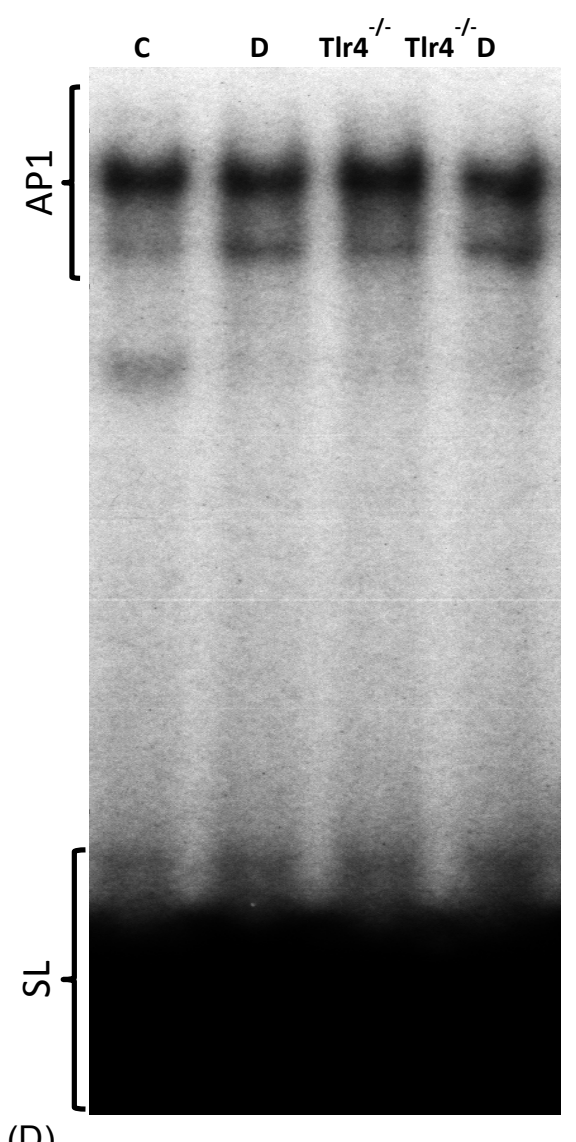

(D)

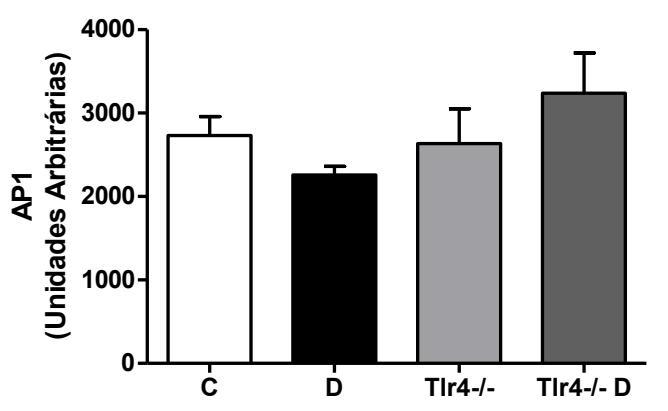


(E) Hipocampo em TIr2 ${ }^{-/}$

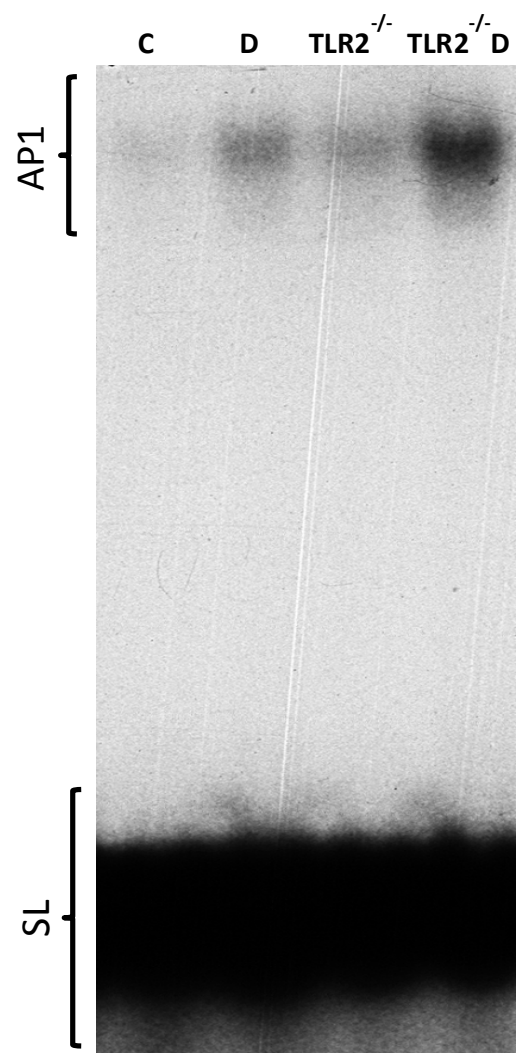

(F)

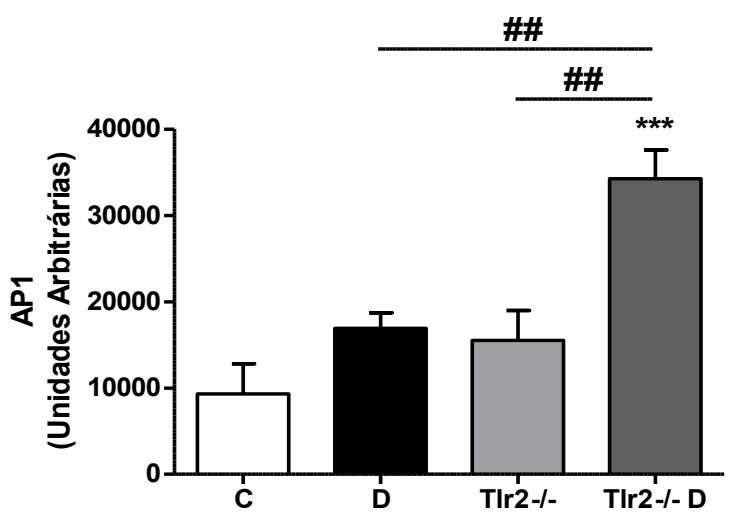

(G) Hipotálamo em TIr2 $2^{-/}$

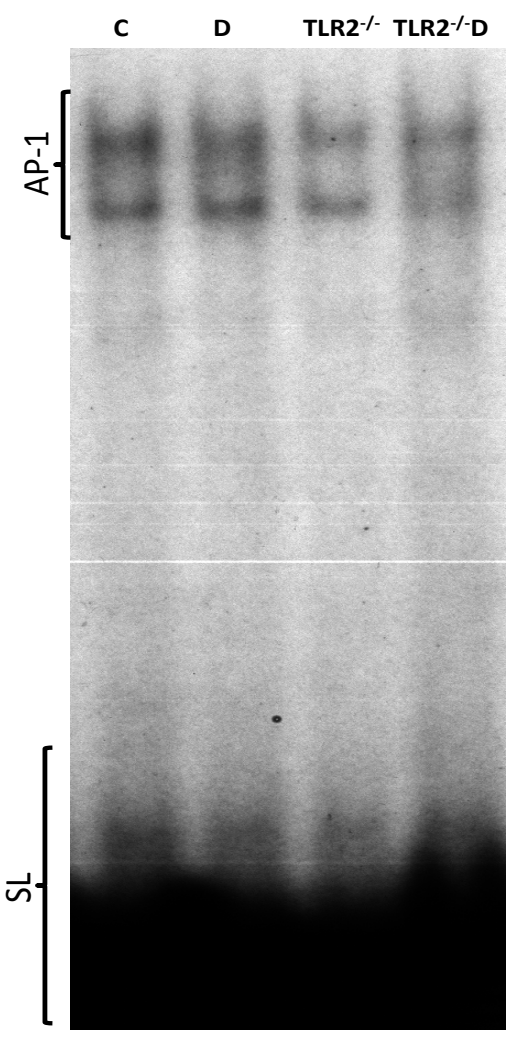

(H)

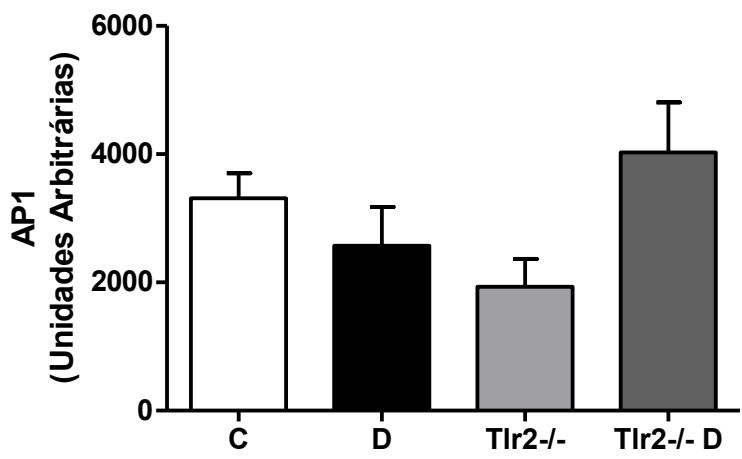

Figura 5. Efeito da dieta intermitente na atividade do fator de transcrição APl em camundongos Tlr2 ${ }^{-/}$e Tlr $4^{-/-}$ - As proteínas nucleares $(10 \mu \mathrm{g})$ foram extraídas do hipocampo e hipotálamo de camundongos e usadas para o ensaio de gel shift. Estão indicadas as posições do complexo AP1/DNA e a sonda livre (SL) não ligada ao AP1. As amostras no gel shift são de animais pertencentes a grupos na mesma ordem dos grupos nos gráficos. (A) Ensaio de gel shift com hipocampo de camundongos $\operatorname{Tlr}^{-{ }^{-/}}$. (B) Análise densitométrica (unidades arbitrárias) da banda do AP1 representada na figura A. (C) Ensaio de gel shift de hipotálamo de camundongos $T l r 4^{-/}$. (D) Análise densitométrica (unidades arbitrárias) da banda do AP1 representada na figura C. (E) Ensaio de gel shift com hipocampo de camundongos $T l r 2^{-/ 2}$. (F) Análise densitométrica (unidades arbitrárias) da banda do AP1 representada na figura E. (G) Ensaio de gel shift com hipotálamo de camundongos $T l r 2^{-/-}$. (H) Análise densitométrica (unidades arbitrárias) da banda do AP1 representada na figura G. Os resultados são expressos como média \pm E.P.M. ${ }^{*} \mathrm{p}<0,05$ vs. C, $* * \mathrm{p}<0,01$ vs. C, \# $\mathrm{p}<0,05, \# \# \mathrm{p}<0,01$ (ANOVA de uma via, seguido de Student-Newman-Kewls). 


\subsection{Efeitos da dieta intermitente sobre as citocinas e quimiocinas na ausência/presença de TLR2 ou TLR4 no hipocampo e soro}

Para avaliar a modulação dos níveis de citocinas e quimiocinas pela dieta intermitente na presença ou ausência dos receptores TLR4 e TLR2, realizamos os ensaios de Multiplex e ELISA com amostras de hipocampo e soro. Na Figura 6G, podemos observar que, na vigência da dieta intermitente, os níveis da citocina pró-inflamatória IL-12 diminuem no hipocampo na ausência do receptor TLR4. O mesmo ocorre com os níveis de IL-15 (Figura 6H) e da quimiocina RANTES (Figura 6I). Não houve nenhuma diferença estatisticamente significativa nos níveis das outras citocinas avaliadas.

Quanto ao hipocampo de camundongos $T l r 2^{-/}$, apenas o RANTES teve alteração significativa. Foi observado que os níveis dessa quimiocina é significativamente maior no grupo $\mathrm{Tlr}^{2 /}$, porém esse aumento é revertido pela dieta intermitente (Figura 7I).

Quanto à avaliação no soro, observamos que o nocaute do receptor TLR4 causa uma redução níveis de IL-1 $\alpha$ (Figura $8 \mathrm{D}$ ). Além disso, o nocaute do TLR2 causa um aumento nos níveis de IFN- $\gamma$ (Figura 9A) e de IL-1 $\beta$ (Figura 9B), que é revertido pela dieta intermitente. Por fim, os níveis de IL-6 no soro são reduzidos pela dieta intermitente e pelo nocaute do TLR2 (Figura 9E). 
(A)

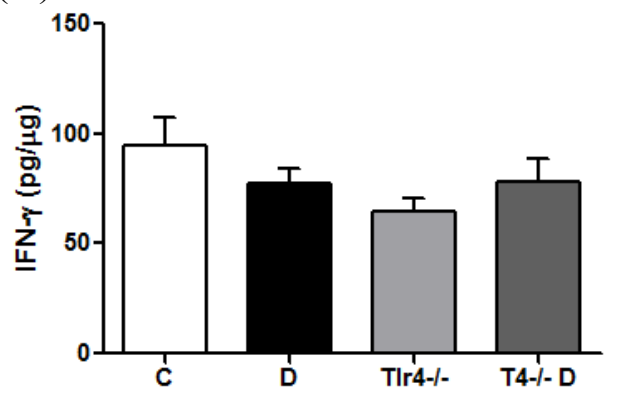

(C)

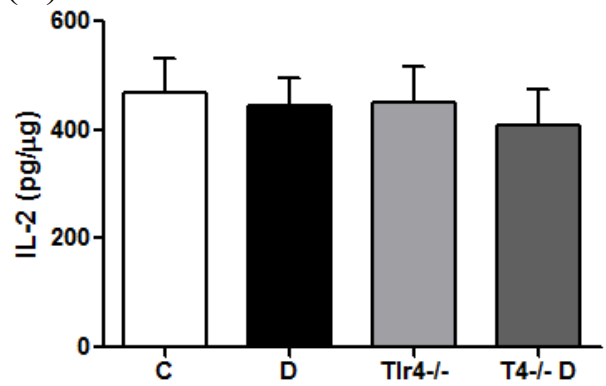

(E)

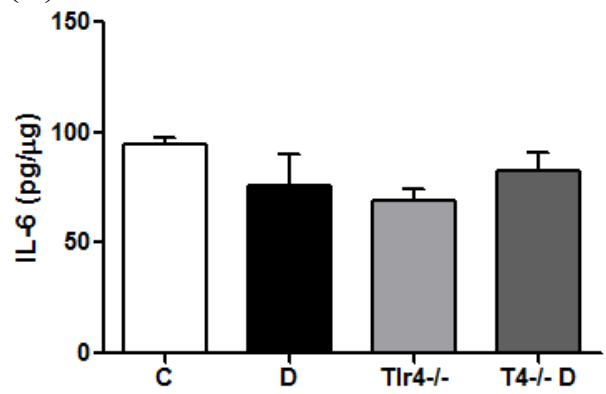

(G)
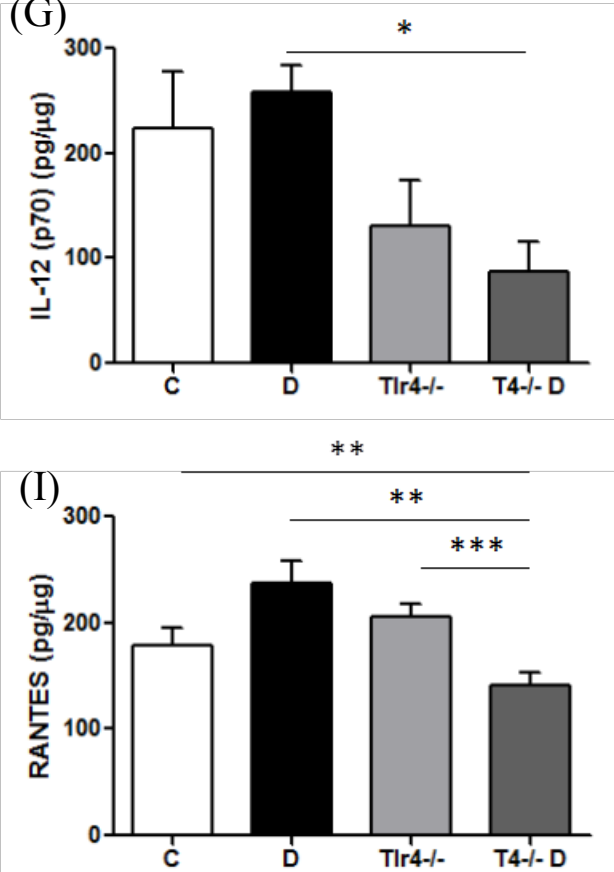

(B)

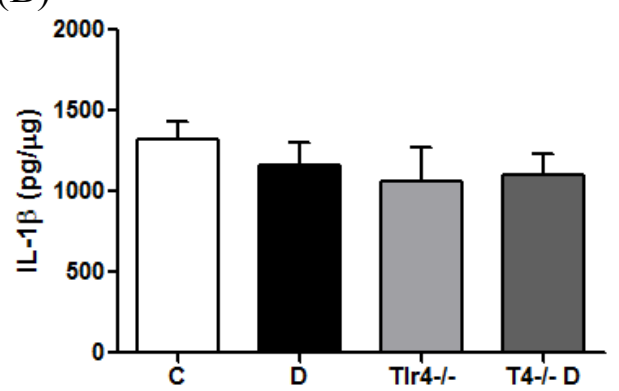

(D)

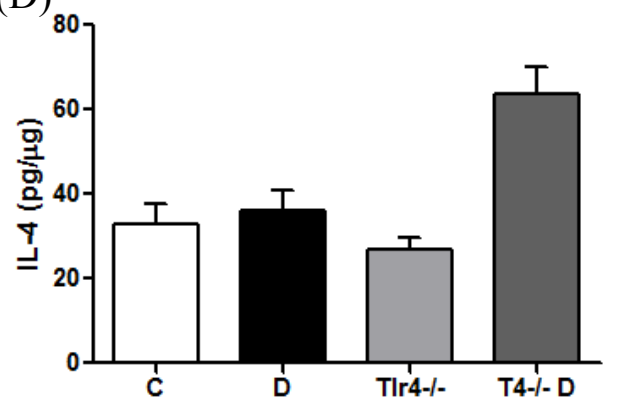

(F)

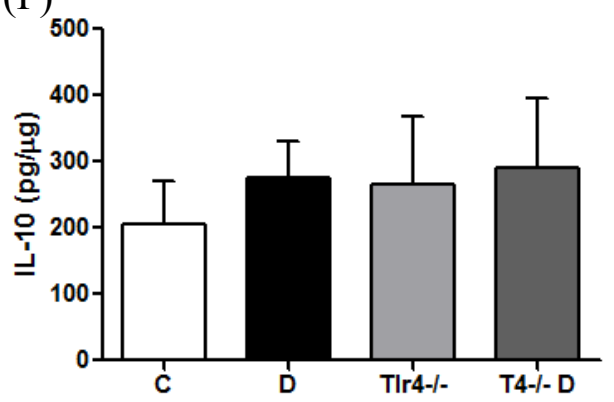

(H)

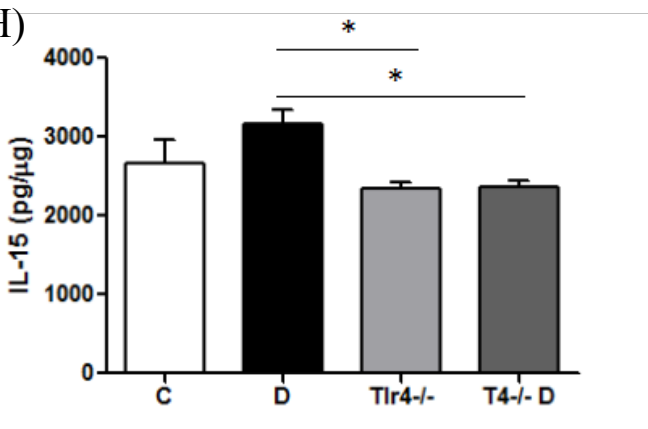

( J)

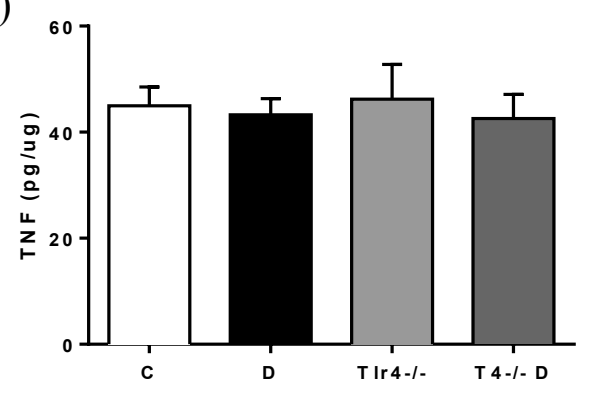

Figura 6. Efeito da dieta intermitente nos níveis de citocinas e quimiocinas no hipocampo de camundongos nocaute $\mathrm{Tlr} 4^{-/}$. Os homogenatos do hipocampo de camundongos controle C57B16 e Tlr $4^{-/-}$submetidos a uma dieta normal ou dieta intermitente foram usadas para o ensaio de Multiplex ou de ELISA. Os resultados são expressos como média \pm E.P.M., $\mathrm{n}=4-5,{ }^{*} \mathrm{p}<0,05,{ }^{* *} \mathrm{p}<0,01 \mathrm{e} * * * \mathrm{p}<0,001$ (ANOVA de uma via, seguido de Student-Newman-Kewls). 


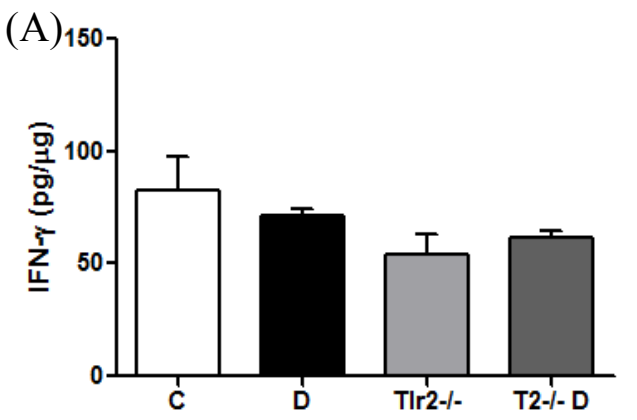

(C)

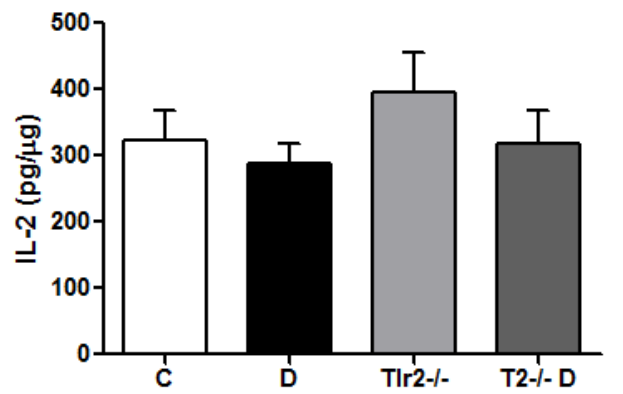

(E)

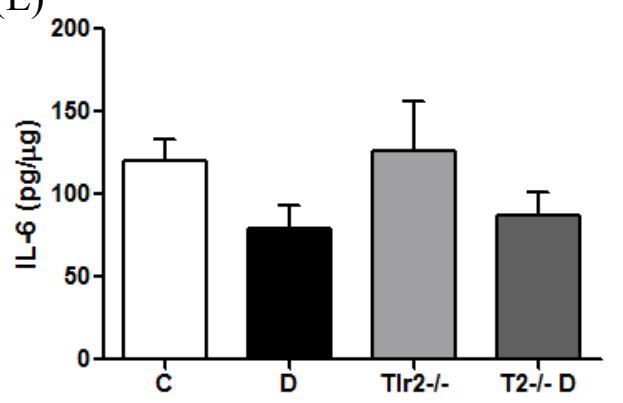

(G)

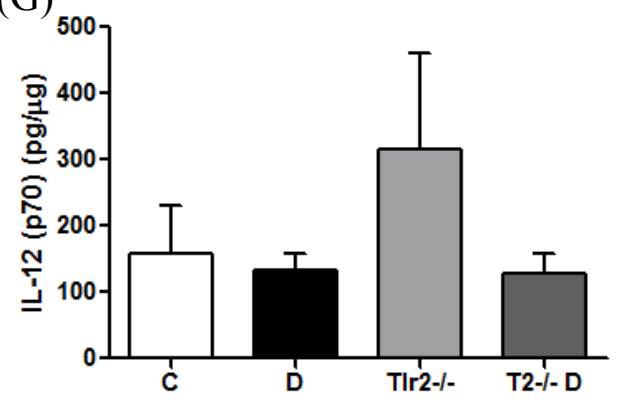

(I)

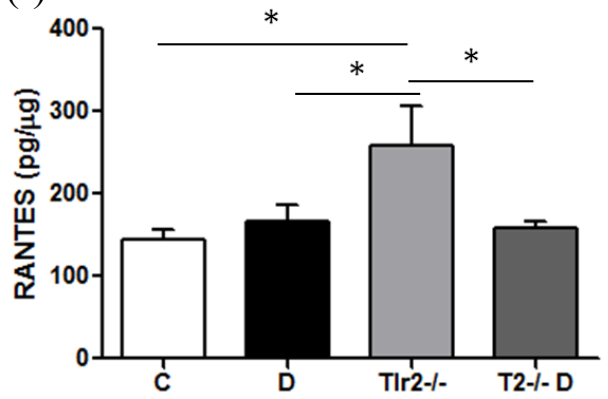

(B)

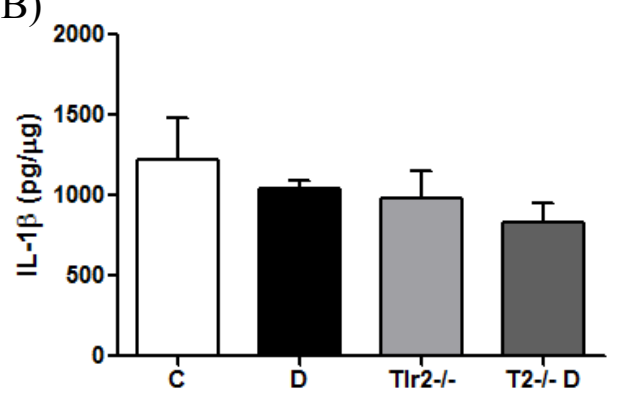

(D)

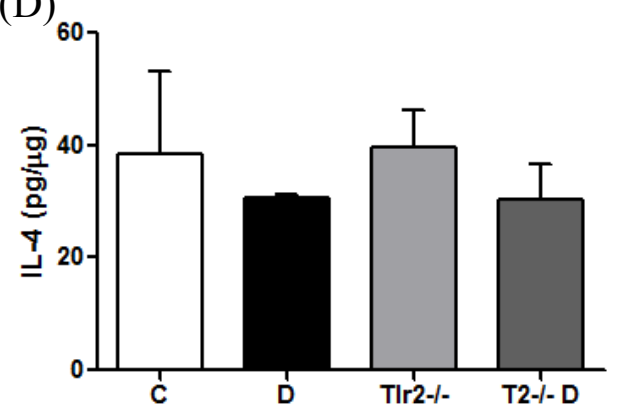

(F)

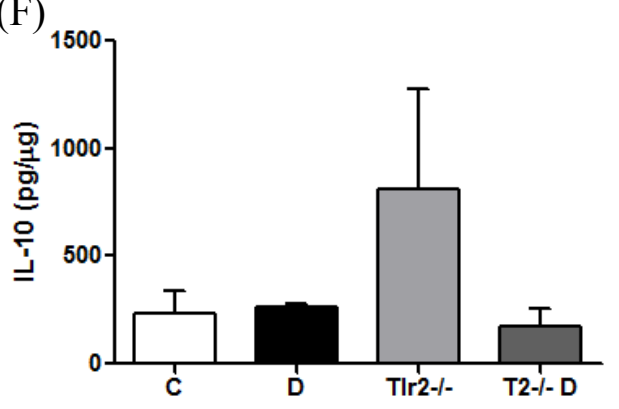

(H)

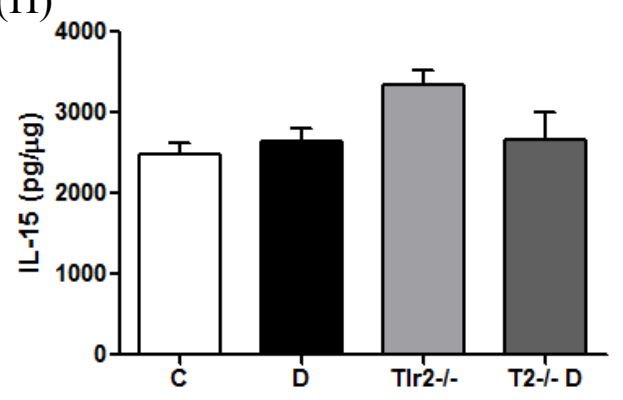

( J)

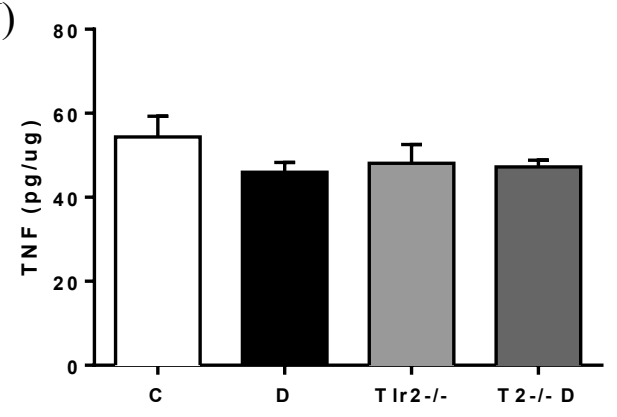

Figura 7. Efeito da dieta intermitente nos niveis de citocinas e quimiocinas no hipocampo de camundongos nocaute $T l r 2^{-/}$. Os homogenatos do hipocampo de camundongos controle C57B16 e $T l r 2^{-/}$submetidos a uma dieta normal ou dieta intermitente foram usadas para o ensaio de Multiplex ou de ELISA. Os resultados são expressos como média \pm E.P.M., $\mathrm{n}=4-5, * \mathrm{p}<0,05$ (ANOVA de uma via, seguido de Student-Newman-Kewls). 

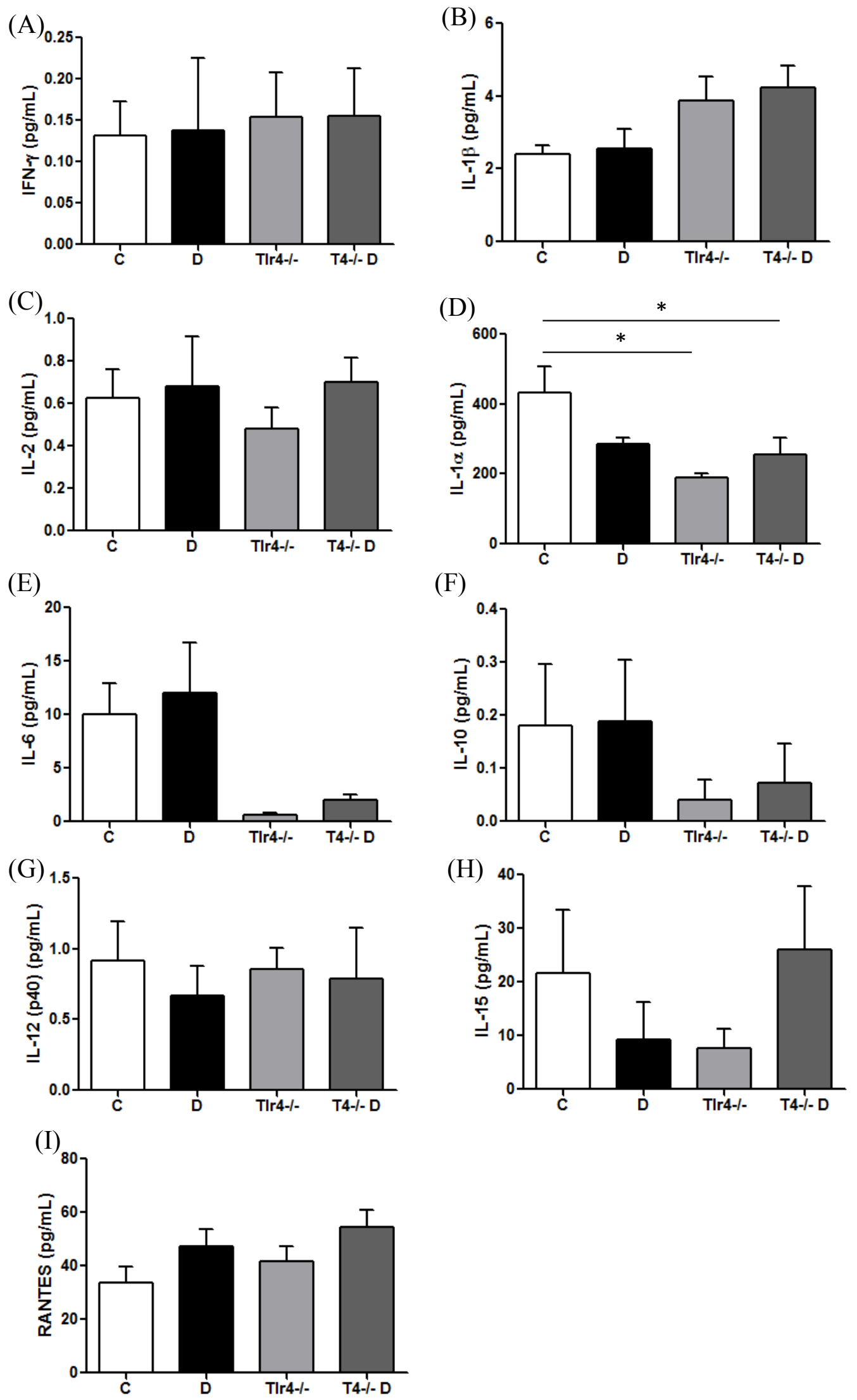

Figura 8. Efeito da dieta intermitente nos níveis de citocinas e quimiocinas no soro de camundongos nocaute $T l r 4^{-/}$. O soro sanguíneo de camundongos controle C57B16 e $T l r 4^{-/-}$submetidos a uma dieta normal ou dieta intermitente foram usadas para o ensaio de Multiplex. Os resultados são expressos como média \pm E.P.M., $\mathrm{n}=4-5, * \mathrm{p}<0,05$ (ANOVA de uma via, seguido de Student-Newman-Kewls). 


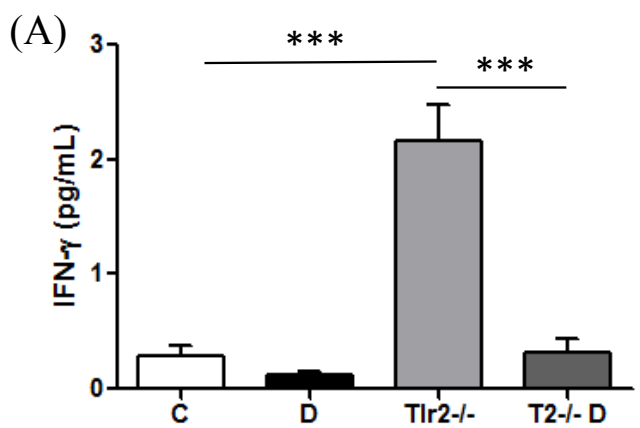

(C)

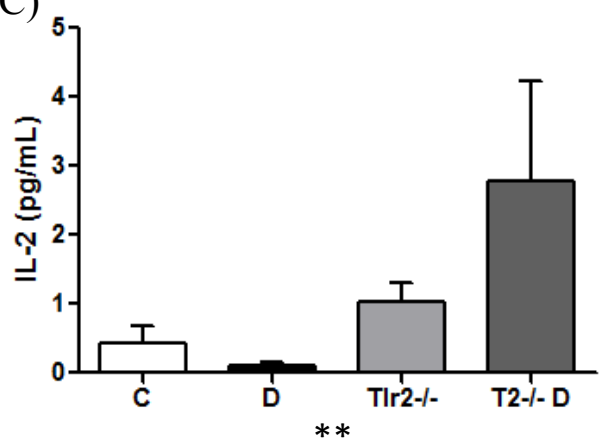

(E)

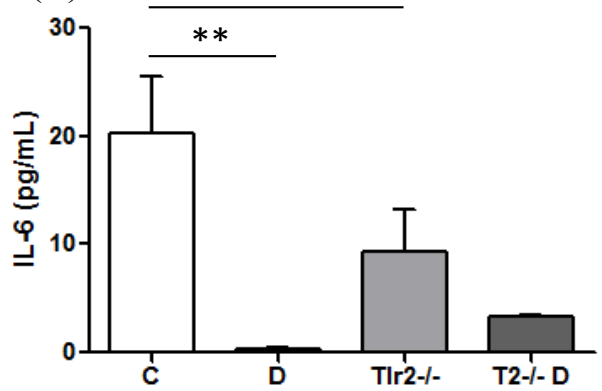

(G)
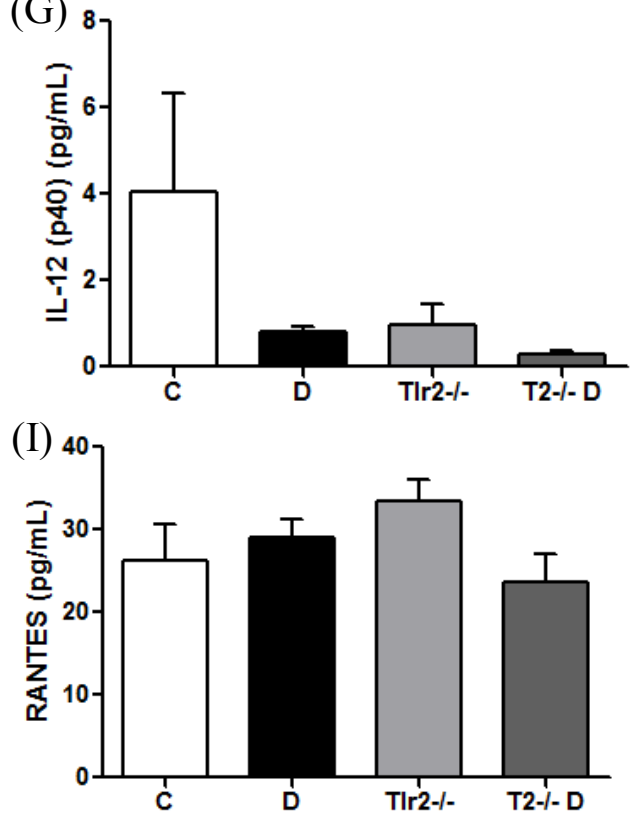

(B)

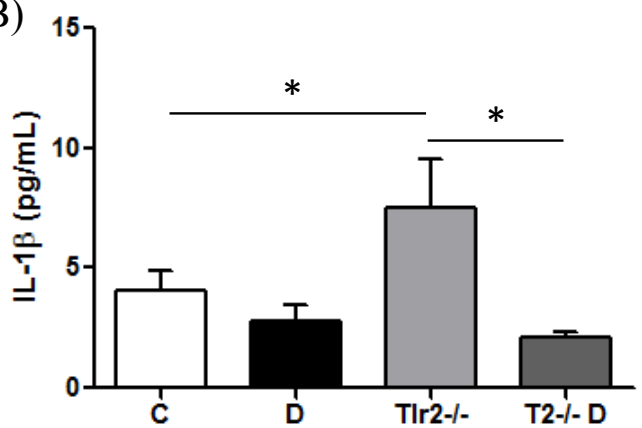

(D)

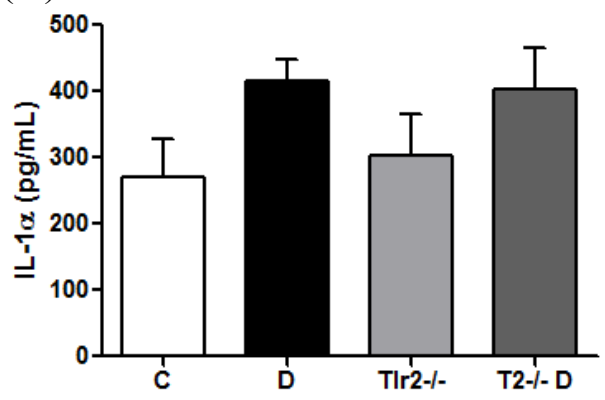

(F)

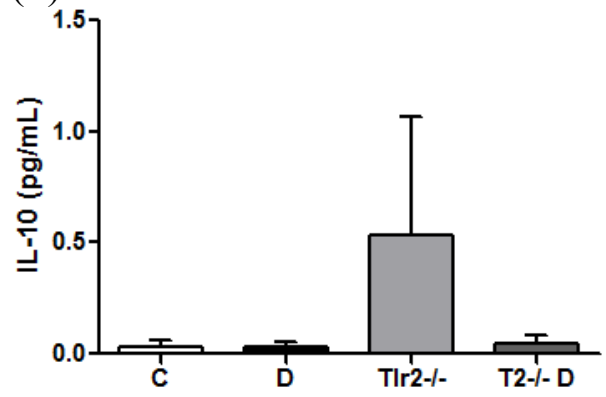

(H)

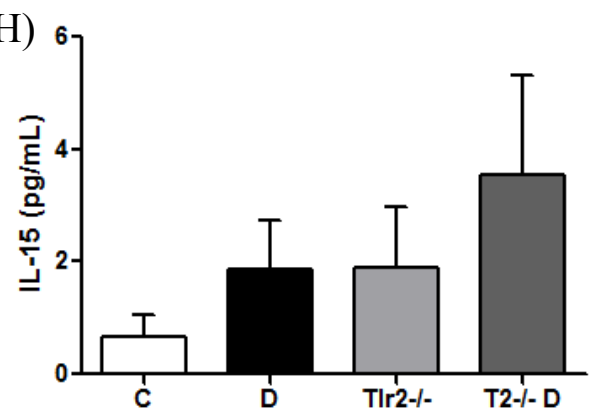

Figura 9. Efeito da dieta intermitente nos niveis de citocinas e quimiocinas no soro de camundongos nocaute $\mathrm{Tlr}_{2}{ }^{-\alpha}$. O soro sanguíneo de camundongos controle C57Bl6 e $\mathrm{Tlr}^{-/}$submetidos a uma dieta normal ou dieta intermitente foram usadas para o ensaio de Multiplex. Os resultados são expressos como média \pm E.P.M., $\mathrm{n}=4-5,{ }^{*} \mathrm{p}<0,05,{ }^{* *} \mathrm{p}<0,01 \mathrm{e}^{* * *} \mathrm{p}<0,001$ (ANOVA de uma via, seguido de StudentNewman-Kewls). 


\subsection{Efeitos da dieta intermitente na expressão proteica de BDNF na presença/ausência de TLR2 ou TLR4 no hipocampo e hipotálamo}

O ensaio de ELISA para BDNF no hipocampo revelou uma diferença significativa dos níveis dessa neurotrofina entre os grupos de animais nocaute TLR4 com dieta controle e dieta intermitente (Figura 10A). Além disso, observamos que o nocaute do TLR2 resulta em uma redução desta neurotrofina no hipocampo quando comparado com os animais controles com ou sem dieta intermitente (Figura 10C). Não observamos diferenças significativas entre os grupos no hipotálamo.

(A)

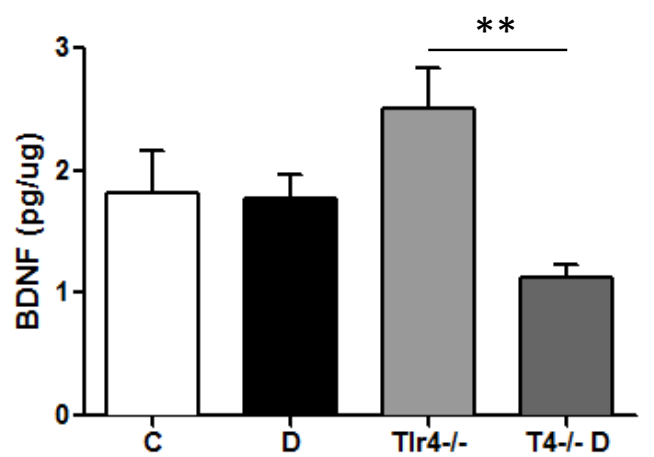

(C)

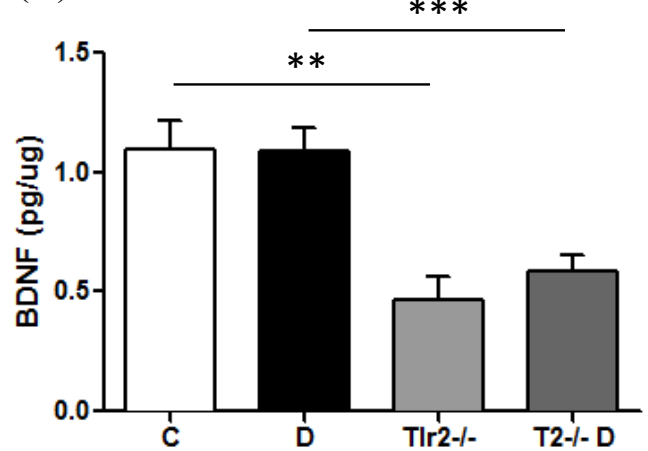

(B) Hipotálamo

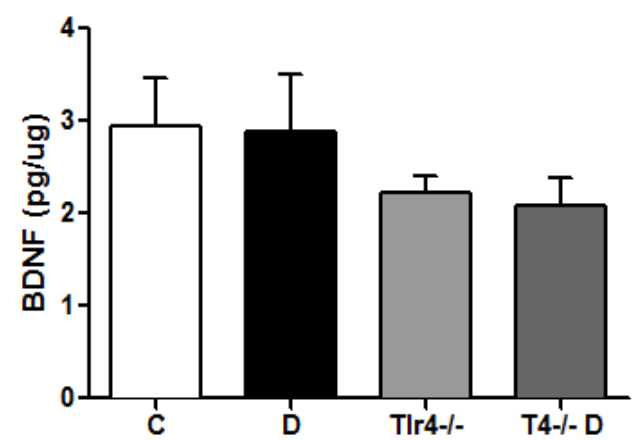

(D)

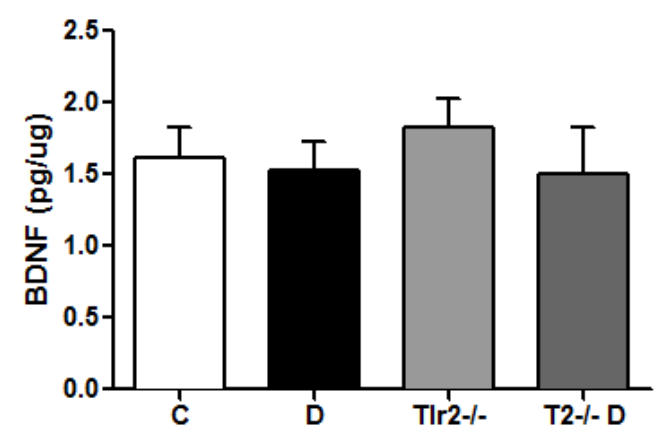

Figura 10. Efeito da dieta intermitente nos niveis proteicos de BDNF de camundongos nocaute $T l r 2^{-/-}$e Tlr $4^{-1}$. Os homogenatos do hipocampo e hipotálamo de camundongos controle C57Bl6 e $\mathrm{Tlr}^{-/-}$ou $\mathrm{Tlr}^{-/-}$ submetidos a uma dieta normal ou dieta intermitente foram usadas para o ensaio de ELISA. Em (A), níveis de BDNF no hipocampo e em (B) no hipotálamo de camundongos $T l r 4^{-/}$. Em (C), níveis de BDNF no hipocampo e em (D) no hipotálamo de camundongos $T l r 2^{-1 /}$. Os resultados são expressos como média \pm E.P.M., $\mathrm{n}=4-5, * * \mathrm{p}<0,01,{ }^{* * *} \mathrm{p}<0,001$ (ANOVA de uma via, seguido de StudentNewman-Kewls).

O ensaio de PCR em tempo real mostrou que a dieta intermitente na presença de TLR2 e TLR4 leva ao aumento da transcrição de $B d n f 1$. Por outro lado, a ausência de TLR4 e TLR2 leva a uma redução da transcrição de $B d n f l$ (Figuras 11A e 11B). Ainda, na ausência de TLR2 também ocorre a redução de expressão de $B d n f 3$ (Figura 11D). Por fim, no nocaute de 
TLR2 leva à redução da expressão de $B d n f 4$, o que não ocorre no grupo submetido à dieta intermitente (Figura 11F).

(A)

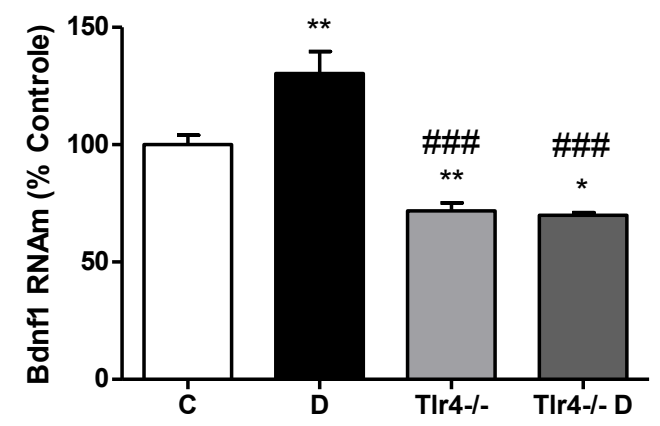

(C)

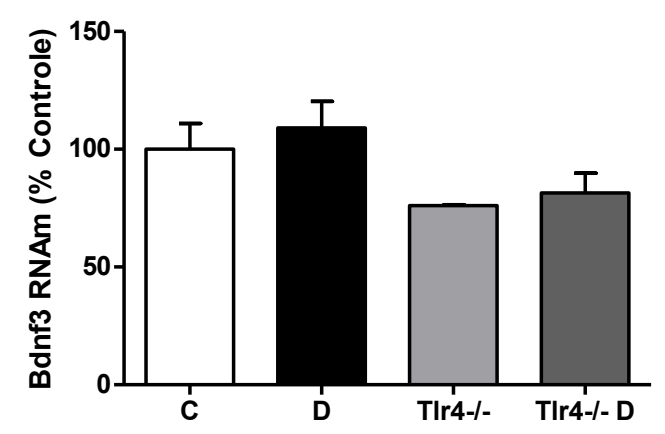

$(\mathrm{E})$

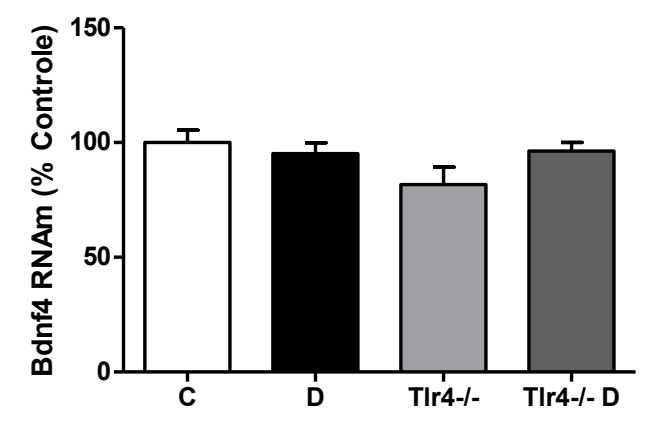

(B)

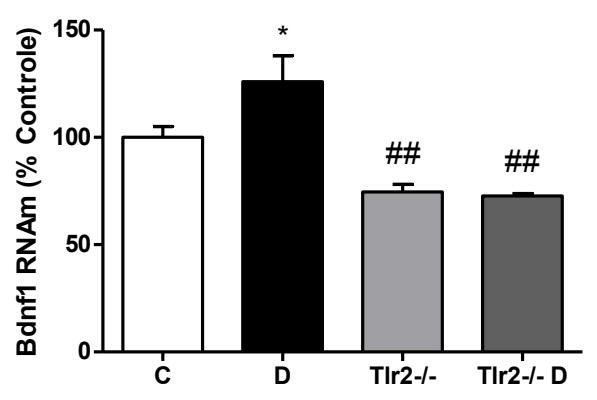

(D)

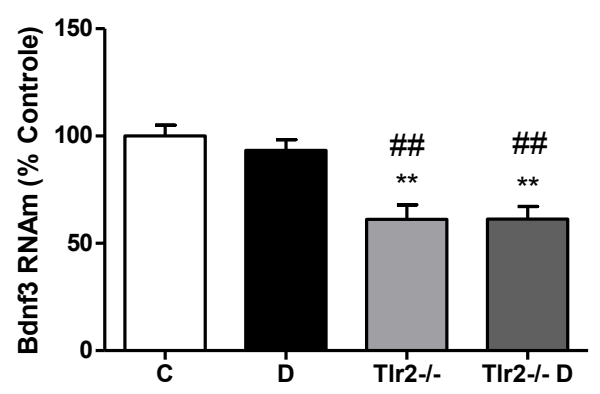

$(\mathrm{F})$

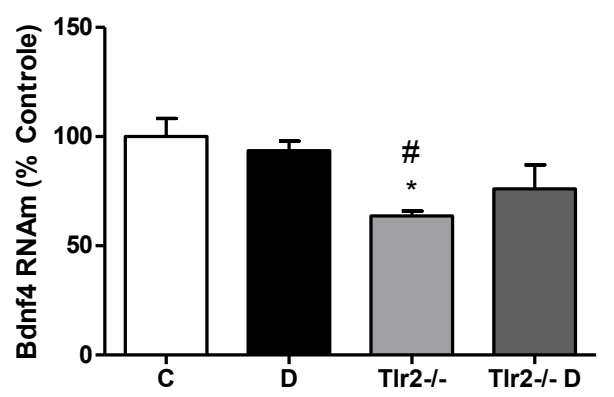

Figura 11. Efeito da dieta intermitente nos niveis de RNAm de isoformas de Bdnf de camundongos nocaute Tlr2-

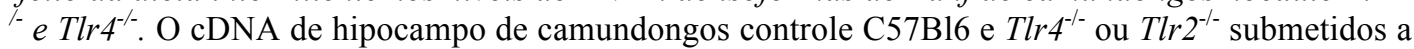
uma dieta normal ou dieta intermitente foram usadas para o ensaio de PCR em tempo real. Foram avaliadas os níveis de RNAm das isoformas $B d n f 1$ (A e B), Bdnf3 (C e D) e $B d n f 4$ (E e F) em camundongos $T l r 4^{-/-}$e $T l r 2^{-/-}$respectivamente. Os valores foram normalizados pelo controle endógeno Hprt em relação ao grupo controle através do método ddCT. Os resultados são expressos como média \pm E.P.M., $\mathrm{n}=4-5, * \mathrm{p}<0,05$ vs. $\mathrm{C}, * * \mathrm{p}<0,01$ vs. C, \# $\mathrm{p}>0,05$ vs. $\mathrm{D}, \# \# \mathrm{p}>0,01$ vs. D (ANOVA de uma via, seguido de Student-Newman-Kewls). 


\subsection{Efeitos da dieta intermitente na expressão proteica na sinalização de NRF2 e HO1 na presença/ausência de TLR4 e TLR2 no hipocampo}

Com relação ao NRF2, pudemos notar que o nocaute do TLR4 causa uma redução na atividade deste fator de transcrição, o que é revertido pela dieta intermitente (Figura 12A). O mesmo efeito é observado com o nocaute do TLR2 no hipocampo (Figura 12C). Por outro lado, no hipotálamo, a dieta intermitente é incapaz de reverter a redução da atividade do NRF2 na ausência do TLR4 (Figura 12B). Por fim, observamos que a ausência do TLR2 não causa alteração significativa na atividade do NRF2 no hipotálamo (Figura 12D).

Hipocampo

(A)

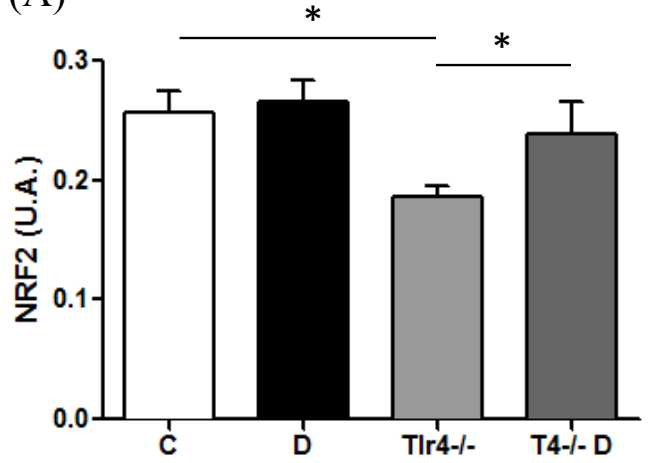

(C)

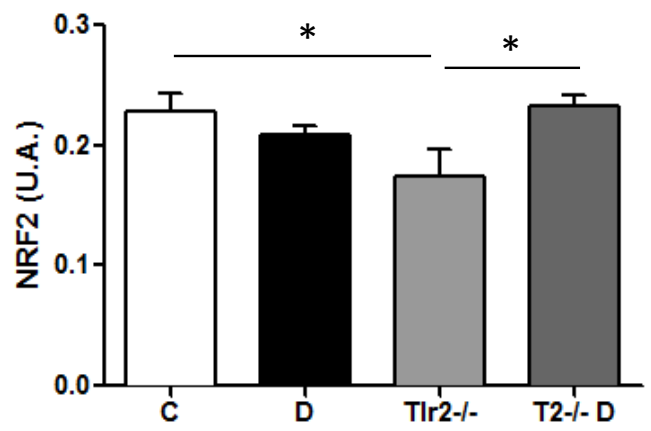

Hipotálamo

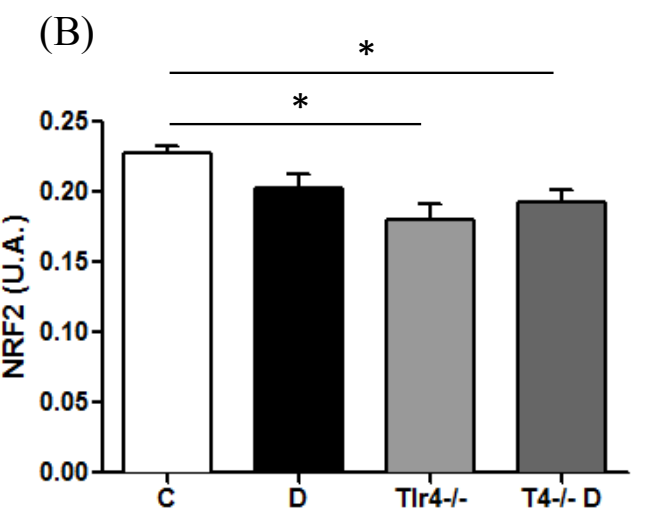

(D)

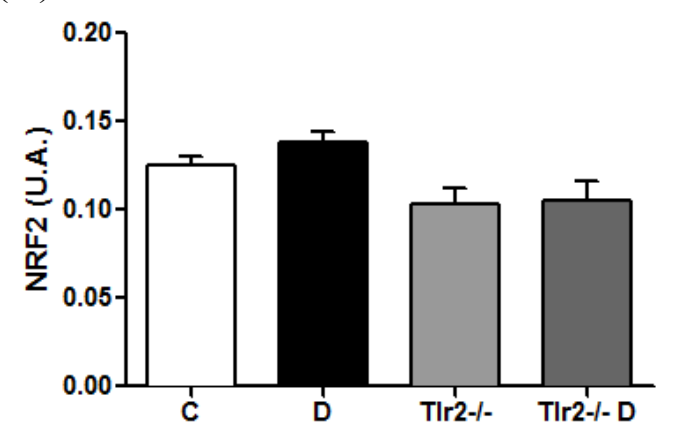

Figura 12. Efeito da dieta intermitente na atividade do fator de transcrição NRF2 em camundongos Tlr ${ }^{-/} e$ $\mathrm{Tlr}_{2}{ }^{--}$. As proteínas nucleares $(10 \mu \mathrm{g})$ foram extraídas do hipocampo e hipotálamo e usadas para analisar a ligação NRF2/ARE pelo ensaio de transativação. Em (A), atividade do NRF2 no hipocampo e em (B) no hipotálamo de camundongos $T l r 4^{-/-}$. Em (C), atividade do NRF2 no hipocampo e em (D) no hipotálamo de camundongos $T l r 2^{-/-}$. Os resultados são expressos como média \pm E.P.M., n=4-5, * p <0,05 (ANOVA de uma via, seguido de Student-Newman-Kewls).

O ensaio de western blot no hipocampo mostrou que não há variação estatisticamente significantes nos níveis de NRF2 pela dieta intermitente ou pelo nocaute de TLR4 (Figura 13B). Porém, observamos que o grupo submetido à dieta intermitente na presença do TLR2 apresenta expressão proteica significativamente maior de NRF2 em comparação ao grupo nocaute para TLR2 (Figura 13D). 
Quanto à HO1, enzima cuja expressão é modulada por NRF2, observamos que apesar de não termos obtido uma significância estatística, há uma tendência de aumento de sua expressão pela dieta intermitente independente do nocaute de TLR4 (Figura 13A). Além disso, o aumento da sua expressão induzida pela dieta intermitente é revertido pelo nocaute de TLR2 (figura 13C).

(A)

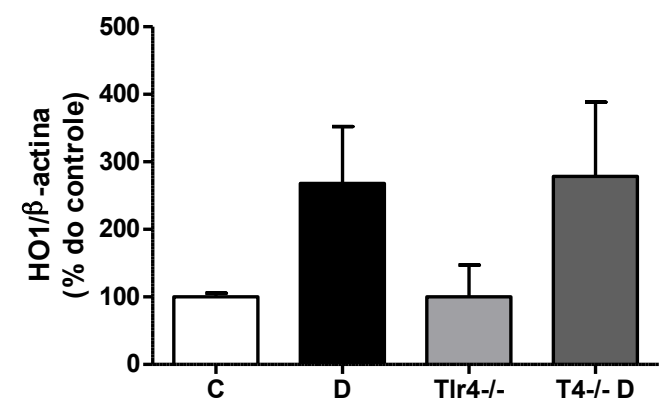

HO1

$\beta$-actina

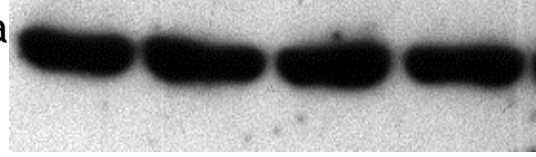

(C)
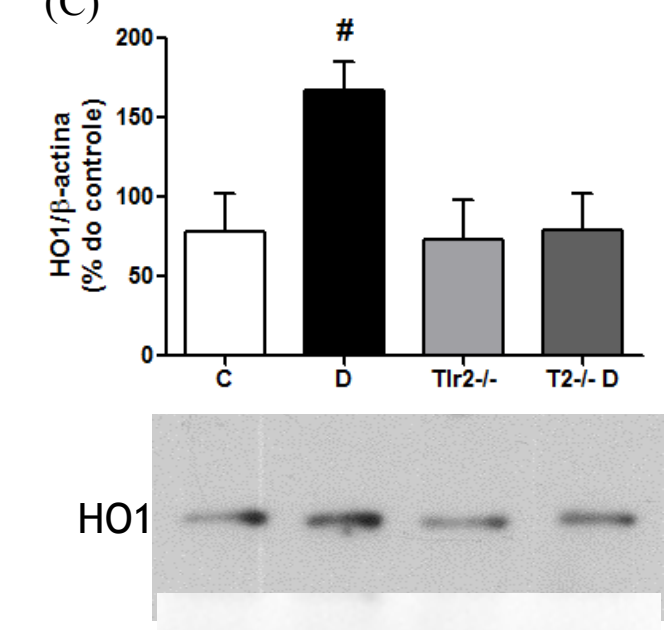

$\beta$-actina
(B)
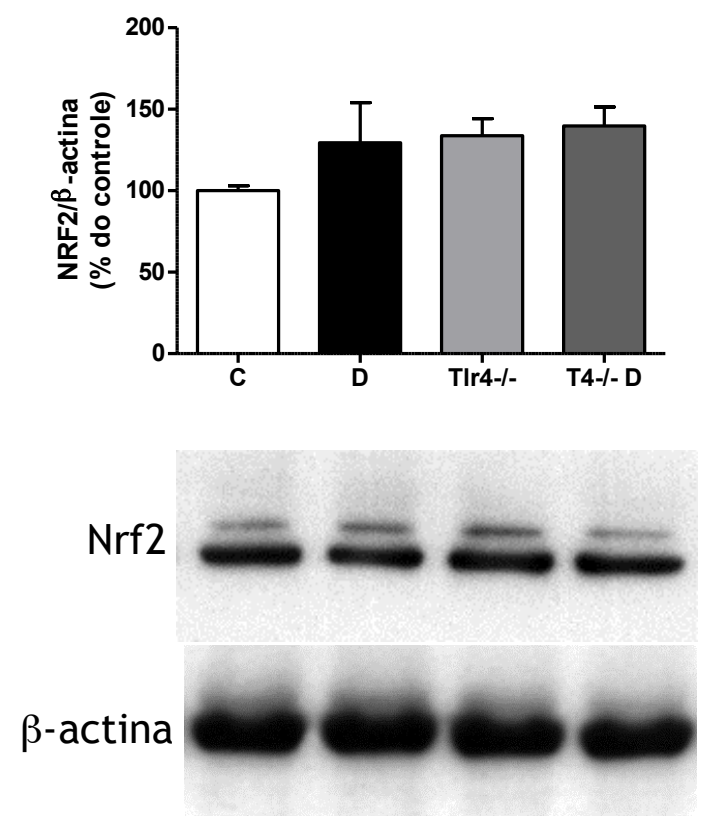

(D)

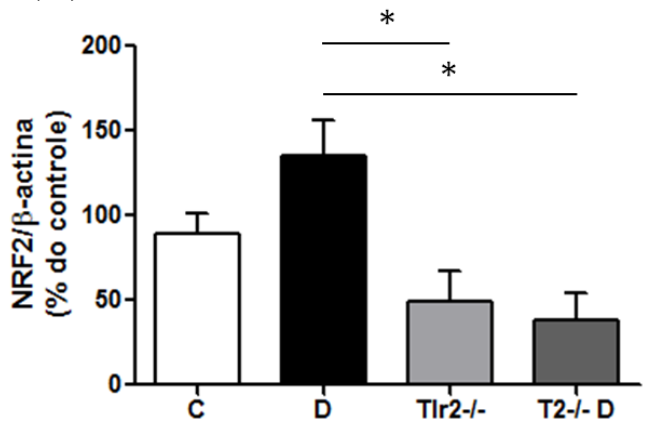

NRF2

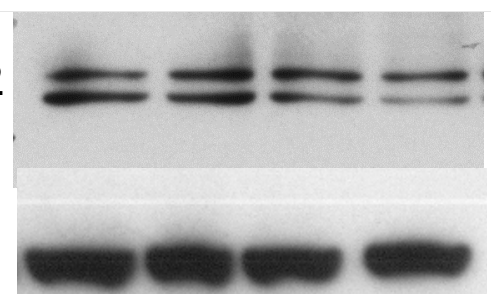

Figura 13. Efeito da dieta intermitente na sinalização do NRF2 em camundongos nocaute $T l r 4^{-/}$e Tlr $2^{-/}$. As proteínas citosólicas $(15 \mu \mathrm{g})$ foram extraídas do hipocampo de camundongos controle C57Bl6 e $T l r 4^{-/ /}$ou $T l r 2^{-/ 2}$ submetidos a uma dieta normal ou dieta intermitente. Os gráficos em (A) e (C) representa a análise densitométrica (unidades arbitrárias) da banda da $\mathrm{HO} 1 \mathrm{em}$ animais $T l r 4^{-1 /}$ e $T l r 2^{-}$ respectivamente, e em (B) e (D) da banda do fator de transcrição NRF2 em relação ao controle interno $\beta$-actina. Os resultados são expressos como média \pm E.P.M., $n=4-5, * \mathrm{p}<0,05$ (ANOVA de uma via, seguido de Student-Newman-Kewls). 


\subsection{Efeitos da dieta intermitente na expressão proteica de AKT total e fosforilada na presença/ausência de TLR2 no hipocampo}

Com relação à sinalização da proteína serina-treonina quinase (AKT), fizemos ensaios de western blot em hipocampo para avaliar a influência do TLR2 e TLR4 na modulação da via pela dieta intermitente. Como podemos notar, não ocorreu nenhuma alteração significativa nos níveis da relação AKT fosforilada / AKT total entre os grupos (Figura 14).

(A)

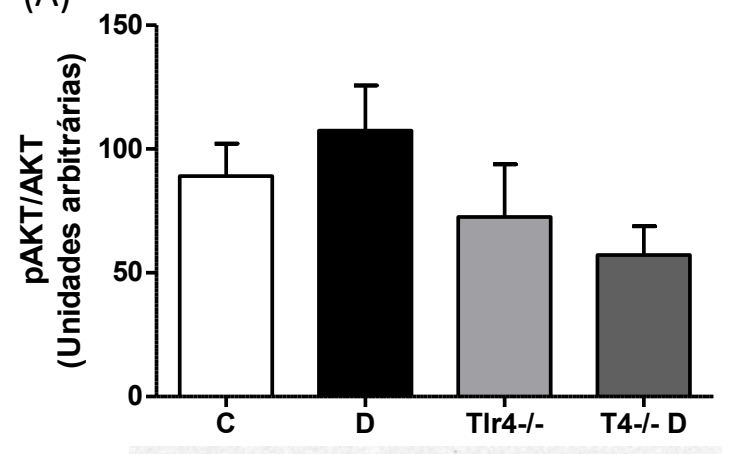

pAKT

AKT

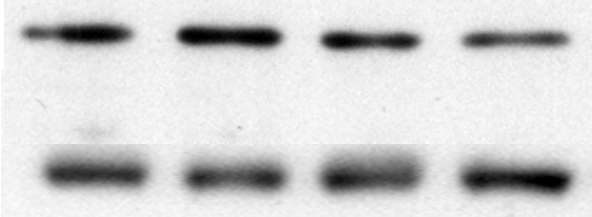

(C)

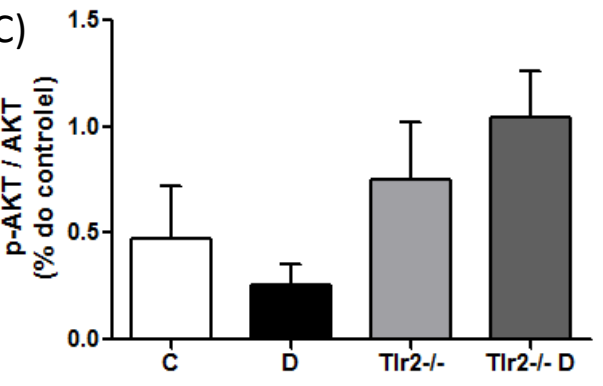

pAKT

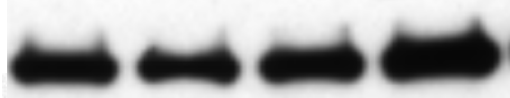

AKT
(B)

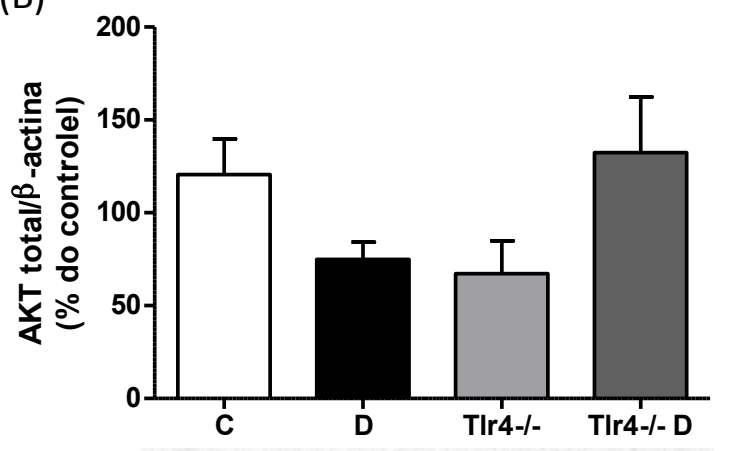

AKT

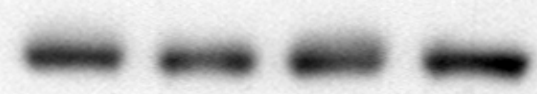

$\beta$-actina
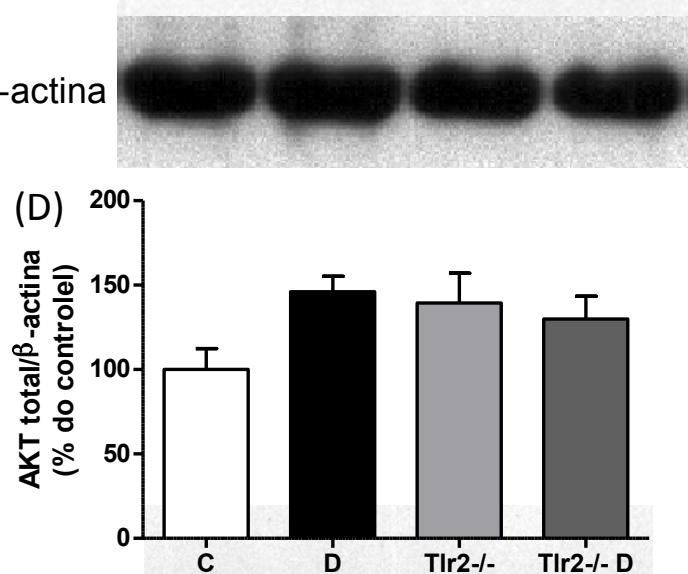

AKT

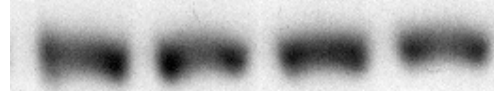

$\beta$-actina

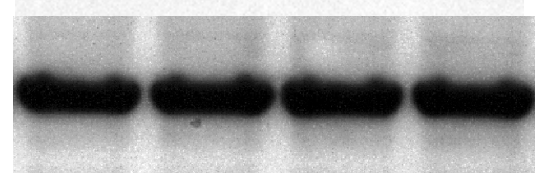

Figura 14. Efeito da dieta intermitente na proteina AKT em camundongos nocaute $T l r 4^{-/} T l r 2^{-/}$. As proteínas citosólicas $(15 \mu \mathrm{g})$ foram extraídas do hipocampo de camundongos controle C57Bl6 e Tlr $4^{-/-}$ou $\mathrm{Tlr}^{-/ 2}$ submetidos a uma dieta normal ou dieta intermitente. Os gráficos em (A) e (C) representam a análise densitométrica (unidades arbitrárias) da banda da AKT fosforilada em relação a AKT total em hipocampo de camundongos $T l r 4^{-/-}$e $T l r 2^{-/-}$respectivamente. Os gráficos em (B) e (D) representam a análise densitométrica (unidades arbitrárias) da banda da AKT total em relação ao controle interno $\beta$-actina em camundongos $T l r 4^{-/}$e $T l r 2^{-/}$. Os resultados são expressos como média \pm E.P.M., n=4-5 (ANOVA de uma via, seguido de Student-Newman-Kewls). 


\subsection{Efeitos da dieta intermitente na expressão proteica de ERK1 e ERK2 total e fosforilada na presença/ausência de TLR4 ou TLR2 no hipocampo}

Ao avaliarmos as quinases regulada por sinal extracelular (ERK) 1 (Figura 15) e ERK2 (Figura 16) totais ou em suas formas fosforiladas no hipocampo de camundongos $T l r 2^{-}$ /- e $T l r 4^{-/-}$, não observamos nenhuma diferença estatisticamente significante entre os grupos analisados.
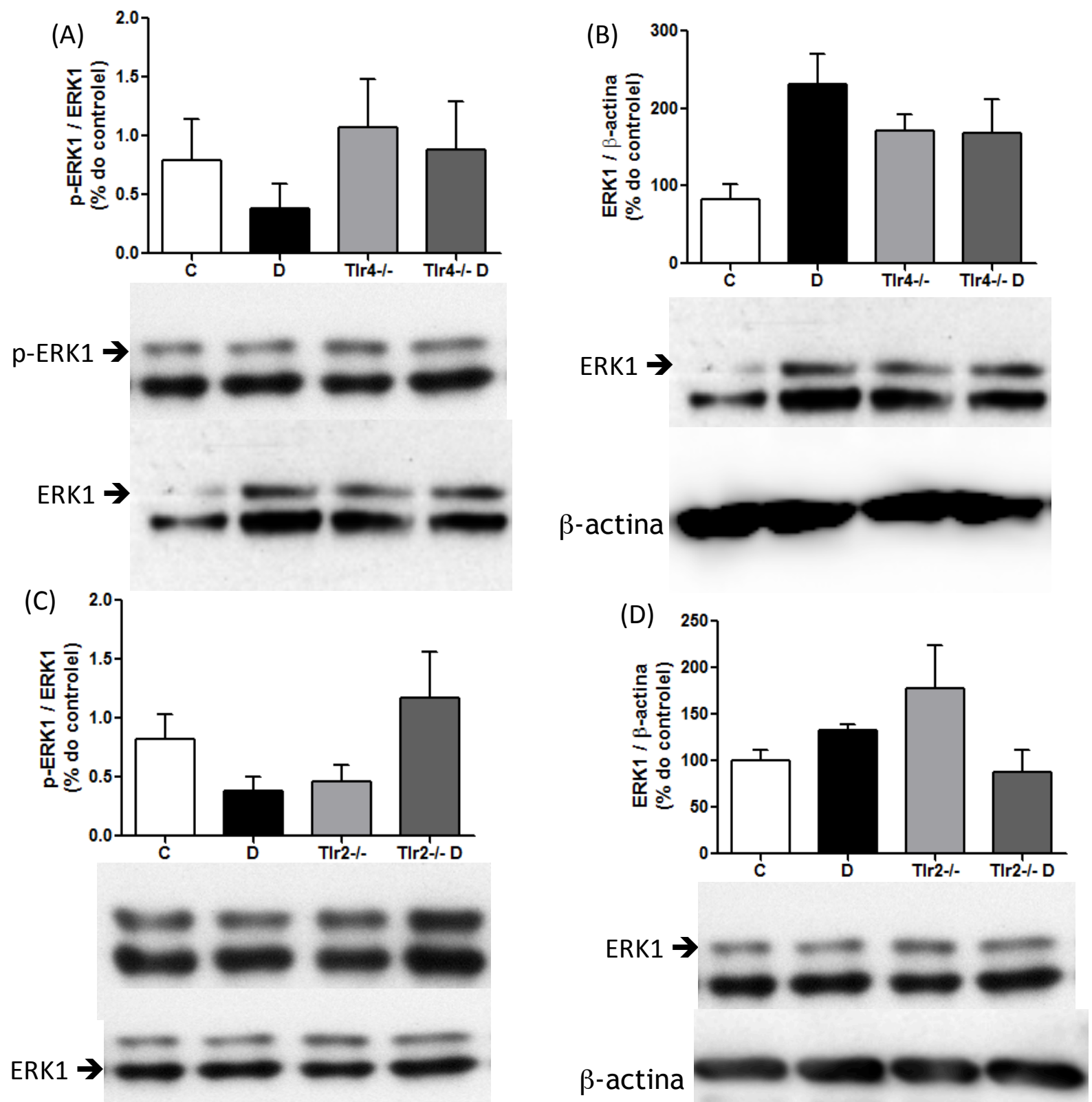

Figura 15. Efeito da dieta intermitente na proteína ERK1 em camundongos nocaute Tlr ${ }^{-/}$e Tlr $2^{-/}$. As proteínas citosólicas $(15 \mu \mathrm{g})$ foram extraídas do hipocampo de camundongos controle C57Bl6 e $\mathrm{Tlr} 4^{-/-}$ou $\mathrm{Tlr} 2^{-/-}$ submetidos a uma dieta normal ou dieta intermitente. Os gráficos indicam a análise densitométrica (unidades arbitrárias) da banda da ERK1 fosforilada em relação a ERK1 total em camundongos $T l r 4^{-/ \text {- }}$ (A), da banda da ERK1 total em relação ao controle interno $\beta$-actina em camundongos $T l r 4^{-/-}$(B), da banda da ERK1 fosforilada em relação a ERK1 total em camundongos Tlr2 ${ }^{-/}$(C) e da banda da ERK1 total em relação ao controle interno $\beta$-actina em camundongos $T l r 2^{-/-}$(D). Os resultados são expressos como média \pm E.P.M., n=4-5 (ANOVA de uma via, seguido de Student-Newman-Kewls). 

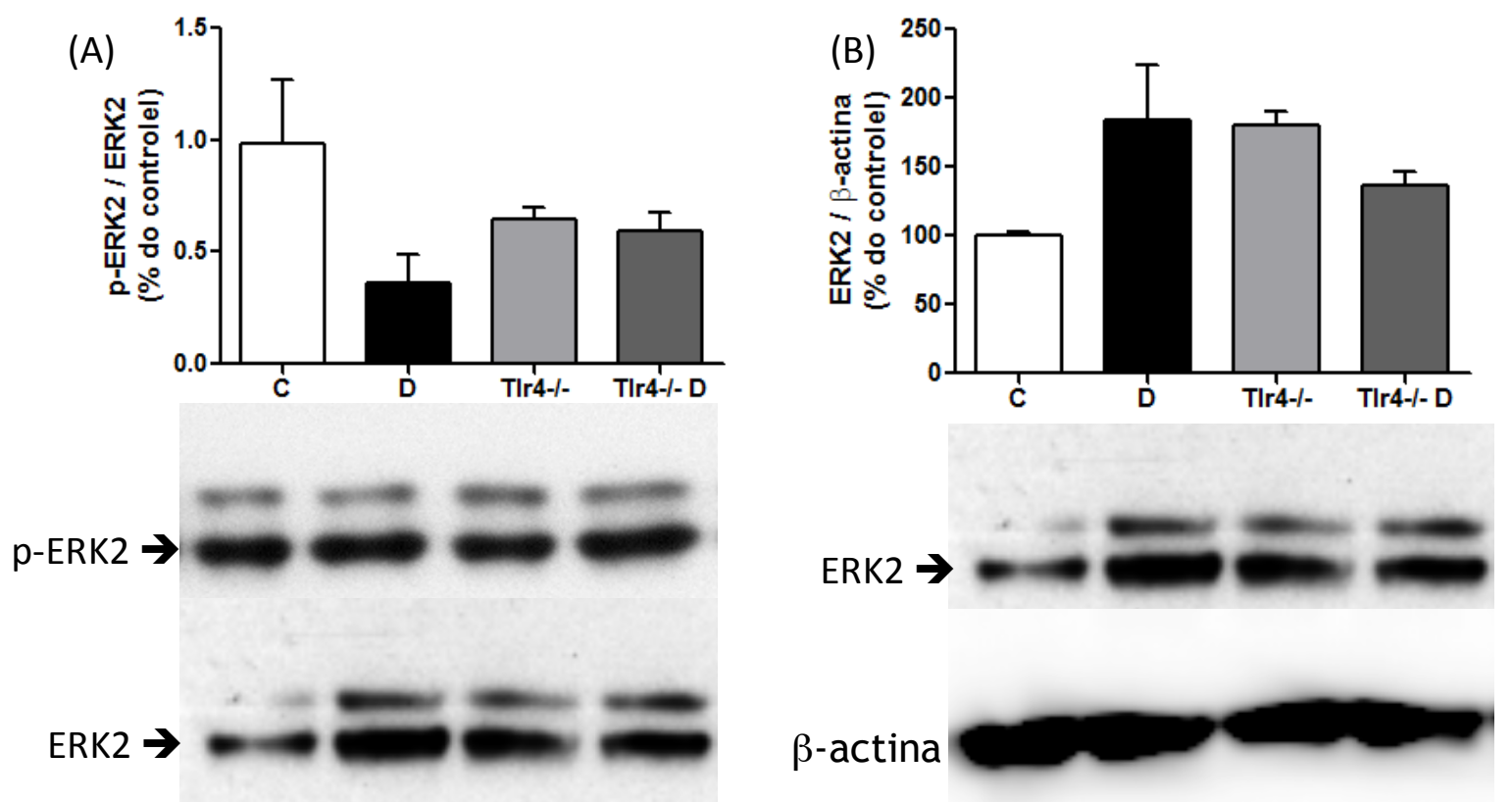

\section{$\beta$-actina}

(C)
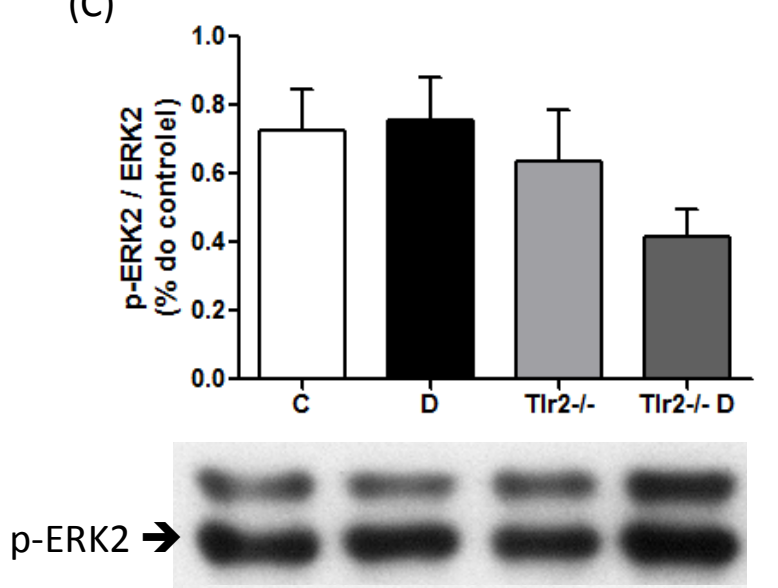

ERK2 $\rightarrow$

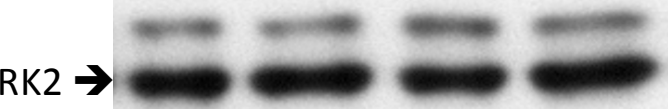

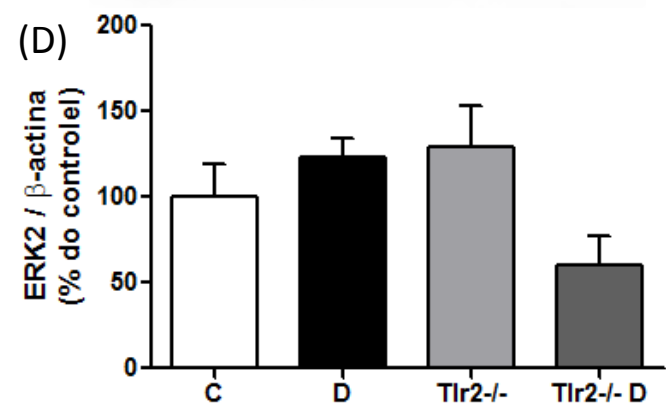

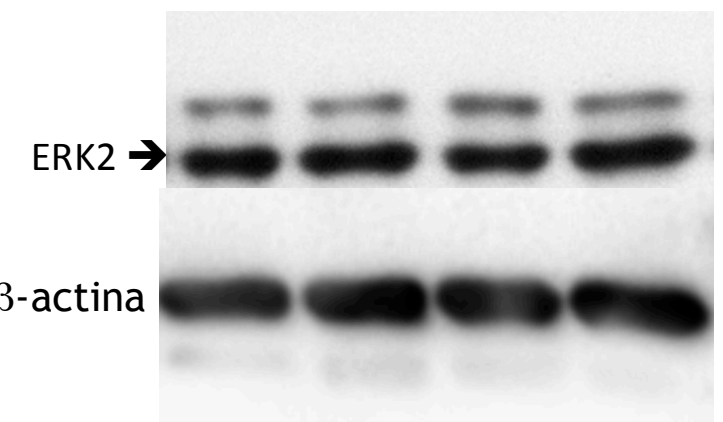

Figura 16. Efeito da dieta intermitente na proteina ERK2 em camundongos nocaute $T l r 4^{-/}$e $T l r 2^{-\alpha}$. As proteínas citosólicas $(15 \mu \mathrm{g})$ foram extraídas do hipocampo de camundongos controle C57B16 e $\operatorname{Tlr}^{-/-}$ou $T l r 2^{-/-}$submetidos a uma dieta normal ou dieta intermitente. Os gráficos indicam a análise densitométrica (unidades arbitrárias) da banda da ERK2 fosforilada em relação a ERK2 total em camundongos Tlr $^{-/-}$(A), da banda da ERK2 total em relação ao controle interno $\beta$-actina em camundongos $T l r 4^{-/-}$(B), da banda da ERK2 fosforilada em relação a ERK2 total em camundongos $T l r 2^{-/}$(C) e da banda da ERK2 total em relação ao controle interno $\beta$-actina em camundongos $T l r 2^{-/-}$ (D). Os resultados são expressos como média \pm E.P.M., $n=4-5$ (ANOVA de uma via, seguido de Student-Newman-Kewls). 


\subsection{Efeitos da dieta intermitente na expressão proteica de mTOR total e fosforilado na presença/ausência de TLR4 ou TLR2 no hipocampo}

Ao investigarmos a modulação da proteína alvo da rapamicina em mamíferos (mTOR) total e em sua forma fosforilada no hipocampo de camundongos $\mathrm{Tlr} 2^{-/-}$e $\mathrm{Tlr} 4^{-/-}$, não observamos nenhuma diferença estatisticamente significante entre os grupos (Figura 17).

(A)

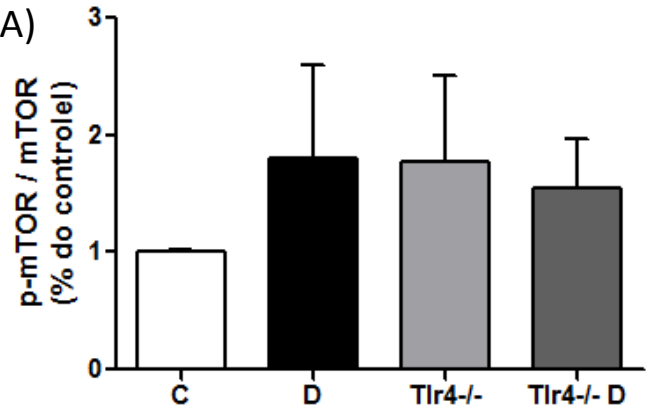

p-mTOR

mTOR
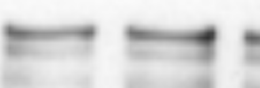

(C)

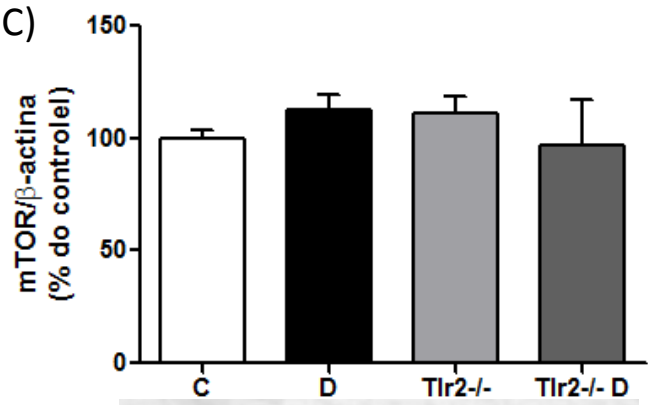

p-mTOR

mTOR
(B)

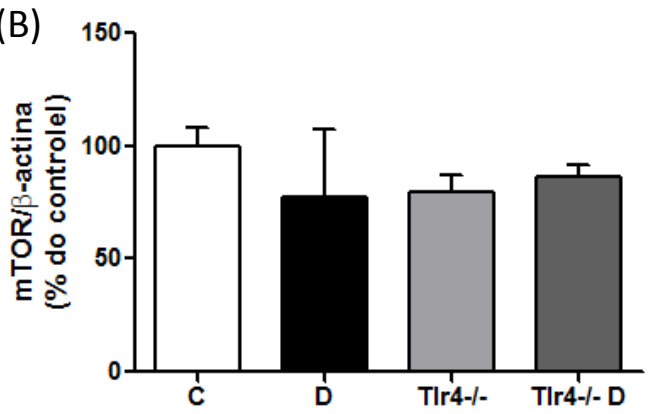

mTOR

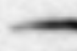

$\beta$-actina

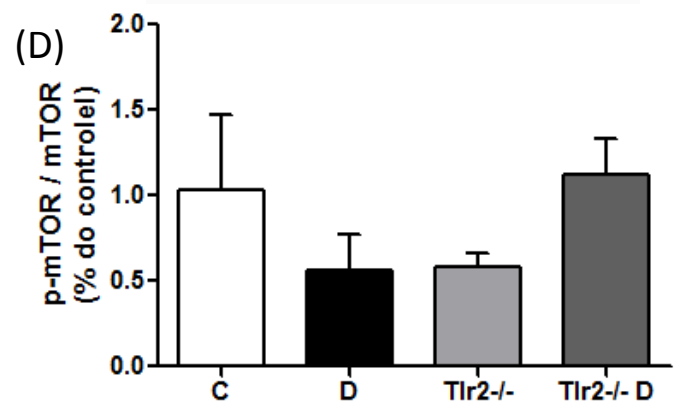

mTOR

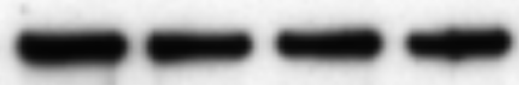

$\beta$-actina

Figura 17. Efeito da dieta intermitente na proteina mTOR em camundongos nocaute Tlr4 ${ }^{-/}$e Tlr2 ${ }^{-/}$. As proteínas citosólicas $(15 \mu \mathrm{g})$ foram extraídas do hipocampo de camundongos controle C57B16 e $T l r 4^{-/}$ou $T l r 2^{-/-}$submetidos a uma dieta normal ou dieta intermitente. (A) Análise densitométrica (unidades arbitrárias) da banda da mTOR fosforilada em relação a mTOR total em hipocampo de camundongos $T l r 4^{-/}$. (B) Análise densitométrica (unidades arbitrárias) da banda da mTOR total em relação ao controle interno $\beta$-actina em camundongos $T l r 4^{-/-}$. (C) Análise densitométrica (unidades arbitrárias) da banda da mTOR fosforilada em relação a mTOR total em hipocampo de camundongos $T l r 2^{-/-}$. (D) Análise densitométrica (unidades arbitrárias) da banda da mTOR total em relação ao controle interno $\beta$-actina em camundongos $T l r 2^{-/-}$. Os resultados são expressos como média \pm E.P.M., n=4-5 (ANOVA de uma via, seguido de Student-Newman-Kewls). 


\subsection{Efeitos da dieta intermitente na expressão proteica de AMPK total e fosforilada na presença/ausência de TLR4 no hipocampo}

Ao investigarmos a modulação da proteína quinase dependente de AMP (AMPK) total e em sua forma fosforilada no hipocampo, observamos que a fosforilação dessa proteína é aumentada pela dieta intermitente e pelo nocaute do receptor TLR4 em relação ao grupo controle (Figura 18).

(A)
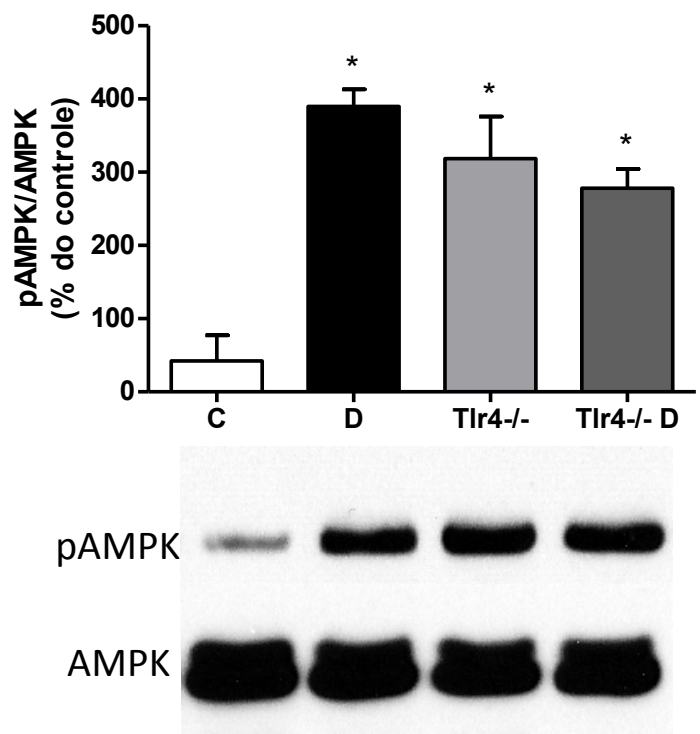

(B)

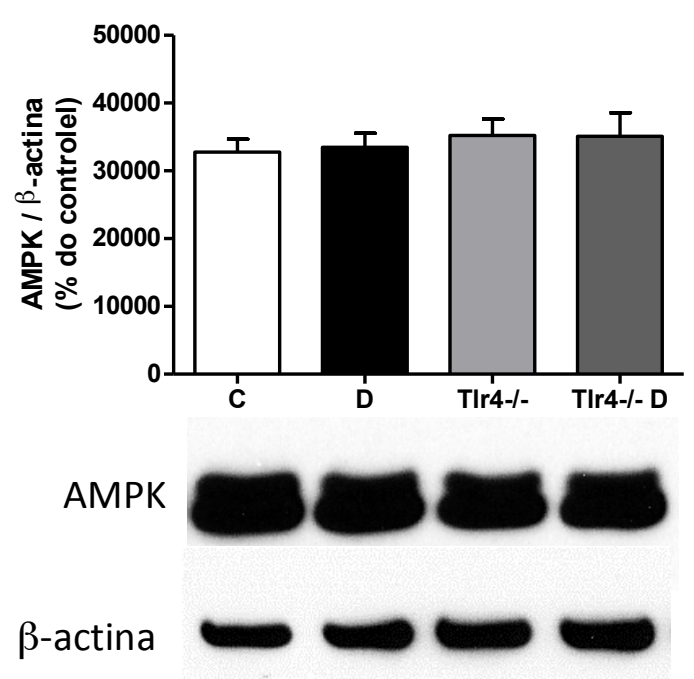

Figura 18. Efeito da dieta intermitente na proteina AMPK em camundongos nocaute Tlr ${ }^{-1-}$. As proteínas citosólicas $(15 \mu \mathrm{g})$ foram extraídas do hipocampo de camundongos controle C57B16 e $\mathrm{Tlr}^{-/-}$ submetidos a uma dieta normal ou dieta intermitente. (A) Análise densitométrica (unidades arbitrárias) da banda da AMPK fosforilada em relação a AMPK total em hipocampo de camundongos $\operatorname{Tlr}^{-/-}$. (B) Análise densitométrica (unidades arbitrárias) da banda de AMPK total em relação ao controle interno $\beta$-actina em camundongos $T l r 4^{-/}$. Os resultados são expressos como média \pm E.P.M., $\mathrm{n}=5,{ }^{*} \mathrm{p}<0,05$ vs. C (ANOVA de uma via, seguido de Student-Newman-Kewls). 


\subsection{Efeitos da dieta intermitente na expressão proteica de FOXO1 total e fosforilado na presença/ausência de TLR4 ou TLR2 no hipocampo}

O ensaio de western blot não mostrou nenhuma diferença estatisticamente significante entre os grupos ao investigarmos na modulação da proteína FOXO1 total e em sua forma fosforilada no hipocampo de camundongos $T l r 2^{-/-}$e $T l r 4^{-/-}$(Figura 19).
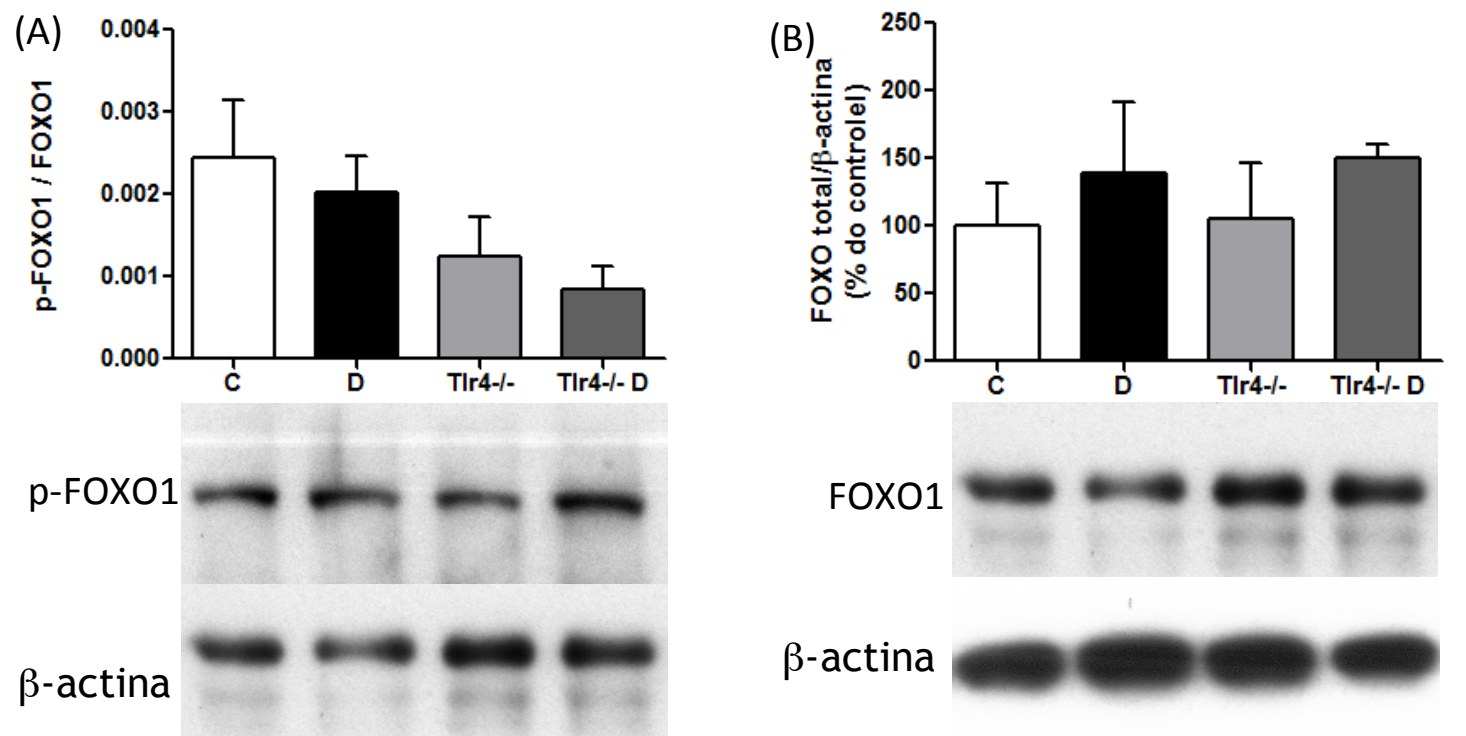

FOXO1

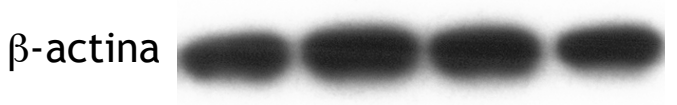

(C)

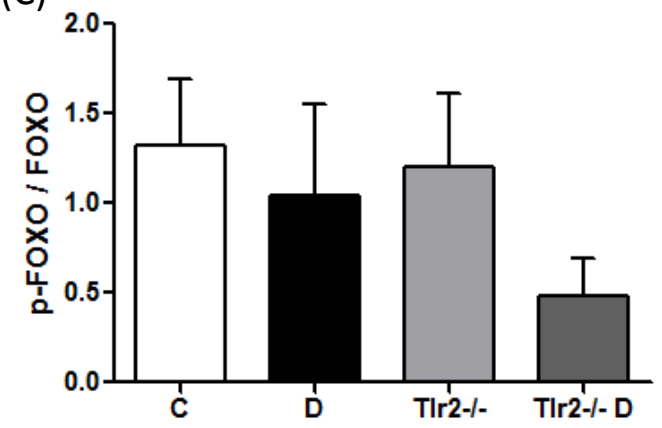

(D)

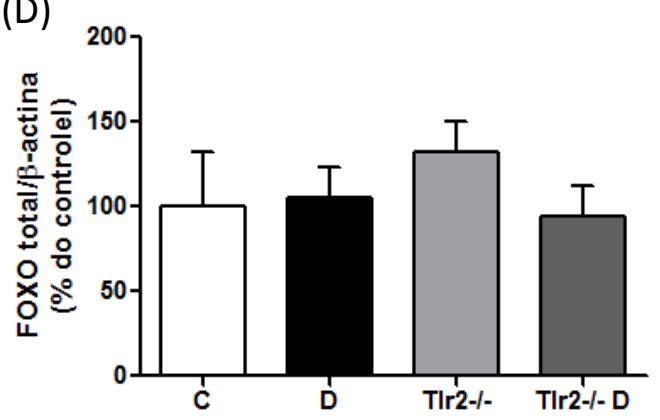

p-FOXO1

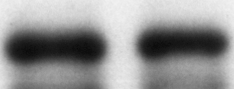

FOXO1

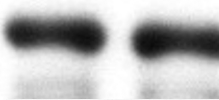

FOXO1

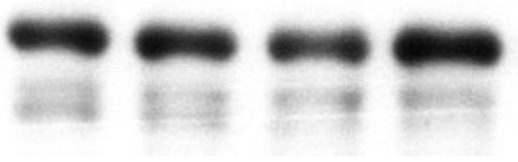

$\beta$-actina

Figura 19. Efeito da dieta intermitente na proteina FOXO1 em camundongos nocaute $\mathrm{Tlr}^{-1 /}$ e $\mathrm{Tlr}^{-1}{ }^{-1}$. As proteínas nucleares $(15 \mu \mathrm{g})$ foram extraídas do hipocampo de camundongos controle C57B16 e Tlr $4^{-}$ - ou $\mathrm{Tlr}^{2-/}$ submetidos a uma dieta normal ou dieta intermitente. Os gráficos representam a análise densitométrica (unidades arbitrárias) da banda da FOXO1 fosforilada em relação a FOXO1 total em camundongos $\mathrm{Tlr}^{-1-}$ (A), da banda da FOXO1 total em relação ao controle interno $\beta$-actina em camundongos $\mathrm{Tlr}^{-1 /}$ (B), da banda da FOXO1 fosforilada em relação a FOXO1 total de camundongos $\mathrm{Tlr}^{-/-}$(C) e da banda da FOXO1 total em relação ao controle interno $\beta$-actina em camundongos $\mathrm{Tlr}^{-/}$(D). Os resultados são expressos como média \pm E.P.M., n=4-5 (ANOVA de uma via, seguido de Student-Newman-Kewls). 


\subsection{Efeitos da dieta intermitente nos níveis de estresse oxidativo e na atividade e expressão de enzimas antioxidantes na presença/ausência de TLR4 ou TLR2 no hipocampo}

Em condições de estresse oxidativo, a peroxidação lipídica de ácidos graxos poliinsaturados da série $\omega 6$ levam à produção de 4-hidroxi-2-nonenal (HNE) (184). A quantificação deste biomarcador de estresse oxidativo por western blot mostrou que o nocaute de TLR4 leva a um aumento da banda de 55kDa de HNE independente da dieta intermitente (Figura 20B), e um aumento dependente da dieta intermitente na banda de 22kDa (Figura 20A).

(A)
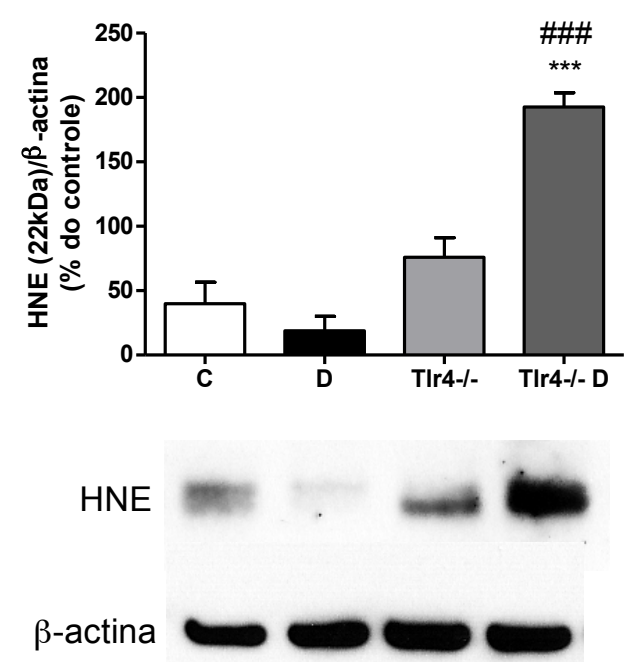

(B)

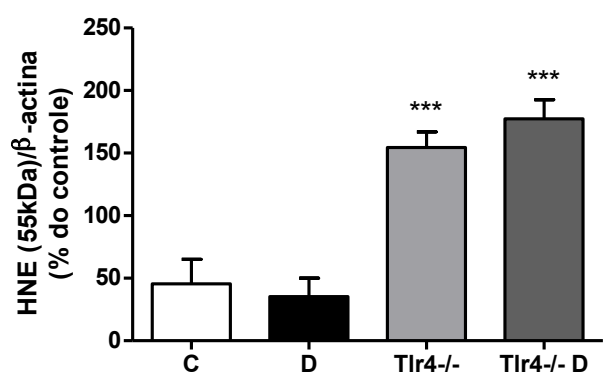

HNE

$\beta$-actina

Figura 20. Efeito da dieta intermitente sobre os níveis de peroxidação lipídica em camundongos nocaute Tlr $4^{-/}$. As proteínas $(15 \mu \mathrm{g})$ do hipocampo de camundongos controle C57B16 e $T l r 4^{-/-}$submetidos a uma dieta normal ou dieta intermitente foram utilizadas para quantificar os níveis de HNE, o principal produto da peroxidação lipídica. Em A, análise densitométrica (unidades arbitrárias) das bandas de HNE de aproximadamente $22 \mathrm{kDa}$ e em B de aproximadamente $55 \mathrm{kDa}$ em relação ao controle interno $\beta$-actina em camundongos $T l r 4^{-/-}$. Os resultados são expressos como média \pm E.P.M., $n=5$, *** $\mathrm{p}<0,001$ vs. C e D, \#\#\# p<0,001 vs. Tlr4 ${ }^{-/-}$(ANOVA de uma via, seguido de Student-NewmanKewls). 
Realizamos ainda ensaios para quantificar a atividade das enzimas antioxidantes glutationa peroxidase (GPx), glutationa redutase (GR) e glutationa-S-transferase (GST). Nossos resultados indicam que a dieta intermitente por si só leva ao aumento da atividade da enzima antioxidante GPx. Além disso, o nocaute de TLR2 leva ao aumento de atividade desta enzima, que é potencializado pela dieta intermitente (Figura 21A).

Quanto à GR, o nocaute de TLR2 resulta em uma redução da atividade desta enzima em relação aos outros grupos, o que é revertido pela dieta intermitente (Figura 21B). Por fim, a dieta intermitente somente na ausência de TLR2 leva à diminuição da atividade da enzima GST (Figura 21D).

A análise da razão da atividade da enzima GR pela GPx demostra que a dieta intermitente gera uma redução da razão em relação ao grupo controle, e que o nocaute de TLR2 leva a uma redução ainda maior (Figura 21C).

(A)

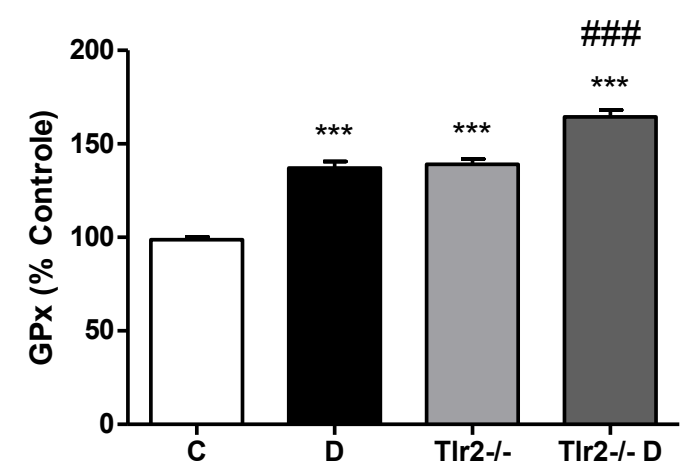

(C)

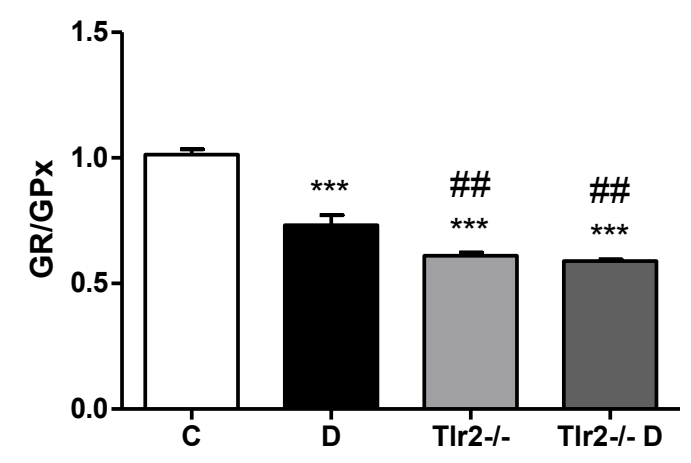

(B)

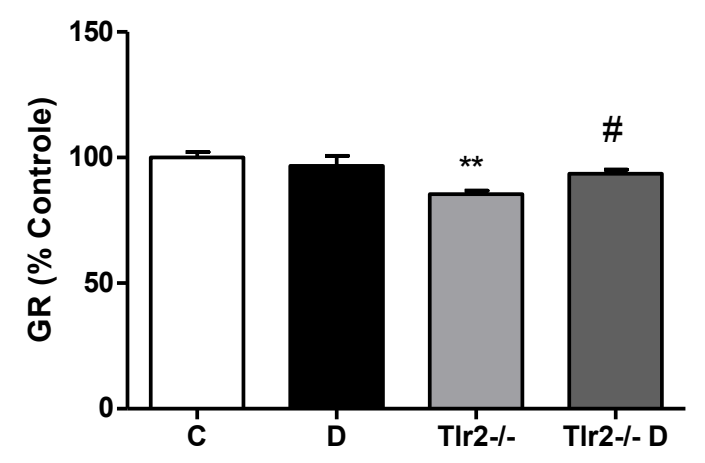

(D)

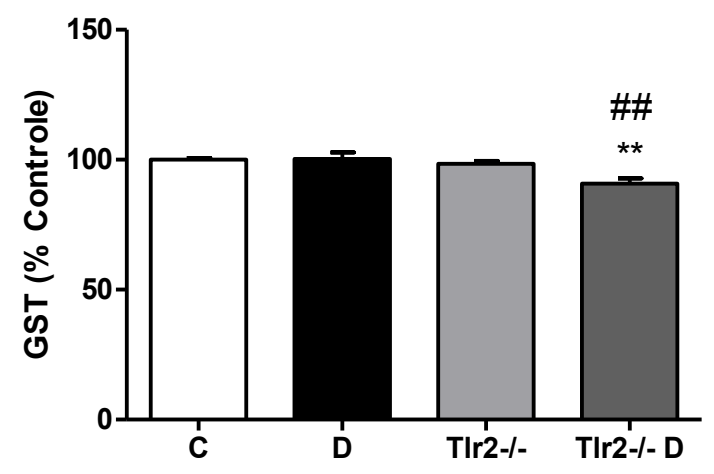

Figura 21. Efeito da dieta intermitente na atividade das enzimas GPx, GR e GST em camundongos nocaute Tlr2. O hipocampo de camundongos C57B16 e $\mathrm{Tlr}^{-/}$submetidos a uma dieta normal ou dieta intermitente foram usadas para determinar a atividade das enzimas GPx (A), GR (B) e GST (D). Também foi calculada a razão entre as atividades de GR e GPx (C). Os resultados são expressos como média \pm E.P.M., $\mathrm{n}=5$, ** $\mathrm{p}<0,01$ vs. C e $T l r 2^{-/}, * * * \mathrm{p}<0,001$ vs. C, \# $\mathrm{p}<0,05$ vs. $T l r 2^{-/}$, \# $\mathrm{p}<0,05$ vs $T l r 2^{-/}, \#$ p $<0,01$ vs. D, \#\# $\mathrm{p}<0,001$ vs. D e Tlr $2^{-/-}$(ANOVA de uma via, seguido de Student-Newman-Kewls). 
A análise da expressão gênica de enzimas antioxidantes no hipocampo dos camundongos $T l r 4^{-/-}$mostrou que a única alteração estatisticamente significativa observada foi o aumento da transcrição do gene da catalase (Cat) no grupo de animais nocaute TLR4 submetidos à dieta intermitente em relação ao grupo controle (Figura 22A).

(A)

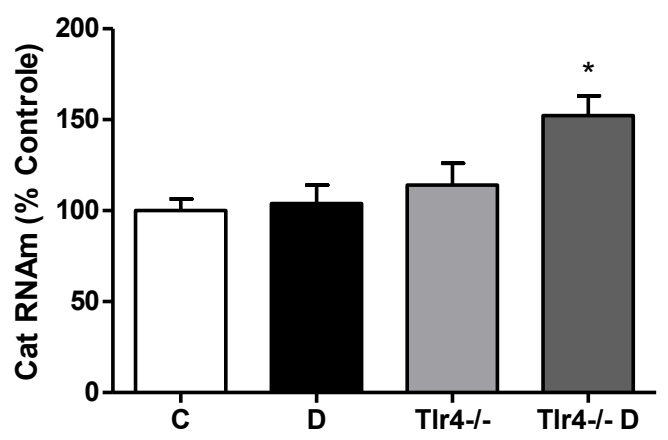

(B)

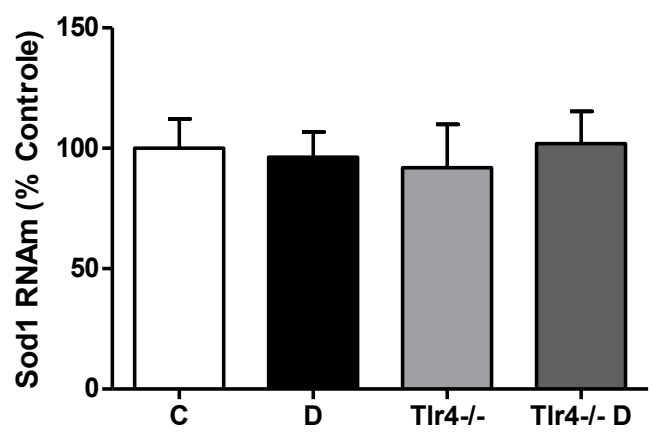

(C)

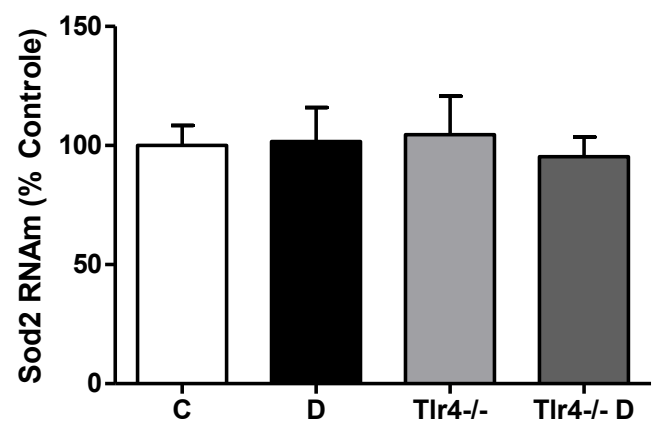

Figura 22. Efeito da dieta intermitente nos niveis de RNAm das enzimas antioxidantes Catalase, SOD1 e SOD2 no hipocampo de camundongos nocaute Tlr $4^{-/}$. O cDNA de hipocampo de camundongos controle C57B16 e $T l r 4^{-/-}$submetidos a uma dieta normal ou dieta intermitente foram usadas para o ensaio de PCR em tempo real. Foram avaliadas os níveis de RNAm dos genes Cat (A), Sod1 (B) e Sod2 (C) em camundongos $T l r 4^{-/-}$. Os valores foram normalizados pelo controle endógeno Hprt em relação ao grupo controle. Os resultados são expressos como média \pm E.P.M., n=5, * p<0,05 vs. C, D e Tlr4 ${ }^{-/-}$ (ANOVA de uma via, seguido de Student-Newman-Kewls).

A análise da expressão gênica de enzimas antioxidantes no hipocampo e hipotálamo de camundongos $T l r 2^{-/-}$mostrou que a única alteração estatisticamente significativa observada foi o aumento da transcrição do gene da $\operatorname{Sod} 2$ pela dieta intermitente e pelo nocaute do receptor TLR2 em relação ao grupo controle no hipotálamo (Figura 23F). É interessante notar que a dieta intermitente reverte o aumento de Sod2 observado nos animais $\mathrm{Tlr}^{-/-}$nessa estrutura cerebral. 
Hipocampo

(A)

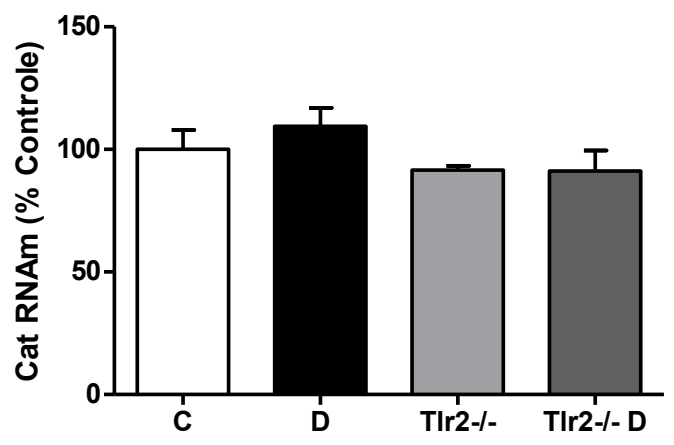

(C)

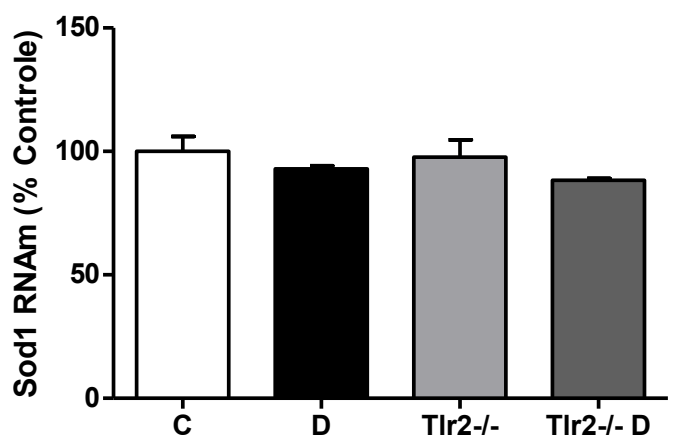

$(\mathrm{E})$

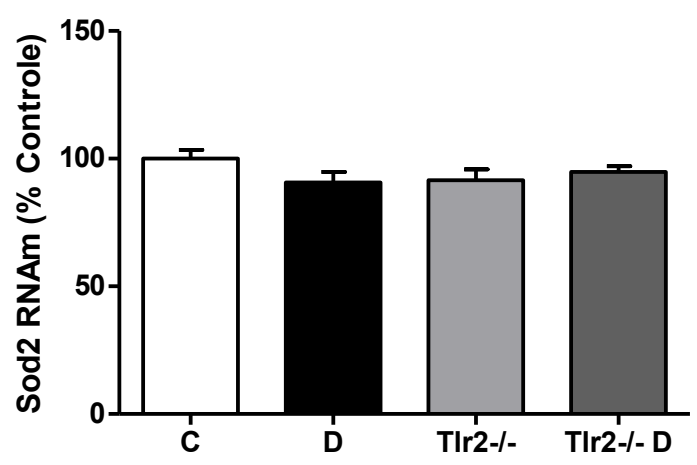

Hipotálamo

(B)

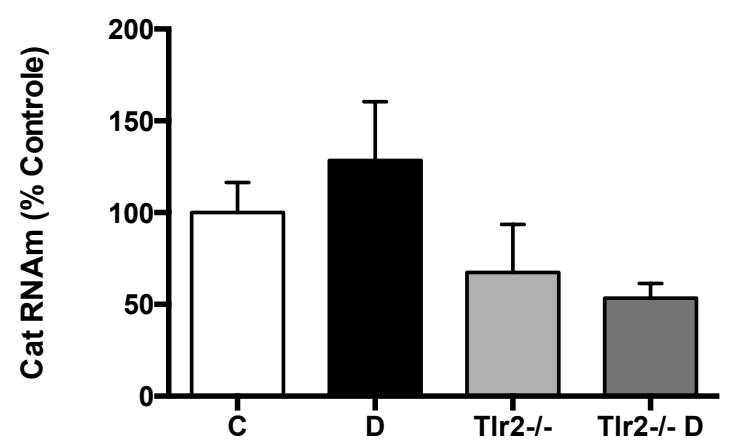

(D)

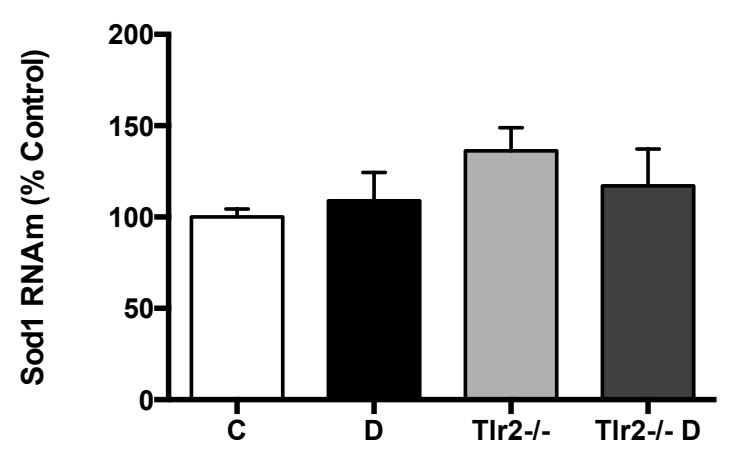

$(\mathrm{F})$

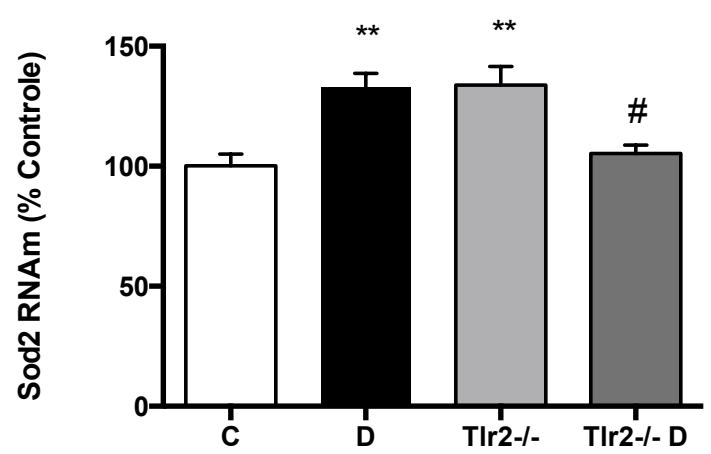

Figura 23. Efeito da dieta intermitente nos niveis de RNAm das enzimas antioxidantes Catalase, SOD1 e SOD2 no hipocampo e hipotálamo de camundongos nocaute $T l r 2^{-/}$. O cDNA do hipocampo e hipotálamo de camundongos controle C57B16 e $T l r 2^{-/-}$submetidos a uma dieta normal ou dieta intermitente foram usadas para o ensaio de PCR em tempo real. Foram avaliadas os níveis de RNAm dos genes Cat (A e B), Sod1 (C e D) e Sod2 (E e F) no hipocampo e hipotálamo de camundongos $T l r 2^{-/-}$, respectivamente. Os valores foram normalizados pelo controle endógeno Hprt em relação ao grupo controle. Os resultados são expressos como média \pm E.P.M., $\mathrm{n}=5$, ${ }^{* *} \mathrm{p}<0,01$ vs. C, \# $\mathrm{p}<0,05$ vs. $T l r 2^{-/-}$(ANOVA de uma via, seguido de Student-Newman-Kewls). 


\subsection{Efeitos da dieta intermitente na expressão proteica de P53 na presença/ausência de TLR4 no hipocampo}

A análise por western blot de P53 no hipocampo demonstrou que a dieta intermitente resulta num aumento da expressão dessa proteína somente na ausência do receptor TLR4 (Figura 24).

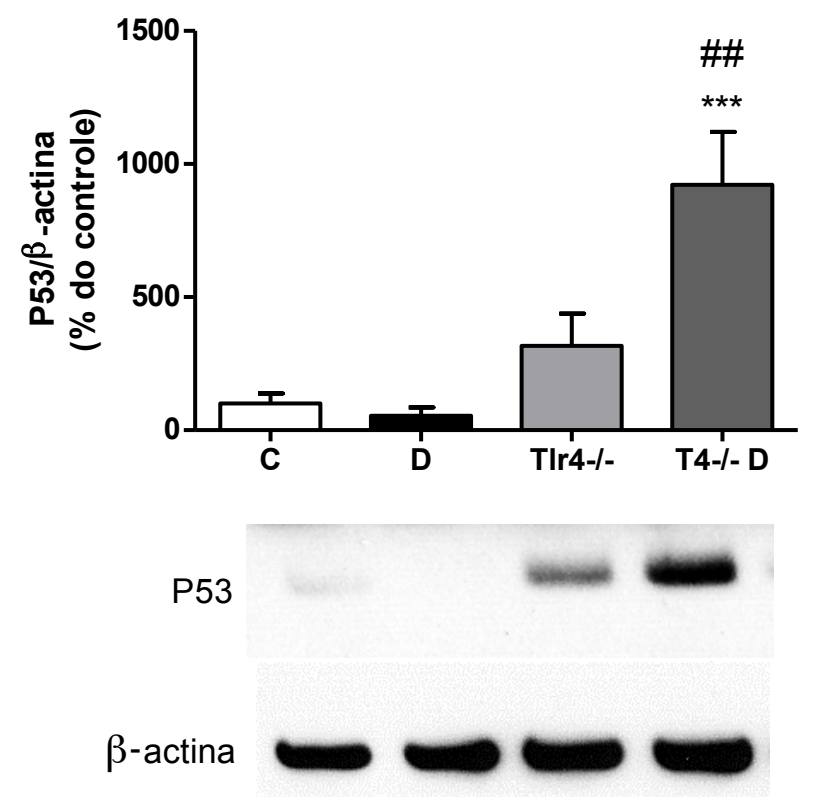

Figura 24. Efeito da dieta intermitente sobre os níveis de P53 em camundongos nocaute Tlr $4^{-/}$. As proteínas (15 $\mu \mathrm{g})$ do hipocampo de camundongos controle C57B16 e $T l r 4^{-/-}$submetidos a uma dieta normal ou dieta intermitente foram utilizadas para quantificar os níveis de P53 em relação ao controle interno $\beta$-actina em camundongos $T l r 4^{-/-}$. Os resultados são expressos como média \pm E.P.M., n=5, *** $\mathrm{p}<0,001$ vs. C e D, \#\# p<0,01 vs. Tlr4 $4^{-/-}$(ANOVA de uma via, seguido de Student-Newman-Kewls).

\subsection{Efeitos da dieta intermitente na expressão proteica de proteínas de choque térmico na presença/ausência de TLR4}

A análise dos níveis proteicos de proteínas de choque térmico demonstrou que a dieta intermitente ou ausência de TLR4 não alteram a expressão de HSP70 (Figura 25A). Porém ao avaliar a HSP90, verificamos que o nocaute de TLR4 na ausência da dieta intermitente leva a uma redução na expressão desta proteína (Figura 25B). 
(A)

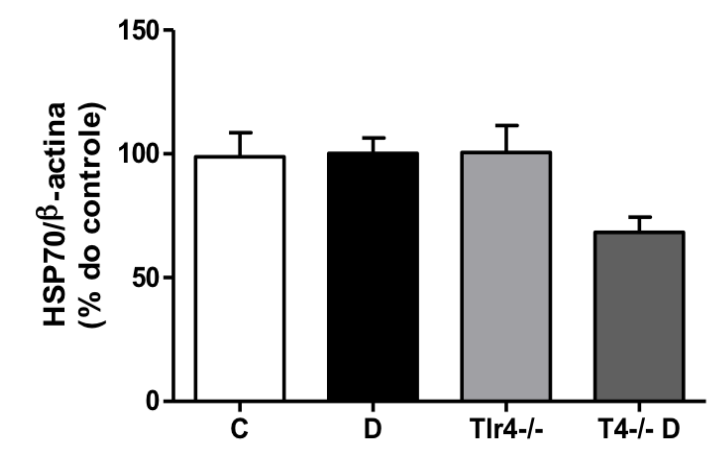

HSP70

$\beta$-actina
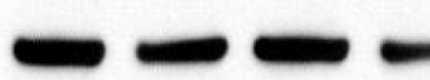

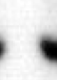

(B)

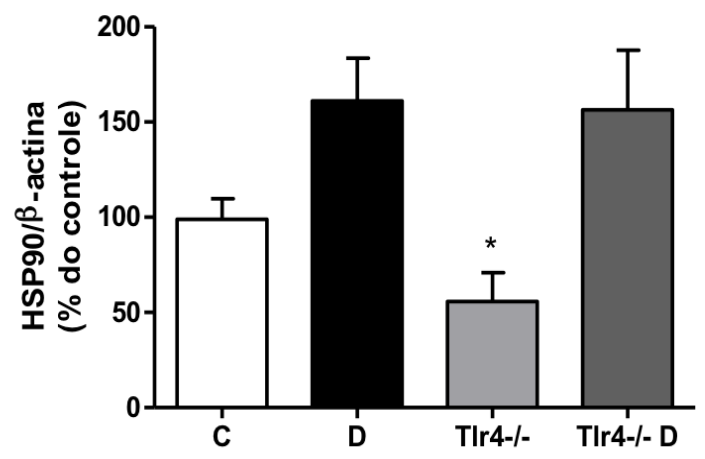

HSP90

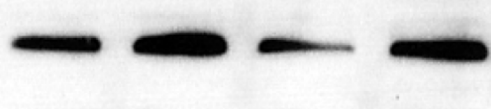

$\beta$-actina
) 
Interessantemente, foi observado que a dieta intermitente induz um aumento nos níveis plasmáticos de creatina, o que não ocorre nos animais $T l r 4^{-/-}$(Figura 26D).

(A)

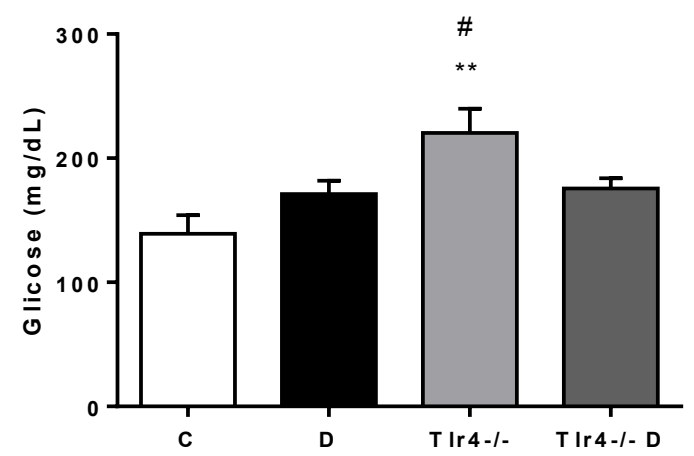

(C)

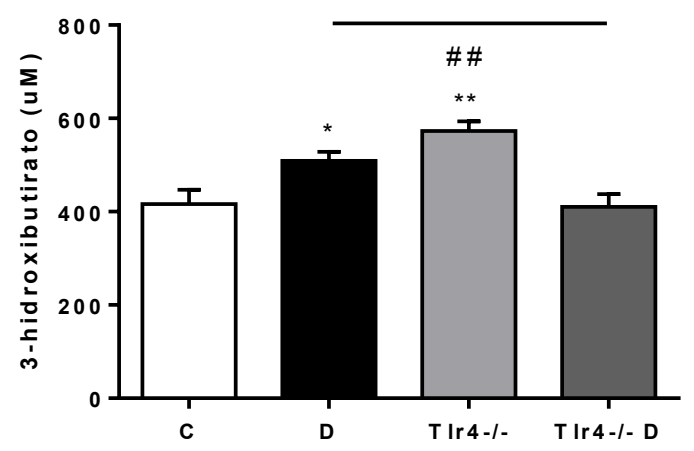

(B)

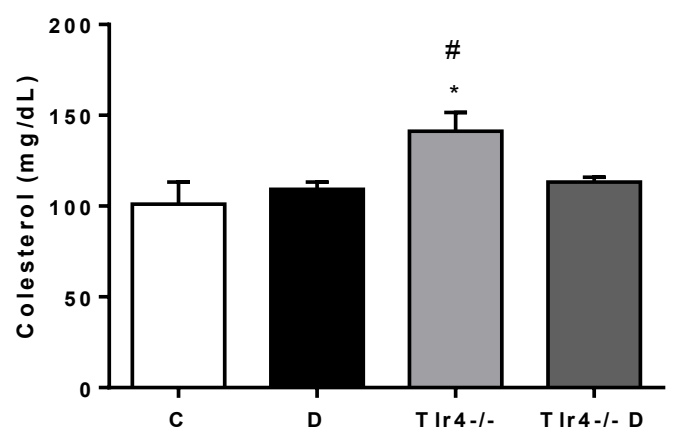

(D)

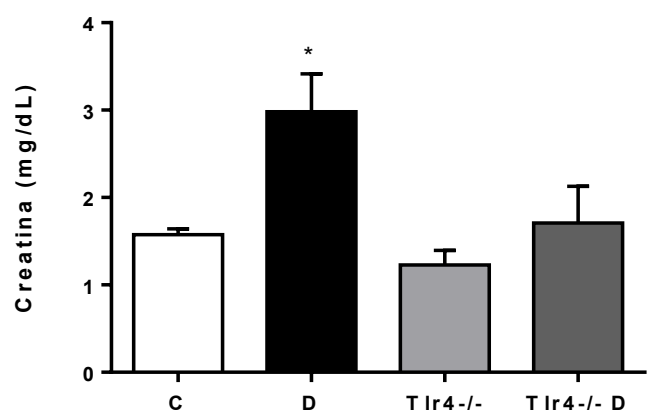

Figura 26. Efeito da dieta intermitente em parâmetros metabólicos em camundongos nocaute $\mathrm{Tlr}^{-1}{ }^{-}$. O soro de camundongos controle C57B16 e Tlr $4^{-/}$submetidos a uma dieta normal ou dieta intermitente foram usadas para dosar os níveis de glicose (A), colesterol (B), corpos cetônicos (C), creatina (D) e 8-epiprostaglandina $\mathrm{F} 2 \alpha(\mathrm{E})$. Os resultados são expressos como média \pm E.P.M., $\mathrm{n}=5, * \mathrm{p}<0,05$ vs. $\mathrm{C}$, ** $\mathrm{p}<0,01$ vs. C, \# $\mathrm{p}<0,05$ vs. D e Tlr $4^{-/} \mathrm{D}$, \#\# $\mathrm{p}<0,01$ vs. Tlr $4^{-/-} \mathrm{D}$ (ANOVA de uma via, seguido de Student-Newman-Kewls). 
Por fim, tanto a dieta intermitente (Figuras 27A e 27B) quanto o nocaute do receptor TLR4 (Figura 27A) levam a uma redução dos níveis de glicocorticoides plasmáticos. É interessante notar que o nocaute do receptor TLR2 também leva a uma redução de corticosterona, que é potencializado pela dieta intermitente (Figura 27B).

(A)

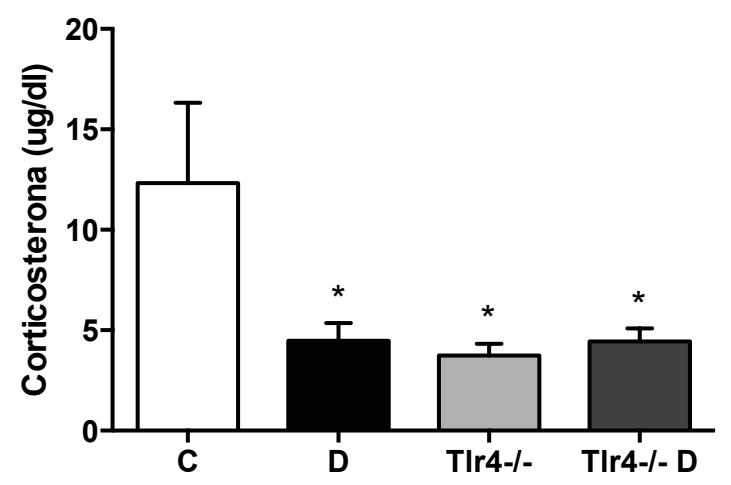

(B)

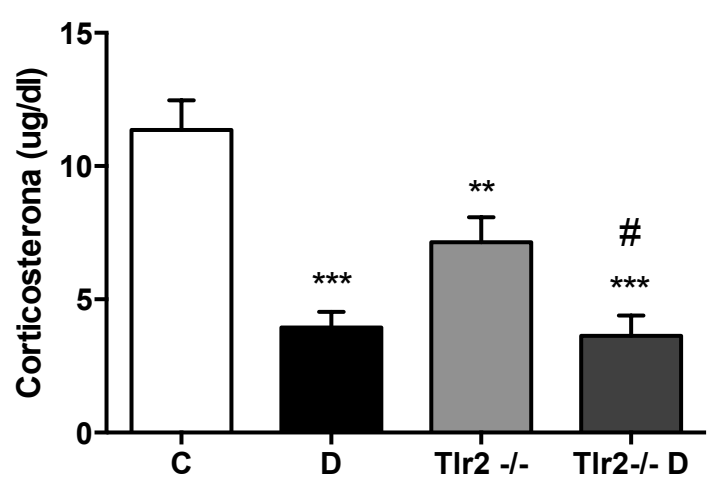

Figura 27. Efeito da dieta intermitente nos niveis de corticosterona em camundongos nocaute $T l r 2^{-/}$e Tlr $4^{-/}$. $\mathrm{O}$ soro de camundongos controle C57B16 e $T l r 4^{-/-}$(A) ou $T l r 2^{-/-}$(B) submetidos a uma dieta normal ou dieta intermitente foram usadas para dosar os níveis de corticosterona. Os resultados são expressos como média \pm E.P.M., $n=5, * p<0,05$ vs. C, ${ }^{* *} \mathrm{p}<0,01$ vs. $\mathrm{C},{ }^{* * *} \mathrm{p}<0,001$ vs. $\mathrm{C}, \# \mathrm{p}<0,05$ vs. $T l r 2^{-/-}$ (ANOVA de uma via, seguido de Student-Newman-Kewls). 


\subsection{Efeitos da dieta intermitente na tolerância à glicose na presença/ausência de TLR4 e TLR2}

No teste de tolerância à glicose, os animais $T l r 4^{-/-}$apresentaram uma maior área sob a curva glicêmica, indicando um potencial efeito no metabolismo de glicose nestes animais. Esse efeito foi revertido após o protocolo de dieta intermitente (Figuras 28A e 28B). Ainda, o nocaute do TLR4 leva a um aumento, enquanto o do TLR2 leva a uma redução da glicemia de jejum. A dieta intermitente parcialmente reverte o aumento de glicemia nos camundongos $\operatorname{Tlr}^{-/-}$(Figura 28E) e reverte totalmente a redução nos camundongos $T l r 2^{-/-}$(Figura 28F).

(A)

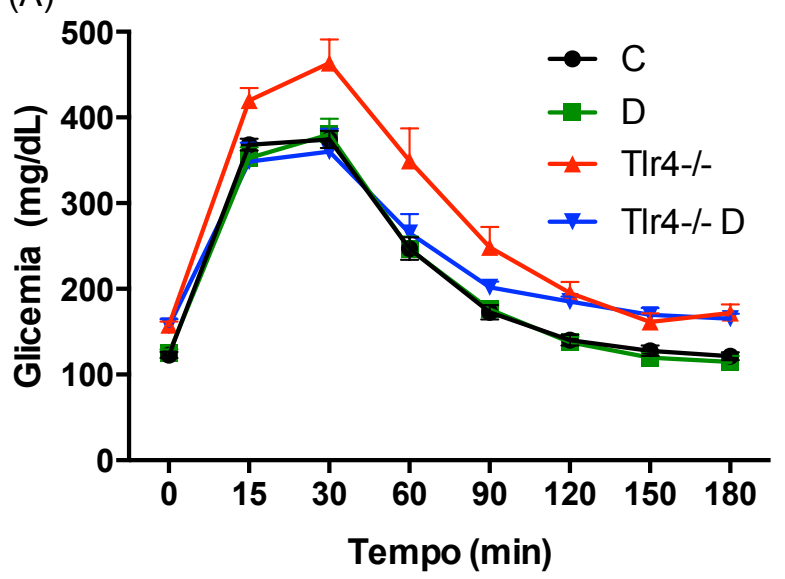

(C)

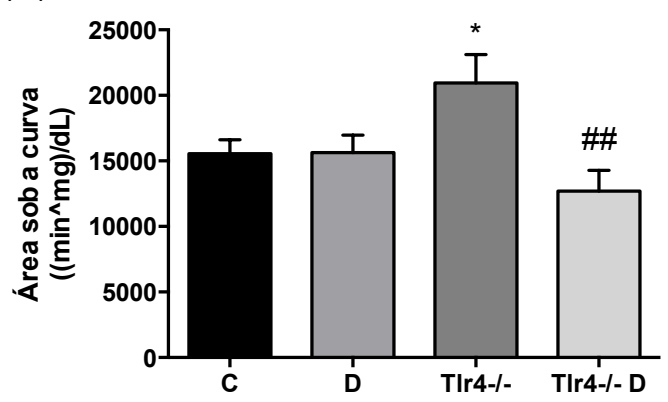

(E)

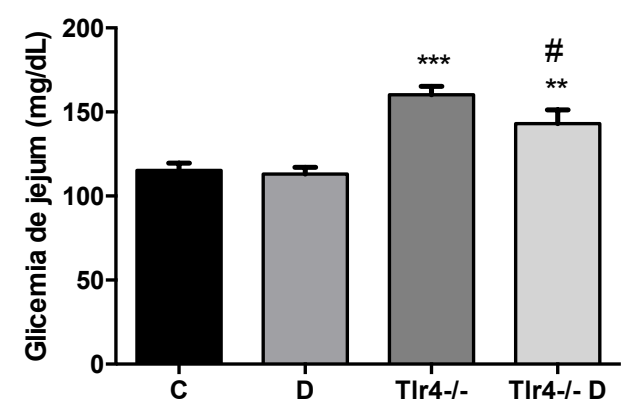

(B)

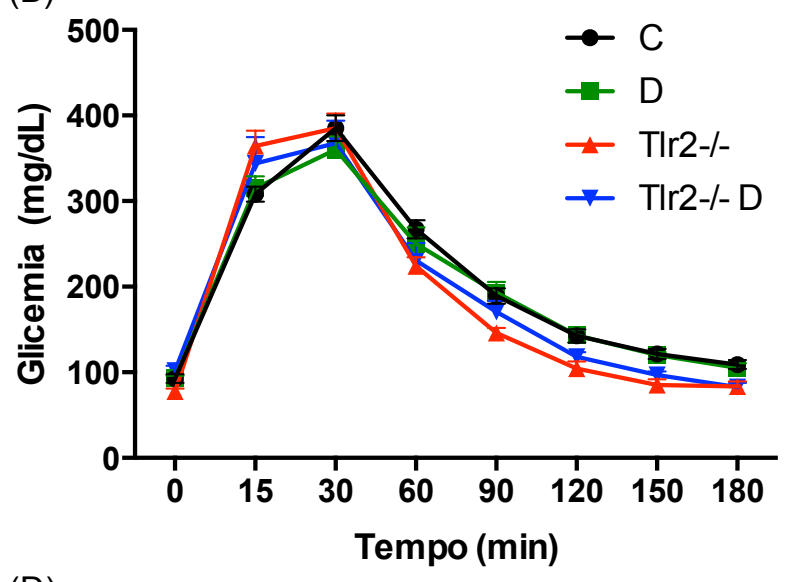

(D)

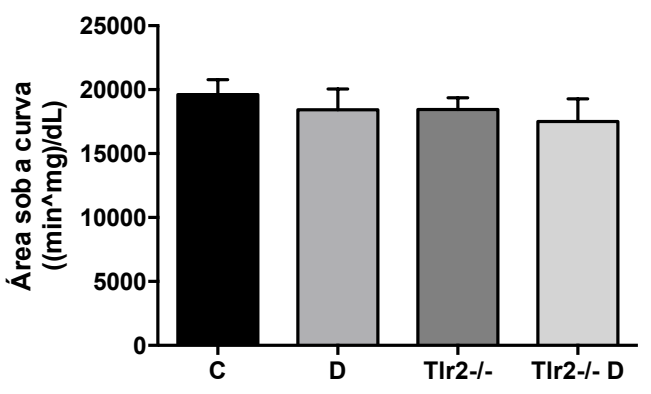

$(\mathrm{F})$

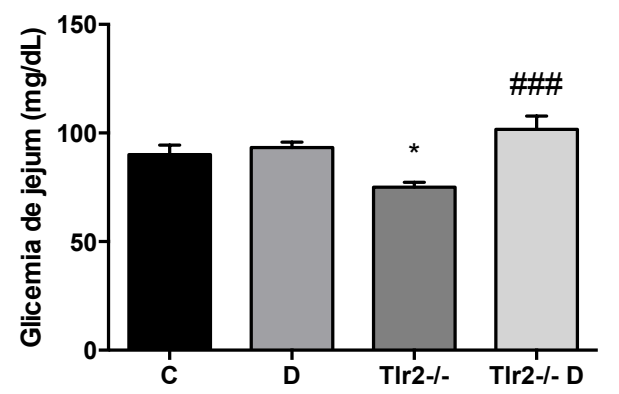

Figura 28. Efeito da dieta intermitente na tolerância à glicose em camundongos nocaute $\mathrm{Tlr}_{2}{ }^{-/}$e $\mathrm{Tlr} 4^{-1}$. Em (C) e (D) está a análise da área sob as curvas representadas em (A) e (B) dos camundongos $T l r 4^{-1 /}$ e $T l r 2^{-/ /}$, respectivamente. O soro de camundongos $\operatorname{Tlr}^{-/-}$(E) ou $\operatorname{Tlr}^{-/-}$(F) submetidos a uma dieta normal ou dieta intermitente foram usadas para dosar a glicemia de jejum. Os resultados são expressos como média \pm E.P.M., $\mathrm{n}=9-11,{ }^{*} \mathrm{p}<0,05$ vs. C, ${ }^{* *} \mathrm{p}<0,01$ vs. C, $\# \mathrm{p}<0,05$ vs. $T l r 4^{-/-}, \# \# \mathrm{p}<0,01$ vs. $\mathrm{T} l r 4^{-1 /}$, \#\#\# $<<0,001$ vs. Tlr $^{-/-}$(ANOVA de uma via, seguido de Student-Newman-Kewls). 


\subsection{Efeitos da dieta intermitente nos ensaios comportamentais na presença/ausência de TLR2 e TLR4}

\subsubsection{Campo aberto}

O teste do campo aberto é utilizado para a avaliação de parâmetros relacionados à ansiedade e a mobilidade livre do animal. Foi observado que os camundongos $\mathrm{Tlr}^{-/-}$ submetidos à dieta intermitente apresentam atividade locomotora significativamente maior em comparação aos outros grupos (Figura 29A e 29B). Contudo, em relação aos animais Tlr4 ${ }^{-/-}$, não foram observadas diferenças estatisticamente significativas entre os grupos estudados, nem em relação ao perfil de mobilidade durante o teste avaliado em períodos de 30 segundos (Figura 29D), quanto em relação à distância total percorrida (Figura 29D).

(A)

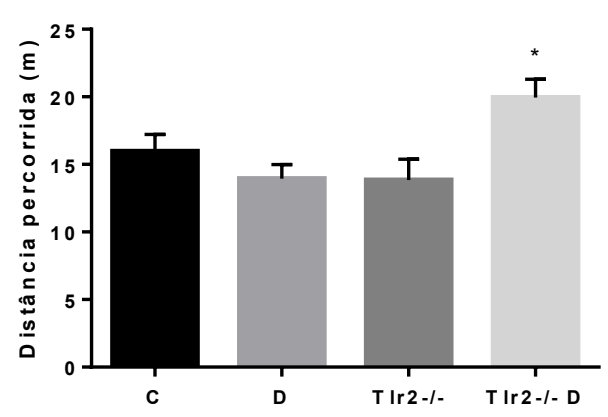

(C)

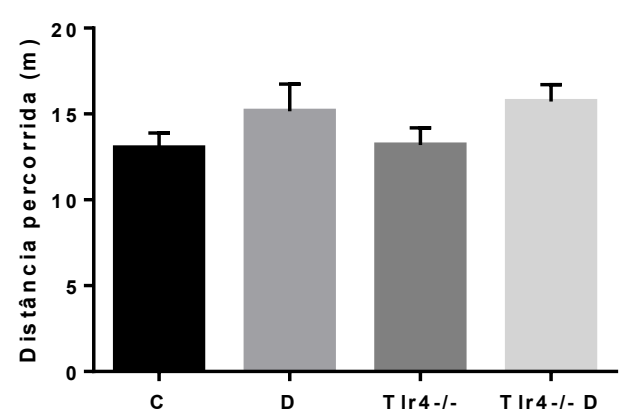

(B)

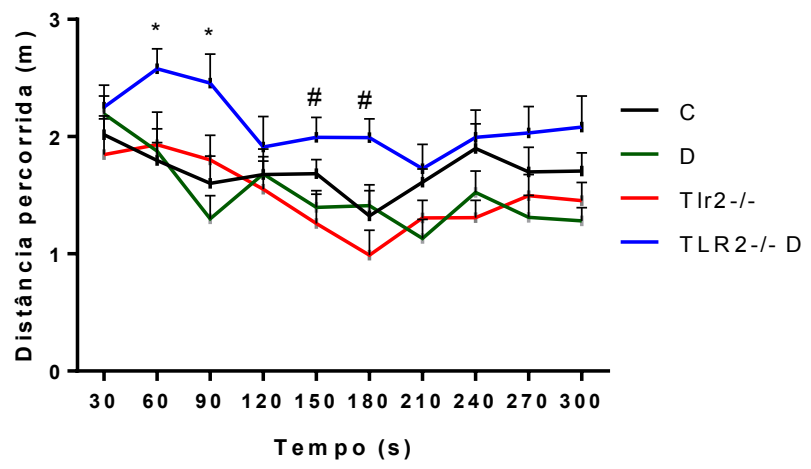

(D)

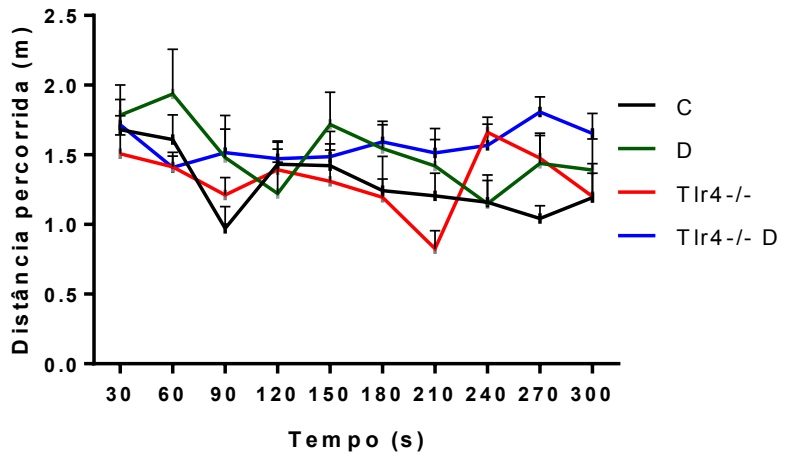

Figura 29. Efeito da dieta intermitente na atividade locomotora de camundongos nocaute Tlr2 ${ }^{-/}$e Tlr $4^{-/}$. Em (A) está representada a distância total percorrida no ensaio de campo aberto após o período de dieta intermitente, e em (B) a curva de distância percorrida em intervalos de 30 segundos ao longo do experimento. Os resultados são expressos como média \pm E.P.M., n=9-11, * p<0,05 vs. C, D e Tlr2 $2^{-/-}$, \# p $<0,05$ vs. Tlr $2^{-/-}$(Em A e C, Kruskal-Wallis seguido de Dunns e em B e D, ANOVA de duas vias seguidos de Student-Newman-Kewls). 
Ainda no campo aberto, é interessante notar que, apesar de nos animais $T l r 2^{-/-}$não ter sido observada diferença estatisticamente significativa entre os grupos em relação tempo total de freezing (Figura 30A), quando avaliamos este parâmetro em intervalos de 30 em 30 segundos, foi evidenciado diferença estatisticamente significativa no intervalo entre 150 e 180 segundos de teste decorrido no grupo $T l r 2^{-/-}$submetido à uma dieta controle quando comparado com todos os outros grupos (Figura 30B). Todavia, isso não foi observado no grupo $T l r 4^{-/}$, onde não foi observada diferença estatisticamente significativa entre os grupos (Figura 30C e 30D), ou tanto no $T l r 2^{-/-}$e $T l r 4^{-/-}$em relação ao tempo de permanência no centro da arena, uma forma de avaliação do comportamento ansioso (Figura 31).

(A)

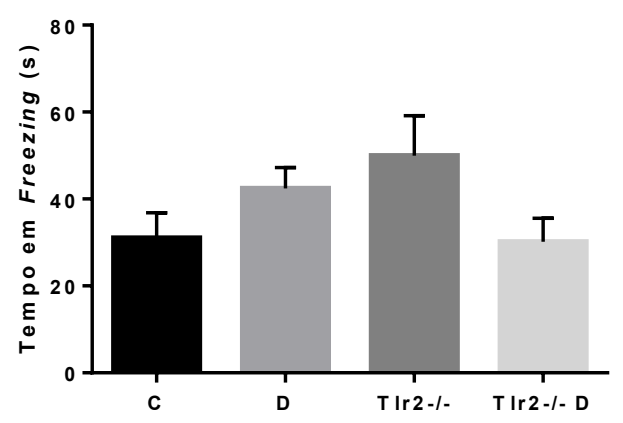

(C)

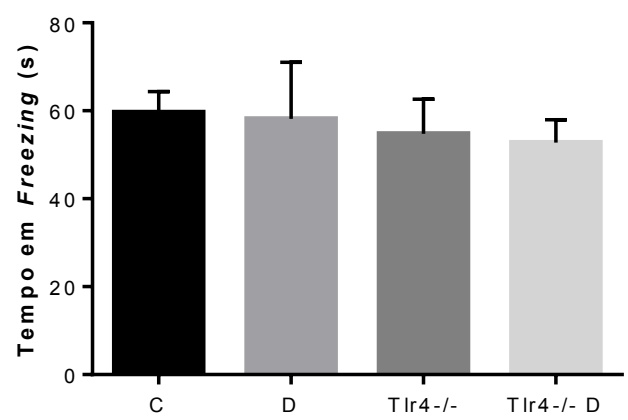

(B)

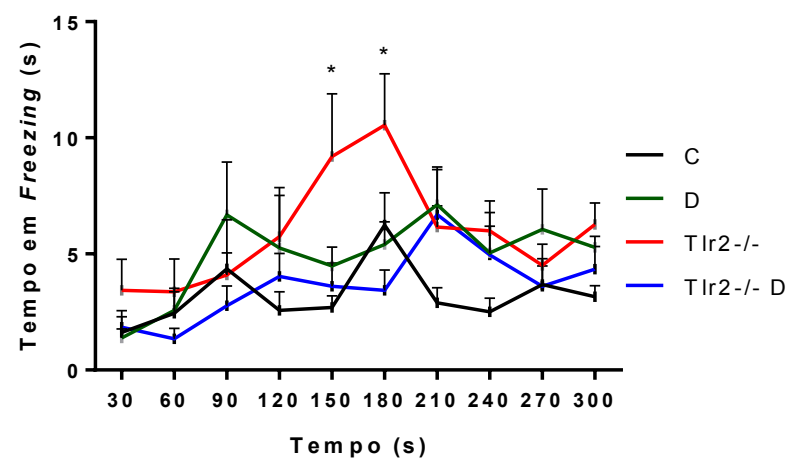

(D)

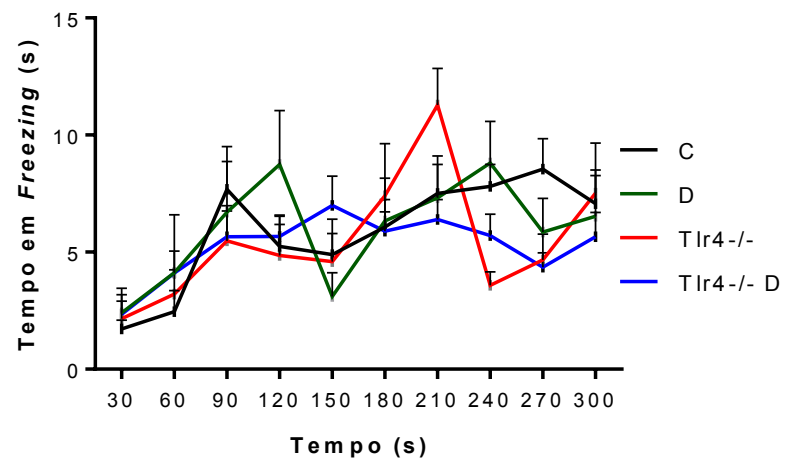

Figura 30. Efeito da dieta intermitente no tempo de freezing de camundongos nocaute Tlr $2^{-/}$e Tlr $4^{-/}$. Em (A) está representado o freezing total no ensaio de campo aberto após o período de dieta intermitente, e em (B) a curva de tempo de freezing em intervalos de 30 segundos ao longo do experimento. Os resultados são expressos como média \pm E.P.M., $\mathrm{n}=9-11$, * $\mathrm{p}<0,05$ vs. C, D e Tlr2 ${ }^{-/} \mathrm{D}$ (Em A, ANOVA de uma via e em B, ANOVA de duas vias, ambos seguidos de Student-Newman-Kewls). 
(A)

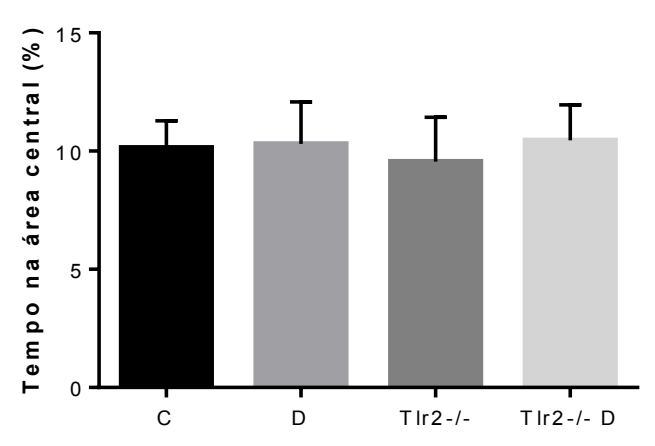

(C)

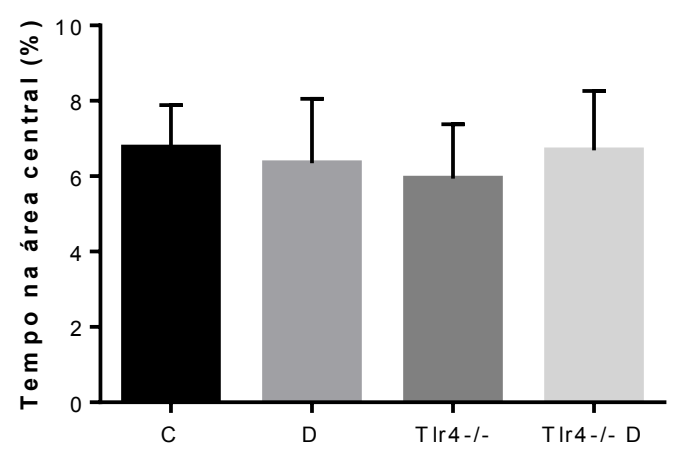

(B)

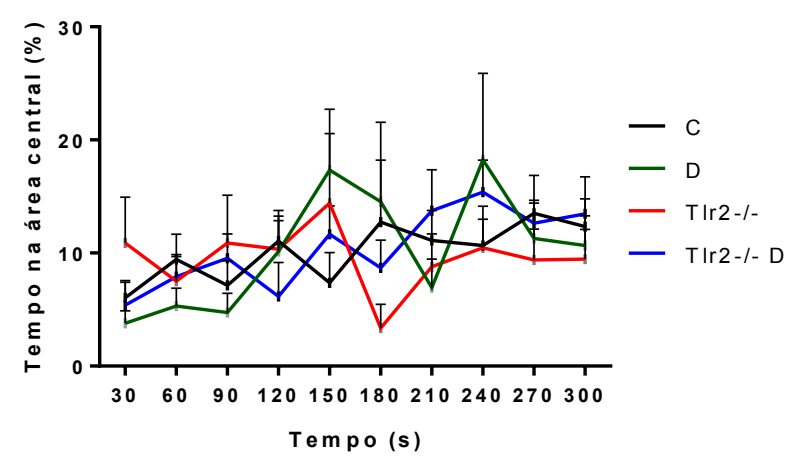

(D)

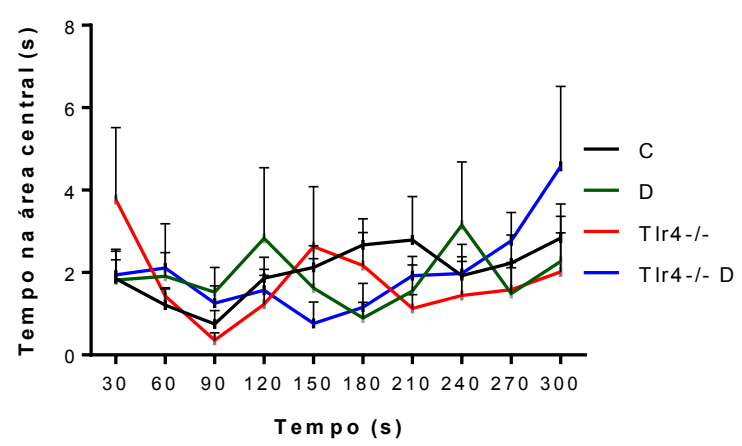

Figura 31. Efeito da dieta intermitente no comportamento ansioso de camundongos nocaute Tlr $2^{-/-}$e Tlr $4^{-/}$. Em (A) está representado o tempo de permanência na área central do campo aberto, e em (B) a curva de tempo de permanência na área central em intervalos de 30 segundos ao longo do experimento. Os resultados são expressos como média \pm E.P.M., n=9-11 (Em A, ANOVA de uma via e em B, ANOVA de duas vias, ambos seguidos de Student-Newman-Kewls).

\subsubsection{Labirinto em cruz elevado}

O ensaio do labirinto em cruz elevado pode ser utilizado para a avaliação de parâmetros relacionados ao medo e ansiedade. Foi observado que os animais Tlr2 ${ }^{-/-}$ submetidos à dieta intermitente permaneceram significativamente mais tempo no braço aberto do labirinto em comparação aos seus respectivos controles submetidos ou não à dieta intermitente (Figura 32C). Não foi observada nenhuma diferença estatisticamente significativa entre os grupos nos outros parâmetros avaliados, incluindo o tempo de exploração nas outras regiões do labirinto (Figura 32), a mobilidade pelo labirinto (Figuras 33A e 33B) e o tempo em freezing (Figuras 33C e 33D). 
(A)

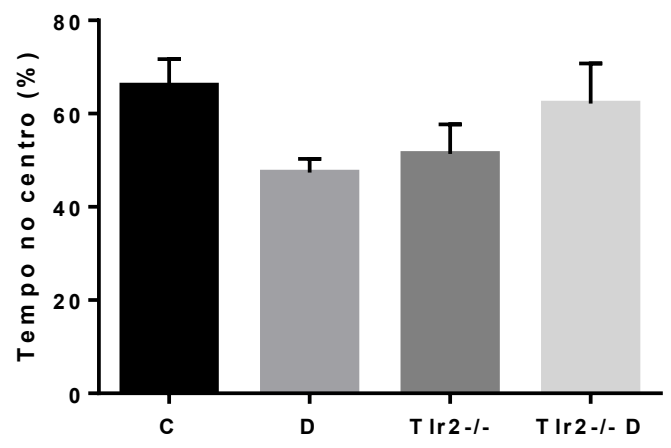

(C)

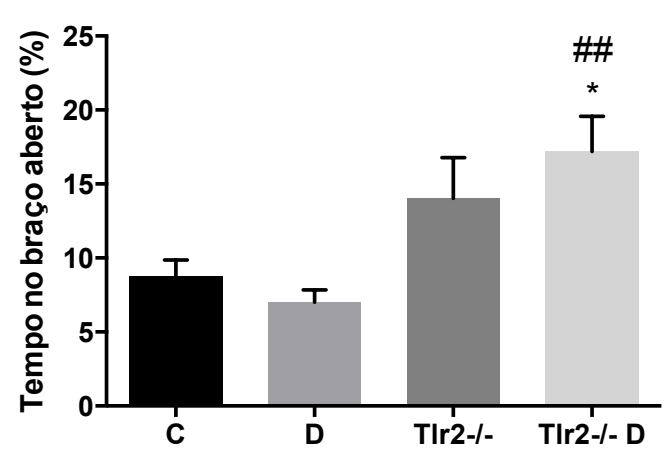

(E)

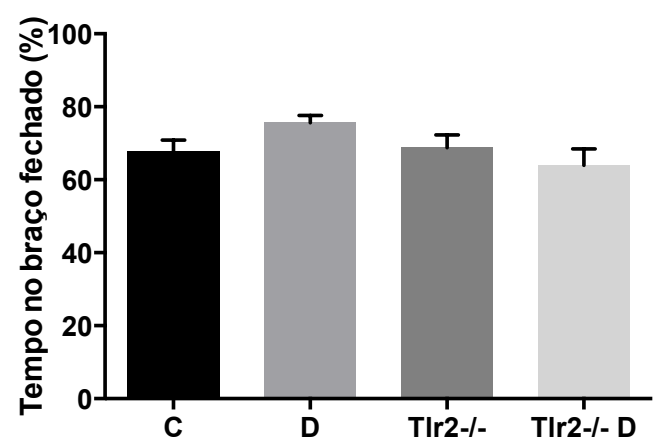

(B)

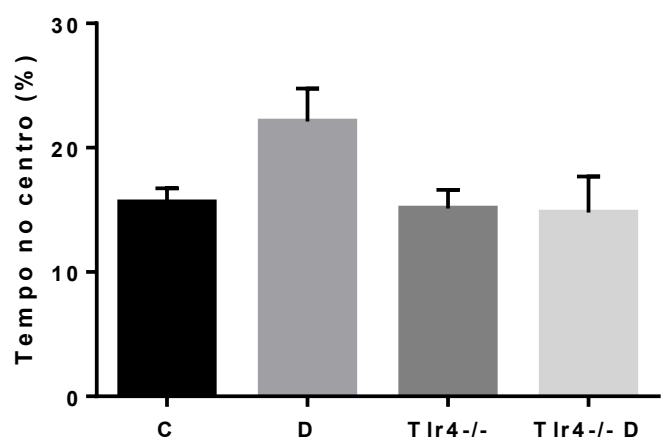

(D)

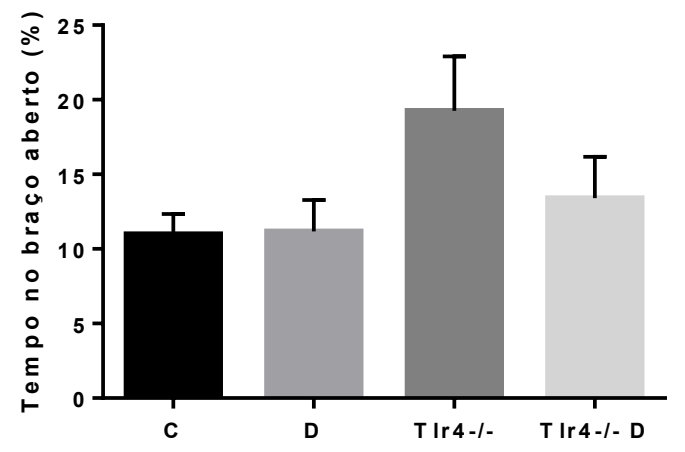

(F)

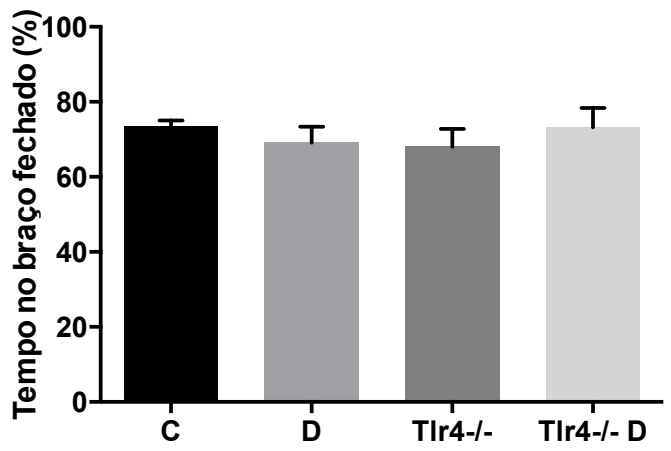

Figura 32. Efeito da dieta intermitente no perfil de exploração do labirinto em cruz elevado de camundongos nocaute $T l r 2^{-/}$e $T l r 4^{-/}$. Foram avaliados o tempo de exploração das diferentes regiões do labirinto em cruz elevado: (A) tempo de permanência na área central (A e B), no braço aberto (C e D) ou no braço fechado (E e F). Os resultados são expressos como média \pm E.P.M., n=9-11, * p <0,05 vs. C, $\# \# \mathrm{p}<0,01$ vs. D (ANOVA de duas vias seguido de Student-Newman-Kewls). 
(A)

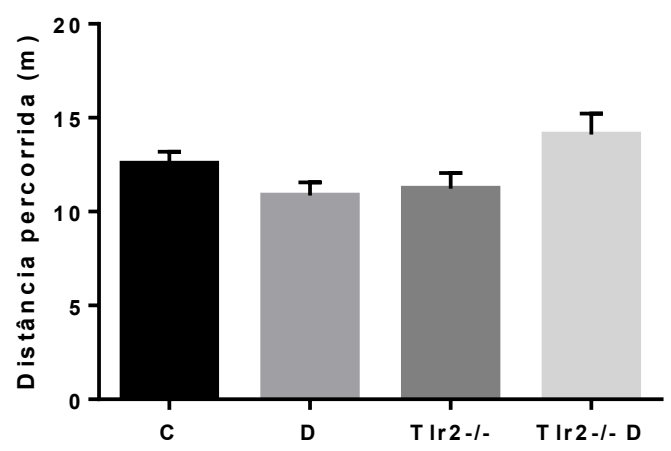

(C)

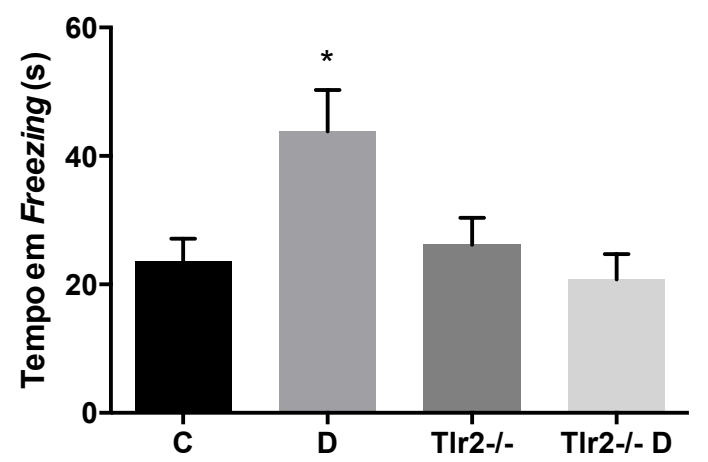

(B)

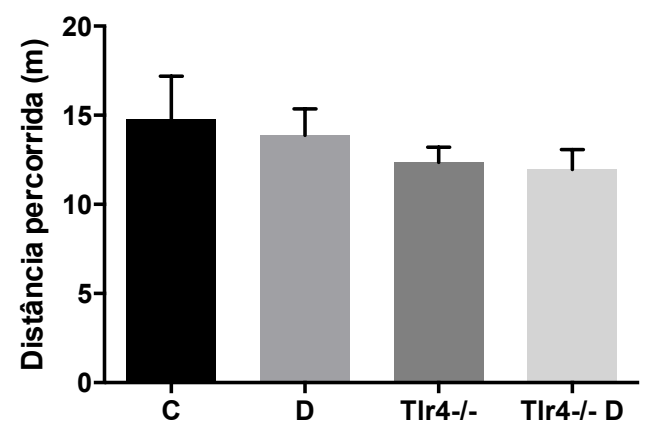

(D)

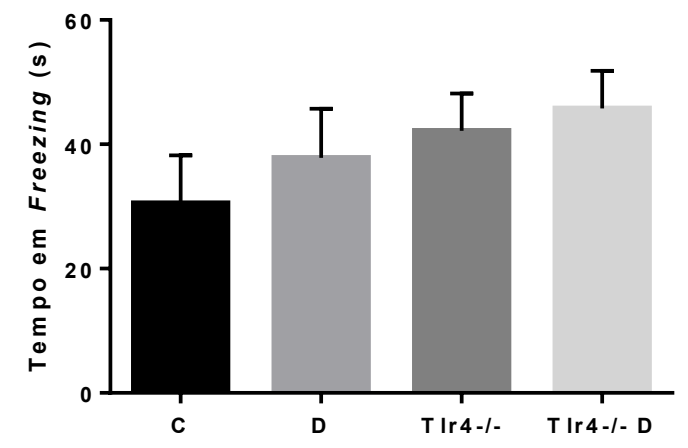

Figura 33. Efeito da dieta intermitente no comportamento ansioso e locomoção de camundongos nocaute $T l 2^{-1-}$ e Tlr $4^{-/}$. Foram avaliados os seguintes parâmetros do ensaio de labirinto em cruz elevado: (A) distância total percorrida (A e B) e tempo de freezing (C e D). Os resultados são expressos como média \pm E.P.M., $\mathrm{n}=9-11,{ }^{*} \mathrm{p}<0,05$ vs. C e D (ANOVA de uma via seguido de Student-NewmanKewls).

\subsubsection{Labirinto aquático de Morris}

O labirinto aquático de Morris é uma poderosa ferramenta de estudo do aprendizado e memória, em especial da memória espacial de referência e operacional, constituindo uma análise interessante de tipos de memória que também podem ser consideradas hipocampo- e córtex-dependentes (185). Inicialmente, através da avaliação do desempenho do animal em localizar a plataforma escondida sob a água ao longo de 5 dias de treino, pode-se avaliar possíveis déficits no aprendizado. Neste experimento, foi observado que os animais nocaute para TLR2 ou TLR4 submetidos ou não ao protocolo de dieta intermitente levam um tempo significativamente maior para encontrar a plataforma em relação aos animais controle a partir do terceiro dia de treino, sugerindo uma modulação do genótipo sobre o aprendizado desses animais (Figuras 34A e 34B). Em relação aos animais $T l r 2^{-/-}$, observou-se que a dieta intermitente retarda em 1 dia a diferença de latência entre os grupos, uma vez que no terceiro dia de treino não há diferença entre os animais $T l r 2^{-/-} \mathrm{D}$ e os outros grupos (Figura 34A). 
(A)

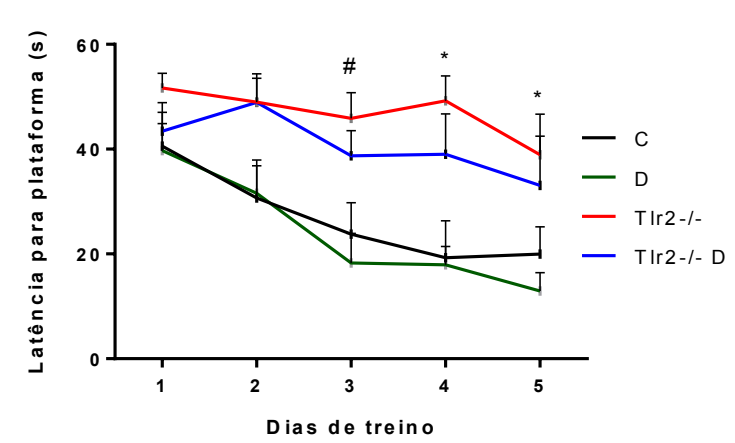

(B)

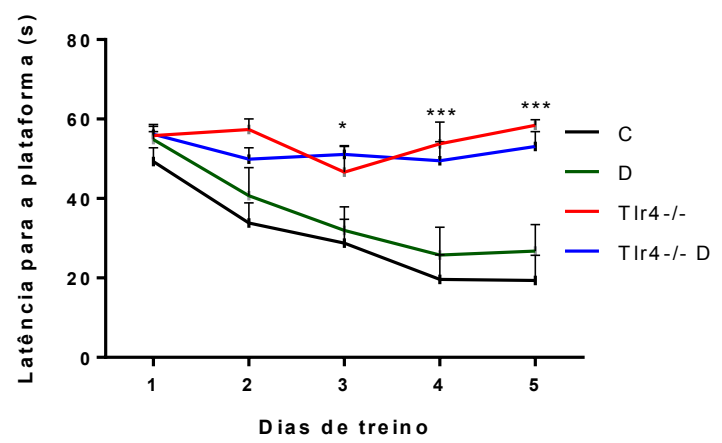

Figura 34. Efeito da dieta intermitente no aprendizado de camundongos nocaute $T l r 2^{-/-}$e $T l r 4^{-/-}$. Foi avaliada a latência para escape pela plataforma na etapa de treinamento no ensaio do labirinto aquático de Morris ao longo de 5 dias. Os resultados são expressos como média \pm E.P.M., n=9-11, \# p $<0,05$ $T l r 2^{-/}$vs. C e D, * $\mathrm{p}<0,05 \mathrm{C}$ e D vs. Tlr $2^{-/-}$e $T l r 2^{-/-}$D ou $T l r 4^{-/-}$e $T l r 4^{-/-}$D, $* * *$ p $<0,001$ C e D vs. $T l r 4^{-/-}$e $T l r 4^{-/-}$D (ANOVA de duas vias de medidas repetidas seguido de Student-Newman-Kewls).

Transcorridas $24 \mathrm{~h}$ após o último treino, a plataforma foi retirada e foi verificada a capacidade dos animais em recordar a posição da plataforma, avaliada pela insistência em nadar na região no quadrante no qual a plataforma estava localizada durante os treinos. Não foram observadas diferenças estatisticamente significativas entre os grupos dos animais $\mathrm{Tlr}^{-/-}$ (Figura 35A), possivelmente indicando que não há um déficit de memória espacial de referência nos animais desta linhagem com esta idade. Contudo, em relação aos animais Tlr4/-, observou-se que quando submetidos à dieta intermitente apresentam uma menor insistência em permanecer no quadrante onde previamente estava a plataforma, indicando um possível prejuízo de memória espacial desses animais (Figura 35B).

(A)

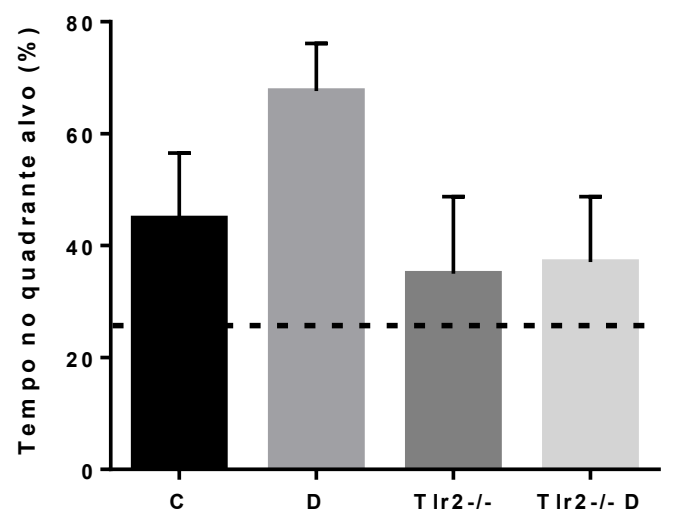

(B)

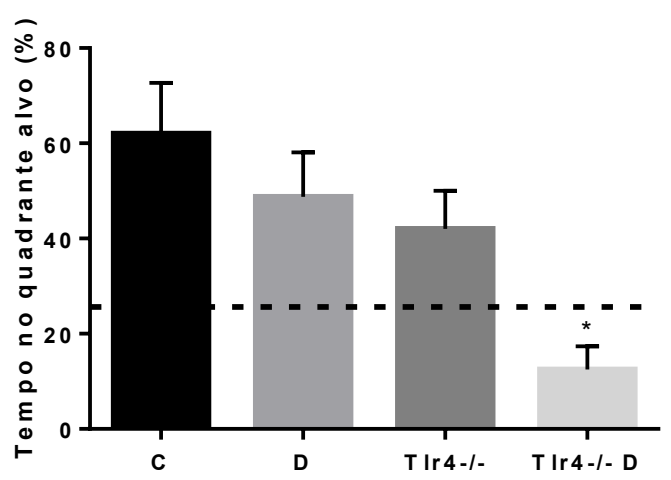

Figura 35. Efeito da dieta intermitente na memória de referência de camundongos nocaute Tlr2 $2^{-/}$e Tlr4 ${ }^{-/}$. Foi feita a avaliação do tempo de permanência no quadrante alvo no ensaio do labirinto aquático de Morris na etapa de avaliação da memória de referência $24 \mathrm{~h}$ após o último treinamento. A linha pontilhada indica o valor de $25 \%$ do tempo total do teste. Os resultados são expressos como média \pm E.P.M., n=9-11, * p<0,05 vs. C e D (ANOVA de uma via, seguido de Student-Newman-Kewls). 
Por outro lado, a memória operacional pode ser avaliada por um protocolo semelhante à etapa de treinamento. Entretanto, neste teste, a localização da plataforma é modificada a cada dia. Sendo assim, em cada dia o animal deve buscar e aprender a nova localização da plataforma e a comparação da memorização da nova localização entre as quatro tentativas (ou trials) diárias são utilizadas para avaliar este tipo de memória.

Através desse teste, foi verificado que os animais nocautes para TLR2 e TLR4 apresentaram um pior desempenho nesse teste independente do protocolo de dieta intermitente. Esse possível déficit de memória operacional foi evidenciado em todos os dias de teste para os animais $\mathrm{Tlr}^{-/-}$e no segundo dia de teste para os camundongos $\mathrm{Tlr}^{-\mathrm{I}^{-}}$(figura 36).

(A)

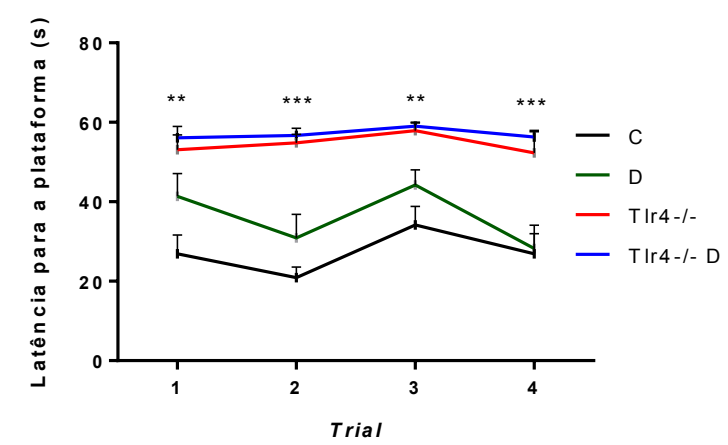

(B)

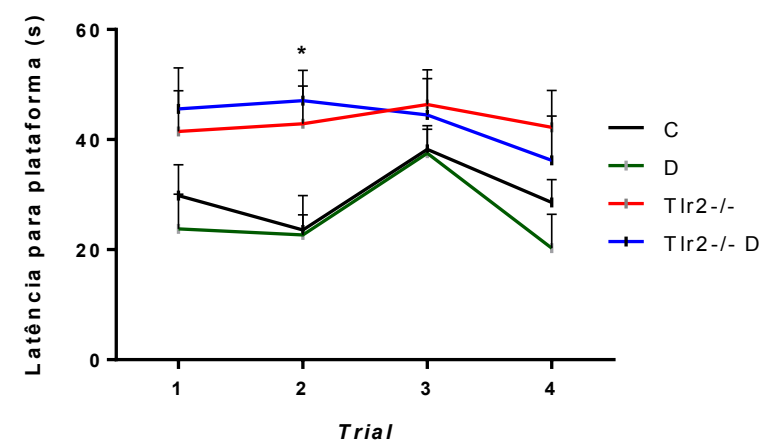

Figura 36. Efeito da dieta intermitente na memória operacional de camundongos nocaute Tlr $2^{-/-}$e Tlr $4^{-/}$. Foi avaliada a latência para escape pela plataforma no ensaio do labirinto aquático de Morris na etapa de avaliação da memória operacional. Os pontos representam as médias dos quatro dias de avaliação para cada tentativa (trial) em encontrar a posição da plataforma. Os resultados são expressos como média \pm E.P.M., $\mathrm{n}=9-11, * \mathrm{p}<0,05 \mathrm{C}$ e D vs. Tlr $2^{-/-}$e $T l r 2^{-/-} \mathrm{D}, * * \mathrm{p}<0,01 \mathrm{C}$ e D vs. Tlr $4^{-/-}$e $T l r 4^{-/-} \mathrm{D}$, *** $\mathrm{p}<0,001 \mathrm{C}$ e D vs. Tlr $4^{-/}$e $T l r 4^{-/-}$D (ANOVA de duas vias de medidas repetidas, seguido de Student-Newman-Kewls).

\subsubsection{Esquiva inibitória}

Por fim, optou-se pela realização do ensaio da esquiva inibitória como uma outra forma de avaliação da memória. A memória de medo contextual avaliada pela esquiva inibitória é majoritariamente associada ao processamento pelo hipocampo e pela amígdala, embora regiões corticais - como o córtex entorrinal - também tenham um papel importante (186). Observou-se que os animais WT - tanto do grupo controle quanto do grupo dieta apresentaram um aumento significativo da latência para a passagem para a câmara escura, indicando a consolidação e efetiva evocação da memória do choque ministrado no dia anterior (Figura 37). Contudo, apesar dos camundongos $T l r 2^{-/-}$também terem apresentado a consolidação de memória, os camundongos $T l r 4^{-/-}$submetidos ou não à dieta intermitente não 
lembraram do estímulo aversivo, indicando um possível déficit de memória nesses animais, resultante da ausência da sinalização associada ao TLR4 (Figura 37).

(A)

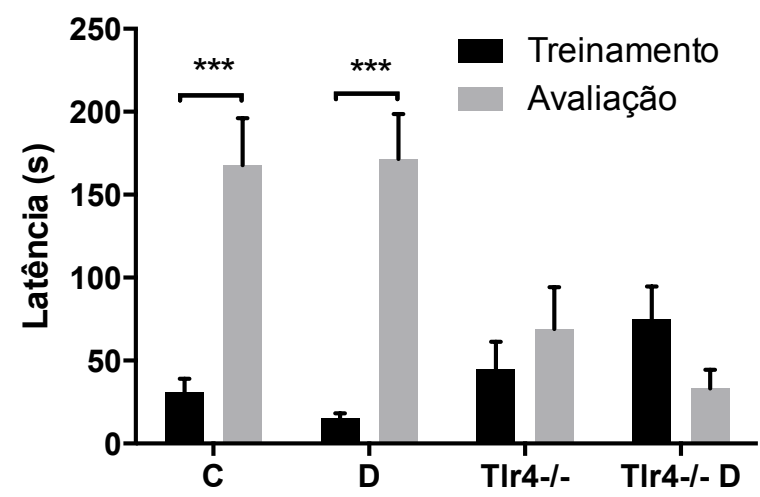

(C)

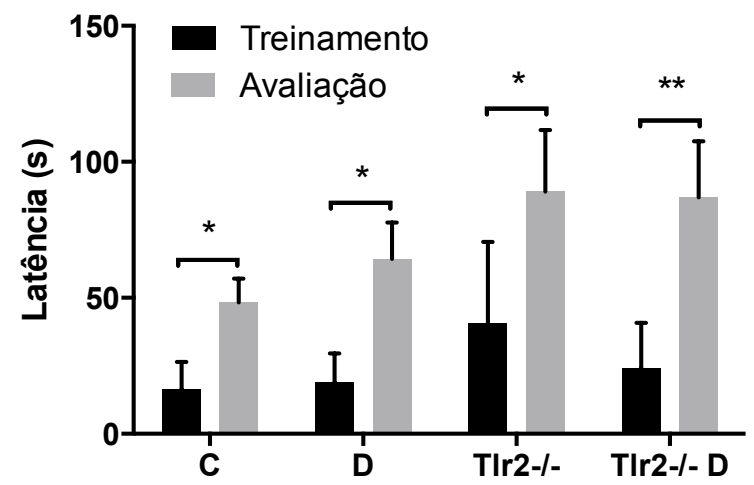

(B)

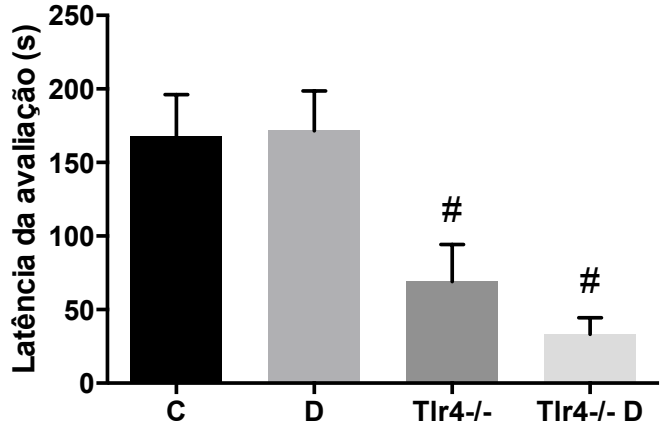

(D)

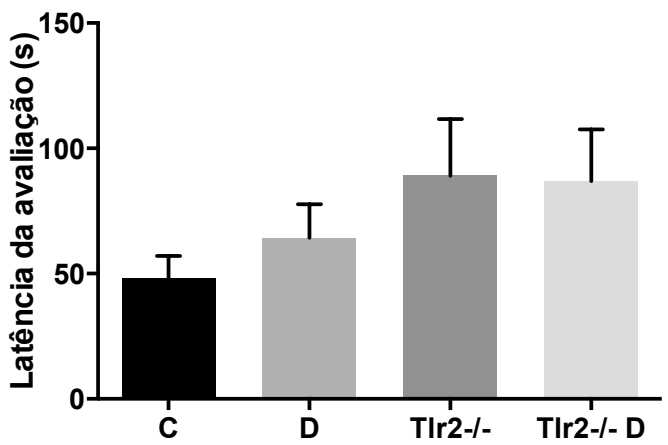

Figura 37. Efeito da dieta intermitente na memória de medo contextual de camundongos nocaute Tlr ${ }^{-1-}$ e Tlr $4^{-1-}$ . Foi avaliada a latência para entrada na câmara escura no ensaio da esquiva inibitória nas etapas de treinamento e avaliação. Os resultados são expressos como média \pm E.P.M., n=9-11, * p $<0,05$, ${ }^{* *} \mathrm{p}<0,01,{ }^{* * *} \mathrm{P}<0,001, \# \mathrm{p}<0,05$ vs. C e D (em A e C, ANOVA de duas vias de medidas repetidas seguido de Student-Newman-Kewls e em B e D, Kruskal-Wallis seguido de Dunns).

\subsubsection{Teste de suspensão da cauda}

O teste de suspensão da cauda é frequentemente empregado para investigar o comportamento depressivo de camundongos, que é proporcional ao tempo de imobilidade observado durante o teste. Por fim, foi observado que enquanto o nocaute do TLR4 reduz o tempo de imobilidade nos 4 minutos finais do teste de suspensão da cauda, efeito esse revertido pela dieta intermitente. Por outro lado, o nocaute do TLR2 por si só aumenta o tempo de imobilidade, o que também foi revertido pelo protocolo de dieta intermitente (Figura 38). 
(A)

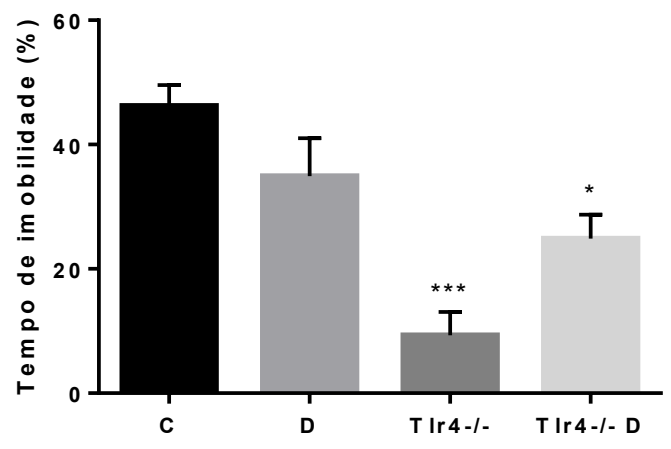

(B)

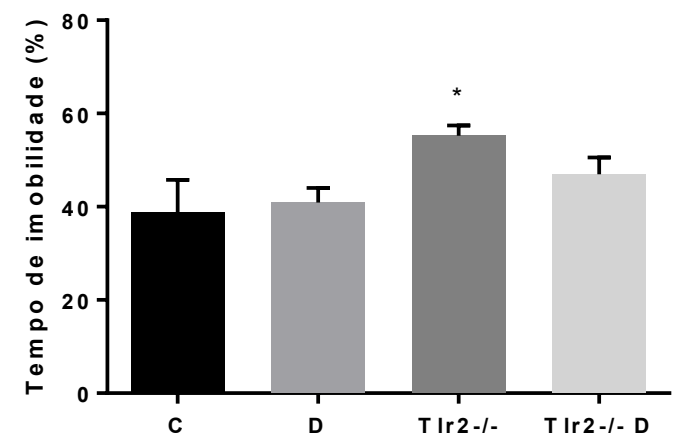

Figura 38. Efeito da dieta intermitente no comportamento depressivo de camundongos nocaute Tlr $2^{-/}$e Tlr $4^{-/}$. Foi avaliado o tempo de imobilidade nos 4 últimos minutos do teste de suspensão da cauda. Os resultados são expressos como média \pm E.P.M., $\mathrm{n}=9-11,{ }^{*} \mathrm{p}<0,05$ vs. $\mathrm{C}$ e ${ }^{* * *} \mathrm{p}<0,001$ vs. $\mathrm{C}$ (ANOVA de uma via, seguido de Student-Newman-Kewls). 


\section{DISCUSSÃO}

Nossa primeira preocupação foi avaliar se o protocolo de dieta intermitente poderia ser um estímulo estressor forte ou acarretar um prejuízo de saúde aos nossos animais. Ao contrário, durante todo o período de observação os animais apresentaram, em geral, boa saúde, e observamos que os animais submetidos à dieta tiveram um ganho de peso após os 30 dias do protocolo, o que mostra que não houve desnutrição e nem um estresse maior que acarretasse perda de peso dos animais.

Além do peso, foi avaliado também o consumo de alimento dos animais. Foi observado que no dia de livre acesso ao alimento, os camundongos em dieta intermitente consomem maior quantidade de ração do que os animais do grupo controle, porém a média de consumo de alimento por dia dos animais em dieta é significativamente menor do que o grupo controle, o que pode justificar o fato de eles apresentarem menor ganho de peso quando comparados com os animais dos grupos de alimentação ad libitum. É interessante notar que o genótipo dos animais não exerceu influência no peso ou consumo de alimento dos animais, uma vez que tantos animais WT como os $T l r 2^{-/-}$ou $T l r 4^{-/-}$apresentaram a mesma alteração de peso antes e depois da dieta controle ou intermitente.

Os TLRs são proteínas que ficam na membrana celular que reconhecem lipídeos, carboidratos, peptídeos e ácidos nucléicos que são expressos por diferentes grupos de microorganismos (PAMPs), além de ligantes endógenos (DAMPs) (187). Após a ativação, os TLRs podem induzir citocinas inflamatórias, moléculas co-estimuladoras, interferons do tipo I, e quimiocinas. Em humanos, há 10 tipos de TLRs, incluindo o TLR2 e TLR4. Os maiores mecanismos de sinalização ativados pelo TLR incluem as cascatas que levam à ativação do $\mathrm{NF}-\kappa \mathrm{B}$, um fator de transcrição de grande relevância por modular uma enorme quantidade de genes implicados em vários processos celulares, tais como desenvolvimento, plasticidade, morte e defesa celular $(188,189)$.

Nesse estudo foi mostrado que a dieta intermitente, na ausência tanto do receptor TLR2 quanto do TLR4, leva a uma redução da atividade do NF-KB no hipocampo. Esses resultados sugerem que a dieta intermitente gera um estímulo para a ativação do NF- $\mathrm{B}$ no hipocampo que depende desses receptores. De fato, nosso estudo publicado recentemente demonstra que a dieta intermitente por si só ativa esse fator de transcrição na mesma região do SNC de ratos, o que provavelmente envolve o TLR4, uma vez que a expressão desse receptor é modulada no hipocampo pelo protocolo de dieta intermitente (36). 
É interessante ressaltar que esses resultados podem estar relacionados com o fato de que os níveis das citocinas IL-12 e IL-15 e da quimiocina RANTES, na vigência da dieta intermitente, também são significativamente menores nos animais nocaute para TLR4, uma vez que os promotores dos genes de IL-12 (190), IL-15 (191) e RANTES (192) contêm

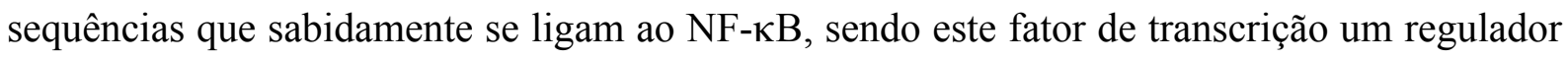
positivo da síntese destes agentes pró-inflamatórios. Similarmente, assim como observado na atividade do NF- $\mathrm{B}$, foi demonstrado que, dentre os animais nocaute para o TLR2, os submetidos à dieta intermitente também apresentaram níveis de RANTES no hipocampo menores do que os em dieta controle, possivelmente devido ao mesmo mecanismo citado relacionado ao TLR4.

Além da modulação central no hipocampo, também investigamos a modulação de citocinas e quimiocinas periféricas no soro sanguíneo. Os níveis das citocinas próinflamatórias IL-1 $\beta$ e IFN- $\gamma$ são significativamente maiores nos animais $T l r 2^{-/-}$, o que não é observado após a dieta intermitente. Esse resultado é sugere que a ausência do TLR2 induz um quadro pró-inflamatório indicado pelo aumento dos níveis dessas citocinas, que por sua vez é contraposto pelos efeitos anti-inflamatórios da dieta intermitente já confirmados na literatura, mesmo na ausência desse receptor. Vários trabalhos apontam para um efeito sinérgico dessas duas citocinas inflamatórias (193-195), o que poderia justificar o mesmo perfil de modulação observado. Além disso, o papel anti-inflamatório da dieta intermitente também foi demonstrado no meu estudo durante o mestrado em várias citocinas inflamatórias no hipocampo e soro de ratos após o estímulo inflamatório do LPS (36).

As neurotrofinas como o BDNF controlam a sobrevivência celular, diferenciação e sinaptogênese, além de exercerem importantes funções na plasticidade sináptica no SNC (124). O BDNF é sintetizado predominantemente em neurônios e é altamente expresso no hipocampo e córtex, duas regiões cerebrais importantes para o aprendizado e memória (196198). Os efeitos do BDNF dependem de sua ligação ao receptor TrkB e subsequente ativação de tirosinas quinases presentes no citoplasma, resultando em uma importante função na proteção neuronal, podendo proteger os neurônios de danos oxidativos resultantes de vários tipos de injúrias (125). Os resultados obtidos durante o meu mestrado mostraram que a dieta intermitente é capaz de prevenir a redução de BDNF induzida pela administração intravenosa de LPS (36). Entretanto, no presente estudo observamos que a dieta intermitente na ausência do TLR4 causa uma redução dos níveis desta neurotrofina no hipocampo. Isso parece sugerir que os efeitos protetores da dieta intermitente na modulação do BDNF são dependentes do TLR4. Quanto ao nocaute do TLR2, este por si só, na presença ou ausência da dieta 
intermitente, causa uma redução nos níveis de BDNF no hipocampo, o que indica uma dependência desse receptor para a manutenção dos níveis basais de BDNF. Não observamos alterações do BDNF no hipotálamo.

Além da avaliação dos níveis proteicos de BDNF por ELISA, também determinamos através do ensaio de PCR em tempo real os níveis de diferentes transcritos de $B d n f$ (Bdnfl, $B d n f 3$ e $B d n f 4$ ), uma vez que a expressão de cada um deles é regulada por promotores independentes (199). Esse controle por diferentes promotores permite uma grande flexibilidade da modulação da expressão de $B d n f$ em resposta a vários estímulos ambientais (200). Dentre os transcritos de $B d n f$, o $B d n f 1$ está entre os mais responsivos à atividade neuronal (199). É interessante ressaltar que observamos que a dieta intermitente por si só aumenta especificamente a transcrição de $B d n f 1$, o que não ocorre com $B d n f 3$ e $B d n f 4$. Além disso, assim como observado no ensaio de ELISA, o nocaute do TLR2, e não de TLR4, leva a uma redução da expressão de $B d n f 1$ e $B d n f 3$ de forma independente da dieta intermitente. $\mathrm{O}$ nocaute de TLR2 também resulta numa redução da transcrição de $B d n f 4$, porém a dieta intermitente é capaz de restaurar os níveis basais do mesmo.

A curcumina, assim como a dieta intermitente, é um outro exemplo de estímulo hormético que exerce efeitos benéficos anti-inflamatórios, antioxidantes e neuroprotetores (201). Estudos anteriores do nosso laboratório mostram que esse fitoterápico modula a expressão de $B d n f 4$ (181). Como vimos no presente estudo que a dieta intermitente reverte a redução da expressão de $B d n f 4$ nos animais $T l r 2^{-/}$, esse seria mais um indício da participação deste transcrito de $B d n f$ nos efeitos neuroprotetores da hormese.

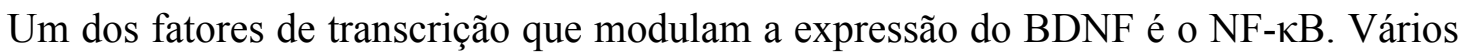
estudos evidenciaram que o NF- $\mathrm{kB}$ medeia, pelo menos em parte, os efeitos neurotropetores da ativação do receptor N-metil-D-aspartato (NMDA) nos neurônios do cerebelo e que o

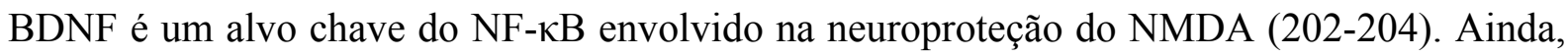
estudos do nosso laboratório mostraram que o BDNF, possivelmente mediado pelo NF- $\mathrm{B}$, promove resistência à toxicidade do peptídeo $\beta$-amilóide relacionado à DA em cultura de células do cerebelo (203) assim como a resistência de células PC12 à morte celular induzida por cocaína (205). De fato, observamos uma correlação das alterações de BDNF e da atividade do NF- $\mathrm{B}$ nos diferentes grupos. Mostramos aqui que a dieta intermitente na ausência de TLR4 ou TLR2 causa uma redução na atividade do NF-אB que se correlaciona com a redução dos níveis proteicos de BDNF.

É muito provável que o NF-кB coopere com a atividade de outros fatores de transcrição envolvidos com a plasticidade neuronal, como por exemplo o CREB. Isso foi 
comprovado em um estudo que mostrou que o NF-אB controla a formação de memória espacial e a plasticidade sináptica através da regulação da expressão da enzima PKA, que é capaz de fosforilar e ativar CREB, consequentemente regulando a via deste fator de transcrição (206). Ainda, dados do meu estudo durante o mestrado mostraram que a dieta intermitente é capaz de ativar o NF-אB e aumentar a fosforilação de CREB no hipocampo de ratos (36). Curiosamente, nós observamos um padrão de modulação deste fator de transcrição

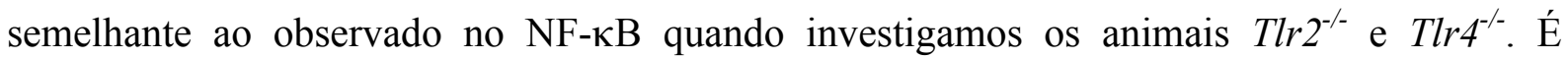
provável que a correlação de modulação observada do BDNF também com o CREB seja devido ao fato de que este fator de transcrição é um importante modulador da expressão de BDNF (207).

O mesmo não ocorre no hipotálamo, região na qual não observamos diferenças na ativação de NF-אB e CREB entre os grupos assim como de BDNF, o que sugere que esse fenômeno observado no hipocampo é específico desta região cerebral, que se sabe que desempenha um importante papel na memória espacial em humanos e roedores $(208,209)$.

Os TLRs podem ativar cascatas do jun N-terminal quinase (JNK) e p38 MAPK que resultam na ativação de diferentes subunidades do AP1 e de fatores de transcrição que interagem com AP1 $(71,210-213)$. Este outro fator de transcrição ativado pelos TLRs é um dímero composto de proteínas de várias famílias. As subfamílias Jun e Fos são as principais componentes de AP1, porém a ampla possibilidade de combinação do grande número de proteínas componentes do AP1 determina a sua especificidade e afinidade de ligação ao DNA e, consequentemente, o espectro de genes regulados (214). Desde a sua descoberta em 1987, o AP1 foi extensivamente estudado primeiramente para elucidar seu papel na proliferação celular relacionada ao câncer, mas rapidamente se tornou claro que a sua atividade está relacionado com muitas outras funções associadas à modulação de vários genes envolvidos em respostas de ativação e adaptação neuronal. Várias evidências mostram que o AP1 medeia a regulação gênica em resposta a uma grande gama de estímulos patológicos e fisiológicos, como inflamação, diferenciação, apoptose, migração celular, cicatrização de feridas e estímulos estressores ambientais (214-216). Apesar de não haver na literatura estudos sobre o tema, acreditamos que a dieta intermitente, como um estímulo estressor ao organismo, possa também exercer um papel modulatório sobre o AP1 no SNC.

Ao investigarmos a função dos receptores TLR2 e TLR4 na modulação do fator de transcrição AP1 no hipocampo, observamos que, apesar da dieta intermitente não ter modulado este fator de transcrição, o nocaute do receptor TLR4 por si só levou ao aumento da atividade do AP1 no hipocampo, provavelmente mediado por outro TLR presente nesta região 
cerebral. Além disso, observamos que a dieta intermitente somente na ausência do TLR2 leva a um aumento da atividade deste fator de transcrição. Porém, os resultados referentes à investigação da atividade do AP1 no hipotálamo não revelaram diferenças significativas entre os grupos, mostrando que a modulação do AP1 pelo nocaute do TLR2 e TLR4 ou pela dieta intermitente mais um fenômeno que ocorre especificamente no hipocampo.

Além do NF-кB e AP1, hoje também se sabe que a ativação dos TLRs leva à modulação de diversas vias de sinalização intracelulares que ditam a magnitude, tipo e duração da resposta inflamatória. Uma dessas vias é a fosfatidilinositol-3-quinase $(\mathrm{PI} 3 \mathrm{~K}) /$ serina-treonina quinase (AKT). Ambas PI3K e AKT foram identificadas como quinases envolvidas na habilidade dos TLRs de mediar a fosforilação e inativação de proteínas (217). Nossos resultados indicam que, apesar do envolvimento dos TLRs na modulação da via da AKT, a fosforilação ou a expressão proteica total desta quinase não são moduladas pela dieta intermitente ou pela ausência da sinalização do receptor TLR4 ou TLR2 no hipocampo de camundongos.

Já se sabe que a RED exerce efeitos modulatórios sobre a ativação dos receptores de BDNF, de insulina ou de fator de crescimento semelhante à insulina tipo 1 (IGF-1). A ativação desses receptores desencadeia duas vias de sinalização nos neurônios, a da PI3K/AKT e a da quinase regulada por sinal extracelular (ERK) (revisão em (218)). Como observamos a modulação do BDNF e não verificamos nenhuma alteração na via da AKT, decidimos investigar a ERK. Os resultados de western blot tanto para a ERK1 quanto para a ERK2 não mostraram alterações dos níveis proteicos totais ou na fosforilação dessas proteínas entre os grupos tanto pela dieta intermitente quanto pelo nocaute de TLR2 ou TLR4.

Outro fator de transcrição investigado nesse estudo foi o NRF2. A via de sinalização que desencadeia a ativação do NRF2 é complexa e é alvo de intensa investigação (revisão em (219-221)). Em condições normais, os níveis de NRF2 são mantidos baixos devido à sua contínua ubiquitinação e degradação por proteossomas, que é facilitada pela associação deste fator de transcrição com a proteína associada à ECH semelhante à kelch 1 (KEAP1) no citoplasma. Na presença de diversos estímulos extracelulares, a proteína inibitória KEAP1 é inativada, e o NRF2 livre é translocado para o núcleo, onde ele dimeriza com uma proteína pequena Maf e pode modular a expressão de vários genes que possuem o elemento de resposta antioxidante (ARE) em suas regiões promotoras $(125,222)$.

Vários estudos demonstraram uma função protetora do NRF2 contra diversas patologias que são causadas ou agravadas por estresse oxidativo. Essa função é evidente pelo aumento da incidência de câncer, doenças pulmonares e condições inflamatórias em 
camundongos deficientes em NRF2 ( $\left.\mathrm{Nrf}^{-/}\right)$, além do aumento da susceptibilidade a compostos tóxicos, substâncias irritantes inaladas e agentes químicos carcinogênicos (revisão em $(146,148,149,223))$. Evidências da atuação do NRF2 como um efetor da RED foram mostradas em estudos com humanos e roedores. Pearson et al., (2008) (224) demonstrou que a RED induz a expressão de genes antioxidantes em camundongos e que esta resposta é suprimida em animais $\mathrm{Nrf}^{-/}$. Além disso, o conhecido efeito protetor da RED contra o câncer foi diminuído em camundongos $\mathrm{Nrf}^{-/}(225,226)$. Esses experimentos demonstraram que a RED aumenta a expressão de genes dependente de NRF2 e que este fator de transcrição é necessário para vários efeitos benéficos proporcionados pela $\operatorname{RED}(225,226)$.

É importante notar que nossos resultados sugerem a dependência do TLR2 e TLR4 para o funcionamento normal do NRF2. Foi demonstrado aqui que a atividade desse fator de transcrição no hipocampo é reduzida pelo nocaute tanto do TLR2 quanto do TLR4. No entanto, esse efeito da ausência desses receptores é revertido após o protocolo de dieta intermitente em ambos os casos. Apesar de, no nosso estudo, a dieta intermitente por si só não alterar a atividade do NRF2, a reversão da redução pelo nocaute acaba sendo mais um indício da modulação do NRF2 pela RED mediando seus efeitos protetores. Por outro lado, esse efeito da dieta intermitente é específico do hipocampo, uma vez que a avaliação no hipotálamo mostrou que o nocaute de TLR4 reduz a atividade do NRF2 mesmo na vigência da dieta intermitente, enquanto que o nocaute do TLR2 não causa modulação em sua atividade.

Um dos genes alvos modulados pelo NRF2 é a HO1, que é uma isoforma indutível de hemeoxigenase pertencente ao grupo das proteínas de choque térmico e que apresenta um importante papel fisiológico, protegendo as células da agressão oxidativa do heme livre. Além da sua função antioxidante, essa enzima vem sendo reconhecida pelo seu importante papel anti-inflamatório e imunomodulatório, o que foi mostrado em camundongos nocaute para HO1 (227) e em um caso humano de deficiência genética de HO1 (228).

Nesse estudo pudemos notar que a dieta intermitente por si só aumentou significativamente os níveis de $\mathrm{HO} 1$ nos animais WT do $T l r 2^{-/}$e teve uma tendência a aumentar nos WT do $T l r 4^{-/}$. Ainda, a dieta intermitente mostrou uma tendência a induzir um aumento na expressão proteica de HO1 independentemente do TLR4, o que pode estar contribuindo para os efeitos antioxidantes e neuroprotetores desse protocolo já relatados anteriormente (60). É interessante notar que a ausência do TLR2 abole o aumento da HO1 induzido pela dieta intermitente. Em conjunto, esses dados sugerem que o aumento da expressão de HO1 induzido pela dieta intermitente é dependente de TLR2 e independe da 
sinalização do TLR4. De fato, apesar da relação entre a HO1 e o TLR4 ainda não ser clara, Park et al., (2008) mostrou que o TLR2 contribui para a expressão de HO1 no dano cerebral traumático (229).

Ao contrário do esperado, não encontramos uma correlação entre os níveis de $\mathrm{HO} 1$ e a atividade do fator de transcrição NRF2. Possivelmente pode estar ocorrendo uma modulação pós-transcricional da enzima HO1. Porém, ao avaliar a expressão proteica nuclear do NRF2, um indicativo de sua provável translocação para o núcleo onde este fator se encontra ativo e exercendo modulação transcricional, observamos níveis significativamente menores de NRF2 nuclear no hipocampo de animais submetidos à dieta intermitente na ausência de TLR2, o que vai de acordo com a modulação de HO1 observada nesses animais.

O último fator de transcrição avaliado foi o FOXO1. Os mecanismos regulados pelo FOXO devem-se ao controle da expressão de genes que modulam o metabolismo da glicose (glicose 6 fosfatase e fosfoenolpiruvato carboxilase); a detoxificação de EROs em situações de estresse oxidativo (catalase [CAT] e manganês superóxido dismutase [MnSOD ou SOD2]); a regulação do ciclo celular; o reparo do DNA; a longevidade; a resistência a estímulos potencialmente deletérios e a sobrevivência ou morte celular em resposta a estímulos estressores (230-235). Durante o jejum, o FOXO1 também regula a gliconeogênese hepática em mamíferos $(236,237)$. Devido a esse controle dual da resposta a estímulos estressores e do metabolismo energético, é provável que o FOXO1 exerça um papel importante nos efeitos mediados pela RED. Porém, ao contrário do que acreditávamos, não observamos modulação significativa do FOXO1 no hipocampo pela dieta intermitente e nem pelo nocaute do TLR2 ou TLR4.

Os fatores de transcrição FOXO são negativamente regulados pela via de sinalização PI3K/AKT. Durante o consumo calórico, a estimulação dos receptores de insulina leva à ativação da via PI3K/AKT que resulta na fosforilação de FOXOs em mamíferos. O FOXO fosforilado é reconhecido por proteínas que facilitam o seu transporte pra fora do núcleo, reduzindo sua atividade transcricional. De fato, não observamos alterações da proteína AKT nos diferentes grupos, o que pode estar associado à ausência de modulação do FOXO1, uma vez que a AKT fosforila e inativa o FOXO1.

A autofagia é o mecanismo pelo qual substratos do citoplasma celular podem ser renovados e reaproveitados através da degradação por lisossomos. Através do catabolismo, a autofagia fornece aminoácidos e energia às células, permitindo que elas mantenham suas funções vitais e se adaptem a estresses ambientais. Esse processo pode ser induzido em resposta a vários estímulos estressores, incluindo a privação de alimento e estresse oxidativo 
(238). A autofagia é predominantemente citoprotetora e é responsável por diversas funções fisiológicas, como a adaptação ao estresse, aumento da expectativa de vida e proteção contra doenças neurodegenerativas. Sabe-se atualmente que a RED é o maior indutor fisiológico de autofagia (239).

Devido à participação do processo de autofagia nos efeitos mediados pela RED, investigamos também a expressão de alvo da rapamicina em mamíferos (mTOR), proteína que sabe-se que é fosforilada e inibida durante o jejum, ativando a autofagia (239). Há uma constante busca das indústrias farmacêuticas por uma substância que mimetize os efeitos benéficos da RED. Talvez o melhor mimético da RED até hoje encontrado é a rapamicina, um fármaco que inibe o mTOR (revisão em (218)). Este composto mimetiza a RED por ser um potente ativador de autofagia, suprimindo a síntese global de proteínas e favorecendo a produção seletiva de proteínas críticas para a sobrevivência celular e plasticidade (240). A rapamicina pode aumentar a expectativa de vida em camundongos (241) e exibir ações neuroprotetoras em modelos de várias doenças neurodegenerativas (242-244). Ainda, foi visto que a inibição de mTOR pela rapamicina melhora a performance em testes de aprendizado e memória e previne o declínio cognitivo com a idade em camundongos (245). A rapamicina parece ser particularmente efetiva em combater o acúmulo de proteínas e organelas danificadas que são comuns no envelhecimento e doenças neurodegenerativas já que, ao inibir mTOR, tanto a autofagia (243) como a degradação de proteínas ubiquitinadas por proteassomas (246) são aumentadas.

Apesar de esses serem fortes indícios da participação do mTOR nos efeitos mediados pela dieta intermitente, os resultados provenientes dos ensaios de western blot com a forma total e fosforilada do mTOR no hipocampo não mostraram modulação dessa proteína por esse protocolo. Como sabe-se que o mTOR é ativado em situação de jejum e deprivação de alimento, o fato de não termos observado modulação de mTOR pode ser porque os animais desse estudo são submetidos à eutanásia para a remoção de suas estruturas cerebrais para análise no dia em que tem livre acesso ao alimento, e não em jejum. É provável que a ativação do mTOR ocorra apenas durante os períodos de jejum da dieta intermitente, sendo essa ativação intervalada suficiente para desencadear efeitos adaptativos do protocolo. Além disso, muitas vezes o efeito modulatório protetor da dieta intermitente em vias de sinalização só é evidenciado após um estímulo que desafie a homeostasia do organismo, uma vez que a dieta intermitente, como um exemplo de hormese, aumenta a capacidade do organismo de lidar com situações de estresse mais graves (31). Isso foi demonstrado nos estudos durante o meu mestrado, onde em muitos casos os efeitos protetores da dieta intermitente não eram revelados 
nos grupos submetidos a esse protocolo por si só, mas sim após o estímulo inflamatório induzido pelo LPS (36).

Como não observamos alterações no mTOR, decidimos avaliar se a autofagia poderia estar ocorrendo por outras vias, uma vez que sabe-se que a autofagia pode ser ativada por vias independentes de mTOR, como por exemplo a via da proteína quinase dependente de AMP (AMPK), um sensor de energia celular (239). De fato, observamos que a dieta intermitente aumenta a fosforilação de AMPK, um indicativo da ativação dessa proteína. Portanto, nossos dados sugerem que a dieta intermitente induz autofagia independente dos períodos de jejum através da ativação de AMPK e de forma independente de mTOR.

Além disso, interessantemente notamos que os animais $T l r 4^{-/-}$também apresentam aumento da fosforilação de AMPK de forma independente da dieta intermitente. Esses dados são inéditos, uma vez que, até o momento, não há estudos que correlacionam o papel do receptor TLR4 com a indução de autofagia no SNC.

Apesar da proteína P53 ser mais estudada em relação ao seu controle do ciclo e morte celular, cada vez mais estudos indicam que o P53 desempenha um papel central nas vias relacionadas à respostas nutricionais e ao estresse. Essas várias funções do P53 são importantes não somente na supressão de tumores, mas também no metabolismo, envelhecimento e neurodegeneração. Outro processo celular descrito que também é regulado por p53 é a autofagia. Alguns estudos inicialmente indicaram que a ativação de P53 induz a autofagia, porém, outros estudos apontam que níveis basais de P53 inibem a autofagia (238).

Ao avaliarmos o P53 afim de correlacionar sua modulação com a autofagia, verificamos que sua expressão é aumentada somente nos animais $T l r 4^{-/}$submetidos à dieta intermitente. Portanto, sua expressão no nosso estudo não está diretamente correlacionada com o aumento da fosforilação de AMPK como um indicativo da ocorrência de autofagia.

A peroxidação lipídica induzida por estresse oxidativo leva ao acúmulo de 4-hidroxi2-nonenal (HNE) no cérebro. As células neuronais são particularmente vulneráveis ao estresse oxidativo e à peroxidação lipídica decorrente, que pode resultar em uma desestabilização da homeostase do cálcio e, por fim, em apoptose (247-249), uma forma de morte celular programada mediada, em partes, por P53 (250). A peroxidação lipídica em excesso pode ocasionar a degeneração de neurônios tanto no dano agudo do SNC quanto em doenças neurodegenerativas, como DA e DP (251). Ao analisar por western blot os níveis de estresse oxidativo através da quantificação de HNE, um produto estável da peroxidação lipídica (184), observamos a presença de duas bandas de aproximadamente $55 \mathrm{kDa}$ e $22 \mathrm{kDa}$. Nossos resultados mostraram um aumento dos níveis de HNE resultante do nocaute do TLR4 
independente da dieta intermitente na banda de peso mais alto e somente no grupo submetido à dieta intermitente na banda de peso mais baixo. Interessantemente, a análise de P53 mostra que a modulação dessa proteína citoplasmática segue o mesmo padrão dos níveis de peroxidação lipídica.

Mais conhecido pelo sua função nas respostas de dano de DNA e apoptose, o P53 também é importante para as respostas adaptativas ao estresse celular. Por exemplo, foi mostrado que células deficientes em P53 são mais vulneráveis à morte por estresse oxidativo (252). Foi sugerido também que o P53 pode proteger os neurônios contra baixos níveis de estresse oxidativo através da redução da síntese de proteínas e, dessa forma, conservando os substratos energéticos celulares importantes para a sobrevivência celular em situações de estresse. Baseado nisso, os nossos dados sugerem que, na ausência do receptor TLR4, a dieta intermitente resulta em um aumento de P53 para possivelmente combater o maior estresse oxidativo indicado pelo aumento de HNE.

Quando a produção de EROs está em excesso em relação à capacidade antioxidante intracelular, ocorre o dano celular mediado por radicais livres (253). As enzimas antioxidantes são cruciais para a manutenção de agentes oxidantes dentro dos níveis fisiológicos. Um desequilíbrio dessas enzimas pode causar o acúmulo de EROs levando à morte celular. Por exemplo, o radical livre $\mathrm{O}_{2}{ }^{-}$sofre desmutação pela enzima $\mathrm{SOD}$, que gera $\mathrm{H}_{2} \mathrm{O}_{2}$ que pode ser removido por GPx através da oxidação de GSH para GSSG, que é reduzido de volta a GSH pela GR (254).

Para melhor analisar a regulação do ciclo da glutationa e avaliar as defesas antioxidantes, a razão da atividade das enzimas GR e GPx foi calculada. Os nossos resultados mostram um desbalanço das defesas antioxidantes decorrente do nocaute de TLR2, indicado pela redução da razão GR/GPx apesar do aumento de HNE. Analisando a atividade das enzimas separadamente, foi observado um aumento da atividade de GPx e uma concomitante redução da atividade de GR nos grupos nocautes para TLR2. Dado que a enzima GR é importante para reciclar GSH que é necessário para a atividade antioxidante de GPx, a redução da atividade de GR e da razão GR/GPx indicam um desbalanço da atividade enzimática do ciclo de GSH. Esses resultados sugerem que o nocaute de TLR2 pode tornar o organismo mais vulnerável aos efeitos do estresse oxidativo, uma vez que suas defesas antioxidantes são deficientes.

Por outro lado, foi observado que a dieta intermitente por si só causa um aumento da atividade de GPx concomitante com atividade normal de GR. Dado que a análise dos níveis de HNE indicam níveis normais de peroxidação lipídica no grupo em dieta intermitente, esse 
aumento da atividade da GPx pode ser interpretado como um aumento da capacidade de defesa antioxidante, e não como uma resposta adaptativa à presença de maiores níveis de estresse oxidativo.

Quanto à modulação da enzima antioxidante SOD, não foram observadas alterações significativas entre os grupos na expressão de $\operatorname{Sod} 1$ e $\operatorname{Sod} 2$, ou dos níveis proteicos de SOD2 no hipocampo. A análise de PCR em tempo real da expressão das enzimas antioxidantes mostrou que a única alteração significativa que obtivemos no hipocampo foi em camundongos nocaute para TLR4 submetido à dieta intermitente, onde se observou o aumento da expressão de Cat. Como foi observado um aumento de HNE nos grupos nocaute TLR4, o aumento da expressão de Cat pode ser uma resposta adaptativa induzida pela dieta intermitente para combater o aumento de estresse oxidativo nesse grupo.

Já no hipotálamo, apesar de não termos dados relativos aos níveis de estresse oxidativo nessa região cerebral que permitam uma melhor interpretação dos dados, foram constatados níveis elevados de RNAm de Sod2 após o protocolo de dieta intermitente em relação ao grupo controle, indicando um aumento de defesas antioxidantes por esse protocolo nessa estrutura cerebral. Interessantemente, o nocaute de TLR2 por si só leva a um aumento de Sod2, que é revertido pela dieta intermitente. Apesar do possível efeito protetor antioxidante da dieta intermitente do hipotálamo indicado pelo aumento de Sod2, parece que a ausência de TLR2 impede essa resposta do protocolo, indicando que possivelmente esse efeito é dependente da sinalização associada ao TLR2.

Sabe-se que a exposição a estresse oxidativo leva a um aumento da atividade do NRF2. Nossos resultados mostraram que o nocaute de TLR4 leva a um aumento nos níveis de HNE indicadores de estresse oxidativo. Porém, o que de fato observamos foi uma redução da atividade do NRF2 na ausência do TLR4. Esses resultados sugerem que a ativação de NRF2 parece ser dependente do receptor TLR4 (149).

Além do NRF2, sabe-se que outros fatores de transcrição também são ativados por

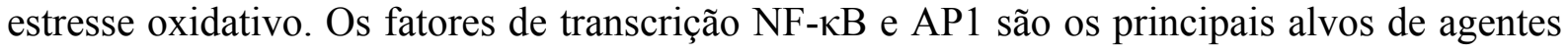
oxidantes (255). O NF- $\kappa$ B pode ser ativado por EROs, especialmente $\mathrm{H}_{2} \mathrm{O}_{2}$, em diversos tipos celulares. Os EROs também podem ativar a ligação de AP1 ao DNA por mecanismos redox em cooperação com tiredoxina, e esta, por sua vez, aumenta a atividade de ligação ao DNA de ambos AP1 e NF-kB (255). De fato, nossos resultados demonstram que o aumento dos níveis de HNE indicativos de maior estresse oxidativo também são acompanhados pelo aumento da atividade de AP1, sendo este independente de TLR4. Porém, ao contrário do que ocorre com o AP1, a atividade do NF- $\mathrm{B}$ não é aumentada nos grupos com maiores níveis de HNE, 
sugerindo que a ativação do NF-אB por altos níveis de estresse oxidativo no hipocampo é dependente de TLR4.

É importante notar que estudos indicam que EROs interferem na função do CREB, fator de transcrição que desempenha um papel importante na sobrevivência celular $(256,257)$. $\mathrm{O}$ HNE leva à morte celular em neurônios granulares no cerebelo acompanhado pela menor ligação à região promotora CRE (256). Além disso, foi demonstrado que a exposição a EROs interfere na fosforilação de CREB e reduz os níveis proteicos desse fator de transcrição, que pode ocorrer pela degradação por proteases no $\operatorname{SNC}(258,259)$. Baseado nesses estudos, é possível que os altos níveis no marcador de peroxidação lipídica encontrados no hipocampo de camundongos $\mathrm{Tlr}^{-/-}$submetidos à dieta intermitente estejam relacionados à menor atividade do CREB constatada nesse mesmo grupo experimental.

A HSP70 e HSP90 são chaperonas cuja expressão é regulada pelo fator de transcrição NF-אB (260-262). Essas proteínas são críticas para a resposta de proteção do organismo à diferentes formas de estresses fisiológicos e ambientais, incluindo o estresse nutricional e o oxidativo. Ainda, elas são responsáveis por reparar danos às proteínas e reestabelecer sua homeostasia, resultando dessa forma em maior tolerância ao estresse (263). Sabe-se que várias situações de estresse levam ao aumento da expressão de HSP70 e HSP90 (264). Além disso, estudos mostram que o aumento da expressão dessas chaperonas pode prevenir a apoptose neuronal e diminuir o estresse oxidativo em doenças neurodegenerativas $(265,266)$. Como verificamos uma diferença nos níveis de estresse oxidativo entre os grupos, resolvemos avaliar também a modulação dessas chaperonas. Apesar de não observarmos alterações significativas nos níveis de HSP70, observamos que o nocaute de TLR4 leva a uma redução dos níveis de HSP90 em relação ao grupo controle, que é revertido pelo protocolo de dieta intermitente. Esse resultado, juntamente com os dados que mostram uma menor atividade do fator de transcrição NRF2, sugerem que o nocaute do TLR4 leva a uma resposta defectiva das células do hipocampo ao estresse oxidativo, que provavelmente é reestabelecida pela dieta intermitente.

Sabe-se que altos níveis de glicose podem ser prejudiciais para os neurônios, uma vez que, em condições hiperglicêmicas, o aumento da utilização de glicose pode levar ao mal funcionamento do ciclo da glutationa, aumento de estresse oxidativo e da glicação não enzimática de proteínas, o que pode resultar em morte celular (267). Estudos anteriores geralmente indicam que a glicose de jejum é reduzida em resposta ao protocolo de dieta intermitente em modelo animal $(60,268)$, apesar de também já ter sido relatada uma diminuição da sensibilidade à insulina sem alteração na glicemia basal após um período de 
dieta intermitente (269). Três estudos apontaram para redução dos níveis de glicose circulante após 20 a 24 semanas de dieta intermitente $(101,270)$, enquanto outro estudo não indica alteração após 16 semanas do protocolo (271).

Com relação aos camundongos $T l r 4^{-/}$, fizemos avaliação da glicemia tanto após o período de livre acesso ao alimento quanto em jejum antes do teste de tolerância à glicose. Surpreendentemente, não observamos alterações significativas na glicemia basal dos animais WT após 30 dias de dieta intermitente em ambas as situações. No entanto, verificamos que o nocaute de TLR4 leva a um aumento da glicemia. Contudo, o aumento dos níveis de glicose é revertido totalmente pela dieta intermitente nos animais com livre acesso ao alimento, e parcialmente nos animais em jejum.

Os persistentes níveis elevados de glicemia basal dos camundongos $T l r 4^{-/}$mesmo durante a privação de alimento (jejum), podem também estar correlacionados com, e contribuir para, os altos níveis de estresse oxidativo nesses animais e com o baixo desempenho nos testes comportamentais que avaliam diferentes tipos de memória como discutido adiante, uma vez que sabe-se que a hiperglicemia persistente é neurotóxica e prejudicial para a função neuronal, resultando no aumento de estresse oxidativo no SNC (267).

Em relação aos camundongos $T l r 2^{-/}$, somente a glicemia de jejum foi avaliada. Como resultado, vimos que, ao contrário do nocaute do TLR4, o do TLR2 leva a uma redução da glicemia basal, que é revertida pela dieta intermitente.

Nos últimos anos, a avaliação da resposta a um desafio da homeostase tem se tornado uma importante ferramenta em estudos nutricionais e metabólicos, uma vez que desafiar um indivíduo é muito mais informativo do que medidas feitas durante a homeostasia estática $(272,273)$. Uma dessas ferramentas é o teste de tolerância à glicose, onde é feita a avaliação da glicemia em diferentes intervalos de tempo após um desafio representado por uma injeção intraperitoneal de glicose. Ao realizar esse teste e compararmos a área sob a curva glicêmica entre os grupos nos camundongos $T l r 4^{-/}$, verificamos que os resultados apresentam o mesmo padrão de modulação da glicemia basal após livre acesso ao alimento, reforçando os dados obtidos. Assim, observamos que os animais com nocaute para TLR4 apresentam uma tendência a terem menor tolerância à glicose (maior área sob a curva glicêmica) enquanto a dieta intermitente nesses animais aumenta significativamente a tolerância à glicose (menor área sob a curva glicêmica). Estes resultados, em conjunto com os dados da glicemia basal, apontam para uma possível modulação metabólica nesta linhagem $T l r 4^{-/}$com alterações na homeostase glicêmica, que parece ser revertido pela dieta intermitente. Estes dados 
corroboram estudos anteriores que apontam uma relação da sinalização do TLR4 com o diabetes $(83,85,274)$. $\mathrm{O}$ fato da dieta intermitente ter revertido as alterações observadas nos animais $T l r 4^{-/}$nesse estudo sugere que este protocolo poderia ser eficaz no manejo da diabetes, através da reversão de alterações de sinalização associadas ao TLR4 no curso dessa doença.

Além da modulação dos níveis de glicemia, dados da literatura mostraram que 8 semanas de dieta intermitente são capazes de reduzir os níveis do colesterol total em camundongos adultos (275). Interessantemente, apesar de não termos observado diferença nos níveis de colesterol de camundongos em 30 dias de dieta intermitente em relação ao grupo controle, observamos que esse protocolo foi capaz de prevenir seu aumento induzidas pelo nocaute de TLR4.

Os diferentes resultados apresentados nos diversos estudos da literatura em relação à glicemia e colesterolemia que por vezes não condizem com os resultados do presente estudo, podem ter origem nos diferentes modelos utilizados, estado alimentar dos animais no momento da análise e tempos de tratamento, fatores que apresentam grandes variações entre estudos. A duração do protocolo empregado no presente estudo é de 30 dias, enquanto os estudos citados anteriormente aplicam o protocolo geralmente por no mínimo 8 semanas. Ainda, vale ressaltar que os animais nesse estudo não estavam em jejum no momento da coleta de soro para análise da colesterolemia, o que poderia prejudicar a comparação com os estudos citados anteriormente.

A oxidação dos ácidos graxos de cadeia longa é uma via central liberadora de energia nos animais. O produto desta oxidação, o acetil-CoA, pode ser completamente oxidado até $\mathrm{CO}_{2}$ através do ciclo do ácido cítrico, ou em vertebrados pode ser convertido em corpos cetônicos (combustíveis hidrossolúveis exportados para o cérebro e outros tecidos), quando a glicose não está disponível. Em situação de jejum e com a queda da glicemia, o cérebro utiliza como substrato energético, além da glicose, os corpos cetônicos beta-hidroxibutirato e acetoacetato (63).

Estudos anteriores apontam um aumento da oxidação de gordura no fígado e músculos após 8 semanas de dieta intermitente (276). Como se sabe que o prejuízo da oxidação de gordura pode contribuir para o acúmulo ectópico de lipídios intracelulares e para o desenvolvimento de resistência à insulina (277), o aumento da oxidação de gordura pode aumentar a sensibilidade à insulina. Ainda, estudos apontam para o aumento dos níveis plasmáticos de hidroxibutirato nos grupos submetidos à dieta intermitente, mas não à dieta de restrição calórica (101). 
De fato, corroborando com estudos anteriores, também observamos que a dieta intermitente aumenta os níveis de 3-hidroxibutirato em camundongos, um indicativo de ocorrência de maiores níveis de oxidação de ácidos graxos que resulta em cetogênese. Dados da literatura mostram que o metabolismo de corpos cetônicos resulta em menor produção de EROs e menor estresse mitocondrial quando comparado com a glicólise (267). Além disso, estudos indicam que a utilização de corpos cetônicos como fonte de energia está relacionada com os efeitos benéficos da dieta intermitente sobre a saúde e longevidade (63).

Curiosamente, observamos que os camundongos $\mathrm{Tlr}^{-/-}$nesse estudo apresentaram níveis de 3-hidroxibutirato ainda maiores quando comparados com os animais WT em dieta intermitente, e que a dieta intermitente nesses animais $T l r 4^{-/-}$reverte o aumento de 3hidroxibutirato. Apesar dos poucos estudos na literatura sobre o assunto, sabe-se que a ativação de TLR4 diminui a beta-oxidação de ácidos graxos (278), o que vai de encontro com os nossos resultados que mostram que a ausência de TLR4 leva a um aumento de 3hidroxibutirato, um indicativo de aumento de beta-oxidação.

Estudos indicam que a creatina apresenta propriedades anti-apoptóticas (279), antiexcitotóxicas (280), e antioxidante (281), além de melhorar a saúde e expectativa de vida em modelo animal (282). Ainda, dados da literatura apontam efeitos neuroprotetores mediados pela creatina em doenças neurodegenerativas, em particular DP e Huntington $(283,284)$. Nossos resultados nesse estudo mostram que a dieta intermitente aumenta os níveis de creatina em relação ao grupo controle, alteração que pode estar relacionada com os efeitos benéficos da dieta intermitente sobre a saúde e longevidade. Porém, é interessante notar que o nocaute de TLR4 reverteu o aumento de creatina induzido pela dieta intermitente.

Dados da literatura indicam que tanto a creatina quanto os corpos cetônicos são capazes de melhorar a função cognitiva e prevenir o declínio cognitivo associado à idade e doenças neurodegenerativas (revisão em (285)). Sendo assim, a redução dos níveis circulantes desses biomarcadores podem estar associados ao pior desempenho nos testes de memória verificados nos camundongos $T l r 4^{-/}$submetidos à dieta intermitente, como discutido adiante.

Para que pudéssemos averiguar o efeito funcional das alterações nas sinalizações discutidas até aqui, submetemos os camundongos a testes comportamentais para avaliação de diversos parâmetros de memória e comportamento ansioso ou depressivo.

No labirinto aquático de Morris, os animais nocaute para TLR4 com ou sem a dieta intermitente apresentaram latências significativamente maiores para encontrar a plataforma durante os 5 dias de treino em comparação com os outros grupos, demonstrando um pior desempenho no aprendizado desses animais. Já no teste de memória de referência, que ocorre 
24 horas após o último dia de treino com a remoção da plataforma, somente o grupo nocaute para TLR4 submetido à dieta intermitente permaneceu significativamente menos tempo no quadrante alvo. Como não houve preferência para os camundongos desse grupo de se manterem no quadrante onde a plataforma estava localizada durante o treino, isso demonstra que não se recordaram da localização da mesma, sugerindo um prejuízo da memória espacial de referência nesses animais. Quanto aos camundongos $T l r 2^{-/}$, apesar destes também terem apresentado maior latência para encontrar a plataforma durante os 5 dias de treino, não foi observado diferença significativa no tempo de permanência no quadrante alvo durante o teste.

O teste do labirinto aquático de Morris não somente revelou um déficit de memoria de referência nos camundongos $T l r 2^{-/}$e $T l r 4^{-/-}$, mas também de memória operacional - um tipo de memória de curtíssima duração que constitui-se majoritariamente de um processo cortical.

Os fatores de transcrição NF-אB e CREB desempenham funções fundamentais para a função cognitiva $(141,286)$. O NF-אB está associado com a plasticidade sináptica e memória de longa duração (286), sendo ativado durante a potenciação de longa duração (LTP) no hipocampo de camundongos (287). Da mesma forma, o CREB é considerado um modulador universal de processos necessários para a formação de memória (141). Sabe-se ainda que NF$\kappa \mathrm{B}$ regula a memória espacial e plasticidade através da via PKA/CREB (206). Dessa forma, o possível prejuízo de memória de referência nos camundongos $T l r 4^{-/-}$submetidos à dieta intermitente pode estar correlacionado com a menor atividade desses fatores de transcrição no hipocampo. Além disso, o BDNF é uma neurotrofina cuja expressão é regulada por esses fatores de transcrição e que exerce um papel fundamental na memória (288). Essa neurotrofina também apresenta níveis reduzidos nos animais $T l r 4^{-/}$submetidos à dieta intermitente.

Além da associação do déficit de memória dos camundongos $T l r 4^{-/-}$com a redução da atividade ou expressão de proteínas importantes para esse processo, pode haver também uma correlação com os níveis de estresse oxidativo, que encontram-se elevados nesses animais sem a dieta intermitente ou principalmente após esse protocolo, como evidenciado pelo aumento dos níveis de HNE nas duas bandas de western blot verificadas. Sabe-se que o estresse oxidativo no SNC, especialmente nas regiões do hipocampo e córtex, pode causar prejuízo da neurotransmissão, resultando em déficit das funções cognitivas, processo comum durante o envelhecimento $(289,290)$.

Um segundo teste realizado para avaliação de memória nos animais foi o de esquiva inibitória, com o qual é possível estudar a memória gerada por um estímulo aversivo (291). Segundo Izquierdo (292), a maioria das informações que adquirimos diariamente se extingue 
por falta de reforço, ou pelo processo natural de esquecimento, que pode evitar a sobrecarga de certas regiões cerebrais, além de filtrar as informações (293). A esquiva inibitória, por utilizar o choque como um estímulo de dor para reforço da memória, é um modelo experimental marcante para os animais. Da mesma forma, em humanos, eventos marcantes fazem com que os indivíduos se recordem dos acontecimentos automaticamente. Exemplos são os casos de lembranças positivas do passado ou, ao contrário, situações muito negativas que gerem distúrbio de estresse pós-traumático (294). Nesse teste, os camundongos Tlr $4^{-/-}$ apresentaram um pior desempenho do que os outros grupos de forma independente da dieta intermitente, uma vez que não se lembraram do estímulo aversivo 24 horas após o choque ter sido deflagrado. Isso sugere que esses camundongos apresentam uma pior memória de medo contextual. Esse dado reforça o resultado obtido no labirinto aquático de Morris, onde esses grupos também apresentaram um prejuízo de função cognitiva. Ao contrário do que ocorreu com os animais $T l r 4^{-/}$, a ausência do TLR2 não causou déficit de memória no teste de esquiva inibitória.

Como controle dos experimentos, para avaliar se o pior desempenho dos grupos nos testes de memória foi devido a um prejuízo na locomoção dos animais, estes foram submetidos ao teste de campo aberto para a avaliação da atividade locomotora espontânea e da resposta a novos ambientes. Enquanto não foram observadas alterações locomotoras nos camundongos $T l r 4^{-/-}$, observamos um aumento de locomoção espontânea nos camundongos $\mathrm{Tlr}^{2 /-}$ submetidos à dieta intermitente. Além disso, esse mesmo grupo apresentou um maior comportamento exploratório ao permanecer significativamente mais tempo no braço aberto no labirinto em cruz elevado. Apesar da maior atividade locomotora e comportamento exploratório, isso não resultou em um melhor desempenho dos camundongos $T l r 2^{-/}$em dieta intermitente na execução dos testes comportamentais, uma vez que este grupo apresentou um pior desempenho de memória e aprendizagem no labirinto aquático de Morris em relação aos outros grupos.

Ainda, para averiguar se o pior desempenho dos camundongos $T l r 2^{-/}$e $T l r 4^{-/-}$nos testes comportamentais poderia estar relacionado a um possível quadro depressivo que reduzisse a motivação para desempenharem os testes de forma satisfatória, realizamos o teste de suspensão da cauda. Nesse teste, o tempo de imobilidade dos camundongos ao serem suspensos pela cauda é correlacionado com um comportamento depressivo (183). Surpreendentemente, os camundongos $T l r 4^{-/-}$permaneceram menos tempo imóveis do que os animais controles submetidos ou não à dieta intermitente, refutando a hipótese de uma possível depressão nesses animais. Quanto aos camundongos $T l r 2^{-/}$, estes permaneceram 
significativamente mais tempo imóveis em comparação ao grupo controle, o que foi revertido pela dieta intermitente. 


\section{CONCLUSÃO}

Em conclusão, os nossos resultados sugerem que os receptores TLR4 e TLR2

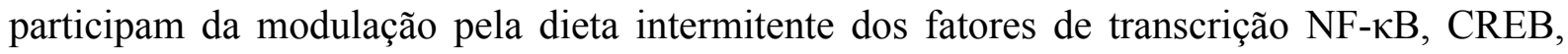
AP1, NRF2 e das proteínas moduladas por esses fatores de transcrição como o BDNF, HO1, enzimas antioxidantes, chaperonas e diversas citocinas inflamatórias. Estas alterações, principalmente o aumento dos níveis de estresse oxidativo, a redução de BDNF e a redução da atividade dos fatores de transcrição NF-kB e AP-1 no hipocampo, estão possivelmente correlacionadas com o déficit de memória de referência, contextual e operacional apresentado nos animais $T l r 2^{-/}$e/ou Tlr $4^{-/}$. Os resultados estão resumidos nos Esquemas 3 e 4 e nos Anexos E e F. Devido à abrangência de sinalizações envolvidas nos resultados inéditos deste trabalho, mais estudos nessa área poderiam contribuir para a completa elucidação dos mecanismos moleculares envolvidos. 


\section{TIr4 $^{-/-}$D vs. D}

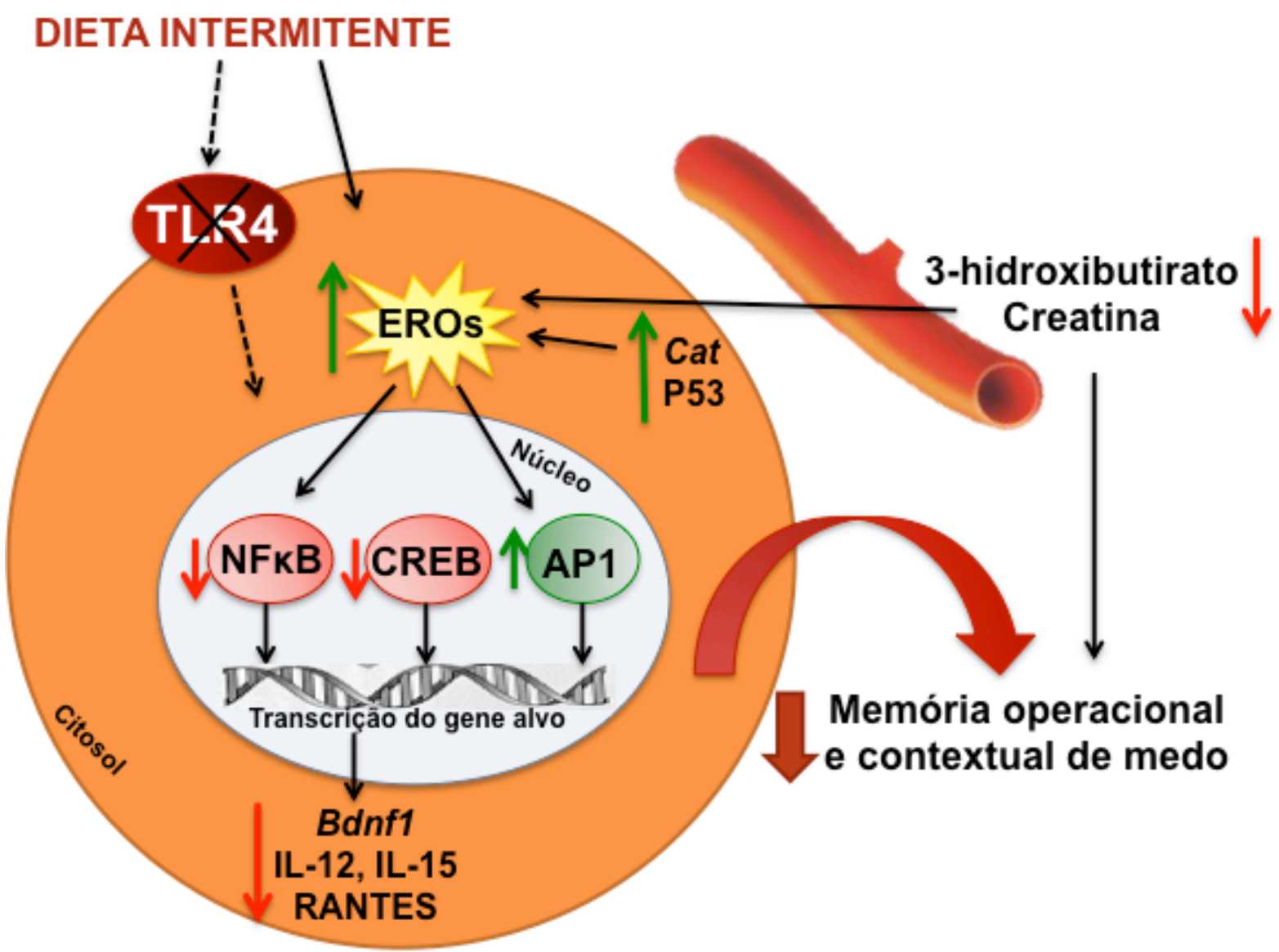

Esquema 3. Representação dos resultados do grupo $T l r 4^{-/-}$submetido ao protocolo de dieta intermitente em relação ao grupo controle submetido à dieta intermitente, demonstrando o resultado da ausência de TLR4 na dieta. Os resultados sugerem que, na ausência do receptor TLR4, a dieta intermitente leva a um aumento dos níveis de estresse oxidativo (EROs), que pode contribuir para a redução observada na atividade dos fatores de transcrição NF- $\mathrm{B}$ e CREB, e aumento da atividade de AP1 no SNC. Consequentemente, há uma redução da expressão dos genes alvos modulados por NF- $\kappa \mathrm{B}$ e CREB, como Bdnf1, IL-12, IL-15 e RANTES. Há ainda um aumento dos níveis de Cat e P53, provavelmente em resposta aos elevados níveis de EROs. Perifericamente, foi observado uma redução dos níveis de 3-hidroxibutirato e creatina circulantes, que podem, juntamente com o aumento de EROs e a redução de $B d n f 1$ e da atividade e NF- $\kappa$ B e CREB, contribuir para a redução da função cognitiva observada nos camundongos $T l r 4^{-/}$submetido à dieta intermitente. 
TIr2-- D vs. D

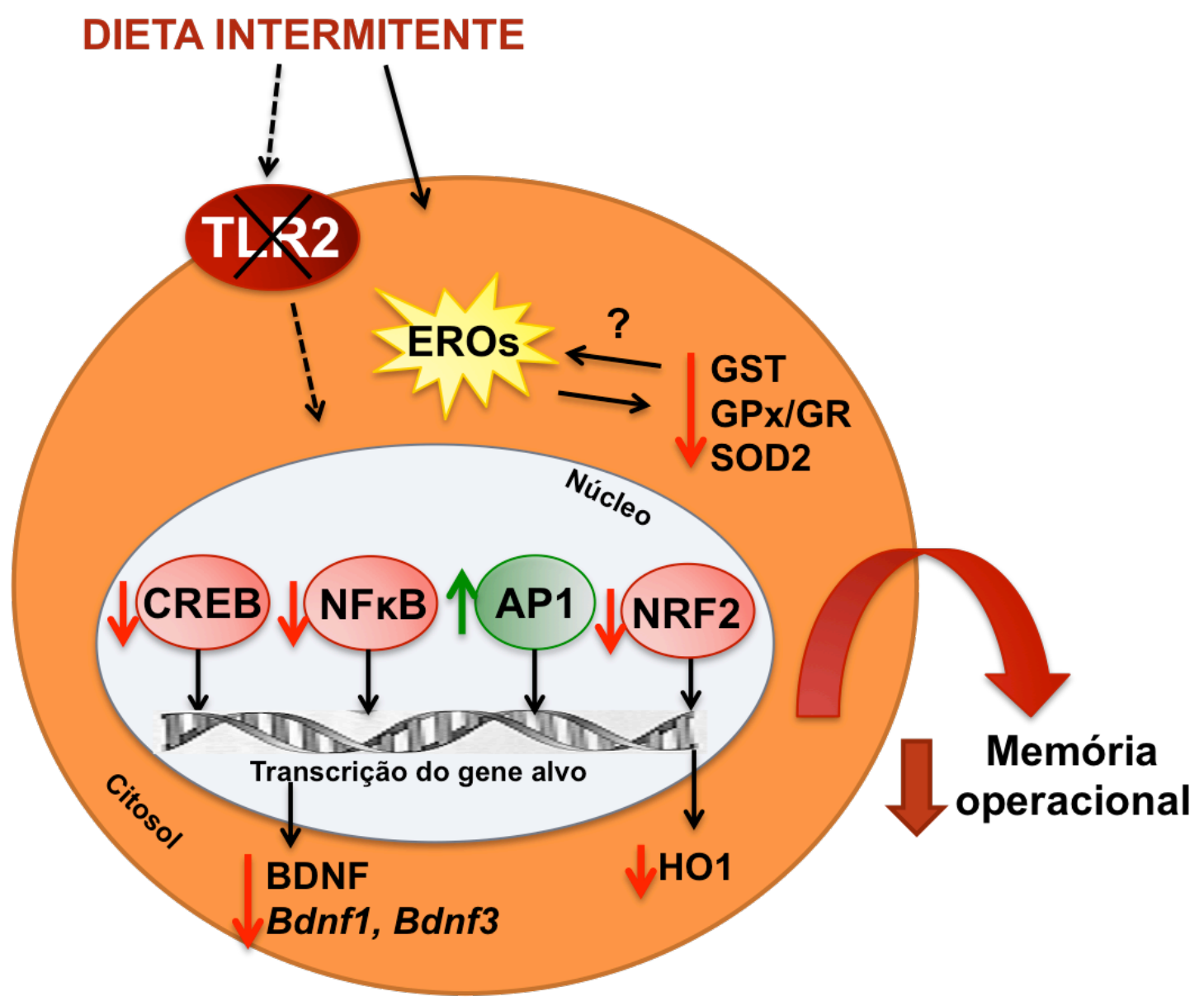

Esquema 4. Representação dos resultados do grupo $T l r 2^{-/-}$submetido ao protocolo de dieta intermitente em relação ao grupo controle submetido à dieta intermitente, demonstrando o resultado da ausência de TLR2 na dieta. Os resultados sugerem que, na ausência do receptor TLR2, a dieta intermitente leva a uma redução na atividade dos fatores de transcrição NF- $\kappa B$, CREB e NRF2 e aumento da atividade de AP1 no SNC. Consequentemente, há uma redução da expressão dos genes alvos

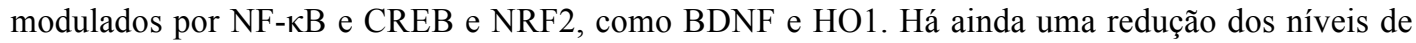
GST e SOD2, e da razão GPx/GR. Contudo, na ausência de dados relativos aos níveis de estresse oxidativo impede uma melhor interpretação desses dados. A redução dos níveis de BDNF e da

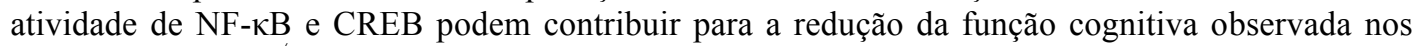
camundongos $\mathrm{Tlr} 2^{-/}$submetido à dieta intermitente. 


\section{REFERÊNCIAS}

1. Calabrese EJ. Converging concepts: adaptive response, preconditioning, and the Yerkes-Dodson Law are manifestations of hormesis. Ageing Res Rev. 2008;7(1):8-20.

2. Calabrese EJ. Hormesis and medicine. Br J Clin Pharmacol. 2008;66(5):594-617.

3. Calabrese EJ. Overcompensation stimulation: a mechanism for hormetic effects. Crit Rev Toxicol. 2001;31(4-5):425-70.

4. Weindruch R, Sohal RS. Seminars in medicine of the Beth Israel Deaconess Medical Center. Caloric intake and aging. N Engl J Med. 1997;337(14):986-94.

5. Frame LT, Hart RW, Leakey JE. Caloric restriction as a mechanism mediating resistance to environmental disease. Environ Health Perspect. 1998;106 (Suppl 1):313-24.

6. McCay CM, Crowell MF, Maynard LA. The effect of retarded growth upon the length of life span and upon the ultimate body size. 1935. Nutrition. 1989;5(3):155-71; discussion 72.

7. Comfort A. Effect of Delayed and Resumed Growth on the Longevity of a Fish (Lebistes Reticulatus, Peters) in Captivity. Gerontologia. 1963;49:150-5.

8. Partridge L, Green A, Fowler K. Effects of egg-production and of exposure to males on female survival in Drosophila melanogaster. J Insect Physiol. 1987;33(10):745-9.

9. Klass MR. Aging in the nematode Caenorhabditis elegans: major biological and environmental factors influencing life span. Mech Ageing Dev. 1977;6(6):413-29.

10. Lin SJ, Defossez PA, Guarente L. Requirement of NAD and SIR2 for life-span extension by calorie restriction in Saccharomyces cerevisiae. Science. 2000;289(5487):2126-8.

11. Colman RJ, Anderson RM, Johnson SC, Kastman EK, Kosmatka KJ, Beasley TM, et al. Caloric restriction delays disease onset and mortality in rhesus monkeys. Science. 2009;325(5937):201-4.

12. Chen RF, Good RA, Engelman RW, Hamada N, Tanaka A, Nonoyama M, et al. Suppression of mouse mammary tumor proviral DNA and protooncogene expression: association with nutritional regulation of mammary tumor development. Proc Natl Acad Sci U S A. 1990;87(7):2385-9.

13. Birt DF, Yaktine A, Duysen E. Glucocorticoid mediation of dietary energy restriction inhibition of mouse skin carcinogenesis. J Nutr. 1999;129(2S Suppl):571S-4S.

14. Yoshida K, Inoue T, Nojima K, Hirabayashi Y, Sado T. Calorie restriction reduces the incidence of myeloid leukemia induced by a single whole-body radiation in $\mathrm{C} 3 \mathrm{H} / \mathrm{He}$ mice. Proc Natl Acad Sci U S A. 1997;94(6):2615-9.

15. Yu ZF, Mattson MP. Dietary restriction and 2-deoxyglucose administration reduce focal ischemic brain damage and improve behavioral outcome: evidence for a preconditioning mechanism. $\mathrm{J}$ Neurosci Res. 1999;57(6):830-9.

16. Ahmet I, Wan R, Mattson MP, Lakatta EG, Talan M. Cardioprotection by intermittent fasting in rats. Circulation. 2005;112(20):3115-21.

\footnotetext{
*De acordo com:

International Committee of Medical Journal Editors. Uniform requirements for manuscripts submitted of Biomedical Journal: sample references. Avaible from: http://www.icmje.org [2007 May 22].
} 
17. Kubo C, Gajar A, Johnson BC, Good RA. The effects of dietary restriction on immune function and development of autoimmune disease in BXSB mice. Proc Natl Acad Sci U S A. 1992;89(7):31459.

18. Fan W, Kouda K, Nakamura H, Takeuchi H. Effects of dietary restriction on spontaneous dermatitis in NC/Nga mice. Exp Biol Med (Maywood). 2001;226(11):1045-50.

19. Nakamura H, Kouda K, Tokunaga R, Takeuchi H. Suppressive effects on delayed type hypersensitivity by fasting and dietary restriction in ICR mice. Toxicol Lett. 2004;146(3):259-67.

20. Bruce-Keller AJ, Umberger G, McFall R, Mattson MP. Food restriction reduces brain damage and improves behavioral outcome following excitotoxic and metabolic insults. Ann Neurol. 1999;45(1):8-15.

21. Duan W, Mattson MP. Dietary restriction and 2-deoxyglucose administration improve behavioral outcome and reduce degeneration of dopaminergic neurons in models of Parkinson's disease. J Neurosci Res. 1999;57(2):195-206.

22. Halagappa VK, Guo Z, Pearson M, Matsuoka Y, Cutler RG, Laferla FM, et al. Intermittent fasting and caloric restriction ameliorate age-related behavioral deficits in the triple-transgenic mouse model of Alzheimer's disease. Neurobiol Dis. 2007;26(1):212-20.

23. Johnson JB, Summer W, Cutler RG, Martin B, Hyun DH, Dixit VD, et al. Alternate day calorie restriction improves clinical findings and reduces markers of oxidative stress and inflammation in overweight adults with moderate asthma. Free Radic Biol Med. 2007;42(5):665-74.

24. Wachsman JT. The beneficial effects of dietary restriction: reduced oxidative damage and enhanced apoptosis. Mutat Res. 1996;350(1):25-34.

25. Yu BP, Chung HY. Stress resistance by caloric restriction for longevity. Ann N Y Acad Sci. 2001;928:39-47.

26. Grant WB. Dietary links to Alzheimer's disease: 1999 update. J Alzheimers Dis. 1999;1(45):197-201.

27. Logroscino G, Marder K, Cote L, Tang MX, Shea S, Mayeux R. Dietary lipids and antioxidants in Parkinson's disease: a population-based, case-control study. Ann Neurol. 1996;39(1):89-94.

28. Dubey A, Forster MJ, Lal H, Sohal RS. Effect of age and caloric intake on protein oxidation in different brain regions and on behavioral functions of the mouse. Arch Biochem Biophys. 1996;333(1):189-97.

29. Mattson MP. Dietary factors, hormesis and health. Ageing Res Rev. 2008;7(1):43-8.

30. Sohal RS, Weindruch R. Oxidative stress, caloric restriction, and aging. Science. 1996;273(5271):59-63.

31. Lane MA, Baer DJ, Rumpler WV, Weindruch R, Ingram DK, Tilmont EM, et al. Calorie restriction lowers body temperature in rhesus monkeys, consistent with a postulated anti-aging mechanism in rodents. Proc Natl Acad Sci U S A. 1996;93(9):4159-64.

32. Chung HY, Sung B, Jung KJ, Zou Y, Yu BP. The molecular inflammatory process in aging. Antioxid Redox Signal. 2006;8(3-4):572-81. 
33. Jolly CA, Muthukumar A, Avula CP, Troyer D, Fernandes G. Life span is prolonged in foodrestricted autoimmune-prone (NZB x NZW)F(1) mice fed a diet enriched with (n-3) fatty acids. J Nutr. 2001;131(10):2753-60.

34. Chung HY, Kim HJ, Kim JW, Yu BP. The inflammation hypothesis of aging: molecular modulation by calorie restriction. Ann N Y Acad Sci. 2001;928:327-35.

35. Kim HJ, Yu BP, Chung HY. Molecular exploration of age-related NF-kappaB/IKK downregulation by calorie restriction in rat kidney. Free Radic Biol Med. 2002;32(10):991-1005.

36. Vasconcelos AR, Yshii LM, Viel TA, Buck HS, Mattson MP, Scavone C, et al. Intermittent fasting attenuates lipopolysaccharide-induced neuroinflammation and memory impairment. J Neuroinflammation. 2014;11:85.

37. Ye SM, Johnson RW. Increased interleukin-6 expression by microglia from brain of aged mice. J Neuroimmunol. 1999;93(1-2):139-48.

38. Richwine AF, Godbout JP, Berg BM, Chen J, Escobar J, Millard DK, et al. Improved psychomotor performance in aged mice fed diet high in antioxidants is associated with reduced ex vivo brain interleukin-6 production. Brain Behav Immun. 2005;19(6):512-20.

39. Fito M, Guxens M, Corella D, Saez G, Estruch R, de la Torre R, et al. Effect of a traditional Mediterranean diet on lipoprotein oxidation: a randomized controlled trial. Arch Intern Med. 2007;167(11):1195-203.

40. DeLegge MH, Smoke A. Neurodegeneration and inflammation. Nutr Clin Pract. 2008;23(1):3541.

41. Akiyama H, Barger S, Barnum S, Bradt B, Bauer J, Cole GM, et al. Inflammation and Alzheimer's disease. Neurobiol Aging. 2000;21(3):383-421.

42. Rogers J, Cooper NR, Webster S, Schultz J, McGeer PL, Styren SD, et al. Complement activation by beta-amyloid in Alzheimer disease. Proc Natl Acad Sci U S A. 1992;89(21):10016-20.

43. Aisen PS. Inflammation and Alzheimer's disease: mechanisms and therapeutic strategies. Gerontology. 1997;43(1-2):143-9.

44. Mitrou PN, Kipnis V, Thiebaut AC, Reedy J, Subar AF, Wirfalt E, et al. Mediterranean dietary pattern and prediction of all-cause mortality in a US population: results from the NIH-AARP Diet and Health Study. Arch Intern Med. 2007;167(22):2461-8.

45. Heydari AR, Wu B, Takahashi R, Strong R, Richardson A. Expression of heat shock protein 70 is altered by age and diet at the level of transcription. Mol Cell Biol. 1993;13(5):2909-18.

46. Guo Z, Ersoz A, Butterfield DA, Mattson MP. Beneficial effects of dietary restriction on cerebral cortical synaptic terminals: preservation of glucose and glutamate transport and mitochondrial function after exposure to amyloid beta-peptide, iron, and 3-nitropropionic acid. J Neurochem. 2000;75(1):314-20.

47. Mathers J, Fraser JA, McMahon M, Saunders RD, Hayes JD, McLellan LI. Antioxidant and cytoprotective responses to redox stress. Biochem Soc Symp. 2004(71):157-76.

48. Hyun DH, Emerson SS, Jo DG, Mattson MP, de Cabo R. Calorie restriction up-regulates the plasma membrane redox system in brain cells and suppresses oxidative stress during aging. Proc Natl Acad Sci U S A. 2006;103(52):19908-12. 
49. Lee J, Duan W, Mattson MP. Evidence that brain-derived neurotrophic factor is required for basal neurogenesis and mediates, in part, the enhancement of neurogenesis by dietary restriction in the hippocampus of adult mice. J Neurochem. 2002;82(6):1367-75.

50. Maswood N, Young J, Tilmont E, Zhang Z, Gash DM, Gerhardt GA, et al. Caloric restriction increases neurotrophic factor levels and attenuates neurochemical and behavioral deficits in a primate model of Parkinson's disease. Proc Natl Acad Sci U S A. 2004;101(52):18171-6.

51. Mattson MP, Cutler RG, Camandola S. Energy intake and amyotrophic lateral sclerosis. Neuromolecular Med. 2007;9(1):17-20.

52. Reiser $\mathrm{K}$, McGee $\mathrm{C}$, Rucker R, McDonald R. Effects of aging and caloric restriction on extracellular matrix biosynthesis in a model of injury repair in rats. J Gerontol A Biol Sci Med Sci. 1995;50A(1):B40-7.

53. Martin B, Pearson M, Kebejian L, Golden E, Keselman A, Bender M, et al. Sex-dependent metabolic, neuroendocrine, and cognitive responses to dietary energy restriction and excess. Endocrinology. 2007;148(9):4318-33.

54. Dirks AJ, Leeuwenburgh C. Caloric restriction in humans: potential pitfalls and health concerns. Mech Ageing Dev. 2006;127(1):1-7.

55. Holloszy JO, Fontana L. Caloric restriction in humans. Exp Gerontol. 2007;42(8):709-12.

56. Redman LM, Martin CK, Williamson DA, Ravussin E. Effect of caloric restriction in non-obese humans on physiological, psychological and behavioral outcomes. Physiol Behav. 2008;94(5):643-8.

57. Johnson BC, Gajjar A, Kubo C, Good RA. Calories versus protein in onset of renal disease in NZB x NZW mice. Proc Natl Acad Sci U S A. 1986;83(15):5659-62.

58. Lueker CE, Meyer JH, Smith JD. Influence of food and energy restriction and subsequent recovery on body composition and food utilization of rats. J Nutr. 1956;60(1):121-8.

59. Goodrick CL, Ingram DK, Reynolds MA, Freeman JR, Cider N. Effects of intermittent feeding upon body weight and lifespan in inbred mice: interaction of genotype and age. Mech Ageing Dev. 1990;55(1):69-87.

60. Mattson MP, Wan R. Beneficial effects of intermittent fasting and caloric restriction on the cardiovascular and cerebrovascular systems. J Nutr Biochem. 2005;16(3):129-37.

61. Masoro EJ. Dietary restriction-induced life extension: a broadly based biological phenomenon. Biogerontology. 2006;7(3):153-5.

62. Masoro EJ. Overview of caloric restriction and ageing. Mech Ageing Dev. 2005;126(9):913-22.

63. Longo VD, Mattson MP. Fasting: molecular mechanisms and clinical applications. Cell Metab. 2014;19(2):181-92.

64. Medzhitov R, Preston-Hurlburt P, Janeway CA, Jr. A human homologue of the Drosophila Toll protein signals activation of adaptive immunity. Nature. 1997;388(6640):394-7.

65. Anderson KV, Bokla L, Nusslein-Volhard C. Establishment of dorsal-ventral polarity in the Drosophila embryo: the induction of polarity by the Toll gene product. Cell. 1985;42(3):791-8.

66. Anderson KV, Jurgens G, Nusslein-Volhard C. Establishment of dorsal-ventral polarity in the Drosophila embryo: genetic studies on the role of the Toll gene product. Cell. 1985;42(3):779-89. 
67. Hashimoto C, Hudson KL, Anderson KV. The Toll gene of Drosophila, required for dorsalventral embryonic polarity, appears to encode a transmembrane protein. Cell. 1988;52(2):269-79.

68. Olson JK, Miller SD. Microglia initiate central nervous system innate and adaptive immune responses through multiple TLRs. J Immunol. 2004;173(6):3916-24.

69. Bowman CC, Rasley A, Tranguch SL, Marriott I. Cultured astrocytes express toll-like receptors for bacterial products. Glia. 2003;43(3):281-91.

70. Aravalli RN, Peterson PK, Lokensgard JR. Toll-like receptors in defense and damage of the central nervous system. J Neuroimmune Pharmacol. 2007;2(4):297-312.

71. Tang SC, Arumugam TV, Xu X, Cheng A, Mughal MR, Jo DG, et al. Pivotal role for neuronal Toll-like receptors in ischemic brain injury and functional deficits. Proc Natl Acad Sci U S A. 2007;104(34):13798-803.

72. Gangloff M, Weber AN, Gibbard RJ, Gay NJ. Evolutionary relationships, but functional differences, between the Drosophila and human Toll-like receptor families. Biochem Soc Trans. 2003;31(Pt 3):659-63.

73. Kawai T, Akira S. TLR signaling. Semin Immunol. 2007;19(1):24-32.

74. Kawai T, Akira S. Signaling to NF-kappaB by Toll-like receptors. Trends Mol Med. 2007;13(11):460-9.

75. Pandey S, Agrawal DK. Immunobiology of Toll-like receptors: emerging trends. Immunol Cell Biol. 2006;84(4):333-41.

76. Lehnardt S, Schott E, Trimbuch T, Laubisch D, Krueger C, Wulczyn G, et al. A vicious cycle involving release of heat shock protein 60 from injured cells and activation of toll-like receptor 4 mediates neurodegeneration in the CNS. J Neurosci. 2008;28(10):2320-31.

77. Miyake K. Innate immune sensing of pathogens and danger signals by cell surface Toll-like receptors. Semin Immunol. 2007;19(1):3-10.

78. Liu Y, Chen GY, Zheng P. CD24-Siglec G/10 discriminates danger- from pathogen-associated molecular patterns. Trends Immunol. 2009;30(12):557-61.

79. Shimada M, Yanai Y, Okazaki T, Noma N, Kawashima I, Mori T, et al. Hyaluronan fragments generated by sperm-secreted hyaluronidase stimulate cytokine/chemokine production via the TLR2 and TLR4 pathway in cumulus cells of ovulated COCs, which may enhance fertilization. Development. 2008;135(11):2001-11.

80. Rolls A, Shechter R, London A, Ziv Y, Ronen A, Levy R, et al. Toll-like receptors modulate adult hippocampal neurogenesis. Nat Cell Biol. 2007;9(9):1081-8.

81. Okun E, Griffioen K, Barak B, Roberts NJ, Castro K, Pita MA, et al. Toll-like receptor 3 inhibits memory retention and constrains adult hippocampal neurogenesis. Proc Natl Acad Sci U S A. 2010;107(35):15625-30.

82. Kawamoto EM, Cutler RG, Rothman SM, Mattson MP, Camandola S. TLR4-dependent metabolic changes are associated with cognitive impairment in an animal model of type 1 diabetes. Biochem Biophys Res Commun. 2014;443(2):731-7.

83. Shi H, Kokoeva MV, Inouye K, Tzameli I, Yin H, Flier JS. TLR4 links innate immunity and fatty acid-induced insulin resistance. J Clin Invest. 2006;116(11):3015-25. 
84. Poggi M, Bastelica D, Gual P, Iglesias MA, Gremeaux T, Knauf C, et al. C3H/HeJ mice carrying a toll-like receptor 4 mutation are protected against the development of insulin resistance in white adipose tissue in response to a high-fat diet. Diabetologia. 2007;50(6):1267-76.

85. Tsukumo DM, Carvalho-Filho MA, Carvalheira JB, Prada PO, Hirabara SM, Schenka AA, et al. Loss-of-function mutation in Toll-like receptor 4 prevents diet-induced obesity and insulin resistance. Diabetes. 2007;56(8):1986-98.

86. Kim F, Pham M, Luttrell I, Bannerman DD, Tupper J, Thaler J, et al. Toll-like receptor-4 mediates vascular inflammation and insulin resistance in diet-induced obesity. Circ Res. 2007;100(11):1589-96.

87. Staiger H, Staiger K, Stefan N, Wahl HG, Machicao F, Kellerer M, et al. Palmitate-induced interleukin-6 expression in human coronary artery endothelial cells. Diabetes. 2004;53(12):3209-16.

88. Senn JJ. Toll-like receptor-2 is essential for the development of palmitate-induced insulin resistance in myotubes. J Biol Chem. 2006;281(37):26865-75.

89. Nguyen MT, Favelyukis S, Nguyen AK, Reichart D, Scott PA, Jenn A, et al. A subpopulation of macrophages infiltrates hypertrophic adipose tissue and is activated by free fatty acids via Toll-like receptors 2 and 4 and JNK-dependent pathways. J Biol Chem. 2007;282(48):35279-92.

90. Schaeffler A, Gross P, Buettner R, Bollheimer C, Buechler C, Neumeier M, et al. Fatty acidinduced induction of Toll-like receptor-4/nuclear factor-kappaB pathway in adipocytes links nutritional signalling with innate immunity. Immunology. 2009;126(2):233-45.

91. Reyna SM, Ghosh S, Tantiwong P, Meka CS, Eagan P, Jenkinson CP, et al. Elevated toll-like receptor 4 expression and signaling in muscle from insulin-resistant subjects. Diabetes. 2008;57(10):2595-602.

92. Cani PD, Delzenne NM. Interplay between obesity and associated metabolic disorders: new insights into the gut microbiota. Curr Opin Pharmacol. 2009;9(6):737-43.

93. Turnbaugh PJ, Ley RE, Mahowald MA, Magrini V, Mardis ER, Gordon JI. An obesityassociated gut microbiome with increased capacity for energy harvest. Nature. 2006;444(7122):102731.

94. Cani PD, Amar J, Iglesias MA, Poggi M, Knauf C, Bastelica D, et al. Metabolic endotoxemia initiates obesity and insulin resistance. Diabetes. 2007;56(7):1761-72.

95. De Souza CT, Araujo EP, Bordin S, Ashimine R, Zollner RL, Boschero AC, et al. Consumption of a fat-rich diet activates a proinflammatory response and induces insulin resistance in the hypothalamus. Endocrinology. 2005;146(10):4192-9.

96. Kleinridders A, Schenten D, Konner AC, Belgardt BF, Mauer J, Okamura T, et al. MyD88 signaling in the CNS is required for development of fatty acid-induced leptin resistance and dietinduced obesity. Cell Metab. 2009;10(4):249-59.

97. Posey KA, Clegg DJ, Printz RL, Byun J, Morton GJ, Vivekanandan-Giri A, et al. Hypothalamic proinflammatory lipid accumulation, inflammation, and insulin resistance in rats fed a high-fat diet. Am J Physiol Endocrinol Metab. 2009;296(5):E1003-12.

98. Milanski M, Degasperi G, Coope A, Morari J, Denis R, Cintra DE, et al. Saturated fatty acids produce an inflammatory response predominantly through the activation of TLR4 signaling in hypothalamus: implications for the pathogenesis of obesity. J Neurosci. 2009;29(2):359-70. 
99. Grassi G, Seravalle G, Colombo M, Bolla G, Cattaneo BM, Cavagnini F, et al. Body weight reduction, sympathetic nerve traffic, and arterial baroreflex in obese normotensive humans. Circulation. 1998;97(20):2037-42.

100. Lane MA, Ball SS, Ingram DK, Cutler RG, Engel J, Read V, et al. Diet restriction in rhesus monkeys lowers fasting and glucose-stimulated glucoregulatory end points. Am J Physiol. 1995;268(5 Pt 1):E941-8.

101. Anson RM, Guo Z, de Cabo R, Iyun T, Rios M, Hagepanos A, et al. Intermittent fasting dissociates beneficial effects of dietary restriction on glucose metabolism and neuronal resistance to injury from calorie intake. Proc Natl Acad Sci U S A. 2003;100(10):6216-20.

102. Mraz M, Lacinova Z, Drapalova J, Haluzikova D, Horinek A, Matoulek M, et al. The effect of very-low-calorie diet on mRNA expression of inflammation-related genes in subcutaneous adipose tissue and peripheral monocytes of obese patients with type 2 diabetes mellitus. J Clin Endocrinol Metab. 2011;96(4):E606-13.

103. Gill R, Tsung A, Billiar T. Linking oxidative stress to inflammation: Toll-like receptors. Free Radic Biol Med. 2010;48(9):1121-32.

104. Vabulas RM, Ahmad-Nejad P, Ghose S, Kirschning CJ, Issels RD, Wagner H. HSP70 as endogenous stimulus of the Toll/interleukin-1 receptor signal pathway. $J$ Biol Chem. 2002;277(17):15107-12.

105. Lee KM, Yeo M, Choue JS, Jin JH, Park SJ, Cheong JY, et al. Protective mechanism of epigallocatechin-3-gallate against Helicobacter pylori-induced gastric epithelial cytotoxicity via the blockage of TLR-4 signaling. Helicobacter. 2004;9(6):632-42.

106. Deva R, Shankaranarayanan P, Ciccoli R, Nigam S. Candida albicans induces selectively transcriptional activation of cyclooxygenase-2 in HeLa cells: pivotal roles of Toll-like receptors, p38 mitogen-activated protein kinase, and NF-kappa B. J Immunol. 2003;171(6):3047-55.

107. Kaltschmidt C, Kaltschmidt B, Neumann H, Wekerle H, Baeuerle PA. Constitutive NF-kappa B activity in neurons. Mol Cell Biol. 1994;14(6):3981-92.

108. Hoffmann A, Baltimore D. Circuitry of nuclear factor kappaB signaling. Immunol Rev. 2006;210:171-86.

109. Mattson MP, Meffert MK. Roles for NF-kappaB in nerve cell survival, plasticity, and disease. Cell Death Differ. 2006;13(5):852-60.

110. Ghosh S, May MJ, Kopp EB. NF-kappa B and Rel proteins: evolutionarily conserved mediators of immune responses. Annu Rev Immunol. 1998;16:225-60.

111. Woronicz JD, Gao X, Cao Z, Rothe M, Goeddel DV. IkappaB kinase-beta: NF-kappaB activation and complex formation with IkappaB kinase-alpha and NIK. Science. 1997;278(5339):8669.

112. Mercurio F, Zhu H, Murray BW, Shevchenko A, Bennett BL, Li J, et al. IKK-1 and IKK-2: cytokine-activated IkappaB kinases essential for NF-kappaB activation. Science. 1997;278(5339):8606.

113. Zandi E, Rothwarf DM, Delhase M, Hayakawa M, Karin M. The IkappaB kinase complex (IKK) contains two kinase subunits, IKKalpha and IKKbeta, necessary for IkappaB phosphorylation and NF-kappaB activation. Cell. 1997;91(2):243-52. 
114. DiDonato JA, Hayakawa M, Rothwarf DM, Zandi E, Karin M. A cytokine-responsive IkappaB kinase that activates the transcription factor NF-kappaB. Nature. 1997;388(6642):548-54.

115. Yamaoka S, Courtois G, Bessia C, Whiteside ST, Weil R, Agou F, et al. Complementation cloning of NEMO, a component of the IkappaB kinase complex essential for NF-kappaB activation. Cell. 1998;93(7):1231-40.

116. Rothwarf DM, Zandi E, Natoli G, Karin M. IKK-gamma is an essential regulatory subunit of the IkappaB kinase complex. Nature. 1998;395(6699):297-300.

117. Ghosh S, Karin M. Missing pieces in the NF-kappaB puzzle. Cell. 2002;109 (Suppl):S81-96.

118. Meberg PJ, Kinney WR, Valcourt EG, Routtenberg A. Gene expression of the transcription factor NF-kappa B in hippocampus: Regulation by synaptic activity. Mol Brain Res. 1996;38(2):17990.

119. Mattson MP. NF-kappaB in the survival and plasticity of neurons. Neurochem Res. 2005;30(67):883-93.

120. Guerrini L, Blasi F, Denis-Donini S. Synaptic activation of NF-kappa B by glutamate in cerebellar granule neurons in vitro. Proc Natl Acad Sci U S A. 1995;92(20):9077-81.

121. Meffert MK, Chang JM, Wiltgen BJ, Fanselow MS, Baltimore D. NF-kappa B functions in synaptic signaling and behavior. Nat Neurosci. 2003;6(10):1072-8.

122. Mattson MP, Camandola S. NF-kappaB in neuronal plasticity and neurodegenerative disorders. J Clin Invest. 2001;107(3):247-54.

123. Reichardt LF. Neurotrophin-regulated signalling pathways. Philos Trans R Soc Lond B Biol Sci. 2006;361(1473):1545-64.

124. Manadas BJ, Melo CV, Gomes JR, Duarte CB. Neurotrophin signaling and cell survival. In: Malva JO, Rego AC, Cunha RA, Oliveira CR, editors. Interaction between neurons and glia in aging and disease: Springer US; 2007. p. 137-72.

125. Zhang DD, Lo SC, Cross JV, Templeton DJ, Hannink M. Keap1 is a redox-regulated substrate adaptor protein for a Cul3-dependent ubiquitin ligase complex. Mol Cell Biol. 2004;24(24):10941-53.

126. Hunot S, Brugg B, Ricard D, Michel PP, Muriel MP, Ruberg M, et al. Nuclear translocation of NF-kappaB is increased in dopaminergic neurons of patients with parkinson disease. Proc Natl Acad Sci U S A. 1997;94(14):7531-6.

127. Kaltschmidt B, Uherek M, Volk B, Baeuerle PA, Kaltschmidt C. Transcription factor NFkappaB is activated in primary neurons by amyloid beta peptides and in neurons surrounding early plaques from patients with Alzheimer disease. Proc Natl Acad Sci U S A. 1997;94(6):2642-7.

128. Chen J, Buchanan JB, Sparkman NL, Godbout JP, Freund GG, Johnson RW. Neuroinflammation and disruption in working memory in aged mice after acute stimulation of the peripheral innate immune system. Brain Behav Immun. 2008;22(3):301-11.

129. Shaw KN, Commins S, O'Mara SM. Lipopolysaccharide causes deficits in spatial learning in the watermaze but not in BDNF expression in the rat dentate gyrus. Behav Brain Res. 2001;124(1):4754. 
130. Sparkman NL, Buchanan JB, Heyen JR, Chen J, Beverly JL, Johnson RW. Interleukin-6 facilitates lipopolysaccharide-induced disruption in working memory and expression of other proinflammatory cytokines in hippocampal neuronal cell layers. J Neurosci. 2006;26(42):10709-16.

131. Takao T, Culp SG, Newton RC, De Souza EB. Type I interleukin-1 receptors in the mouse brain-endocrine-immune axis labelled with [125I]recombinant human interleukin-1 receptor antagonist. J Neuroimmunol. 1992;41(1):51-60.

132. Parnet P, Kelley KW, Bluthe RM, Dantzer R. Expression and regulation of interleukin-1 receptors in the brain. Role in cytokines-induced sickness behavior. J Neuroimmunol. 2002;125(12):5-14.

133. Camandola S, Mattson MP. NF-kappa B as a therapeutic target in neurodegenerative diseases. Expert Opin Ther Targets. 2007;11(2):123-32.

134. O'Neill LA, Kaltschmidt C. NF-kappa B: a crucial transcription factor for glial and neuronal cell function. Trends Neurosci. 1997;20(6):252-8.

135. Tang SC, Lathia JD, Selvaraj PK, Jo DG, Mughal MR, Cheng A, et al. Toll-like receptor-4 mediates neuronal apoptosis induced by amyloid beta-peptide and the membrane lipid peroxidation product 4-hydroxynonenal. Exp Neurol. 2008;213(1):114-21.

136. Benito E, Barco A. CREB's control of intrinsic and synaptic plasticity: implications for CREBdependent memory models. Trends Neurosci. 2010;33(5):230-40.

137. Sakamoto K, Karelina K, Obrietan K. CREB: a multifaceted regulator of neuronal plasticity and protection. J Neurochem. 2011;116(1):1-9.

138. Lonze BE, Ginty DD. Function and regulation of CREB family transcription factors in the nervous system. Neuron. 2002;35(4):605-23.

139. Shaywitz AJ, Greenberg ME. CREB: a stimulus-induced transcription factor activated by a diverse array of extracellular signals. Annu Rev Biochem. 1999;68:821-61.

140. Pugazhenthi S, Boras T, O'Connor D, Meintzer MK, Heidenreich KA, Reusch JE. Insulin-like growth factor I-mediated activation of the transcription factor cAMP response element-binding protein in PC12 cells. Involvement of p38 mitogen-activated protein kinase-mediated pathway. J Biol Chem. 1999;274(5):2829-37.

141. Silva AJ, Kogan JH, Frankland PW, Kida S. CREB and memory. Annu Rev Neurosci. 1998;21:127-48.

142. Bozon B, Kelly A, Josselyn SA, Silva AJ, Davis S, Laroche S. MAPK, CREB and zif268 are all required for the consolidation of recognition memory. Philos Trans R Soc Lond B Biol Sci. 2003;358(1432):805-14.

143. Guzowski JF, McGaugh JL. Antisense oligodeoxynucleotide-mediated disruption of hippocampal cAMP response element binding protein levels impairs consolidation of memory for water maze training. Proc Natl Acad Sci U S A. 1997;94(6):2693-8.

144. Porte Y, Buhot MC, Mons N. Alteration of CREB phosphorylation and spatial memory deficits in aged 129T2/Sv mice. Neurobiol Aging. 2008;29(10):1533-46.

145. Calkins MJ, Johnson DA, Townsend JA, Vargas MR, Dowell JA, Williamson TP, et al. The Nrf2/ARE pathway as a potential therapeutic target in neurodegenerative disease. Antioxid Redox Signal. 2009;11(3):497-508. 
146. Kensler TW, Wakabayashi N, Biswal S. Cell survival responses to environmental stresses via the Keap1-Nrf2-ARE pathway. Annu Rev Pharmacol Toxicol. 2007;47:89-116.

147. Kobayashi M, Yamamoto M. Nrf2-Keap1 regulation of cellular defense mechanisms against electrophiles and reactive oxygen species. Adv Enzyme Regul. 2006;46:113-40.

148. Sykiotis GP, Bohmann D. Stress-activated cap'n'collar transcription factors in aging and human disease. Sci Signal. 2010;3(112):re3.

149. Lee JM, Li J, Johnson DA, Stein TD, Kraft AD, Calkins MJ, et al. Nrf2, a multi-organ protector? FASEB J. 2005;19(9):1061-6.

150. Tenhunen R, Marver HS, Schmid R. The enzymatic conversion of heme to bilirubin by microsomal heme oxygenase. Proc Natl Acad Sci U S A. 1968;61(2):748-55.

151. Ryter SW, Alam J, Choi AM. Heme oxygenase-1/carbon monoxide: from basic science to therapeutic applications. Physiol Rev. 2006;86(2):583-650.

152. Maines MD. The heme oxygenase system: a regulator of second messenger gases. Annu Rev Pharmacol Toxicol. 1997;37:517-54.

153. Stocker R. Antioxidant activities of bile pigments. Antioxid Redox Signal. 2004;6(5):841-9.

154. Kapitulnik J, Maines MD. Pleiotropic functions of biliverdin reductase: cellular signaling and generation of cytoprotective and cytotoxic bilirubin. Trends Pharmacol Sci. 2009;30(3):129-37.

155. Shih PH, Yen GC. Differential expressions of antioxidant status in aging rats: the role of transcriptional factor Nrf2 and MAPK signaling pathway. Biogerontology. 2007;8(2):71-80.

156. Suh JH, Shenvi SV, Dixon BM, Liu H, Jaiswal AK, Liu RM, et al. Decline in transcriptional activity of Nrf2 causes age-related loss of glutathione synthesis, which is reversible with lipoic acid. Proc Natl Acad Sci U S A. 2004;101(10):3381-6.

157. Thimmulappa RK, Lee H, Rangasamy T, Reddy SP, Yamamoto M, Kensler TW, et al. Nrf2 is a critical regulator of the innate immune response and survival during experimental sepsis. J Clin Invest. 2006;116(4):984-95.

158. Nagai N, Thimmulappa RK, Cano M, Fujihara M, Izumi-Nagai K, Kong X, et al. Nrf2 is a critical modulator of the innate immune response in a model of uveitis. Free Radic Biol Med. 2009;47(3):300-6.

159. Innamorato NG, Rojo AI, Garcia-Yague AJ, Yamamoto M, de Ceballos ML, Cuadrado A. The transcription factor $\mathrm{Nrf2}$ is a therapeutic target against brain inflammation. $\mathrm{J}$ Immunol. 2008;181(1):680-9.

160. Thimmulappa RK, Scollick C, Traore K, Yates M, Trush MA, Liby KT, et al. Nrf2-dependent protection from LPS induced inflammatory response and mortality by CDDO-Imidazolide. Biochem Biophys Res Commun. 2006;351(4):883-9.

161. Kaestner KH, Knochel W, Martinez DE. Unified nomenclature for the winged helix/forkhead transcription factors. Genes Dev. 2000;14(2):142-6.

162. Storz P. Forkhead homeobox type $\mathrm{O}$ transcription factors in the responses to oxidative stress. Antioxid Redox Signal. 2011;14(4):593-605. 
163. Coffer P. OutFOXing the grim reaper: novel mechanisms regulating longevity by forkhead transcription factors. Sci STKE. 2003;2003(201):PE39.

164. Furukawa-Hibi Y, Yoshida-Araki K, Ohta T, Ikeda K, Motoyama N. FOXO forkhead transcription factors induce $\mathrm{G}(2)-\mathrm{M}$ checkpoint in response to oxidative stress. J Biol Chem. 2002;277(30):26729-32.

165. van der Horst A, Tertoolen LG, de Vries-Smits LM, Frye RA, Medema RH, Burgering BM. FOXO4 is acetylated upon peroxide stress and deacetylated by the longevity protein hSir2(SIRT1). J Biol Chem. 2004;279(28):28873-9.

166. Sonntag WE, Lynch CD, Cefalu WT, Ingram RL, Bennett SA, Thornton PL, et al. Pleiotropic effects of growth hormone and insulin-like growth factor (IGF)-1 on biological aging: inferences from moderate caloric-restricted animals. J Gerontol A Biol Sci Med Sci. 1999;54(12):B521-38.

167. Al-Regaiey KA, Masternak MM, Bonkowski M, Sun L, Bartke A. Long-lived growth hormone receptor knockout mice: interaction of reduced insulin-like growth factor $\mathrm{i} /$ insulin signaling and caloric restriction. Endocrinology. 2005;146(2):851-60.

168. Argentino DP, Dominici FP, Munoz MC, Al-Regaiey K, Bartke A, Turyn D. Effects of longterm caloric restriction on glucose homeostasis and on the first steps of the insulin signaling system in skeletal muscle of normal and Ames dwarf (Prop1df/Prop1df) mice. Exp Gerontol. 2005;40(1-2):2735 .

169. Imae $\mathrm{M}, \mathrm{Fu} \mathrm{Z}$, Yoshida $\mathrm{A}$, Noguchi $\mathrm{T}$, Kato H. Nutritional and hormonal factors control the gene expression of FoxOs, the mammalian homologues of DAF-16. J Mol Endocrinol. 2003;30(2):253-62.

170. Furuyama T, Kitayama K, Yamashita H, Mori N. Forkhead transcription factor FOXO1 (FKHR)-dependent induction of PDK4 gene expression in skeletal muscle during energy deprivation. Biochem J. 2003;375(Pt 2):365-71.

171. Tsuchiya T, Dhahbi JM, Cui X, Mote PL, Bartke A, Spindler SR. Additive regulation of hepatic gene expression by dwarfism and caloric restriction. Physiol Genomics. 2004;17(3):307-15.

172. Hayashi H, Yamaza H, Komatsu T, Park S, Chiba T, Higami Y, et al. Calorie restriction minimizes activation of insulin signaling in response to glucose: potential involvement of the growth hormone-insulin-like growth factor 1 axis. Exp Gerontol. 2008;43(9):827-32.

173. Kalaany NY, Sabatini DM. Tumours with PI3K activation are resistant to dietary restriction. Nature. 2009;458(7239):725-31.

174. Yamaza H, Komatsu T, Wakita S, Kijogi C, Park S, Hayashi H, et al. FoxO1 is involved in the antineoplastic effect of calorie restriction. Aging Cell. 2010;9(3):372-82.

175. Becker T, Loch G, Beyer M, Zinke I, Aschenbrenner AC, Carrera P, et al. FOXO-dependent regulation of innate immune homeostasis. Nature. 2010;463(7279):369-73.

176. Rong Y, Baudry M. Seizure activity results in a rapid induction of nuclear factor-kappa B in adult but not juvenile rat limbic structures. J Neurochem. 1996;67(2):662-8.

177. Laemmli UK. Cleavage of structural proteins during the assembly of the head of bacteriophage T4. Nature. 1970;227(5259):680-5.

178. Bradford MM. A rapid and sensitive method for the quantitation of microgram quantities of protein utilizing the principle of protein-dye binding. Anal Biochem. 1976;72:248-54. 
179. Pfaffl MW, Horgan GW, Dempfle L. Relative expression software tool (REST) for group-wise comparison and statistical analysis of relative expression results in real-time PCR. Nucleic Acids Res. 2002;30(9):e36.

180. Andrikopoulos S, Blair AR, Deluca N, Fam BC, Proietto J. Evaluating the glucose tolerance test in mice. Am J Physiol Endocrinol Metab. 2008;295(6):E1323-32.

181. Kawamoto E, Scavone C, Mattson M, Camandola S. Curcumin requires tumor necrosis factor $\alpha$ signaling to alleviate cognitive impairment elicited by lipopolysaccharide. Neurosignals. 2013;21(12):75-88.

182. Texel SJ, Camandola S, Ladenheim B, Rothman SM, Mughal MR, Unger EL, et al. Ceruloplasmin deficiency results in an anxiety phenotype involving deficits in hippocampal iron, serotonin, and BDNF. J Neurochem. 2012;120(1):125-34.

183. Steru L, Chermat R, Thierry B, Simon P. The tail suspension test: a new method for screening antidepressants in mice. Psychopharmacology (Berl). 1985;85(3):367-70.

184. Pillon NJ, Croze ML, Vella RE, Soulere L, Lagarde M, Soulage CO. The lipid peroxidation byproduct 4-hydroxy-2-nonenal (4-HNE) induces insulin resistance in skeletal muscle through both carbonyl and oxidative stress. Endocrinology. 2012;153(5):2099-111.

185. D'Hooge R, De Deyn PP. Applications of the Morris water maze in the study of learning and memory. Brain Res Brain Res Rev. 2001;36(1):60-90.

186. Burwell RD, Saddoris MP, Bucci DJ, Wiig KA. Corticohippocampal contributions to spatial and contextual learning. J Neurosci. 2004;24(15):3826-36.

187. Trinchieri G, Sher A. Cooperation of Toll-like receptor signals in innate immune defence. Nat Rev Immunol. 2007;7(3):179-90.

188. Helenius M, Hanninen M, Lehtinen SK, Salminen A. Aging-induced up-regulation of nuclear binding activities of oxidative stress responsive NF-kB transcription factor in mouse cardiac muscle. $\mathrm{J}$ Mol Cell Cardiol. 1996;28(3):487-98.

189. Helenius M, Hanninen M, Lehtinen SK, Salminen A. Changes associated with aging and replicative senescence in the regulation of transcription factor nuclear factor-kappa B. Biochem J. 1996;318 ( Pt 2):603-8.

190. Murphy TL, Cleveland MG, Kulesza P, Magram J, Murphy KM. Regulation of interleukin 12 p40 expression through an NF-kappa B half-site. Mol Cell Biol. 1995;15(10):5258-67.

191. Washizu J, Nishimura H, Nakamura N, Nimura Y, Yoshikai Y. The NF-kappaB binding site is essential for transcriptional activation of the IL-15 gene. Immunogenetics. 1998;48(1):1-7.

192. Nelson PJ, Ortiz BD, Pattison JM, Krensky AM. Identification of a novel regulatory region critical for expression of the RANTES chemokine in activated $\mathrm{T}$ lymphocytes. $\mathrm{J}$ Immunol. 1996;157(3):1139-48.

193. Hunter CA, Chizzonite R, Remington JS. IL-1 beta is required for IL-12 to induce production of IFN-gamma by NK cells. A role for IL-1 beta in the T cell-independent mechanism of resistance against intracellular pathogens. J Immunol. 1995;155(9):4347-54.

194. Suschek C, Rothe H, Fehsel K, Enczmann J, Kolb-Bachofen V. Induction of a macrophage-like nitric oxide synthase in cultured rat aortic endothelial cells. IL-1 beta-mediated induction regulated by tumor necrosis factor-alpha and IFN-gamma. J Immunol. 1993;151(6):3283-91. 
195. Herrmann F, Cannistra SA, Lindemann A, Blohm D, Rambaldi A, Mertelsmann RH, et al. Functional consequences of monocyte IL-2 receptor expression. Induction of IL-1 beta secretion by IFN gamma and IL-2. J Immunol. 1989;142(1):139-43.

196. Ernfors P, Wetmore C, Olson L, Persson H. Identification of cells in rat brain and peripheral tissues expressing mRNA for members of the nerve growth factor family. Neuron. 1990;5(4):511-26.

197. Hofer M, Pagliusi SR, Hohn A, Leibrock J, Barde YA. Regional distribution of brain-derived neurotrophic factor mRNA in the adult mouse brain. EMBO J. 1990;9(8):2459-64.

198. Phillips HS, Hains JM, Laramee GR, Rosenthal A, Winslow JW. Widespread expression of BDNF but not NT3 by target areas of basal forebrain cholinergic neurons. Science. 1990;250(4978):290-4.

199. Pruunsild P, Sepp M, Orav E, Koppel I, Timmusk T. Identification of cis-elements and transcription factors regulating neuronal activity-dependent transcription of human BDNF gene. J Neurosci. 2011;31(9):3295-308.

200. Karpova NN, Lindholm JS, Kulesskaya N, Onishchenko N, Vahter M, Popova D, et al. TrkB overexpression in mice buffers against memory deficits and depression-like behavior but not all anxiety- and stress-related symptoms induced by developmental exposure to methylmercury. Front Behav Neurosci. 2014;8:315.

201. Hatcher H, Planalp R, Cho J, Torti FM, Torti SV. Curcumin: from ancient medicine to current clinical trials. Cell Mol Life Sci. 2008;65(11):1631-52.

202. Lipsky RH, Xu K, Zhu D, Kelly C, Terhakopian A, Novelli A, et al. Nuclear factor kappaB is a critical determinant in N-methyl-D-aspartate receptor-mediated neuroprotection. $\mathrm{J}$ Neurochem. 2001;78(2):254-64.

203. Kawamoto EM, Lepsch LB, Boaventura MF, Munhoz CD, Lima LS, Yshii LM, et al. Amyloid beta-peptide activates nuclear factor-kappaB through an N-methyl-D-aspartate signaling pathway in cultured cerebellar cells. J Neurosci Res. 2008;86(4):845-60.

204. Jiang X, Tian F, Mearow K, Okagaki P, Lipsky RH, Marini AM. The excitoprotective effect of $\mathrm{N}$-methyl-D-aspartate receptors is mediated by a brain-derived neurotrophic factor autocrine loop in cultured hippocampal neurons. J Neurochem. 2005;94(3):713-22.

205. Lepsch LB, Munhoz CD, Kawamoto EM, Yshii LM, Lima LS, Curi-Boaventura MF, et al. Cocaine induces cell death and activates the transcription nuclear factor kappa-B in PC12 cells. Mol Brain. 2009;2:3.

206. Kaltschmidt B, Ndiaye D, Korte M, Pothion S, Arbibe L, Prullage M, et al. NF-kappaB regulates spatial memory formation and synaptic plasticity through protein kinase A/CREB signaling. Mol Cell Biol. 2006;26(8):2936-46.

207. Tao X, Finkbeiner S, Arnold DB, Shaywitz AJ, Greenberg ME. Ca2+ influx regulates BDNF transcription by a CREB family transcription factor-dependent mechanism. Neuron. 1998;20(4):70926.

208. O'Keefe J. Do hippocampal pyramidal cells signal non-spatial as well as spatial information? Hippocampus. 1999;9(4):352-64.

209. Burgess N, Maguire EA, O'Keefe J. The human hippocampus and spatial and episodic memory. Neuron. 2002;35(4):625-41. 
210. Chen R, Lim JH, Jono H, Gu XX, Kim YS, Basbaum CB, et al. Nontypeable Haemophilus influenzae lipoprotein P6 induces MUC5AC mucin transcription via TLR2-TAK1-dependent p38 MAPK-AP1 and IKKbeta-IkappaBalpha-NF-kappaB signaling pathways. Biochem Biophys Res Commun. 2004;324(3):1087-94.

211. Doyle SL, O'Neill LA. Toll-like receptors: from the discovery of NFkappaB to new insights into transcriptional regulations in innate immunity. Biochem Pharmacol. 2006;72(9):1102-13.

212. Hoebe K, Jiang Z, Georgel P, Tabeta K, Janssen E, Du X, et al. TLR signaling pathways: opportunities for activation and blockade in pursuit of therapy. Curr Pharm Des. 2006;12(32):4123-34.

213. Krishnan J, Selvarajoo K, Tsuchiya M, Lee G, Choi S. Toll-like receptor signal transduction. Exp Mol Med. 2007;39(4):421-38.

214. Hess J, Angel P, Schorpp-Kistner M. AP-1 subunits: quarrel and harmony among siblings. J Cell Sci. 2004;117(Pt 25):5965-73.

215. Shaulian E, Karin M. AP-1 as a regulator of cell life and death. Nat Cell Biol. 2002;4(5):E1316.

216. Wagner EF, Eferl R. Fos/AP-1 proteins in bone and the immune system. Immunol Rev. 2005;208:126-40.

217. Martin M, Schifferle RE, Cuesta N, Vogel SN, Katz J, Michalek SM. Role of the phosphatidylinositol 3 kinase-Akt pathway in the regulation of IL-10 and IL-12 by Porphyromonas gingivalis lipopolysaccharide. J Immunol. 2003;171(2):717-25.

218. Mattson MP. Energy intake and exercise as determinants of brain health and vulnerability to injury and disease. Cell Metab. 2012;16(6):706-22.

219. Zhang DD. Mechanistic studies of the Nrf2-Keap1 signaling pathway. Drug Metab Rev. 2006;38(4):769-89.

220. Li W, Kong AN. Molecular mechanisms of Nrf2-mediated antioxidant response. Mol Carcinog. 2009;48(2):91-104.

221. Kaspar JW, Niture SK, Jaiswal AK. Nrf2:INrf2 (Keap1) signaling in oxidative stress. Free Radic Biol Med. 2009;47(9):1304-9.

222. Kobayashi A, Kang MI, Okawa H, Ohtsuji M, Zenke Y, Chiba T, et al. Oxidative stress sensor Keap1 functions as an adaptor for Cul3-based E3 ligase to regulate proteasomal degradation of Nrf2. Mol Cell Biol. 2004;24(16):7130-9.

223. Motohashi H, Yamamoto M. Nrf2-Keap1 defines a physiologically important stress response mechanism. Trends Mol Med. 2004;10(11):549-57.

224. Pearson KJ, Lewis KN, Price NL, Chang JW, Perez E, Cascajo MV, et al. Nrf2 mediates cancer protection but not prolongevity induced by caloric restriction. Proc Natl Acad Sci U S A. 2008;105(7):2325-30.

225. Gross L, Dreyfuss Y. Reduction in the incidence of radiation-induced tumors in rats after restriction of food intake. Proc Natl Acad Sci U S A. 1984;81(23):7596-8.

226. Weindruch R, Walford RL, Fligiel S, Guthrie D. The retardation of aging in mice by dietary restriction: longevity, cancer, immunity and lifetime energy intake. J Nutr. 1986;116(4):641-54. 
227. Poss KD, Tonegawa S. Reduced stress defense in heme oxygenase 1-deficient cells. Proc Natl Acad Sci U S A. 1997;94(20):10925-30.

228. Yachie A, Niida Y, Wada T, Igarashi N, Kaneda H, Toma T, et al. Oxidative stress causes enhanced endothelial cell injury in human heme oxygenase-1 deficiency. J Clin Invest. 1999;103(1):129-35.

229. Park C, Cho IH, Kim D, Jo EK, Choi SY, Oh SB, et al. Toll-like receptor 2 contributes to glial cell activation and heme oxygenase-1 expression in traumatic brain injury. Neurosci Lett. 2008;431(2):123-8.

230. Tran H, Brunet A, Grenier JM, Datta SR, Fornace AJ, Jr., DiStefano PS, et al. DNA repair pathway stimulated by the forkhead transcription factor FOXO3a through the Gadd45 protein. Science. 2002;296(5567):530-4.

231. Nakae J, Kitamura T, Silver DL, Accili D. The forkhead transcription factor Foxo1 (Fkhr) confers insulin sensitivity onto glucose-6-phosphatase expression. J Clin Invest. 2001;108(9):1359-67.

232. Yeagley D, Guo S, Unterman T, Quinn PG. Gene- and activation-specific mechanisms for insulin inhibition of basal and glucocorticoid-induced insulin-like growth factor binding protein-1 and phosphoenolpyruvate carboxykinase transcription. Roles of forkhead and insulin response sequences. J Biol Chem. 2001;276(36):33705-10.

233. Kops GJ, Dansen TB, Polderman PE, Saarloos I, Wirtz KW, Coffer PJ, et al. Forkhead transcription factor FOXO3a protects quiescent cells from oxidative stress. Nature. 2002;419(6904):316-21.

234. Furukawa-Hibi Y, Kobayashi Y, Chen C, Motoyama N. FOXO transcription factors in cellcycle regulation and the response to oxidative stress. Antioxid Redox Signal. 2005;7(5-6):752-60.

235. van der Horst A, Burgering BM. Stressing the role of FoxO proteins in lifespan and disease. Nat Rev Mol Cell Biol. 2007;8(6):440-50.

236. Daitoku H, Yamagata K, Matsuzaki H, Hatta M, Fukamizu A. Regulation of PGC-1 promoter activity by protein kinase B and the forkhead transcription factor FKHR. Diabetes. 2003;52(3):642-9.

237. Barthel A, Schmoll D, Unterman TG. FoxO proteins in insulin action and metabolism. Trends Endocrinol Metab. 2005;16(4):183-9.

238. Levine B, Abrams J. p53: The Janus of autophagy? Nat Cell Biol. 2008;10(6):637-9.

239. Rubinsztein DC, Marino G, Kroemer G. Autophagy and aging. Cell. 2011;146(5):682-95.

240. Inoki K, Kim J, Guan KL. AMPK and mTOR in cellular energy homeostasis and drug targets. Annu Rev Pharmacol Toxicol. 2012;52:381-400.

241. Wilkinson JE, Burmeister L, Brooks SV, Chan CC, Friedline S, Harrison DE, et al. Rapamycin slows aging in mice. Aging Cell. 2012;11(4):675-82.

242. Boland B, Kumar A, Lee S, Platt FM, Wegiel J, Yu WH, et al. Autophagy induction and autophagosome clearance in neurons: relationship to autophagic pathology in Alzheimer's disease. J Neurosci. 2008;28(27):6926-37.

243. Carloni S, Girelli S, Scopa C, Buonocore G, Longini M, Balduini W. Activation of autophagy and Akt/CREB signaling play an equivalent role in the neuroprotective effect of rapamycin in neonatal hypoxia-ischemia. Autophagy. 2010;6(3):366-77. 
244. Spilman P, Podlutskaya N, Hart MJ, Debnath J, Gorostiza O, Bredesen D, et al. Inhibition of mTOR by rapamycin abolishes cognitive deficits and reduces amyloid-beta levels in a mouse model of Alzheimer's disease. PLoS One. 2010;5(4):e9979.

245. Halloran J, Hussong SA, Burbank R, Podlutskaya N, Fischer KE, Sloane LB, et al. Chronic inhibition of mammalian target of rapamycin by rapamycin modulates cognitive and non-cognitive components of behavior throughout lifespan in mice. Neuroscience. 2012;223:102-13.

246. Chotechuang N, Azzout-Marniche D, Bos C, Chaumontet C, Gaudichon C, Tome D. Downregulation of the ubiquitin-proteasome proteolysis system by amino acids and insulin involves the adenosine monophosphate-activated protein kinase and mammalian target of rapamycin pathways in rat hepatocytes. Amino Acids. 2011;41(2):457-68.

247. Mark RJ, Hensley K, Butterfield DA, Mattson MP. Amyloid beta-peptide impairs ion-motive ATPase activities: evidence for a role in loss of neuronal $\mathrm{Ca} 2+$ homeostasis and cell death. J Neurosci. 1995;15(9):6239-49.

248. Kruman I, Bruce-Keller AJ, Bredesen D, Waeg G, Mattson MP. Evidence that 4hydroxynonenal mediates oxidative stress-induced neuronal apoptosis. J Neurosci. 1997;17(13):5089100 .

249. Peng ZF, Koh CH, Li QT, Manikandan J, Melendez AJ, Tang SY, et al. Deciphering the mechanism of HNE-induced apoptosis in cultured murine cortical neurons: transcriptional responses and cellular pathways. Neuropharmacology. 2007;53(5):687-98.

250. Jacobs WB, Kaplan DR, Miller FD. The p53 family in nervous system development and disease. J Neurochem. 2006;97(6):1571-84.

251. Mattson MP. Metal-catalyzed disruption of membrane protein and lipid signaling in the pathogenesis of neurodegenerative disorders. Ann N Y Acad Sci. 2004;1012:37-50.

252. Arguelles S, Camandola S, Hutchison ER, Cutler RG, Ayala A, Mattson MP. Molecular control of the amount, subcellular location, and activity state of translation elongation factor 2 in neurons experiencing stress. Free Radic Biol Med. 2013;61:61-71.

253. Facchinetti F, Dawson VL, Dawson TM. Free radicals as mediators of neuronal injury. Cell Mol Neurobiol. 1998;18(6):667-82.

254. Halliwell B, Gutteridge JMC. Free Radical in Biology and Medicine. fourth ed. New York: Oxford University Press; 2007.

255. Stavridis JC. Oxidation: The Cornerstone of Carcinogenesis: Oxidation and Tabacco Smoke Carcinogenesis. A Relationship Between Cause and Effect: Springer; 2007.

256. Ito $\mathrm{Y}$, Arakawa M, Ishige $\mathrm{K}$, Fukuda $\mathrm{H}$. Comparative study of survival signal withdrawal- and 4-hydroxynonenal-induced cell death in cerebellar granule cells. Neurosci Res. 1999;35(4):321-7.

257. Zhang L, Jope RS. Oxidative stress differentially modulates phosphorylation of ERK, p38 and CREB induced by NGF or EGF in PC12 cells. Neurobiol Aging. 1999;20(3):271-8.

258. Pugazhenthi S, Nesterova A, Jambal P, Audesirk G, Kern M, Cabell L, et al. Oxidative stressmediated down-regulation of bcl-2 promoter in hippocampal neurons. J Neurochem. 2003;84(5):98296.

259. See V, Loeffler JP. Oxidative stress induces neuronal death by recruiting a protease and phosphatase-gated mechanism. J Biol Chem. 2001;276(37):35049-59. 
260. Hamilton KL, Mbai FN, Gupta S, Knowlton AA. Estrogen, heat shock proteins, and NFkappaB in human vascular endothelium. Arterioscler Thromb Vasc Biol. 2004;24(9):1628-33.

261. Hamilton KL, Gupta S, Knowlton AA. Estrogen and regulation of heat shock protein expression in female cardiomyocytes: cross-talk with NF kappa B signaling. J Mol Cell Cardiol. 2004;36(4):57784.

262. Ammirante M, Rosati A, Gentilella A, Festa M, Petrella A, Marzullo L, et al. The activity of hsp90 alpha promoter is regulated by NF-kappa B transcription factors. Oncogene. 2008;27(8):1175-8.

263. Morimoto RI, Santoro MG. Stress-inducible responses and heat shock proteins: new pharmacologic targets for cytoprotection. Nat Biotechnol. 1998;16(9):833-8.

264. Pratt WB, Morishima Y, Peng HM, Osawa Y. Proposal for a role of the Hsp90/Hsp70-based chaperone machinery in making triage decisions when proteins undergo oxidative and toxic damage. Exp Biol Med (Maywood). 2010;235(3):278-89.

265. Bienemann AS, Lee YB, Howarth J, Uney JB. Hsp70 suppresses apoptosis in sympathetic neurones by preventing the activation of c-Jun. J Neurochem. 2008;104(1):271-8.

266. Chaudhury S, Welch TR, Blagg BS. Hsp90 as a target for drug development. ChemMedChem. 2006;1(12):1331-40.

267. Tomlinson DR, Gardiner NJ. Glucose neurotoxicity. Nat Rev Neurosci. 2008;9(1):36-45.

268. Varady KA, Hellerstein MK. Alternate-day fasting and chronic disease prevention: a review of human and animal trials. Am J Clin Nutr. 2007;86(1):7-13.

269. Cerqueira FM, da Cunha FM, Caldeira da Silva CC, Chausse B, Romano RL, Garcia CC, et al. Long-term intermittent feeding, but not caloric restriction, leads to redox imbalance, insulin receptor nitration, and glucose intolerance. Free Radic Biol Med. 2011;51(7):1454-60.

270. Pedersen CR, Hagemann I, Bock T, Buschard K. Intermittent feeding and fasting reduces diabetes incidence in BB rats. Autoimmunity. 1999;30(4):243-50.

271. Mager DE, Wan R, Brown M, Cheng A, Wareski P, Abernethy DR, et al. Caloric restriction and intermittent fasting alter spectral measures of heart rate and blood pressure variability in rats. FASEB J. 2006;20(6):631-7.

272. van Ommen B, Keijer J, Heil SG, Kaput J. Challenging homeostasis to define biomarkers for nutrition related health. Mol Nutr Food Res. 2009;53(7):795-804.

273. Pellis L, van Erk MJ, van Ommen B, Bakker GC, Hendriks HF, Cnubben NH, et al. Plasma metabolomics and proteomics profiling after a postprandial challenge reveal subtle diet effects on human metabolic status. Metabolomics. 2012;8(2):347-59.

274. Velloso LA, Folli F, Saad MJ. TLR4 at the Crossroads of Nutrients, Gut Microbiota, and Metabolic Inflammation. Endocr Rev. 2015;36(3):245-71.

275. Krizova E, Simek V. Influence of intermittent fasting and high-fat diet on morphological changes of the digestive system and on changes of lipid metabolism in the laboratory mouse. Physiol Res. 1996;45(2):145-51.

276. Krizova E, Simek V. Effect of intermittent feeding with high-fat diet on changes of glycogen, protein and fat content in liver and skeletal muscle in the laboratory mouse. Physiol Res. 1996;45(5):379-83. 
277. Heilbronn L, Smith SR, Ravussin E. Failure of fat cell proliferation, mitochondrial function and fat oxidation results in ectopic fat storage, insulin resistance and type II diabetes mellitus. Int J Obes Relat Metab Disord. 2004;28 Suppl 4:S12-21.

278. Liu TF, Vachharajani VT, Yoza BK, McCall CE. NAD+-dependent sirtuin 1 and 6 proteins coordinate a switch from glucose to fatty acid oxidation during the acute inflammatory response. $\mathrm{J}$ Biol Chem. 2012;287(31):25758-69.

279. O'Gorman E, Beutner G, Dolder M, Koretsky AP, Brdiczka D, Wallimann T. The role of creatine kinase in inhibition of mitochondrial permeability transition. FEBS Lett. 1997;414(2):253-7.

280. Xu CJ, Klunk WE, Kanfer JN, Xiong Q, Miller G, Pettegrew JW. Phosphocreatine-dependent glutamate uptake by synaptic vesicles. A comparison with atp-dependent glutamate uptake. J Biol Chem. 1996;271(23):13435-40.

281. Lawler JM, Barnes WS, Wu G, Song W, Demaree S. Direct antioxidant properties of creatine. Biochem Biophys Res Commun. 2002;290(1):47-52.

282. Bender A, Beckers J, Schneider I, Holter SM, Haack T, Ruthsatz T, et al. Creatine improves health and survival of mice. Neurobiol Aging. 2008;29(9):1404-11.

283. Matthews RT, Ferrante RJ, Klivenyi P, Yang L, Klein AM, Mueller G, et al. Creatine and cyclocreatine attenuate MPTP neurotoxicity. Exp Neurol. 1999;157(1):142-9.

284. Andreassen OA, Dedeoglu A, Ferrante RJ, Jenkins BG, Ferrante KL, Thomas M, et al. Creatine increase survival and delays motor symptoms in a transgenic animal model of Huntington's disease. Neurobiol Dis. 2001;8(3):479-91.

285. Maalouf M, Rho JM, Mattson MP. The neuroprotective properties of calorie restriction, the ketogenic diet, and ketone bodies. Brain Res Rev. 2009;59(2):293-315.

286. Salles A, Romano A, Freudenthal R. Synaptic NF-kappa B pathway in neuronal plasticity and memory. J Physiol Paris. 2014;108(4-6):256-62.

287. Freudenthal R, Romano A, Routtenberg A. Transcription factor NF-kappaB activation after in vivo perforant path LTP in mouse hippocampus. Hippocampus. 2004;14(6):677-83.

288. Marosi K, Mattson MP. BDNF mediates adaptive brain and body responses to energetic challenges. Trends Endocrinol Metab. 2014;25(2):89-98.

289. Urano S, Asai Y, Makabe S, Matsuo M, Izumiyama N, Ohtsubo K, et al. Oxidative injury of synapse and alteration of antioxidative defense systems in rats, and its prevention by vitamin $\mathrm{E}$. Eur $\mathrm{J}$ Biochem. 1997;245(1):64-70.

290. Urano S, Sato Y, Otonari T, Makabe S, Suzuki S, Ogata M, et al. Aging and oxidative stress in neurodegeneration. Biofactors. 1998;7(1-2):103-12.

291. Gold PE. The use of avoidance training in studies of modulation of memory storage. Behav Neural Biol. 1986;46(1):87-98.

292. Izquierdo I, Medina JH. Memory formation: the sequence of biochemical events in the hippocampus and its connection to activity in other brain structures. Neurobiol Learn Mem. 1997;68(3):285-316.

293. Bear MF, Connors BW, Paradiso MA. Neurociências: desvendando o sistema nervoso. $2^{\mathrm{a}}$ ed: Artmed; 2002. 
294. Quevedo J, Martins MR, Izquierdo I. Alterações Cerebrais e Memória. In: Demência e Transtornos Cognitivos em Idosos, cap. 1. RJ: Guanabara Koogan; 2006. 


\title{
ANEXOS
}

\section{Anexo A - Sequência do RNAm do gene Bdnf-I}

\author{
NM_007540.4 Mus musculus brain derived neurotrophic factor (Bdnf), transcript variant 1, \\ mRNA
}

TAAAGCAGTAGCCGGCTGGTGCAGAAAAGCAACAAGTTCCCCAGCGGTCTTCCCGCCCTAGCTTGACAAGGCGAAGGGTTTCT TACCTGGCGACAGGGAAATCTCCTGAGCCGAGCTCATCTTTGCCAGAGCCCCAGGTGTGACCTGAGCAGTGGGCAAAGGATCG GCGTGCAAATTGGATTATTTTTATGGGGGTACTCTGAAACTCCCTCACTTTCTCTGGGAACTTTTTGTGCTAGGGCTCAGTGA CAGGCGTTGAGAAAGCTGCTTCAGGAAACGCCCGCTATATAGCAGGGCAATTGGACAGTCATTGGTAACCTCGCTCATTCATT AGAATCACGTAAGAACTCAAAGGGAAACGTGTCTCTCAGAATGAGGGCGTTTGCGTAAATCTATAGGTTTTTCAACATCGATG CCAGTTGCTTTGTCTTCTGTAGTCGCCAAGGTGGATGAGAGTTGAAGCTTTGCGGATATTGCGAAGGGTTATTAGATTCATAA GTCACACCAAGTGGTGGGCGATCCACTGAGCAAAGCCGAACTTCTCACATGATGACTTCAAACAAGACACATTACCTTCCTGC ATCTGTTGGGGAGACAAGATTTTAAGACACTGAGTCTCCAGGACAGCAAAGCCACAATGTTCCACCAGGTGAGAAGAGTGATG АССАTCСTTTTCCTTACTATGGTTATTTCATACTTCGGTTGCATGAAGGCGGCGCCCATGAAAGAAGTAAACGTCCACGGACA AGGCAACTTGGCCTACCCAGGTGTGCGGACCCATGGGACTCTGGAGAGCGTGAATGGGCCCAGGGCAGGTTCGAGAGGTCTGA CGACGACATCACTGGCTGACACTTTTGAGCACGTCATCGAAGAGCTGCTGGATGAGGACCAGAAGGTTCGGCCCAACGAAGAA AACCATAAGGACGCGGACTTGTACACTTCCCGGGTGATGCTCAGCAGTCAAGTGCCTTTGGAGCCTCCTCTACTCTTTCTGCT GGAGGAATACAAAAATTACCTGGATGCCGCAAACATGTCTATGAGGGTTCGGCGCCACTCCGACCCTGCCCGCCGTGGGGAGC TGAGCGTGTGTGACAGTATTAGCGAGTGGGTCACAGCGGCAGATAAAAAGACTGCAGTGGACATGTCTGGCGGGACGGTCACA GTCCTAGAGAAAGTCCCGGTATCCAAAGGCCAACTGAAGCAGTATTTCTACGAGACCAAGTGTAATCCCATGGGTTACACCAA GGAAGGCTGCAGGGGCATAGACAAAAGGCACTGGAACTCGCAATGCCGAACTACCCAATCGTATGTTCGGGCCCTTACTATGG ATAGCAAAAAGAGAATTGGCTGGCGATTCATAAGGATAGACACTTCCTGTGTATGTACACTGACCATTAAAAGGGGAAGATAG TGGATTTATGTTGTATAGATTATATTGAGACAAAATTATCTATTTGTATATATACATAACAGGGTAAATTATTCAGTTAAGAA AAAATAATTTTATGAACTGCATGTATAAATGAAGTTTATACAGTACAGTGGTTCTACAATCTATTTATTGGACATATCCATGA CCTGAAAGGAAACAGTCATTTGCGCACAACTTTAAAAGTCTGCATTACATTCCTCGATAATGTTGTGGTTTGTTGCCGTTGCC AAGAATTGAAAACAAAAAGTTTAAAAAAAATAATAATAAATTGCATGCTGCTTTAATTGTGAATTGATAATAAACTGTCCCTC TTTCAGAAAACAGATTAAAAAAACAAAAAACAAAAAAAAAAAAACAAAAAACAAAAACAAAAATTGGAACCAAAACATTCCGT TTACATTTTAGACACTAAGTATCTTCGTTCTTGTTAGTACTCTGTTTTACTGCTTTCGACTTCTGATAGCGTTGGAATTAAAA CAATGTCAAGGTGCTGTTGTCATTGCTTTACTGGCGTAAGGGACGGGGAATGGGAGGGGTAGATTTCTGTTTGTTTTGTGTTT TATTTTGTTTGTTTGTTTGTTTTGTTTTTTAGTTCCACCCGGAGTAGGGATGGAGAAAATTTCTTCACTATCCATTCTGGTTG ATAAAGCGTTACATTTGTATGTTGTAAAGATGTTTGCAAAATCCAATCAGATGACTGGAAAACAAATAAAAATTAAGGCAACT GAATAAAATGCTCACACTCCACTGCCCATGATGTATCTCCCTGGTCCCCCTCAGCTCACTCTTCTGGCATGGGTCAGGGAAAA TTGCTTTTATTGGAAAGACCAGCATTTGTTCAAAGCATACTCTTTCCCTCCCTCCTCCCATTTTGGTCCCTTCTTTTTGTTTT GTTTTAAGAAAGAAAATTAAGTTGCGCGCTTTAAAATATTTTACTACTGCTACAAACAGATGAACAATGTGTGTCATTTTATG ACACTCATGGAAAACAGTGATTTTTTTTTACCCTAAAGAAAAACAAATAAAAATAACCCAAAATATTCTTTTTTTAAAAGGCA TAAATATTGGGTAAATTGTAATATGGCCTAACAGTGTTTGCAGATAAAAGTTATTGTATACACCCAGATACTTAGATAAGAGC AGGGATCCACACTGCCATTGAAATAGGACTGAATGGCCCTGCGGAGGCTAAGTGGAGCTGACATACTATTTCCTGGCAGTGCA GGAGGAATTTCTGAGTGGCCATCCTAAGGTCTAGGATGGAGGTGGGGAATGGTACTTGAGACATTCCTAAAGGAGGCTCGGAA GCACCCTTCAGAGCAGGCTCTGGAATGATGTGTCAAGTTGCTTAGGCCTTCTGCTTTAAGGCCTACATTACCTAACAGTGCTC AAGAGGTTCTCGATTGGAGAACCACACTCAAATCCATTTATAGCCTCATCCCATTTCTAAATAATTGTGTATAAAGTTGGATT AACCTGGAGCAACTTTGGATCCAAATATGGCAAGCAATAATGATATTAATGCAGCATGATGGGAAATGTTTGCTGTGAAGAGA АTTGATTTGCTTTGAGCTAGACTTCAGGAAGCCTAGGTTTTTTATTTTTTTATTTTTGAGACATTTTGGTAAAAGGAAAAAAA GAAAACAAACAAACAAACAAACAAAACCAGAAAAAGCATCAAAACTCAGGCAGAATGAGCAATGTCTGAAAGGGCTAGAAAAA CAAGACATAGCAAGGTGCTTTCACTGTGAAAGAGACAAGAACACAGGAGGAAATATTGCTTCAGTGAAGAGCACAGACGGCTC CTGCCAATTTATTACAAGAGTCCCGTCTGTACTTTACCCTTTGGGGTTAGAAGTCAAGTTGGAAGCCTGAATGAATGGACCCA ATGAGAACTAGTGTTAAGCCCATTTCCCTAGTCAGGTTTTTTTCAAGCGTGAATGTGTTAGTGGTTACTCTCCTGGGTTCCTG AGCATCAGAAAAAAAAAAAAAAAGAGGCAAACAATCGCTTCATCTTAGGAGTGGAAAGGAAACAGAAGTGGACGTCCGCTGTG ACTCAGGGAGTGAAGATACCATCAGCAAATAGTTTCTTTTTTGTTCATTCGTTCCTTTCGAGTTAGCCTGTCTTTTGGAATAC CACTGAATATGCTGTTTTTGAAAGACTTCATGTAGCATAGATTGTTTTGTGCCGTTTACCAAATTAACCTTTGTCATCGTTTT TTAACCTATTCAGGAATGCTTGGAATATCTGCTCTATGTTAACTTTTTGCAGCTTCATTCTGAGAGACATTAGTCAAACAAAC AAAAGGATCCCCATCACAATCTTACAGTACTGCAAGGGCCAGGTCTGTTAATCGGCTTCACAGGAGACATCAGCAATTGTGTG GTCAGTGGCTGGCTCTCTTACCCACTAAGATACATCATAGCTACATGTTGGTGGTTTATGTTGACCTGAGATTTATTTGTTAA AATCTCTTCTTCGTTTCTGTTCGTTCTGGTTCTGTTCTGTTCTGTTCTGTTCTGTTTTGGTTTTAAAGTCTTGCTGTGGTCTC TTGTTGGCAGAAATGTTTTATGCATGGCAGCAGGCCTGTTGCTTTTTTATAGTGATTCCCATTGAAACTGTAAGTAAATGTCT GTGGCCTTGTTCTCTCTATGGTAAAGATATTATTCACCATGTAAAACAAGAAAAAATATTTATTGTATTTTAGTATATTTATA TAATTATGTTATTGAAAAAATTGGCATTAAAACTTAACCACATCAGAAGCCTATTGTAAATACAGGTTCTATTTAAGTGTACC AATTAACATATAATATATGTTTTAAATATAGAATTTTTAATGTTTTTAAATATATTTTCAAAGT

Em vermelho o oligonucleotídeo iniciador direto e em azul a sequência complementar inversa do oligonucleotídeo iniciador reverso do Bdnf-1. 


\title{
Anexo B - Sequência do RNAm do gene Bdnf-III
}

\author{
NM_001048141.1 Mus musculus brain derived neurotrophic factor (Bdnf), transcript variant \\ 3, mRNA
}

ACCCACTTTCCCATTCACCGAGGAGAGGACTGCTCTCGCTGCCGCTCCCCCCACCCACCCCCGGCGAGCTAGCATGAAATCTC CCAGCCTCTGCCTAGATCAAATGGAGCTTCTCGCTGAAGGCGTGCGAGTATTACCTCCGCCATGCAATTTCCACTATCAATAA TTTAACTTCTTTGCTGCAGAACAGGAGTACATATCGGCCACCAAAGACTCGCCCCСTCCСССTTTTAACTGAAGAGAAGGGGA AATATATAGTAAGAGTCTAGAACCTTGGGGACCGGTCTTCCCCAGAGCAGCTGCCTTGATGTTTACTTTGACAAGTAGTGACT GAAAAAGTTCCACCAGGTGAGAAGAGTGATGACCATCCTTTTCCTTACTATGGTTATTTCATACTTCGGTTGCATGAAGGCGG CGCCCATGAAAGAAGTAAACGTCCACGGACAAGGCAACTTGGCCTACCCAGGTGTGCGGACCCATGGGACTCTGGAGAGCGTG AATGGGCCCAGGGCAGGTTCGAGAGGTCTGACGACGACATCACTGGCTGACACTTTTGAGCACGTCATCGAAGAGCTGCTGGA TGAGGACCAGAAGGTTCGGCCCAACGAAGAAAACCATAAGGACGCGGACTTGTACACTTCCCGGGTGATGCTCAGCAGTCAAG TGCCTTTGGAGCCTCCTCTACTCTTTCTGCTGGAGGAATACAAAAATTACCTGGATGCCGCAAACATGTCTATGAGGGTTCGG CGCCACTCCGACCCTGCCCGCCGTGGGGAGCTGAGCGTGTGTGACAGTATTAGCGAGTGGGTCACAGCGGCAGATAAAAAGAC TGCAGTGGACATGTCTGGCGGGACGGTCACAGTCCTAGAGAAAGTCCCGGTATCCAAAGGCCAACTGAAGCAGTATTTCTACG AGACCAAGTGTAATCCCATGGGTTACACCAAGGAAGGCTGCAGGGGCATAGACAAAAGGCACTGGAACTCGCAATGCCGAACT ACCCAATCGTATGTTCGGGCCCTTACTATGGATAGCAAAAAGAGAATTGGCTGGCGATTCATAAGGATAGACACTTCCTGTGT ATGTACACTGACCATTAAAAGGGGAAGATAGTGGATTTATGTTGTATAGATTATATTGAGACAAAATTATCTATTTGTATATA TACATAACAGGGTAAATTATTCAGTTAAGAAAAAATAATTTTATGAACTGCATGTATAAATGAAGTTTATACAGTACAGTGGT TCTACAATCTATTTATTGGACATATCCATGACCTGAAAGGAAACAGTCATTTGCGCACAACTTTAAAAGTCTGCATTACATTC CTCGATAATGTTGTGGTTTGTTGCCGTTGCCAAGAATTGAAAACAAAAAGTTTAAAAAAAATAATAATAAATTGCATGCTGCT TTAATTGTGAATTGATAATAAACTGTCCCTCTTTCAGAAAACAGATTAAAAAAACAAAAAACAAAAAAAAAAAAACAAAAAAC AAAAACAAAAATTGGAACCAAAACATTCCGTTTACATTTTAGACACTAAGTATCTTCGTTCTTGTTAGTACTCTGTTTTACTG СTTTCGACTTCTGATAGCGTTGGAATTAAAACAATGTCAAGGTGCTGTTGTCATTGCTTTACTGGCGTAAGGGACGGGGAATG GGAGGGGTAGATTTCTGTTTGTTTTGTGTTTTATTTTGTTTGTTTGTTTGTTTTGTTTTTTAGTTCCACCCGGAGTAGGGATG GAGAAAATTTCTTCACTATCCATTCTGGTTGATAAAGCGTTACATTTGTATGTTGTAAAGATGTTTGCAAAATCCAATCAGAT GACTGGAAAACAAATAAAAATTAAGGCAACTGAATAAAATGCTCACACTCCACTGCCCATGATGTATCTCCCTGGTCCCCCTC AGCTCACTCTTCTGGCATGGGTCAGGGAAAATTGCTTTTATTGGAAAGACCAGCATTTGTTCAAAGCATACTCTTTCCCTCCC TCCTCCCATTTTGGTCCCTTCTTTTTGTTTTGTTTTAAGAAAGAAAATTAAGTTGCGCGCTTTAAAATATTTTACTACTGCTA CAAACAGATGAACAATGTGTGTCATTTTATGACACTCATGGAAAACAGTGATTTTTTTTTACCCTAAAGAAAAACAAATAAAA ATAACCCAAAATATTCTTTTTTTAAAAGGCATAAATATTGGGTAAATTGTAATATGGCCTAACAGTGTTTGCAGATAAAAGTT ATTGTATACACCCAGATACTTAGATAAGAGCAGGGATCCACACTGCCATTGAAATAGGACTGAATGGCCCTGCGGAGGCTAAG TGGAGCTGACATACTATTTCCTGGCAGTGCAGGAGGAATTTCTGAGTGGCCATCCTAAGGTCTAGGATGGAGGTGGGGAATGG TACTTGAGACATTCCTAAAGGAAGGCTCGGAAGCACCCTTCAGAGCAGGCTCTGGAATGATGTGTCAAGTTGCTTAGGCCTTC TGCTTTAAGTGCCTACATTACCTAACAGTGCTCAAGAGGTTCTCGATTGGAGAACCACACTCAAATCCATTTATAGCCTCCAT CCCATTTCTAAATAATTGTGTATAAAGTTGGATTAACCTGGAGCAACTTTGGATCCAAATATGGCACAGCAATAATGATATTA ATGCAGCATGATGGGAAATGTTTGCTGTGAAGAGAATTGATTTGCTTTGAGCTTAGACTTCAGGAAGCCTAGGTTTTTTATTT TTTTATTTTTGAGACATTTTGGTAAAAGGAAAAAAAGAAAACAAACAAACAAACAAACAAAACCAGAAAAAGCATCAAAACTC AGGCAGAATGAGCAATGTCTGAAAGGGCTAGAAAAACAAGACATAGCAAGGTGCTTTCACTGTGAAAGAGACAAGAACACAGG AGGAAATATTGCTTCAGTGAAGAGCACAGACGGCTCCTGCCAATTTATTACAAGAGTCCCGTCTGTACTTTACCCTTTGGGGT TAGAAGTCAAGTTGGAAGCCTGAATGAATGGACCCAATGAGAACTAGTGTTAAGCCCATTTCCCTAGTCAGGTTTTTTTCAAG CGTGAATGTGTTAGTGGTTACTCTCCTGGGTTCCTGAGCATCAGAAAAAAAAAAAAAAAGAGGCAAACAATCGCTTCATCTTA GGAGTGGAAAGGAAACAGAAGTGGACGTCCGCTGTGACTCAGGGAGTGAAGATACCATCAGCAAATAGTTTCTTTTTTGTTCA TTCGTTCCTTTCGAGTTAGCCTGTCTTTTGGAATACCACTGAATATGCTGTTTTTGAAAGACTTCATGTAGCATAGATTGTTT TGTGCCGTTTACCAAATTAACCTTTGTCATCGTTTTTTAACCTATTCAGGAATGCTTGGAATATCTGCTCTATGTTAACTTTT TGCAGCTTCATTCTGAGAGACATTAGTCAAACAAACAAAAGGATCCCCATCACAATCTTACAGTACTGCAAGGGCCAGGTCTG TTAATCGGCTTCACAGGAGACATCAGCAATTGTGTGGTCAGTGGCTGGCTCTCTTACCCACTAAGATACATCATAGCTACATG TTGGTGGTTTATGTTGACCTGAGATTTATTTGTTAAAATCTCTTCTTCGTTTCTGTTCGTTCTGGTTCTGTTCTGTTCTGTTC TGTTCTGTTTTGGTTTTAAAGTCTTGCTGTGGTCTCTTGTTGGCAGAAATGTTTTATGCATGGCAGCAGGCCTGTTGCTTTTT TATAGTGATTCCCATTGAAACTGTAAGTAAATGTCTGTGGCCTTGTTCTCTCTATGGTAAAGATATTATTCACCATGTAAAAC AAGAAAAAATATTTATTGTATTTTAGTATATTTATATAATTATGTTATTGAAAAAATTGGCATTAAAACTTAACCACATCAGA AGCCTATTGTAAATACAGGTTCTATTTAAGTGTACCAATTAACATATAATATATGTTTTAAATATAGAATTTTTAATGTTTTT AAATATATTTTCAAAGT

Em vermelho o oligonucleotídeo iniciador direto e em azul a sequência complementar inversa do oligonucleotídeo iniciador reverso do Bdnf-III. 


\title{
Anexo C - Sequência do RNAm do gene Bdnf-IV
}

\author{
NM_001048142.1 Mus musculus brain derived neurotrophic factor (Bdnf), transcript variant \\ 4, mRNA
}

CCAATCGAAGCTCAACCGAAGAGCTAAATAATGTCTGACCCCAGTGCCTGGCTCTGGCTGAGCTCTGGGTGCCCGTCGCTGCT GCCGTGCCGGGGCGCACCCGCTGGCTGGCTGTCGCACGGTTCCCAGTGCGCCCGGGACTCCCGGGCTTGGAGAAGGAAACCGC CTGGGGCGGCGCGCCACCTCCGCCTGGGAGGCTTTGATGAGACCCGGTTCCTTCAACTGCCACCACTGCCTTGGGGCAGACGA GAAAGCGCACGGGGCCCAGGGCAGGGCGCAGGGACCAGAAGCGTGACAACAATGTGACTCCACTGCCGGGGATCCGAGAGCTT TGTGTGGACCCTGAGTTCCACCAGGTGAGAAGAGTGATGACCATCCTTTTCCTTACTATGGTTATTTCATACTTCGGTTGCAT GAAGGCGGCGCCCATGAAAGAAGTAAACGTCCACGGACAAGGCAACTTGGCCTACCCAGGTGTGCGGACCCATGGGACTCTGG AGAGCGTGAATGGGCCCAGGGCAGGTTCGAGAGGTCTGACGACGACATCACTGGCTGACACTTTTGAGCACGTCATCGAAGAG CTGCTGGATGAGGACCAGAAGGTTCGGCCCAACGAAGAAAACCATAAGGACGCGGACTTGTACACTTCCCGGGTGATGCTCAG CAGTCAAGTGCCTTTGGAGCCTCCTCTACTCTTTCTGCTGGAGGAATACAAAAATTACCTGGATGCCGCAAACATGTCTATGA GGGTTCGGCGCCACTCCGACCCTGCCCGCCGTGGGGAGCTGAGCGTGTGTGACAGTATTAGCGAGTGGGTCACAGCGGCAGAT AAAAAGACTGCAGTGGACATGTCTGGCGGGACGGTCACAGTCCTAGAGAAAGTCCCGGTATCCAAAGGCCAACTGAAGCAGTA TTTCTACGAGACCAAGTGTAATCCCATGGGTTACACCAAGGAAGGCTGCAGGGGCATAGACAAAAGGCACTGGAACTCGCAAT GCCGAACTACCCAATCGTATGTTCGGGCCCTTACTATGGATAGCAAAAAGAGAATTGGCTGGCGATTCATAAGGATAGACACT TCCTGTGTATGTACACTGACCATTAAAAGGGGAAGATAGTGGATTTATGTTGTATAGATTATATTGAGACAAAATTATCTATT TGTATATATACATAACAGGGTAAATTATTCAGTTAAGAAAAAATAATTTTATGAACTGCATGTATAAATGAAGTTTATACAGT ACAGTGGTTCTACAATCTATTTATTGGACATATCCATGACCTGAAAGGAAACAGTCATTTGCGCACAACTTTAAAAGTCTGCA TTACATTCCTCGATAATGTTGTGGTTTGTTGCCGTTGCCAAGAATTGAAAACAAAAAGTTTAAAAAAAATAATAATAAATTGC ATGCTGCTTTAATTGTGAATTGATAATAAACTGTCCCTCTTTCAGAAAACAGATTAAAAAAACAAAAAACAAAAAAAAAAAAA CAAAAAACAAAAACAAAAATTGGAACCAAAACATTCCGTTTACATTTTAGACACTAAGTATCTTCGTTCTTGTTAGTACTCTG TTTTACTGCTTTCGACTTCTGATAGCGTTGGAATTAAAACAATGTCAAGGTGCTGTTGTCATTGCTTTACTGGCGTAAGGGAC GGGGAATGGGAGGGGTAGATTTCTGTTTGTTTTGTGTTTTATTTTGTTTGTTTGTTTGTTTTGTTTTTTAGTTCCACCCGGAG TAGGGATGGAGAAAATTTCTTCACTATCCATTCTGGTTGATAAAGCGTTACATTTGTATGTTGTAAAGATGTTTGCAAAATCC AATCAGATGACTGGAAAACAAATAAAAATTAAGGCAACTGAATAAAATGCTCACACTCCACTGCCCATGATGTATCTCCCTGG TCCСССTCAGCTCACTCTTCTGGCATGGGTCAGGGAAAATTGCTTTTATTGGAAAGACCAGCATTTGTTCAAAGCATACTCTT TCССTCССTCCTCCCATTTTGGTCCCTTCTTTTTGTTTTGTTTTAAGAAAGAAAATTAAGTTGCGCGCTTTAAAATATTTTAC TACTGCTACAAACAGATGAACAATGTGTGTCATTTTATGACACTCATGGAAAACAGTGATTTTTTTTTACCCTAAAGAAAAAC AAATAAAAATAACCCAAAATATTCTTTTTTTAAAAGGCATAAATATTGGGTAAATTGTAATATGGCCTAACAGTGTTTGCAGA TAAAAGTTATTGTATACACCCAGATACTTAGATAAGAGCAGGGATCCACACTGCCATTGAAATAGGACTGAATGGCCCTGCGG AGGCTAAGTGGAGCTGACATACTATTTCCTGGCAGTGCAGGAGGAATTTCTGAGTGGCCATCCTAAGGTCTAGGATGGAGGTG GGGAATGGTACTTGAGACATTCCTAAAGGAAGGCTCGGAAGCACCCTTCAGAGCAGGCTCTGGAATGATGTGTCAAGTTGCTT AGGCCTTCTGCTTTAAGTGCCTACATTACCTAACAGTGCTCAAGAGGTTCTCGATTGGAGAACCACACTCAAATCCATTTATA GCCTCCATCCCATTTCTAAATAATTGTGTATAAAGTTGGATTAACCTGGAGCAACTTTGGATCCAAATATGGCACAGCAATAA TGATATTAATGCAGCATGATGGGAAATGTTTGCTGTGAAGAGAATTGATTTGCTTTGAGCTTAGACTTCAGGAAGCCTAGGTT TTTTATTTTTTTATTTTTGAGACATTTTGGTAAAAGGAAAAAAAGAAAACAAACAAACAAACAAACAAAACCAGAAAAAGCAT CAAAACTCAGGCAGAATGAGCAATGTCTGAAAGGGCTAGAAAAACAAGACATAGCAAGGTGCTTTCACTGTGAAAGAGACAAG AACACAGGAGGAAATATTGCTTCAGTGAAGAGCACAGACGGCTCCTGCCAATTTATTACAAGAGTCCCGTCTGTACTTTACCC TTTGGGGTTAGAAGTCAAGTTGGAAGCCTGAATGAATGGACCCAATGAGAACTAGTGTTAAGCCCATTTCCCTAGTCAGGTTT TTTTCAAGCGTGAATGTGTTAGTGGTTACTCTCCTGGGTTCCTGAGCATCAGAAAAAAAAAAAAAAAGAGGCAAACAATCGCT TCATCTTAGGAGTGGAAAGGAAACAGAAGTGGACGTCCGCTGTGACTCAGGGAGTGAAGATACCATCAGCAAATAGTTTCTTT TTTGTTCATTCGTTCCTTTCGAGTTAGCCTGTCTTTTGGAATACCACTGAATATGCTGTTTTTGAAAGACTTCATGTAGCATA GATTGTTTTGTGCCGTTTACCAAATTAACCTTTGTCATCGTTTTTTAACCTATTCAGGAATGCTTGGAATATCTGCTCTATGT TAACTTTTTGCAGCTTCATTCTGAGAGACATTAGTCAAACAAACAAAAGGATCCCCATCACAATCTTACAGTACTGCAAGGGC CAGGTCTGTTAATCGGCTTCACAGGAGACATCAGCAATTGTGTGGTCAGTGGCTGGCTCTCTTACCCACTAAGATACATCATA GCTACATGTTGGTGGTTTATGTTGACCTGAGATTTATTTGTTAAAATCTCTTCTTCGTTTCTGTTCGTTCTGGTTCTGTTCTG TTCTGTTCTGTTCTGTTTTGGTTTTAAAGTCTTGCTGTGGTCTCTTGTTGGCAGAAATGTTTTATGCATGGCAGCAGGCCTGT TGCTTTTTTATAGTGATTCCCATTGAAACTGTAAGTAAATGTCTGTGGCCTTGTTCTCTCTATGGTAAAGATATTATTCACCA TGTAAAACAAGAAAAAATATTTATTGTATTTTAGTATATTTATATAATTATGTTATTGAAAAAATTGGCATTAAAACTTAACC ACATCAGAAGCCTATTGTAAATACAGGTTCTATTTAAGTGTACCAATTAACATATAATATATGTTTTAAATATAGAATTTTTA ATGTTTTTAAATATATTTTCAAAGT

Em vermelho o oligonucleotídeo iniciador direto e em azul a sequência complementar inversa do oligonucleotídeo iniciador reverso do $B d n f-I V$. 


\title{
Anexo D - Sequência do RNAm do gene Hprt1
}

NM_013556.2 Mus musculus hypoxanthine guanine phosphoribosyl transferase (Hprt), mRNA

\begin{abstract}
GGAGCCTGGCCGGCAGCGTTTCTGAGCCATTGCTGAGGCGGCGAGGGAGAGCGTTGGGCTTACCTCACTGCTTTCCGGAGCGG TAGCACCTCCTCCGCCGGCTTCCTCCTCAGACCGCTTTTTGCCGCGAGCCGACCGGTCCCGTCATGCCGACCCGCAGTCCCAG CGTCGTGATTAGCGATGATGAACCAGGTTATGACCTAGATTTGTTTTGTATACCTAATCATTATGCCGAGGATTTGGAAAAAG TGTTTATTCCTCATGGACTGATTATGGACAGGACTGAAAGACTTGCTCGAGATGTCATGAAGGAGATGGGAGGCCATCACATT GTGGCCCTCTGTGTGCTCAAGGGGGGCTATAAGTTCTTTGCTGACCTGCTGGATTACATTAAAGCACTGAATAGAAATAGTGA TAGATCCATTCCTATGACTGTAGATTTTATCAGACTGAAGAGCTACTGTAATGATCAGTCAACGGGGGACATAAAAGTTATTG GTGGAGATGATCTCTCAACTTTAACTGGAAAGAATGTCTTGATTGTTGAAGATATAATTGACACTGGTAAAACAATGCAAACT TTGCTTTCCCTGGTTAAGCAGTACAGCCCCAAAATGGTTAAGGTTGCAAGCTTGCTGGTGAAAAGGACCTCTCGAAGTGTTGG ATACAGGCCAGACTTTGTTGGATTTGAAATTCCAGACAAGTTTGTTGTTGGATATGCCCTTGACTATAATGAGTACTTCAGGG ATTTGAATCACGTTTGTGTCATTAGTGAAACTGGAAAAGCCAAATACAAAGCCTAAGATGAGCGCAAGTTGAATCTGCAAATA CGAGGAGTCCTGTTGATGTTGCCAGTAAAATTAGCAGGTGTTCTAGTCCTGTGGCCATCTGCCTAGTAAAGCTTTTTGCATGA ACCTTCTATGAATGTTACTGTTTTATTTTTAGAAATGTCAGTTGCTGCGTCCCCAGACTTTTGATTTGCACTATGAGCCTATA GGCCAGCCTACCCTCTGGTAGATTGTCGCTTATCTTGTAAGAAAAACAAATCTCTTAAATTACCACTTTTAAATAATAATACT GAGATTGTATCTGTAAGAAGGATTTAAAGAGAAGCTATATTAGTTTTTTAATTGGTATTTTAATTTTTATATATTCAGGAGAG AAAGATGTGATTGATATTGTTAATTTAGACGAGTCTGAAGCTCTCGATTTCCTATCAGTAACAGCATCTAAGAGGTTTTGCTC AGTGGAATAAACATGTTTCAGCAGTGTTGGCTGTATTTTCCCACTTTCAGTAAATCGTTGTCAACAGTTCCTTTTAAATGCAA ATAAATAAATTCTAAAAATTC
\end{abstract}

Em vermelho o oligonucleotídeo iniciador direto e em azul a sequência complementar inversa do oligonucleotídeo iniciador reverso do Hprtl. 


\section{Anexo E - Tabela com o resumo dos resultados do trabalho (TLR4)}

Estão indicados na tabela as seguintes comparações dos resultados com diferenças estatisticamente significativas: D vs. C; $T l r 4^{-/-}$vs. C e $T l r 4^{-/-}$D vs. $T l r 4^{-/}$, D e C. As comparações são indicadas com setas para cima $(\boldsymbol{\uparrow})$ para aumento, ou para baixo $(\boldsymbol{\Downarrow})$ para redução. As cores das setas indicam o grupo ao qual a comparação se refere, sendo verde em relação ao grupo controle $(\mathrm{C})$, vermelha em relação ao grupo controle submetido à dieta intermitente (D) ou azul em relação ao grupo de camundongos nocaute para TLR4 $\left(T l r 4^{-1-}\right)$.

\begin{tabular}{|c|c|c|c|c|c|c|}
\hline & & & $\mathrm{C}$ & D & TLR4-/- & TLR4-/- D \\
\hline Figura 3 & NF- $x B$ & $\mathrm{HC}$ & $=$ & $=$ & $=$ & $\downarrow \downarrow \downarrow$ \\
\hline Figura 4 & CREB & $\mathrm{HC}$ & $=$ & $=$ & $=$ & $\downarrow \downarrow \downarrow$ \\
\hline Figura 5 & $\mathrm{AP}-1$ & $\mathrm{HC}$ & $=$ & $=$ & $\pi$ & 个个 \\
\hline \multirow{3}{*}{ Figura 6} & IL-12 & \multirow{3}{*}{$\mathrm{HC}$} & $=$ & $=$ & $=$ & $\downarrow$ \\
\hline & IL-15 & & $=$ & $=$ & $=$ & $\downarrow$ \\
\hline & RANTES & & $=$ & $=$ & $=$ & $\downarrow \downarrow \downarrow$ \\
\hline Figura 8 & IL-1 $\alpha$ & $\mathrm{S}$ & $=$ & $=$ & $\downarrow$ & $\downarrow$ \\
\hline Figura 10 & BDNF & $\mathrm{HC}$ & $=$ & $=$ & $=$ & $\downarrow$ \\
\hline Figura 11 & Bdnfl & HT & $=$ & T & $\downarrow$ & $\downarrow \downarrow$ \\
\hline \multirow{2}{*}{ Figura 12} & \multirow{2}{*}{ NRF2 } & $\mathrm{HC}$ & $=$ & $=$ & $\downarrow$ & $\uparrow$ \\
\hline & & $\overline{\mathrm{HT}}$ & $=$ & $\overline{=}$ & $\downarrow$ & $\downarrow$ \\
\hline Figura 18 & pAMPK/AMPK & HT & $=$ & T & 个 & $\uparrow$ \\
\hline \multirow{2}{*}{ Figura 20} & HNE (22 kDa) & \multirow{2}{*}{$\mathrm{HC}$} & $=$ & $=$ & $=$ & 个个 \\
\hline & HNE (55 kDa) & & $=$ & $=$ & $\uparrow$ & Ћイ个 \\
\hline Figura 22 & Cat & $\mathrm{HC}$ & $=$ & $=$ & $=$ & Ћイ个 \\
\hline Figura 24 & P53 & $\mathrm{HC}$ & $=$ & $=$ & $=$ & イトィ \\
\hline Figura 25 & HSP90 & $\mathrm{HC}$ & $=$ & $=$ & $=$ & $\uparrow$ \\
\hline \multirow{4}{*}{ Figura 26} & Glicose & \multirow{4}{*}{$\mathrm{S}$} & $=$ & $=$ & $\uparrow$ & $\downarrow$ \\
\hline & Colesterol & & $=$ & $=$ & $\uparrow$ & $\downarrow$ \\
\hline & 3-hidroxibutirato & & $=$ & $\mathbf{T}$ & $\uparrow$ & $\downarrow \downarrow$ \\
\hline & Creatina & & $=$ & $\pi$ & $=$ & $\downarrow$ \\
\hline Figura 27 & Corticosterona & $\mathrm{S}$ & $=$ & $\varpi$ & $\downarrow$ & $\downarrow$ \\
\hline Figura 28 & Curva glicêmica & $\mathrm{S}$ & $=$ & $=$ & $\uparrow$ & $\downarrow$ \\
\hline Figura 33 & Aprendizado & $\mathrm{C}$ & $=$ & $=$ & $\downarrow$ & $\downarrow \downarrow$ \\
\hline Figura 35 & Memória operacional & $\mathrm{C}$ & $=$ & $=$ & $\downarrow$ & $\downarrow \downarrow$ \\
\hline Figura 36 & Memória contextual & $\mathrm{C}$ & $=$ & $=$ & $\downarrow$ & $\downarrow \downarrow$ \\
\hline Figura 37 & Comportamento depressivo & $\bar{C}$ & $=$ & $\overline{=}$ & $\downarrow$ & $\downarrow$ \\
\hline
\end{tabular}


Anexo F - Tabela com o resumo dos resultados do trabalho (TLR2)

Estão indicados na tabela as seguintes comparações dos resultados com diferenças estatisticamente significativas: D vs. C; $T l r 2^{-/-}$vs. C e $T l r 2^{-/-}$D vs. $T l r 2^{-/-}$, D e C. As comparações são indicadas com setas para cima $(\boldsymbol{\uparrow})$ para aumento, ou para baixo $(\boldsymbol{\downarrow})$ para redução. As cores das setas indicam o grupo ao qual a comparação se refere sendo verde em relação ao grupo controle $(\mathrm{C})$, vermelha em relação ao grupo controle submetido à dieta intermitente (D) ou azul em relação ao grupo de camundongos nocaute para TLR2 (Tlr2 $\left.2^{-/-}\right)$.

\begin{tabular}{|c|c|c|c|c|c|c|}
\hline & & & $\mathrm{C}$ & D & TLR2-/- & TLR2-/- D \\
\hline Figura 3 & NF- $x B$ & $\mathrm{HC}$ & $=$ & $=$ & $=$ & $\downarrow \downarrow$ \\
\hline $\begin{array}{l}\text { Figura } 4 \\
\end{array}$ & CREB & $\mathrm{HC}$ & $=$ & $=$ & $=$ & $\downarrow \downarrow \downarrow$ \\
\hline Figura 5 & AP-1 & $\mathrm{HC}$ & $=$ & $=$ & $=$ & イイト \\
\hline Figura 7 & RANTES & $\mathrm{HC}$ & $=$ & $=$ & $\uparrow$ & $\downarrow$ \\
\hline \multirow{3}{*}{ Figura 9} & IFN- $\gamma$ & \multirow{3}{*}{$\mathrm{S}$} & $=$ & $=$ & $\uparrow$ & $\downarrow$ \\
\hline & IL-1 $\beta$ & & $=$ & $=$ & $\uparrow$ & $\downarrow$ \\
\hline & IL-6 & & $=$ & $\downarrow$ & $\downarrow$ & $\downarrow$ \\
\hline Figura 10 & BDNF & $\mathrm{HC}$ & $=$ & $=$ & $\downarrow$ & $\downarrow \downarrow$ \\
\hline \multirow{3}{*}{ Figura 11} & $B d n f 1$ & \multirow{3}{*}{$\mathrm{HC}$} & $=$ & $\uparrow$ & $=$ & $\downarrow$ \\
\hline & $B d n f 3$ & & $=$ & $=$ & $\downarrow$ & $\downarrow \downarrow$ \\
\hline & $B d n f 4$ & & $=$ & $=$ & $\downarrow$ & $=$ \\
\hline Figura 12 & NRF2 & $\mathrm{HC}$ & $=$ & $=$ & $\downarrow$ & $\uparrow$ \\
\hline \multirow{2}{*}{ Figura 13} & HO1 & \multirow{2}{*}{$\mathrm{HC}$} & $=$ & $\uparrow$ & $=$ & $\downarrow$ \\
\hline & NRF2 & & $=$ & $=$ & $=$ & $v$ \\
\hline \multirow{4}{*}{ Figura 21} & GPx & \multirow{4}{*}{$\mathrm{HC}$} & $=$ & $\uparrow$ & $\uparrow$ & 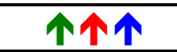 \\
\hline & GR & & $=$ & $=$ & $\downarrow$ & $\downarrow$ \\
\hline & GR/GPx & & $=$ & $\downarrow$ & $\downarrow$ & $\downarrow \downarrow$ \\
\hline & GST & & $=$ & $=$ & $=$ & $\downarrow \downarrow$ \\
\hline Figura 23 & Sod2 & HT & $=$ & $\uparrow$ & $\uparrow$ & $\downarrow \downarrow$ \\
\hline Figura 27 & Corticosterona & $\mathrm{S}$ & $=$ & $\downarrow$ & $\downarrow$ & $\downarrow \downarrow$ \\
\hline Figura 29 & Locomoção & $\mathrm{C}$ & $=$ & $=$ & $=$ & 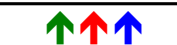 \\
\hline Figura 30 & Freezing & $\mathrm{C}$ & $=$ & $=$ & $\uparrow$ & $\downarrow$ \\
\hline Figura 31 & Ansiedade & $\mathrm{C}$ & $=$ & $=$ & $=$ & $\downarrow \downarrow$ \\
\hline Figura 32 & Freezing & $\mathrm{C}$ & $=$ & $\uparrow$ & $=$ & $\downarrow$ \\
\hline Figura 33 & Aprendizado & $\mathrm{C}$ & $=$ & $=$ & $\downarrow$ & $\downarrow \downarrow$ \\
\hline Figura 35 & Memória operacional & $\mathrm{C}$ & $=$ & $=$ & $\downarrow$ & $\downarrow \downarrow$ \\
\hline Figura 37 & Comportamento depressivo & $\mathrm{C}$ & $=$ & $=$ & $\uparrow$ & $\downarrow$ \\
\hline
\end{tabular}

